\title{
Políticas públicas de saúde e reconhecimento: um estudo sobre prevenção da infecção pelo HIV para homens que fazem sexo com homens
}

\author{
Tese apresentada à Faculdade de Medicina da Universidade de \\ São Paulo para obtenção do título de Doutor em Ciências \\ Programa de Medicina Preventiva \\ Orientador: Prof. Dr. José Ricardo de Carvalho Mesquita Ayres
}

São Paulo

2018 


\title{
Políticas públicas de saúde e reconhecimento: um estudo sobre prevenção da infecção pelo HIV para homens que fazem sexo com homens
}

\author{
Tese apresentada à Faculdade de Medicina da Universidade de \\ São Paulo para obtenção do título de Doutor em Ciências \\ Programa de Medicina Preventiva \\ Orientador: Prof. Dr. José Ricardo de Carvalho Mesquita Ayres
}

(Versão corrigida. Resolução CoPGr 6018/11, de 1 de novembro de 2011.

A versão original está disponível na Biblioteca da FMUSP)

São Paulo

2018 


\section{Dados Internacionais de Catalogação na Publicação (CIP)}

Preparada pela Biblioteca da

Faculdade de Medicina da Universidade de São Paulo

Creprodução autorizada pelo autor

Calazans, Gabriela Junqueira

Políticas públicas de saúde e reconhecimento : um estudo sobre prevenção da infecção pelo HIV para

homens que fazem sexo com homens / Gabriela

Junqueira Calazans. -- São Paulo, 2018.

Tese (doutorado)--Faculdade de Medicina da

Universidade de São Paulo.

Programa de Medicina Preventiva.

Orientador: José Ricardo de Carvalho Mesquita Ayres.

Descritores: 1.Vulnerabilidade em saúde 2.Políticas de saúde 3.Síndrome da imunodeficiência adquirida/prevenção \& controle $4 . \mathrm{HIV}$

5. Homossexualidade masculina 6. Reconhecimento

7. Cuidado 8.Saúde coletiva 9.Honneth

$\mathrm{USP} / \mathrm{FM} / \mathrm{DBD}-2016 / 18$

Responsável: Kátia Maria Bruno Ferreira - CRB-8/6008 
Ao meu pai, que faz falta

À Márcia Giovanetti 
"Alguma coisa aconteceu comigo. Alguma coisa tão estranha que ainda não aprendi o jeito de falar claramente sobre ela. Quando souber finalmente o que foi, essa coisa estranha, saberei também esse jeito. Então serei claro, prometo. Para você, para mim mesmo. Como sempre tentei ser. Mas por enquanto, e por favor, tente entender o que tento dizer."

Caio Fernando Abreu [Carta para além dos muros] 
Esta tese está de acordo com as seguintes normas, em vigor no momento desta publicação:

Referências: adaptado de International Committee of Medical Journals Editors (Vancouver).

Universidade de São Paulo. Faculdade de Medicina. Divisão de Biblioteca e Documentação. Guia de apresentação de dissertações, teses e monografias. Elaborado por Anneliese Carneiro da Cunha, Maria Julia de A. L. Freddi, Maria F. Crestana, Marinalva de Souza Aragão, Suely Campos Cardoso, Valéria Vilhena. 3a ed. São Paulo: Divisão de Biblioteca e Documentação; 2011.

Abreviaturas dos títulos dos periódicos de acordo com List of Journals Indexed in Index Medicus. 


\section{SUMÁRIO}

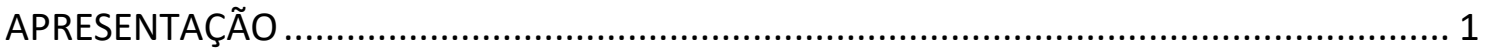

CAPÍTULO 1 - CONSTRUINDO UM OBJETO DE PESQUISA: O ESTUDO DAS POLÍTICAS DE PREVENÇÃO DO HIV PARA GAYS E HSH SOB A ÓTICA DA VULNERABILIDADE, CUIDADO

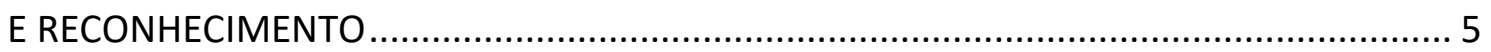

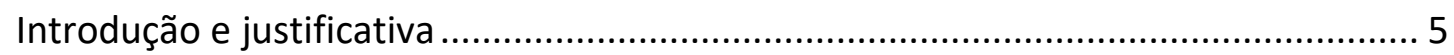

Epidemia HIV/aids no Brasil e em São Paulo e resposta no âmbito do Sistema Único de Saúde

A epidemia de HIV e aids entre homens que fazem sexo com homens ................... 11

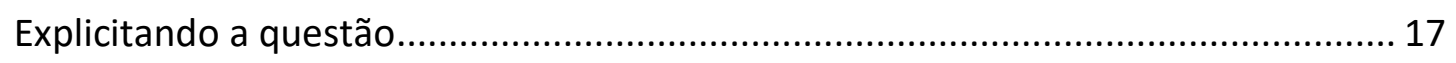

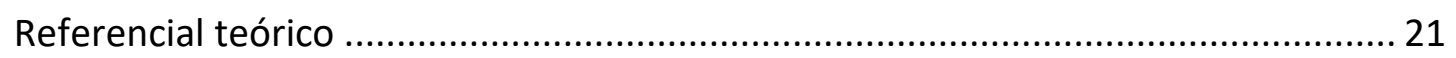

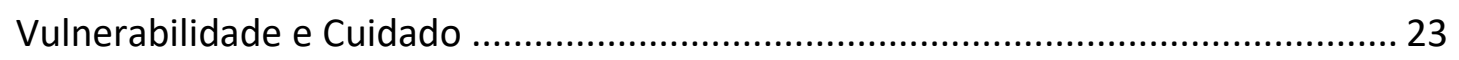

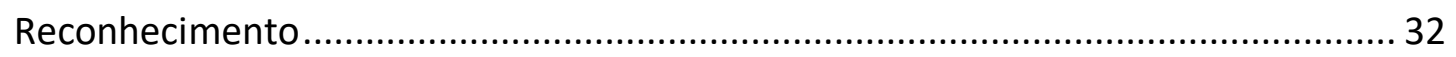

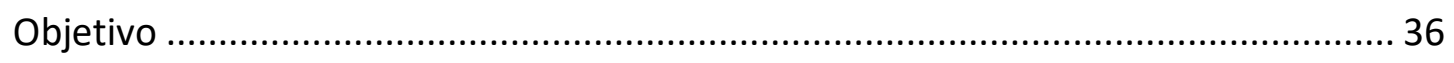

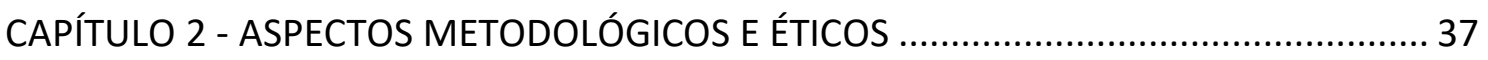

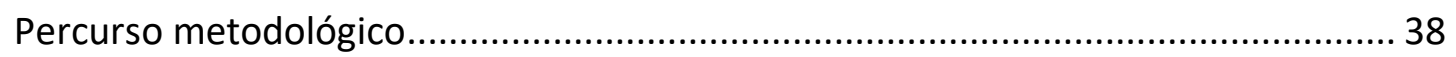

Construindo uma totalidade interpretativa e compreensiva.................................. 40

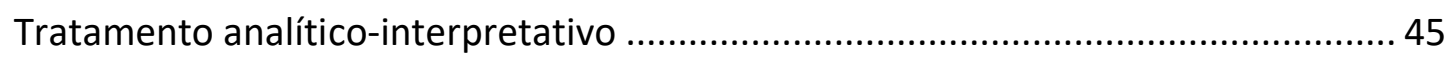

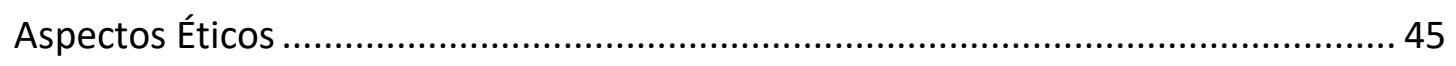

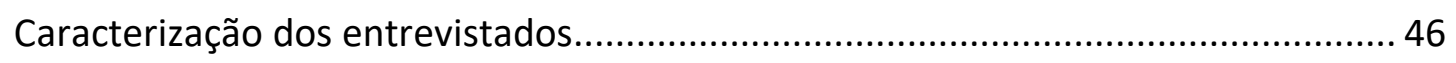

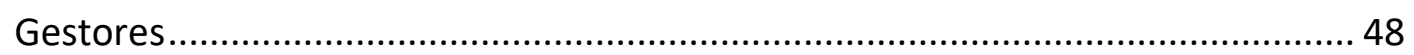

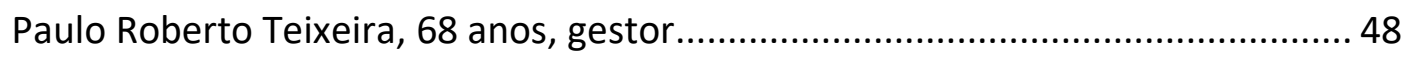

Maria Clara Gianna, 56 anos, gestora ............................................................ 49

Ivo Brito, 63 anos, gestor ...................................................................... 50

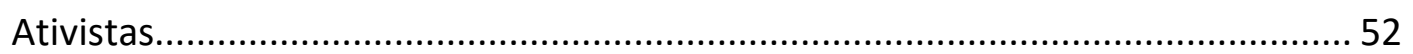

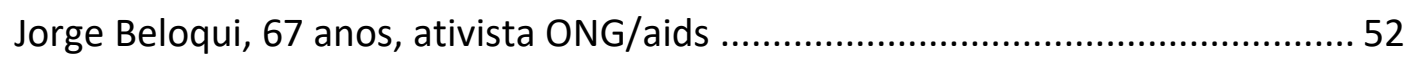

Veriano Terto Júnior, 56 anos, ativista ONG/aids ............................................ 53

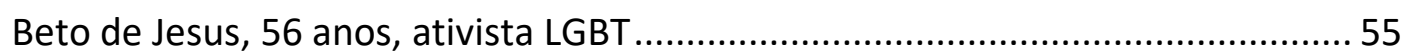

Matheus Emilio Pereira da Silva, 21 anos, ativista ONG/aids e LGBT .................... 56

Gabriel Estrela, 25 anos, ativista em HIV/aids ................................................. 58

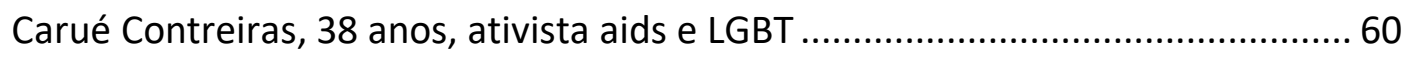

Ramón Soares, 23 anos, ativista em HIV/aids .................................................. 61 
CAPÍTULO 3 - RESPOSTAS POLÍTICO-INSTITUCIONAIS À EPIDEMIA DE AIDS VOLTADAS

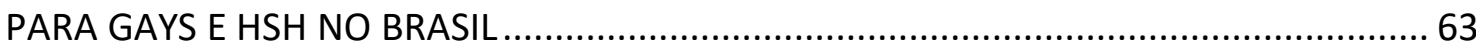

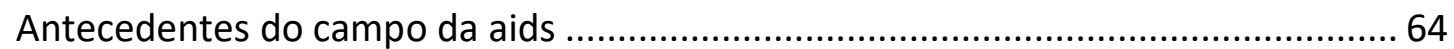

O movimento homossexual e a politização da sexualidade ...................................6 64

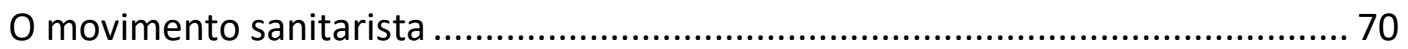

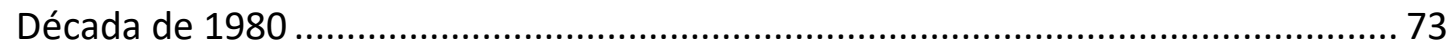

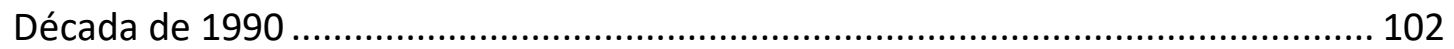

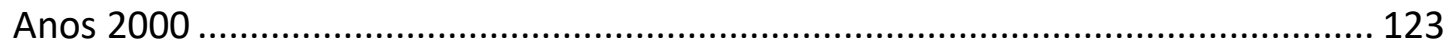

CAPÍTULO 4 - ANÁLISE DO FRACASSO DAS POLÍTICAS DE PREVENÇÃO DO HIV PARA GAYS SOB A ÓTICA DA VULNERABILIDADE, CUIDADO E RECONHECIMENTO ............... 151

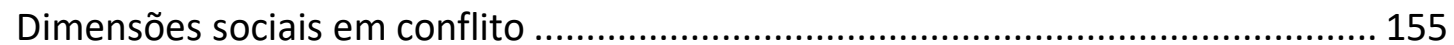

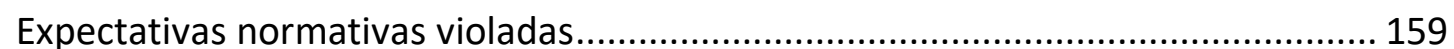

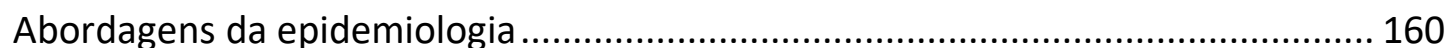

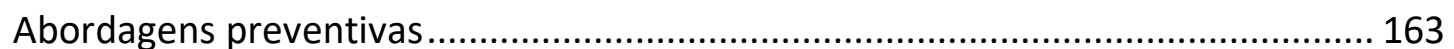

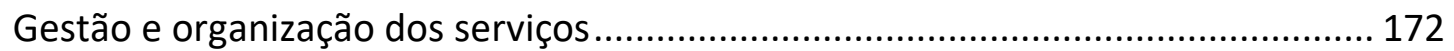

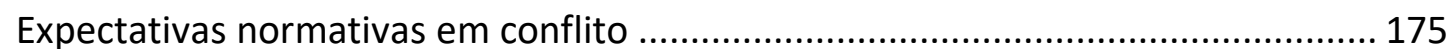

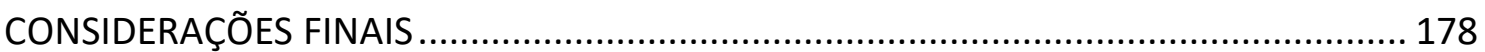

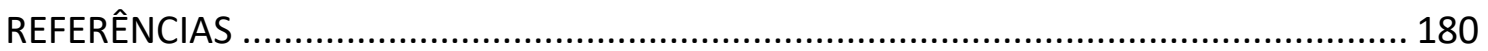

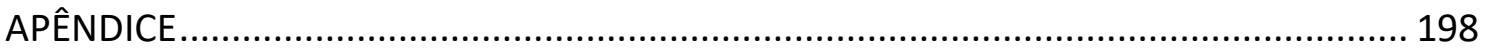

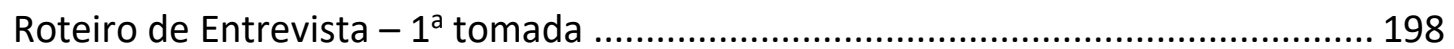

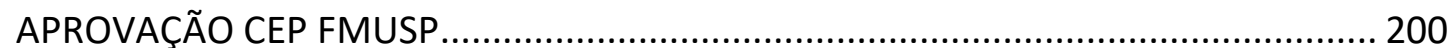

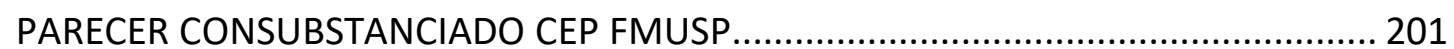

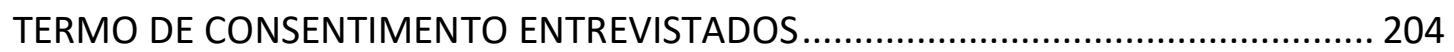




\title{
LISTA DE SIGLAS E ABREVIATURAS
}

\author{
AHF AIDS Healthcare Foundation \\ ARV antirretrovirais \\ ABGLT Associação Brasileira de Lésbicas, Gays, Bissexuais, Travestis, Transexuais \\ e Intersexos \\ APOGLBT Associação da Parada do Orgulho de Gays, Lésbicas, Bissexual e \\ Transgêneros de São Paulo \\ CDC Centers for Disease Control \\ CRT- $\quad$ Centro de Referência e Treinamento em Doenças Sexualmente \\ DST/Aids Transmissíveis e Aids \\ DIAHV Departamento de IST, Aids e Hepatites Virais \\ GT Grupo de Trabalho \\ HSH Homens que fazem sexo com homens \\ ILGA International Lesbian and Gay Association \\ LGBT Lésbicas, Gays, Bissexuais, Transexuais \\ LGBTI Lésbicas, Gays, Bissexuais, Transexuais, Intersexuais \\ MS Ministério da Saúde \\ NGLPT Núcleo de Gays e Lésbicas do PT \\ NTP novas tecnologias de prevenção \\ OMS Organização Mundial da Saúde \\ ONG Organização não-governamental \\ OPAS Organização Pan-Americana da Saúde \\ PEP profilaxia pós-exposição \\ PMDB Partido do Movimento Democrático Brasileiro \\ PrEP profilaxia pré-exposição \\ PT Partido dos Trabalhadores \\ PVHA Pessoas vivendo com HIV e aids \\ RNAJVHA Rede Nacional de Adolescentes e Jovens Vivendo com HIV e Aids \\ RNP + Rede Nacional de Pessoas vivendo com HIV e AIDS de São Paulo \\ SES-SP Secretaria de Estado da Saúde de São Paulo \\ TasP Treatment as prevention \\ TcP tratamento como prevenção \\ UNAIDS Programa Conjunto das Nações Unidas sobre HIV/Aids \\ UNDP Programa das Nações Unidas para o Desenvolvimento (PNUD) \\ UNESCO Organização das Nações Unidas para a Educação, a Ciência e a Cultura \\ UNFPA Fundo de População das Nações Unidas \\ UNICEF Fundo das Nações Unidas para a Infância \\ VE Vigilância Epidemiológica
}


UNGASS United Nations General Assembly Special Session on HIV/AIDS [Sessão Extraordinária da Assembléia Geral das Nações Unidas sobre HIV e Aids] 


\section{RESUMO}

Calazans GJ. Políticas públicas de saúde e reconhecimento: um estudo sobre prevenção da infecção pelo HIV para homens que fazem sexo com homens [tese]. São Paulo: Faculdade de Medicina, Universidade de São Paulo; 2018.

Esta tese examina políticas de prevenção da infecção pelo HIV voltadas para homens que fazem sexo com homens (HSH) no Brasil sob a ótica dos conceitos de vulnerabilidade, Cuidado e reconhecimento. Para tanto, propõe-se a estudar políticas públicas de saúde à luz do referencial da vulnerabilidade e dos direitos humanos. Teve como objetivo compreender de que forma processos de (não)reconhecimento, ou desrespeito, no âmbito do cuidado público de saúde, compreendido como conjunto de políticas, serviços e ações voltadas à prevenção do HIV e da aids, contribuem para os processos de vulnerabilização de HSH ao HIV e à aids no contexto da epidemia e das respostas produzidas no Brasil e no estado de São Paulo, em particular. Trata-se de estudo qualitativo, que adota perspectiva interdisciplinar, em composição que integra diferentes técnicas de pesquisa. Houve produção de material empírico original por meio de entrevistas semiestruturadas com gestores de políticas públicas de prevenção e ativistas dos movimentos de aids e LGBT. A produção e interpretação desse material empírico, orientado pelo quadro teórico acima apresentado, foram cotejadas com documentos das políticas, serviços e ações de saúde, cuidado e prevenção do HIV e da aids voltadas às populações de gays e HSH; observação de caráter etnográfico de eventos presenciais e de atividades no âmbito das redes sociais atinentes à prevenção do HIV e da aids entre gays e outros HSH; conversas informais com informantes-chave; e análise de resultados de outras pesquisas, quantitativas e qualitativas, disponíveis em bases públicas. Caracterizando-se como um estudo de análise de políticas públicas. Foi elaborada uma história narrativa dos diferentes momentos das respostas políticas à epidemia de aids entre gays e outros HSH no Brasil com vistas a compreender e constituir o cenário das políticas públicas de prevenção do HIV voltadas para HSH. Tendo sido identificados os principais paradoxos transformadores das respostas políticas: 0 paradoxo dos "grupos de risco" que reverteu abordagem discriminatória em visibilidade; a maior institucionalização das organizações com atividades em HIV/aids, incorreu em maior despolitização, com reforço ao tecnicismo das ações; a contraposição das políticas de prevenção focadas nos direitos e na visibilidade social à especificidade de uma política de prevenção ancorada e estruturante das políticas de saúde. A partir das narrativas produzidas nas entrevistas, particularmente, daqueles trechos que se referem às tensões e aos conflitos no que tange à prevenção, procedeu-se a duas naturezas de leitura interpretativa: 1) com vistas a caracterizar o cuidado público, identificou-se: como as leituras acerca da doença e da epidemia são usadas para justificar políticas de prevenção; como se dão as diferentes abordagens preventivas, calcadas em distintos conceitos operativos e recursos tecnológicos; e, por fim, como se dão as diferentes modalidades de organização da gestão (recursos financeiros e humanos, as formas de participação e diálogo com a comunidade, continuidade das ações, avaliação, transparência, accountability); e 2) destacou-se, nestes aspectos, 
aquelas respostas que expressam manifestações de indignação e desrespeito, de forma a mirar sob a perspectiva do reconhecimento e das capacidades e possibilidades de respostas das políticas no diálogo com necessidades, desejos e anseios dos sujeitos gays e HSH.

Descritores: vulnerabilidade em saúde; políticas de saúde; síndrome da imunodeficiência adquirida/prevenção \& controle; HIV; homossexualidade masculina; reconhecimento; cuidado; saúde coletiva; Honneth. 


\section{ABSTRACT}

Calazans GJ. Public health policies and recognition: a study on HIV prevention for men who have sex with men [thesis]. São Paulo: "Faculdade de Medicina, Universidade de São Paulo"; 2018.

This thesis examines HIV prevention policies aimed at men who have sex with men (MSM) in Brazil from the standpoint of the concepts of vulnerability, care and recognition. Therefore, it is proposed to study public health policies in the light of the vulnerability and human rights framework. The purpose of this study was to understand how the processes of (non) recognition, or disrespect, in the scope of public health care, understood as a set of policies, services and actions aimed at the prevention of HIV and AIDS, contribute to the processes of vulnerability of MSM to HIV and AIDS in the context of the epidemic and the responses produced in Brazil and the state of São Paulo in particular. It is a qualitative study, which adopts an interdisciplinary perspective, in a composition that integrates different research techniques. Original empirical material was produced through semi-structured interviews with managers of public prevention policies and activists of the AIDS and LGBT movements. The production and interpretation of this empirical material, guided by the theoretical framework presented above, were compared with documents of the policies, services and actions of health care and prevention of HIV and AIDS for the populations of gays and MSM; ethnographic observation of face-to-face events and activities within the social networks related to the prevention of HIV and AIDS among gays and other MSM; informal conversations with key informants; and analysis of the results of other quantitative and qualitative researches available in public databases. Characterized as a study of public policy analysis. A narrative history of the different moments of the political responses to the AIDS epidemic among gays and other MSM in Brazil has been elaborated with a view to understanding and setting the scene of the public policies of prevention of HIV directed to MSM. Having identified the main transforming paradoxes of political responses: the paradox of "risk groups" that reversed discriminatory approach in visibility; the greater institutionalization of organizations with activities on HIV/AIDS, which incurred in greater depoliticization, with reinforcement to the technicality of actions; the contraposition of prevention policies focused on social rights and visibility to the specificity of an anchored and structuring prevention policy based on health policies. From the narratives produced in the interviews, particularly from those excerpts that refer to tensions and conflicts regarding prevention, two types of interpretive reading were performed: 1) with a view to characterizing public care, it was identified: how the readings about the disease and the epidemic are used to justify prevention policies; as are the different preventive approaches, based on different operational concepts and technological resources; (financial and human resources, forms of participation and dialogue with the community, continuity of actions, evaluation, transparency, accountability); and 2) highlighted in those aspects those responses that express manifestations of indignation and disrespect, in order to look from the perspective of 
recognition and the capacities and possibilities of responses of the policies in the dialogue with the needs, desires and aspirations of the gay and MSM.

Descriptors: health vulnerability; health policy; acquired immunodeficiency syndrome/prevention \& control; HIV; homosexuality, male; recognition; health care; public health; Honneth. 


\section{APRESENTAÇÃO}

Esta pesquisa dá sequência e conjuga diferentes interesses temáticos e teóricos. Considero importante destacar que desde 1996, quando comecei a participar da primeira pesquisa sobre prevenção de HIV e aids, estou inserida no campo que me proponho a investigar. Nesta trajetória, atuei como gestora, como técnica de secretarias de saúde, como pesquisadora e integrante de projetos de pesquisa e como professora em inúmeros processos de formação de recursos humanos em saúde e capacitação para movimentos sociais. Trabalhei, inicialmente, na interface da prevenção dirigida a adolescentes e jovens e, desde 2006, por diferentes motivos, comecei a me aproximar das discussões relacionadas aos gays e outros homens que fazem sexo com homens, quando atuei no Centro de Referência e Treinamento em DST/Aids da Secretaria da Saúde de São Paulo (CRT-DST/Aids). Minha principal marca no campo é participar, desde 1996, de grupos acadêmicos envolvidos com a investigação, teorização e formação no que passamos a nomear o quadro teórico da Vulnerabilidade e dos Direitos Humanos. Faço referência a tais informações biográficas para localizar limites e possibilidades da análise aqui apresentada.

O projeto inicial deste trabalho envolvia incorporar a análise de dados sobre prevenção de um estudo desenvolvido no âmbito da parceria entre o CRT-DST/Aids e a Faculdade de Ciências Médicas da Santa Casa de São Paulo - onde também trabalhei intitulado SampaCentro. Por diferentes motivos, esse plano foi abandonado e o projeto foi sendo reconfigurado, principalmente, a partir dos aprendizados do exame de qualificação realizado em 2016.

A partir do diálogo com as questões trazidas pelo Professor Rúrion Melo e do aprofundamento do estudo sobre reconhecimento (Melo, 2014; Mendonça, 2009; Nobre, 2008; Honneth, 2003), redirecionei parcialmente o projeto para examinar a interface entre os movimentos sociais de aids e LGBT no campo das políticas de prevenção de HIV e aids. A abordagem da teoria do reconhecimento aqui desenvolvida pretende estabelecer um diálogo - até agora apenas apontado como possibilidade na produção de meu orientador, Professor José Ricardo Ayres (2011) - com aquela da 
vulnerabilidade e direitos humanos. É também a primeira vez que, em nossa linha de pesquisa, utilizaremos o conceito de Cuidado, relacionado ao quadro da V\&DH, na perspectiva de análises de políticas, ou o que chamamos de Cuidado Público.

Dediquei-me, assim, à escuta das pessoas do grupo afetado - implicadas e engajadas no campo -, à identificação de tensões e conflitos experimentados como destinatários das políticas públicas e o conjunto destes elementos evidenciou as experiências de desrespeito experimentadas na relação com as políticas, tais como desenvolvidas até o momento. Ao mesmo tempo, na escuta aos gestores, ganhou relevo as tensões entre seus esforços e visões relativos à implementação de uma política de saúde coletiva e os problemas enfrentados na construção da resposta programática.

A partir do convite feito pelo Professor Mário Scheffer de explicitar melhor a abordagem das políticas públicas empreendida nesta pesquisa, busquei compreender 0 campo das políticas públicas em aids como um universo de intenso intercâmbio entre agentes do Estado e ativistas da sociedade civil organizada, o que tem sido traduzido no campo pela noção de respostas à epidemia.

A observação do Professor Júlio Simões acerca da intensa circulação destes atores no campo - do movimento para o Estado, para a universidade, para as agências multilaterais - provocou maior atenção às interfaces entre a teoria do reconhecimento e a dimensão da política pública e das lutas dos movimentos sociais.

Motivada pelo aprofundamento no estudo da teoria do reconhecimento e por estes convites, busquei uma aproximação e um diálogo incipientes com o campo de estudos sobre movimentos sociais. A partir daí, nas trocas com a professora e pesquisadora Regina Facchini, ocorreu a sugestão de adotar a noção de campos discursivos de ação (Alvarez, 2014), que constitui, ao mesmo tempo, linguagem conceitual, aparelho interpretativo e uma nova unidade de análise. Esta incorporação resultou em um importante recurso para este estudo.

Parece-me relevante localizar o leitor, já nesta apresentação, em relação a algumas das controvérsias do campo com as quais fui me deparando - algumas delas desde o início, outras a partir do diálogo com os interlocutores da pesquisa - que 
incidem diretamente sobre o objeto pesquisado. Tais controvérsias frequentemente convidam os interlocutores a revisar e reposicionar o objeto. Aprofundar tais discussões, infelizmente, foi algo limitado pelo tempo de execução do estudo.

No campo da aids, convencionou-se usar a categoria de classificação homens que fazem sexo com homens (HSH), configurando-se em uma categoria fundamentada em práticas sexuais e não em identidades. Associada a tal convenção, há o entendimento de que, politicamente, quem representa este segmento populacional é o movimento LGBT, anteriormente nomeado homossexual. Na elaboração de políticas convencionouse usar "gays e outros HSH". Quando elaborei o projeto desta pesquisa, adotei a convenção do campo, mas ao longo do desenvolvimento da pesquisa, entrei em contato com o incômodo de muitos dos interlocutores com o termo, como descrevo no quarto capítulo. A redação reflete meus novos entendimentos, ainda que não tenha sido possível homogeneizar o termo, como é o caso do título do trabalho, não passível de alteração pelas regras acadêmicas aplicáveis. De qualquer forma, se faz importante refletir sobre como os processos de categorização incluem e excluem sujeitos com base em diferentes atributos. Igualmente necessária é a reflexão sobre onde cabem ou faltam abordagens específicas que poderiam contribuir para aprimorar a resposta.

Outro aprendizado relevante foi provocado pelo incômodo, expresso pelos interlocutores, com a abordagem voltada exclusivamente à prevenção - e minha experiência anterior no campo foi principalmente nesta direção. Seus questionamentos mostraram que há discursos do campo que dialogam só com os soronegativos. Nem sempre este trabalho deu conta de contemplar tudo o que inclui, em suas especificidades, soronegativos e soropositivos.

Para que se possa acompanhar o trabalho empreendido nesta tese, é importante apresentar as hipóteses do estudo:

- de que estamos fracassando, enquanto campo de luta, no enfrentamento da epidemia de aids ${ }^{1}$;

\footnotetext{
${ }^{1}$ Chamo a atenção dos leitores aqui para o que Regina Facchini destacou em sua arguição na defesa pública desta tese, de que tenho como hipótese algo que usualmente seria considerado um resultado da análise proposta. Esclareço que sim, parti desta hipótese desde o início da proposição deste projeto de
} 
- de que um dos principais grupos afetados é o daqueles categorizados sob a categoria epidemiológica de exposição "homo/bissexual";

- de que parte do fracasso se deve às políticas, tal como têm sido desenhadas e implementadas;

- de que atentar para as experiências de desrespeito experimentadas pelo grupo afetado nos dá pistas sobre a inadequação das políticas às singularidades que devam ser consideradas na resposta aos desafios colocados pela epidemia;

- de que o estudo sobre políticas públicas à luz dos processos de luta por reconhecimento deve articular diferentes procedimentos metodológicos de forma a compreender o diálogo que se estabelece entre os diferentes atores em campo na produção do cuidado público.

pesquisa, ainda em 2013/2014, com base no que via em minha experiência em campo, como pesquisadora e técnica: pela concentração continuada da epidemia neste grupo, desde o seu início; pelas indicações de crescimento da epidemia neste grupo populacional desde meados dos anos 2000, como apontado por importantes organizações não-governamentais do campo da aids; por o que avaliava como pequena priorização do grupo no âmbito das políticas públicas. Assim, entendia ser necessário compreender melhor a abordagem das políticas públicas e do campo sobre o tema, apesar dos discursos nacionais recorrentes de valorização da resposta nacional à epidemia de HIV/Aids. Mais recentemente, outros pesquisadores, gestores e ativistas do campo têm expressado tal percepção, como se poderá notar a seguir (Grangeiro, Castanheira e Nemes, 2015; Seffner e Parker, 2016a). 


\section{CAPÍTULO 1}

\section{CONSTRUINDO UM OBJETO DE PESQUISA:}

\section{O ESTUDO DAS POLÍTICAS DE PREVENÇÃO DO HIV PARA GAYS E}

\section{HSH SOB A ÓTICA DA VULNERABILIDADE, CUIDADO E}

\section{RECONHECIMENTO}

\section{Introdução e justificativa}

Esta tese examina políticas de prevenção da infecção pelo HIV voltadas para homens que fazem sexo com homens (HSH) no Brasil sob a ótica dos conceitos de vulnerabilidade, Cuidado e reconhecimento. Para tanto, propõe-se a estudar políticas públicas de saúde à luz do referencial da vulnerabilidade e dos direitos humanos (Ayres et al., 2012).

Há mais de uma década, o Programa Conjunto das Nações Unidas sobre HIV/AIDS, o UNAIDS (2007), tem reforçado a recomendação de que os países devem conhecer sua epidemia para melhor enfrentá-la. O Brasil tem uma epidemia de HIV e aids considerada concentrada (Barbosa-Junior et al., 2009). Epidemias concentradas são definidas pelo UNAIDS (2007) como aquelas em que a prevalência de HIV é alta em um ou mais grupos populacionais (com prevalência maior que 5\%) e baixa na população geral (prevalência menor que 1\%). A epidemia de HIV no Brasil concentra-se nos grupos populacionais de HSH, usuários de drogas injetáveis (UDI) e profissionais do sexo (PS) (Ministério da Saúde, 2000; Ministério da Saúde, 2001; Fonseca \& Bastos, 2007; Malta et al., 2010). Estudo de revisão sistemática e metanálise dos estudos que avaliaram a prevalência da infecção pelo HIV nestas populações identificou prevalência combinada de $13,6 \%$ entre $\mathrm{HSH}, 6,2 \%$ entre mulheres profissionais do sexo e $23,1 \%$ entre usuários de drogas (UD), enquanto na população geral identifica-se prevalência de 0,6\% (Malta et al., 2010).

O primeiro foco da política de "Know your epidemics and your current response" (UNAIDS, 2007) foi o de ajudar os países a identificarem características da sua epidemia 
que ajudassem a orientar as ações necessárias ao enfrentamento da mesma. Desta forma, buscava-se reorientar as políticas de enfrentamento em países que priorizavam o desenvolvimento de ações de prevenção voltadas a toda a população em contextos nos quais a epidemia se concentrava em grupos populacionais específicos, assim como em países que só desenvolviam ações voltadas a grupos específicos, mesmo quando sua epidemia se mostrava generalizada.

Um dos primeiros investimentos sugeridos foi a realização de estudos epidemiológicos e a definição de políticas nacionais de vigilância epidemiológica, quando as mesmas não existiam, que pudessem evidenciar a "cara" das epidemias locais. No Brasil, na última década, os esforços neste sentido centraram-se, inicialmente, na realização de revisões sistemáticas dos estudos epidemiológicos existentes no País sobre os grupos populacionais nos quais a epidemia se mostra concentrada. $\mathrm{Na}$ sequência destes esforços, realizaram-se, em 2009 e 2016, inquéritos abrangentes de vigilância comportamental (behavioral surveillance surveys, BSS) da epidemia de HIV e de outras infecções de transmissão sexual (IST), que incluíram marcadores biológicos. 0 objetivo era monitorar as tendências das taxas de infecção por HIV por meio de grandes estudos, que se utilizaram da metodologia de amostragem por redes sociais (respondent-driven sampling, RDS) entre os grupos populacionais mais afetados pela epidemia. Em 2009, as pesquisas voltaram-se a HSH, mulheres profissionais do sexo e usuários de drogas e, em 2016, a HSH, mulheres profissionais do sexo e travestis e transexuais (Malta et al., 2010; Brasil, 2017).

\section{Epidemia HIV/aids no Brasil e em São Paulo e resposta no âmbito do Sistema Único de Saúde}

Até junho de 2017, foram registrados no Brasil 882.810 casos de aids, sendo 576.245 (65,3\%) em homens e 306.444 (34,7\%) em mulheres; com maior concentração em indivíduos com idade entre 25 e 39 anos de ambos os sexos (Brasil, 2017). Segundo o último Boletim Epidemiológico nacional, se observa tendência de crescimento nas 
taxas de detecção de aids em homens nos últimos dez anos; passando de taxa de 24,1 casos/100 mil hab., em 2006, para 25,8 em 2016, o que representa aumento de 7,1\%.

Desde o início da epidemia, a transmissão atribuída a relações desprotegidas entre HSH (homo e bissexuais nas categorias de exposição da vigilância epidemiológica) corresponde a uma parcela importante dos casos de aids entre homens com 13 anos ou mais, variando de $42,8 \%$ no período $1980-2000$ a em torno de $35 \%$ no triênio $2005-2007$, chegando a 41,4\% em 2012 (Brasil, 2013), 45,4\% em 2015 (Brasil, 2016) e 47,3\% em 2016 (Brasil, 2017). Entre homens na faixa etária de 15 a 24 anos, de 1998 a 2010, houve aumento na proporção da categoria de exposição HSH, passando de 31,8\% em 1998 para 46,4\% em 2010 (Brasil, 2011).

A região sudeste registrou 52,3\% (461.988 casos) e o estado de São Paulo 30,1\% (265.689) do total de casos acumulados do país, correspondendo a 57,5\% do total de casos da região sudeste (Brasil, 2017). No estado de São Paulo, apesar da proporção dos casos por transmissão entre HSH ser menor, comparativamente ao início da epidemia, 75\% em 1985 para 48,1\% em 2016², ainda é desproporcionalmente alta em relação ao tamanho da população de HSH. Para compreender melhor o significado destas proporções é importante levar em conta que os estudos populacionais que mensuraram, entre outras questões, o tamanho da população de homens com práticas sexuais com outros homens, nunca chegaram a valores superiores a $10 \%$ no Brasil (Brasil, 2006; 2011). Desta forma, temos que o grupo populacional de HSH, que representa em torno de 3 a 10\% da população de homens adultos do país, responde, na atualidade, por $47,3 \%$ dos casos de aids diagnosticados em homens adultos no ano de 2016 (Brasil, 2017). No boletim epidemiológico publicado no estado em 2012 (São Paulo, 2012), foi apresentada uma análise de tendência dos casos de aids entre homens com 13 anos ou mais no estado de São Paulo segundo categoria de exposição, por meio de modelos de regressão polinomial $(p<0,05 ; I C=95 \%)$. Nesta, identificou-se tendência

\footnotetext{
${ }^{2}$ Até o momento da redação desta tese a Secretaria de Estado da Saúde de São Paulo ainda não havia publicado o Boletim Epidemiológico referente ao ano de 2017, mas sim disponibilizado planilhas com dados preliminares da Base Integrada Paulista de Aids (BIPAIDS - Cooperação Técnica entre o Programa Estadual de DST/Aids-SP e a Fundação Seade, contando com dados também do Departamento Nacional de DST, Aids e Hepatites Virais, MS). Disponível em: http://www.saude.sp.gov.br/centro-de-referencia-etreinamento-dstaids-sp/publicacoes/tabelas-do-boletim-2017. Acesso em: 16.04.2017.
} 
decrescente de 2005 a 2011 para as categorias de exposição heterossexual e UDI, mas uma tendência de crescimento para a categoria de exposição combinada homo e bissexual, ou seja, HSH. O que, segundo esta publicação, "aponta para a necessidade de maior atenção frente à vulnerabilidade desse segmento, se comparado aos demais" (São Paulo, 2012, p. 7). O mais recente Boletim Epidemiológico de Aids e DST do Ministério da Saúde (2017), indica tendência de aumento na proporção de casos em HSH nos últimos dez anos, passando de 35,6\% em 2006 para 47,3\% em 2016, o que representa um incremento de 32,9\%. Dados dos estudos sobre os Conscritos do Exército Brasileiro, rapazes de 17 a 21 anos de idade, também dão destaque ao crescimento da infecção pelo HIV entre jovens HSH. Comparando-se o estudo realizado em 2002 com a versão realizada em 2007, identifica-se que a prevalência da infecção pelo HIV passou de 0,09\% para 0,12\%, e o crescimento mais marcante se deu na população de HSH jovens, cuja prevalência passou de 0,56\% para 1,2\% (Brasil, 2013). Esta mesma comparação entre estudos mostra um crescimento expressivo de comportamentos de maior risco para infecção pelo HIV entre os jovens HSH em função de uma proporção significativamente menor de uso regular do preservativo quando comparados com os jovens com práticas sexuais heterossexuais (Szwarcwald, 2011).

A taxa de prevalência da infecção pelo HIV na população de 15 a 49 anos é considerada estável no país em $0,6 \%$ desde 2004 , sendo $0,4 \%$ entre as mulheres e $0,8 \%$ entre os homens (Szwarcwald et al., 2008). Tais taxas mostram-se significativamente maiores entre os grupos populacionais em que se concentra a epidemia no Brasil conforme dados dos estudos de vigilância comportamental anteriormente mencionados, realizados em 10 municípios brasileiros entre 2008 e 2009. Foram estimadas taxas de prevalências de HIV de 5,9\% entre usuários de drogas ilícitas, de 10,5\% entre HSH e de 4,9\% entre mulheres profissionais do sexo (Brasil, 2011). Os resultados preliminares dos estudos realizados em 2016, indicam, entre HSH com 25 anos ou mais, taxas de prevalência de HIV de $19,8 \%$ e de $9,4 \%$, entre aqueles com idades entre 18 a 24 anos; entre mulheres profissionais do sexo pesquisadas, a prevalência de HIV foi de 5,3\%; não foram apresentados os resultados da prevalência de HIV para travestis e transexuais (Brasil, 2017). 
A resposta brasileira à epidemia de HIV/aids obteve destaque por ter os direitos humanos como referência e por promover a integração entre prevenção, cuidado e tratamento no âmbito do Sistema Único de Saúde (SUS) (Camargo Jr., 2003; Mesquita et al., 2003; Paiva, 2003; Berkman et al., 2005). Esta resposta à epidemia caracterizouse por se dar precocemente e pelo compromisso com o combate ao estigma e à discriminação associados ao HIV e à aids, por meio de esforços que envolveram a população geral, organizações não-governamentais (ONG) e grupos historicamente mais vulneráveis (Camargo Jr., 2003; Chequer et al., 2005), o que recebeu destaque internacional e serviu de inspiração para outros países (Berkman et al., 2005).

Em um contexto em que o direito social à saúde é garantido como direito fundamental no âmbito da Constituição brasileira de 1988 (Brasil, 1988), o conjunto de políticas brasileiras voltadas ao combate da epidemia de aids se ancora nos princípios do SUS, de forma que universalidade, integralidade e equidade constroem as bases para o sucesso e a sustentabilidade de tais esforços. Com isso, o Brasil apresenta-se como o primeiro país de média renda a prover acesso gratuito e universal aos antirretrovirais (ARV) e à testagem anti-HIV, o que reduziu drasticamente a mortalidade e a morbidade por aids e a transmissão vertical do HIV (Malta et al., 2010; Brito et al., 2006).

A base organizacional da resposta brasileira à epidemia de aids se dá na rede hierarquizada de serviços de saúde do SUS, em parceria com organizações da sociedade civil e com outros setores das políticas sociais, como a educação e a assistência social. A rede composta especificamente no âmbito do SUS consiste em serviços de saúde especializados no diagnóstico da infecção pelo HIV, isto é, os Centros de Testagem e Aconselhamento (CTA), bem como nos serviços de referência em assistência especializada às pessoas vivendo com HIV/aids, ou seja, os Serviços de Assistência Especializada (SAE), responsáveis mais diretos pelo cuidado às pessoas vivendo com HIV e aids. Nos estados e municípios, os programas de DST e aids incluem ainda as áreas de prevenção e vigilância epidemiológica, que desenvolvem ações de prevenção e controle da epidemia. A rede nacional de laboratórios de saúde pública em aids serviu de base para a implantação dos testes diagnósticos. É no contexto desta resposta programática e de serviços especializados que as ações de prevenção e acolhimento voltadas aos HSH se dão. 
As políticas de prevenção da infecção pelo HIV no Brasil, até o início da década de 2010, investiram fundamentalmente em duas tecnologias preventivas: a promoção do uso da camisinha e o incentivo à testagem anti-HIV. Mais recentemente, desde 2008, a oferta de profilaxia pós-exposição sexual (PEP) também passou a ser preconizada como método de prevenção da infecção pelo HIV para indivíduos identificados aos grupos populacionais mais afetados pela epidemia que tenham vivido situação de exposição ao vírus, medida efetivamente implantada a partir de 2010 (Brasil, 2010).

A resposta brasileira à epidemia de aids sofreu, no entanto, importantes inflexões nos últimos anos, com situações problemáticas do ponto de vista dos direitos humanos de alguns dos grupos mais afetados (Malta \& Beyrer, 2013; Ferraz et al., 2013).

No início desta última década, enquanto o país vivia um momento crítico no âmbito das políticas de prevenção do HIV e da aids, o contexto internacional experimentava forte biomedicalização na prevenção da infecção pelo HIV, focando-se fortemente nas chamadas "novas tecnologias de prevenção" ou "tecnologias biomédicas" de prevenção (circuncisão, microbicidas, profilaxia pós-exposição-PEP, profilaxia pré-exposição-PrEP), além de estratégias comportamentais (como soroposicionamento, soro-adaptação e outras modalidades de acordo entre parceiros sexuais) (Padian et al., 2008; El-Sadr et al., 2013; Celum et al., 2013; Celum et al., 2013). No Brasil, observou-se dificuldade para se proceder à discussão pública sobre estas novas tecnologias, assim como à sua incorporação. Neste mesmo período, registrou-se um importante recrudescimento da epidemia, com aumento da prevalência de HIV entre os mais jovens, principalmente entre os HSH (Szwarcwald et al., 2011a; Brasil, 2017), prevalências elevadas de HIV em alguns grupos populacionais (Kerr et al., 2013; Szwarcwald et al., 2011b; Brasil, 2013; Veras et al., 2015), e tendência de redução do uso regular do preservativo (Brasil, 2011; Szwarcwald et al., 2011a). Diante deste cenário, a resposta brasileira à aids foi questionada por um movimento social liderado por pesquisadores, profissionais de saúde, ativistas e governos locais iniciado em meados de 2012, que foi denominado "Aids no Brasil: o que nos tira o sono" (http://oquenostiraosono.tumblr.com/home) (Malta \& Beyrer, 2013; Ferraz et al., 2013). Diferentes movimentos sociais apontaram também retrocessos em virtude da censura a campanhas preventivas voltadas para jovens gays e mulheres trabalhadoras 
do sexo e de cartilha com histórias em quadrinhos voltada à educação para a sexualidade dirigido a estudantes do ensino médio ${ }^{3}$ (Malta \& Beyrer, 2013; Beloqui e Terto Jr., 2012 ${ }^{4}$ ).

\section{A epidemia de HIV e aids entre homens que fazem sexo com homens}

Estudos sobre a prevalência da infecção pelo HIV entre HSH indicam risco marcadamente acrescido de infecção em comparação com a população geral (Baral et al., 2007; Malta et al., 2010; Veras et al., 2015; Kerr et al., 2013, 2018). Estudos epidemiológicos nacionais sobre a incidência de aids indicam também maior risco entre os HSH para desenvolver aids (Beloqui, 2008; Barbosa et al., 2009).

A transmissão sexual do HIV entre os homens ocorre prioritariamente pelo sexo anal, que apresenta um maior risco de transmissão do que outras formas de transmissão sexual (Royce et al., 1997). Postula-se também a transmissão pelo sexo oral, apesar de revisão sistemática da literatura ter concluído que os dados disponíveis não são suficientes para estimar o risco de transmissão do HIV via sexo oral (Baggaley et al., 2008). Sabe-se, no entanto, que muitos HSH acreditam expor-se ao risco de se infectar pelo HIV pelo sexo oral, muitos deles afirmam praticar sexo oral sem preservativo e apenas uma parcela destes acredita ter realizado uma prática que possa tê-los exposto, de fato, ao HIV (Funari, 2003).

Em revisão sobre a epidemia de aids na América Latina e Caribe, Cáceres e colaboradores (2002) mencionam que mais de um terço dos casos notificados de aids na região é atribuído à transmissão sexual entre homens, embora os HSH constituamse em uma proporção muito pequena da população masculina.

Compreendem-se como fortes determinantes da vulnerabilidade da população de HSH à epidemia de HIV e aids a homofobia, o estigma e a discriminação a que estão expostos. Cáceres et al. (2008) em relatório do estudo "Review of Legal Frameworks and

\footnotetext{
${ }^{3}$ Material que ficou conhecido como kit anti-homofobia.

${ }^{4}$ Beloqui Jorge e Terto Jr Veriano. A prevenção à AIDS no governo Dilma e a censura dos vídeos da campanha do Carnaval de 2012. [acesso em 25.09.2017]. Disponível em: http://www.clam.org.br/uploads/conteudo/artigoveriano.pdf e http://www.clam.org.br/busca/conteudo.asp?cod=9212.
} 
the Situation of Human Rights related to Sexual Diversity in Low and Middle Income Countries", para o UNAIDS, destacam que a exclusão social - caracterizada como alienação ou privação de direitos experimentados por indivíduos ou grupos sociais guarda relação estreita com o reconhecimento ${ }^{5}$ e a legitimidade sociais estando associados a marcadores sociais das diferenças, tais como classe social, sexo/gênero, idade, raça/etnia, entre outros. Aqueles socialmente excluídos detêm pouco valor social, podendo ser marginalizados econômica, política e socialmente, não podendo desfrutar de oportunidades, de dignidade e de direitos, inclusive, muitas vezes, dos direitos à vida e à saúde (Parker \& Aggleton, 2001).

A proposição do conceito de vulnerabilidade (Mann, Tarantola e Netter, 1993) por um grupo de pesquisadores da Escola de Saúde Pública da Universidade de Harvard, vinculado naquele momento à Coalizão Global de Políticas contra a Aids ${ }^{6}$, e liderado por Jonathan Mann no início dos anos 1990, buscou explicitar a forma como determinantes sociais, políticos, econômicos e culturais, entre outros, propiciam a experiência de riscos por indivíduos e grupos, assim como afetam as possibilidades de que os mesmos respondam a estes riscos. A compreensão da ação de tais determinantes, no entanto, não rejeita a possibilidade de agência destes para resistir ou transformar suas próprias condições de vida (Paiva, 2005). Dentre estes determinantes, o respeito, a proteção e a garantia dos direitos humanos (bem como o reconhecimento de suas violações), são compreendidos como determinantes da epidemia de HIV e aids (Mann et al., 2000). Neste sentido, torna-se fundamental o estudo dos marcos legais, das leis e normas, assim como da violência homofóbica, do estigma e da discriminação para compreender a vulnerabilidade de HSH à infecção pelo HIV e ao desenvolvimento e morte por aids. Segundo Cáceres et al. (2007), alguns dos desafios atuais para a igualdade e, assim, para

\footnotetext{
5 Cáceres et al. (2008) citam Axel Honneth (2007 apud Cáceres et al., 2008) ao referirem-se ao reconhecimento e à legitimidade sociais.

${ }^{6}$ A Coalizão Global de Políticas contra a Aids foi criada por iniciativa de Jonathan Mann, em 1991, na Universidade de Harvard. Configurou-se como um comitê independente interdisciplinar que reunia integrantes provenientes de diferentes partes do mundo com o objetivo de monitorar a pandemia de HIV/aids e analisar criticamente a resposta global. Este foi o espaço de atuação de Mann após sair, em 1990, da coordenação do Programa Global de Aids da Organização Mundial da Saúde (OMS), na qual havia estado desde sua criação em 1986. Sua grande contribuição ao campo foi a publicação do livro "AIDS in the world", em 1992, no qual foi proposto o conceito de vulnerabilidade, inovando as análises sobre a epidemia ao abordar os seus determinantes sociais e programáticos. Os brasileiros Jane Galvão e Herbert Daniel chegaram a compor a iniciativa, que teve dificuldades em se manter e acabou sendo desarticulada em 1996 (Galvão, 2000; Parker, 1993).
} 
a efetivação da saúde entre HSH são: a persistência de leis injustas e irracionais; a presença de barreiras culturais à aplicação de leis protetoras; uma superidentificação do HIV às minorias sexuais, o que gera estigmatização, assim como a rejeição, por grupos de militância e a comunidade LGBT, que lutam para minimizar o papel do HIV na política das minorias sexuais; e serviços de saúde com capacidade insuficiente e falhos em obter plena legitimidade entre os HSH (Cáceres et al., 2008).

Estes desafios também se identificam no Brasil, por exemplo, com a resistência à aprovação do projeto de lei da Câmara Federal 122 que propõe a criminalização dos preconceitos motivados pela orientação sexual e pela identidade de gênero, as dificuldades em se implementar uma política de combate à homofobia no âmbito das escolas (vide toda a polêmica sobre o chamado "kit anti-homofobia"7) e as restrições em pautar ações específicas de prevenção voltadas a homens com condutas homossexuais.

No Brasil, em pesquisa inédita no país, realizada pela Fundação Perseu Abramo (2008), 26\% dos brasileiros (com 16 anos ou mais, residentes nas áreas urbanas) admitiram preconceito pessoal contra gays. Foi desenvolvido neste estudo um índice de homofobia, que apurou que $25 \%$ da população brasileira apresenta tendência média (19\%) ou forte (6\%) para comportamento homofóbico. Nesta mesma pesquisa, identificou-se grande concordância com a afirmação de que "os gays são os principais culpados pelo fato de a aids estar se espalhando pelo mundo", sendo que $21 \%$ concordam totalmente e $12 \%$ concordam em parte, perfazendo total de $33 \%$ de concordância (Calazans, 2011).

\footnotetext{
7 O chamado "kit anti-homofobia" é um conjunto de materiais didáticos produzidos no âmbito do Projeto Escola Sem Homofobia - composto por um caderno; uma série de seis boletins; três audiovisuais com seus respectivos guias; um cartaz; e cartas de apresentação para o/a gestor(a) e para o/a educador(a). Este projeto foi proposto e implementado por meio de uma parceria entre a rede internacional Global Alliance for LGBT Education; a Associação Brasileira de Lésbicas, Gays, Bissexuais, Travestis e Transexuais (ABGLT) e as ONGs Pathfinder do Brasil, ECOS e Reprolatina - Soluções Inovadoras em Saúde Sexual e Reprodutiva, com apoio do Ministério da Educação/Secretaria de Educação Continuada, Alfabetização e Diversidade (MEC/SECADI). Tinha como seus objetivos "contribuir para a implementação do Programa Brasil sem Homofobia pelo Ministério da Educação, através de ações que promovam ambientes políticos e sociais favoráveis à garantia dos direitos humanos e da respeitabilidade das orientações sexuais $e$ identidade de gênero no âmbito escolar brasileiro" (Nota Oficial sobre o KIT, 2011. Disponível em: http://www.inclusive.org.br/arquivos/18368. Acesso em: 16.04.2018).
} 
O grupo de HSH foi um dos mais atingidos pela epidemia de HIV/aids no Brasil desde o seu início nos anos 1980 (Beloqui, 2008; Barbosa et al., 2009). É reconhecido também como o segmento da população que mais se mobilizou para responder à epidemia na área de prevenção, apoio às pessoas afetadas e redução das situações de estigma e preconceito (Altman, 1995). No âmbito das políticas públicas, no entanto, tanto se considerando as políticas da área de saúde, quanto as de outras que atuam com aids, talvez este grupo seja um dos mais negligenciados. Grangeiro e colaboradores (2009) em análise da política de incentivo do Ministério da Saúde para a resposta à aids de estados e municípios concluíram que, no ano de 2006 , somente $1,5 \%$ do conjunto dos recursos investidos por meio da política de incentivo via fundo a fundo foi gasto com os segmentos populacionais de gays, outros HSH e travestis, ainda que $33 \%$ dos casos de aids notificados no Brasil estivessem relacionados a esta população (Brasil, 2008).

Muito do que se sabe sobre a epidemia de HIV entre HSH no Brasil foi produzido no contexto de centros voltados para estudos de coorte preparatórios para ensaios clínicos de vacinas e nos próprios ensaios, mesmo que eventualmente em cortes transversais à entrada dos participantes nas referidas coortes (Harrison et al., 1999; Brasil, 2000; Sutmöller et al., 2002; Carneiro et al., 2003; Carneiro et al., 2000). Em uma revisão sistemática realizada sob encomenda do Departamento Nacional de Doenças Sexualmente Transmissíveis, Aids e Hepatites Virais (DDAHV) ${ }^{8}$ identificaram-se análises referentes à prevalência do HIV entre HSH: por meio de estudo daqueles que faziam uso de drogas injetáveis em estudo transversal sobre UDI em seis cidades brasileiras (Ferreira et al., 2006; prevalência: 36\% e uso de preservativos sempre por 36,4\%); em estudo transversal sobre os jovens conscritos do exército brasileiro (Szwarcwald et al., 2005; prev.: 0,564 e uso regular de preservativos por 34,1\%); em estudo de coorte sobre

\footnotetext{
${ }^{8}$ Em sua história, o programa nacional de aids teve inúmeras denominações e esteve subordinado a diferentes instâncias do Ministério da Saúde. Sendo, atualmente, designado como Departamento de Vigilância, Prevenção e Controle das IST, do HIV/Aids e das Hepatites Virais (DIAHV) e subordinado à Secretaria de Vigilância em Saúde do Ministério da Saúde. Dada a dificuldade em saber a designação correta a cada diferente momento histórico abordado no estudo, optarei, nesta tese, em utilizar a denominação programa nacional de aids, de forma indiscriminada a partir daqui. Inspiro-me, para isso, em Jane Galvão (2000). Avalio que esta denominação se articula à forma como a literatura internacional se refere às instâncias de coordenação nacional das políticas de aids. Destaco, no entanto, o entendimento, compartilhado amplamente no âmbito do campo discursivo de ação em estudo, de que o programa não se restringe às instâncias governamentais, mas espera-se que possam ter papel de coordenação dos diferentes atores (Teixeira, 1997; Galvão, 2000; Laurindo-Teodorescu e Teixeira, 2015).
} 
profilaxia pós-exposição (PEP) entre HSH (Schechter et al., 2004; soroincidência: 2,9/100PY; sexo anal desprotegido nos últimos 6 meses por 47,1\% dos usuários de PEP e 36,4\% dos não usuários de PEP); em estudo transversal sobre usuários de um centro de testagem e aconselhamento (CTA) de Porto Alegre (Barcellos et al., 2003; prev.: 32\%); e somente um estudo transversal dedicado especificamente à investigação de aspectos relacionados à vigilância comportamental da epidemia de HIV entre HSH (Mello et al., 2008; prevalência geral: 7,4\%, sendo 14,9\% entre adolescentes de 14 a 19 anos e 14\% dentre os que relataram sexo comercial; uso de preservativo foi investigado segundo sexo anal insertivo e receptivo e vaginal, com um parceiro ou mais de 2 , no sexo com mulheres e no sexo comercial).

Coortes de HSH estudadas na década de 1990 em São Paulo, Rio de Janeiro e Belo Horizonte apresentaram taxas de prevalência de HIV equivalentes por ocasião da inclusão na coorte: 10,8\%, no Projeto Bela Vista, São Paulo; 11\% no Projeto Praça Onze, Rio de Janeiro; e 11,7\% no Projeto Horizonte, Belo Horizonte. A taxa de incidência, porém, foi de 1,5 por 100 pessoas por ano de acompanhamento em São Paulo, enquanto nas coortes de Belo Horizonte foi 2,2 (Horizonte) e do Rio de Janeiro foi 3,1 (Praça Onze) (Mello et al., 2009).

Considerando-se, ainda, a relevância do grupo de HSH para o enfrentamento da epidemia de HIV e aids no Brasil e a centralidade do preservativo para as políticas de prevenção no Brasil, chama a atenção que dois estudos sobre a literatura nacional sobre uso de preservativo apontem escassez de pesquisas envolvendo a população de HSH, tanto sobre o uso de camisinha (Pinheiro et al., 2013), como sobre fatores associados ao uso de preservativo (Dourado et al., 2014).

Pesquisas relacionadas à vigilância epidemiológica e comportamental da epidemia de HIV e aids no país têm por objetivo orientar o planejamento e o monitoramento de políticas públicas de prevenção (UNAIDS, 2002). Com vistas a orientar o programa nacional, inquéritos nacionais têm sido realizados junto à chamada população geral, tais como: as pesquisas sobre "Comportamento Sexual e Percepções da População Brasileira sobre HIV/Aids" realizadas em 1998 e 2005, numa amostra representativa da população brasileira de 16 a 65 anos pelo Centro Brasileiro de Análise 
e Planejamento (CEBRAP); as Pesquisas de Conhecimentos, Atitudes e Práticas relacionadas às DST e Aids (Brasil, 2005 e 2011), inquéritos domiciliares realizados em 2004 e 2008 representativos da população brasileira de 15 a 64 anos e as pesquisas entre jovens conscritos do exército brasileiro realizadas nos anos de 1997-2000, 2002 e o último recorte em 2007 (Szwarcwald et al., 2005; Szwarcwald et al., 2011).

Segundo Baral (2007), o termo "homens que fazem sexo com homens" ${ }^{9}$ (HSH) foi proposto em 1994 com vistas a reduzir o estigma contra gays, bissexuais, transgêneros e homens auto-identificados como heterossexuais que se envolvem em práticas sexuais com outros homens, pela descrição de comportamentos, ao invés de identidades sociais ou culturais. No entanto, assim como seria sensível para definir um comportamento comum entre homens com identidades diversas, este termo esconderia as especificidades entre os diversos subgrupos que contém. Diferenças significativas no risco à infecção pelo HIV entre diferentes subgrupos de HSH, incluindo transgêneros e homens trabalhadores sexuais, são descritas na literatura (idem, idem). Carrara e Simões (2007, p. 94), identificam a proposição do termo HSH como integrante de uma estratégia epidemiológica que "se supunha contemplar a especificidade do contingente de homens que se relacionavam sexualmente com pessoas do mesmo sexo e não se reconheciam [em categorias identitárias, tais] como 'homossexuais', 'gays', 'entendidos', etc.". Ainda segundo estes autores:

Um problema com a categoria HSH é dissolver a questão da nãocorrespondência entre desejos, práticas e identidades numa formulação que recria a categoria universal "homem" com base na suposta estabilidade fundante do sexo biológico, ao mesmo tempo em que permite evocar as bem conhecidas representações da sexualidade masculina como inerentemente desregrada e perturbadora (Carrara \& Simões, 2007, p. 94).

Estudos voltados à população geral não conseguem investigar a diversidade interna ao grupo de homens com condutas homossexuais ${ }^{10}$, de forma que se tornam

\footnotetext{
${ }^{9} \mathrm{O}$ artigo de Rebecca Young e llan Meyer (2005) e o debate provocado pelo mesmo no American Journal of Public Health ajudam a compreender sobre a proposição original do termo HSH (ou MSM, men who have sex with men) e sobre as críticas que o acompanharam.

${ }^{10}$ Segundo informação de Ivan França-Junior (comunicação pessoal) - integrante do Grupo de Estudos em População, Sexualidade e Aids, responsável pela concepção e realização da pesquisa "Comportamento sexual e percepções da população brasileira sobre HIV/Aids", que foi financiada pelo Programa Nacional
} 
necessários estudos voltados a captar esta diversidade, focados exclusivamente nesta população. É, com este sentido que foi realizado, em 2009, o primeiro inquérito nacional de vigilância biológica e comportamental para HIV especificamente entre HSH no Brasil, caracterizado como um estudo transversal que utilizou amostragem dirigida pelos respondentes (Respondent-Driven Sampling, RDS) em 10 cidades brasileiras (Kerr et al., 2013). No estado de São Paulo, somente a cidade de Santos, no litoral paulista foi incluída. Uma nova versão destes inquéritos nacionais baseados em amostragem RDS foi realizada em 2016, incluindo desta vez a cidade de São Paulo, mas ainda não teve seus resultados publicados ${ }^{11}$, com exceção dos resultados preliminares sobre a prevalência de HIV apresentados anteriormente, conforme constam do Boletim Epidemiológico HIV/Aids de 2017 (Brasil, 2017). Com vistas a atender à necessidade de realizar estudo de vigilância biológica e comportamental para HIV entre HSH na cidade de São Paulo, foi realizado entre 2010 e 2011 o estudo "Comportamentos e práticas sexuais, acesso à prevenção, prevalência de HIV e outras infecções de transmissão sexual entre gays, travestis e homens que fazem sexo com homens (HSH) na região central de São Paulo", cujo nome fantasia é Projeto SampaCentro (Veras et al., 2015; Facchini et al., 2018).

\section{Explicitando a questão}

Em documento de 2009, o UNAIDS destaca que não somente a informação sobre a situação da infecção pelo HIV entre HSH é insuficiente, como conclui que a resposta coletiva tem falhado mais do que tido sucesso (UNAIDS, 2009). Além disso, uma revisão sistemática sobre os estudos de prevalência do HIV em HSH realizados em países de renda média e baixa, nos anos de 2000 a 2006, reafirma que os HSH são inadequadamente estudados em muitos países (Baral et al., 2007).

de DST/Aids do Ministério da Saúde em convênio com o Centro Brasileiro de Análise e Planejamento (CEBRAP) -, nas discussões com o PN para acertar amostra e financiamento para tal pesquisa, se buscou negociar uma amostra maior em que fosse possível uma amostra de LGBT, mas o PN não aceitou.

11 Resultados dos estudos da segunda onda de estudos baseados em RDS foram divulgados em suplemento especial do periódico Medicine, após a defesa desta tese em 2018 (Kerr et al., 2018; Guimarães et al., 2018). 
Em sua proposição de "Know your epidemics and your current response", o UNAIDS (2007) recomenda uma série de medidas aos países de epidemias concentradas, estabelecendo intensa articulação entre a necessidade de conhecimento sobre os diferentes cenários, configurações da epidemia de HIV e aids nos diferentes países e as respostas nacionais e locais. Entre essas medidas: a) indica a necessidade de que os países identifiquem os principais determinantes de sua epidemia, focando nas relações entre a epidemiologia da infecção pelo HIV e os comportamentos e as condições sociais que impedem a habilidade de acessar e usar informações e serviços relacionados ao HIV, avaliando, assim, criticamente quem está e quem deveria estar participando dos esforços de prevenção do HIV; b) aponta que conhecer sua epidemia e conhecer sua resposta permite aos países "combinar e priorizar suas respostas", identificando, selecionando e financiando aquelas medidas de prevenção do HIV mais apropriadas e efetivas para cada país em relação ao(s) seu(s) cenário(s) e configurações da epidemia; c) assinala ser crítico para uma resposta efetiva a identificação das populações em maior risco e vulnerabilidade, avaliando a extensão em que novas infecções pelo HIV ocorrem nessas populações e a extensão em que estas são consultadas e envolvidas na adaptação da resposta para as suas comunidades; e d) que a resposta à epidemia seja desenhada de modo a atingir os grupos mais vulneráveis, que seja identificado o grau de relacionamento entre estes e a população geral e que se mantenha atenção continuada. Com isso, acredita-se ser possível lidar com a discriminação e o estigma, condição necessária para implantar medidas mais efetivas de prevenção e controle da epidemia.

Buse, Dickinson e Sidibé (2008) advertem, no entanto, que se a proposição de "conhecer a sua epidemia, saber a sua resposta" é um esforço para colocar respostas informadas por evidências no centro dos programas nacionais de aids, é igualmente importante que tais programas identifiquem, compreendam e lidem, rotineiramente, com os determinantes políticos das possibilidades de buscar e utilizar essas evidências para orientar as políticas e programas nacionais. Estes autores sugerem que:

Policy emerges through interactions among institutions (the structures and rules which shape how decisions are made), ideas (which include not only evidence but also the way that problems and solutions are framed - often based on underlying values and training) and interests 
(groups and individuals who stand to win or lose from change) (Buse, Dickinson e Sidibé, 2008, p. 572).

Comentam, ainda, que, apesar do destaque para as políticas na resposta à epidemia de aids, resultados de revisão de literatura sobre mudanças de políticas de aids em países de baixa e média renda indicam um pequeno número de estudos de caso empíricos na literatura. A maior parte da atenção desta literatura dedica-se a histórias de grande sucesso e questões altamente polêmicas em um número muito pequeno de países, enquanto permanecem ignoradas ou pouco exploradas questões como a formulação de políticas de facto que abordam a pandemia de HIV no resto do mundo. Segundo estes autores, há forte indicação na literatura sobre políticas em aids a respeito de sua determinação por meio da ação: a) de instituições, como instituições políticas, profissionais, religiosas, organizacionais e sociais (por exemplo, as instituições que regem as normas de gênero e sexualidade), que representam alvos de longo prazo para a mudança política, mas demandam, para ter tais normas alteradas, a condução de um diálogo político transparente e público com estas instituições, para entender como seus valores e costumes afetam os riscos de infecção pelo HIV e as respostas ao vírus; b) de ideias, como o papel das construções sociais sobre quem se acredita estar em risco na epidemia sobre a construção de legitimidade das políticas, ou como valores morais sobre sexualidade e uso de drogas conformam decisões sobre como se deve agir e a natureza da ação decorrente; ou as formas como determinadas questões são colocadas no cenário público, gerando como resultado políticas bastante diferentes. Embora identifiquem caráter quase que intuitivo da associação entre os interesses e as políticas, estes autores apontam que a literatura estudada costuma falhar em explicitar os interesses subjacentes à ação ou à inação das políticas de aids.

Neste sentido, sugerem que juntamente à proposição de aprofundar o conhecimento sobre a epidemia e sua resposta nacional, seja realizada análise das lacunas programáticas com vistas a informar o desenvolvimento de políticas baseadas em evidências, cujas perspectivas de execução julgam dever ser amparadas por uma análise política prospectiva que aborde as interações entre instituições, ideias e interesses no contexto local (Buse, Dickinson e Sidibé, 2008). 
Como são definidas as ações de prevenção? São levadas em consideração, no planejamento e na execução de tais ações, as particularidades da experiência da chamada "população-alvo" com as políticas e ações de prevenção? Consideram-se, nestas políticas e ações, os sentidos, projetos, vidas das populações a quem se destinam? Que papel tem, no planejamento e na execução de tais ações de prevenção, o julgamento dos profissionais acerca das vivências, experiências e afetos dos gays, travestis e outros HSH? Que papel tem na definição das políticas e atividades de prevenção, as percepções e expectativas de reações de grupos políticos - reacionários ou progressistas - e da "sociedade em geral", tanto no sentido do temor de maior discriminação, como no de identificar a ausência de legitimidade na sustentação de políticas públicas que busquem garantir liberdades individuais, ou suporte social, voltadas a grupos marginalizados?

A persistência da concentração da epidemia na categoria epidemiológica dos homens que fazem sexo com homens (HSH) no Brasil me faz questionar se as políticas e ações de prevenção desenvolvidas no país não têm sido suficientes para enfrentar os determinantes desta epidemia. Ademais, ao adotar o quadro da vulnerabilidade e dos direitos humanos, compreendo que tais políticas e ações de prevenção integram indissociavelmente os determinantes da epidemia (Ayres et al., 2010; Ayres et al., 2012).

Neste sentido, as proposições do UNAIDS (2007) de "Know your epidemics and your current response" estabelecem como parâmetros de análise que devem orientar políticas de enfrentamento da epidemia e de prevenção: o aprimoramento dos conhecimentos sobre a epidemia; a identificação dos seus determinantes; a produção de evidências para orientar políticas públicas de prevenção e compreender os determinantes políticos relacionados à incorporação, ou não, destas evidências nas políticas e programas disponíveis. O presente estudo alinha-se a este último aspecto, buscando analisar as políticas de prevenção da infecção pelo HIV voltadas a homens que fazem sexo com homens em diálogo com ativistas e gestores de políticas públicas de aids. 


\section{Referencial teórico}

Esta tese insere-se na tradição de uma "escola de pensamento" no campo da Saúde Coletiva que se desenvolveu tendo por base o Departamento de Medicina Preventiva da Faculdade de Medicina da Universidade de São Paulo a partir do trabalho seminal de Maria Cecília Ferro Donnangelo (Mendes-Gonçalves, 1995; Nunes, 2008).

Entendo, aqui, a ideia de uma "escola de pensamento" tal como expressa por Ricardo Bruno Mendes-Gonçalves (1995), colaborador direto de Cecília Donnangelo:

Uma "escola" de pensamento, investigação e prática educacional não se sustenta, como tantas "igrejas" acadêmicas, na devoção a um referencial teórico-metodológico, nem na obsessão por um qualquer desenho de pesquisa, nem na restrição a um particular objeto de interesse, nem tampouco ao que é evidente em qualquer delas: um certo jargão e uma certa forma tendencial de encadeamento lógico entre as proposições isoladas de um discurso e sua estrutura mais geral. Será sempre um certo número, menor ou maior, de construções conceituais, organizadas ao redor e por dentro de certos valores históricos que dará, ao conjunto dos trabalhos que interagem a partir da adesão operativa àqueles valores e conceitos, o caráter de "escola", aquela quase inefável marca registrada que permite ao observador treinado a identificação da origem e do pertencimento de um trabalho isolado qualquer que lhe caia em mãos. Menos do que um paradigma, portanto: mais do que uma vocação institucional, por outro lado (Mendes-Gonçalves, 1995, p. 1389).

Reconhecendo que esta tese também se filia a esta "escola", torna-se importante apresentar os conceitos e valores em que se ancora sua tradição. Segundo Mendes-Gonçalves (1995), são eles: a historicidade, em contraposição às concepções "naturalistas" de natureza, saúde e doença e fetichista e "neutra" de tecnologia; a socialidade, compreendida como a "busca das formas particulares de estabelecimento e reprodução de relações sociais entre indivíduos, nas práticas que constituem o campo visado pela Saúde Coletiva"; o conceito de estrutura entendido como:

(...) produto intelectual que visa capturar os sentidos e regularidades impressos pelos sujeitos históricos aos processos de reprodução e reprodução ${ }^{12}$ das práticas sociais (...) e a situa como fundamento teórico antes do que ontológico (Mendes-Gonçalves, 1995, p. 140).

\footnotetext{
${ }^{12}$ Ao invés de usar produção (infraestrutural) e reprodução (superestrutural), o autor colocou o re com hífen para assinalar o caráter reiterativo da produção via tecnologia.
} 
Por fim, o conceito de totalidade compreende a relação dialética de determinação recíproca entre parte e todo, individual e coletivo, buscando superar toda oposição conceitual e lógica entre os mesmos. De forma que toda aproximação conceitual e metodológica leve em conta esta mútua determinação.

Dentre os valores que Mendes-Gonçalves (1995) identifica à "escola" encontram-se a Razão e a Esperança, caracterizando-a como herdeira tardia da tradição iluminista com inspiração marxiana. A razão foi traduzida pelo autor como "confiança na racionalidade dos seres humanos como poder capaz de re-organizar e re-orientar suas intervenções práxicas no mundo, na vida, na sociedade, na história, no conhecimento" (Mendes-Gonçalves, 1995, p. 141). A esperança, por sua vez, impõe-se "menos como norma moral que como valor histórico objetivo para os seres humanos" (Mendes-Gonçalves, 1995, p. 141).

Esta "escola" caracteriza-se pela incorporação da teoria marxiana ao campo da saúde. Parte, inicialmente, da contribuição original de Cecília Donnangelo ao estudo das relações entre medicina, saúde e sociedade e, posteriormente, dos estudos de Ricardo Bruno Mendes-Gonçalves sobre a prática médica como trabalho, que vieram conformar sua Teoria do Processo de Trabalho em Saúde (Mendes-Gonçalves, 2017).

Ao pensar as práticas médicas como trabalho - o que se pode estender mais amplamente para as práticas de saúde em geral - e estabelecer diálogo com a obra de Canguilhem (Ayres, 2016), Mendes-Gonçalves abre a possibilidade de que se compreenda que a conformação dos objetos (p. ex.: corpo homossexual), dos instrumentos (p. ex.: anamnese clínica ou aconselhamento para prevenção), dos saberes (conhecimentos científicos acerca da aids, formas de transmissão; conhecimentos técnico-operatórios acerca das formas de prevenção) e os produtos do trabalho médico ( $p$. ex.: controle da doença) são constituídos por normatividades concernentes a modos de andar a vida histórica e socialmente determinados.

Tal compreensão abre a possibilidade para análises críticas acerca dos valores e normatividades que instruem as práticas de saúde. Assim como coloca o desafio da reconstrução das práticas por meio de recursos teórico-conceituais, técnicos e 
científicos que convoquem os profissionais a explicitar esta consubstancialidade tecnosocial das suas práticas e sua participação, como sujeitos políticos, nas mesmas.

Este estudo pauta-se no binômio dos conceitos de vulnerabilidade e Cuidado, entendidos, aqui, como conceitos reconstrutivos das práticas de saúde. A grosso modo, enquanto a vulnerabilidade busca reconstruir as formas de se efetivar diagnósticos em saúde que permitam ampliar a compreensão acerca das necessidades de saúde de segmentos populacionais; o conceito de Cuidado almeja oferecer a tais segmentos práticas de saúde que levem em consideração a autonomia dos sujeitos e o seu próprio saber acerca de sua saúde e vida. Apresento, a seguir, os dois conceitos e seus contextos de construção.

\section{Vulnerabilidade e Cuidado}

Como indicado anteriormente, as análises fundamentadas no conceito de vulnerabilidade foram originalmente apresentadas no livro "Aids in the world"13, publicado, em 1992, por iniciativa da Coalizão Global de Políticas contra a AIDS e organizado por Jonathan Mann, Daniel Tarantola e Thomas Netter (Mann, Tarantola e Netter, 1993).

Dennis Altman (1995), em seu livro "Poder e comunidade", nos ajuda a compreender o contexto de proposição da vulnerabilidade como ferramenta conceitual e técnica no âmbito da saúde pública global. Altman (1995) localiza o surgimento da epidemia de aids, assim como da resposta comunitária a ela, em um mundo sujeito às políticas de ajuste estrutural, lideradas por Ronald Reagan e Margareth Thatcher, que buscavam conter os gastos com saúde. Situa, no entanto também, a emergência da epidemia em um contexto, no âmbito da saúde pública mundial, que favoreceu o entendimento da necessidade de envolvimento das comunidades afetadas como elemento fulcral na construção das respostas à epidemia. O contexto a que o autor se refere é o da emergência de novos paradigmas, como o da "nova saúde pública", como descrita por Altman (1995) e de outros processos de renovação das práticas de saúde,

\footnotetext{
13 Traduzido, parcialmente, no Brasil pela ABIA, em 1993, em edição organizada por Richard Parker, Jane Galvão e José Stalin Pedrosa (Mann, Tarantola e Netter, 1993).
} 
como o movimento de Promoção da Saúde que eclode especialmente a partir dos anos 1980 (Ayres,2009). Estes novos paradigmas buscavam reorientar as práticas de saúde com vistas a aprimorar as condições de saúde das populações em todo o mundo. Fundamentaram, assim, as proposições da Carta de Ottawa, produto da I Conferência Internacional de Promoção da Saúde (Buss, 2003), atribuindo centralidade à participação e ao fortalecimento da comunidade "na definição de prioridades, tomada de decisões, planejamento de estratégias e implementação de todos estes itens para se alcançar uma saúde melhor"(Carta de Ottawa ${ }^{14}$, na tradução de Altman, 1995).

As propostas de reorientação das práticas de saúde pública pretendiam transformar um modelo de ação, caracterizado por Jonathan Mann como:

[...] centrado na descoberta dos agentes externos da doença, impotência e morte prematura. Inevitavelmente, a ênfase era médica e tecnológica, envolvendo especialistas engenheiros e, para determinados objetivos, esta abordagem era bastante eficaz. Entretanto, este paradigma anteviu uma dicotomia fundamental entre os interesses individuais e sociais; consequentemente, e de acordo com o espírito da época, os governos foram convocados a mediar e prevenir a doença através de leis e do trabalho das burocracias. A atenção às considerações comportamentais, sociais e societárias foi, com frequência, rudimentar e ingênua. Os sistemas de saúde pública frequentemente favoreciam a coação e a compulsão sem considerar seus efeitos sobre os direitos humanos (Mann, $1991^{15}$, p. 1 apud Altman, 1995, p. 36).

\footnotetext{
14 Identifiquei na redação deste capítulo que a tradução de trecho da Carta de Ottawa feita para o livro de Altman (1995) difere da tradução da Carta de Ottawa disponibilizada pelo Ministério da Saúde, mas adotei a tradução oferecida pelo livro por se adequar melhor à construção discursiva que elaborei. Para conhecimento dos leitores apresento, aqui, o trecho intitulado "Strengthen community action" no original em inglês e "Reforçando a ação comunitária" na tradução ao português disponibilizada pelo MS:

"Health promotion works through concrete and effective community action in setting priorities, making decisions, planning strategies and implementing them to achieve better health. At the heart of this process is the empowerment of communities, their ownership and control of their own endeavours and destinies."

Disponível em: http://www.euro.who.int/ data/assets/pdf file/0004/129532/Ottawa Charter.pdf [acesso em 19.04.2018].
}

\footnotetext{
"A promoção da saúde trabalha através de ações comunitárias concretas e efetivas no desenvolvimento das prioridades, na tomada de decisão, na definição de estratégias e na sua implementação, visando a melhoria das condições de saúde. O centro deste processo é o incremento do poder das comunidades - a posse e o controle dos seus próprios esforços e destino."

Disponível em: http://bvsms.saude.gov.br/bvs/publicacoes/carta_ottawa.pdf [acesso em 19.04.2018].

15 Mann Jonathan. The new health care paradigm. In: AIDS Health Project. Focus: a guide to AIDS research and counselling. São Francisco: University of California. 1991: 6(3), 1.
} 
Mann, Tarantola e Netter (1993) importaram para o campo da saúde o termo vulnerabilidade - originalmente utilizado na advocacia internacional pelos Direitos Humanos para designar indivíduos e grupos fragilizados em seus direitos de cidadania (Ayres et al., 2003) - para abordar, em sua primeira formulação, a interdependência da vulnerabilidade pessoal à infecção pelo HIV ou ao adoecimento por aids, da capacidade de proteção assegurada pelo programa nacional e pelo contexto de suporte social de seu país de origem. Em suas formulações posteriores, Mann e colaboradores foram ampliando as articulações entre vulnerabilidade e direitos humanos (Mann et al., 1994, Mann e Tarantola, 1996).

No Brasil, a grande receptividade à noção de vulnerabilidade se deu por uma série de motivos inter-relacionados, tais como o contexto social e político da redemocratização do país e a ação e as reivindicações de diferentes movimentos sociais em suas lutas por direitos, como os movimentos da reforma sanitária, feminista, antimanicomial, homossexual e de aids $\neg-$ em articulações com a academia e estendendo-se, para além da sociedade civil, com agentes de governo - que vieram a impulsionar a constituição do Sistema Único de Saúde, no qual se estruturaram modelos de atenção integral à saúde. Neste contexto, contribuições dos campos da medicina social e da saúde coletiva brasileiras - com sua característica interdisciplinaridade permitiram o adensamento conceitual da noção de vulnerabilidade, de forma que se torna possível hoje nomeá-la como um conceito. É neste sentido que se reconhece que, no Brasil, o debate sobre a vulnerabilidade ganhou centralidade, acadêmica e politicamente (Ayres et al., 2012).

Os esforços de reorientação das práticas de saúde e de revisão de paradigmas, representados nas obras já citadas de Mann e colaboradores (1993; 1996), puderam ser adensados e ganhar contornos conceituais reconstrutivos bastante vigorosos no Brasil, dada a especial atenção que recebia, no ambiente acadêmico da Saúde Coletiva, a consubstancialidade da teoria e dos saberes científicos e técnico-operatórios com os processos sócio-políticos da saúde de modo mais amplo (Ayres, 2011, p. 19). Tal adensamento recebeu particular desenvolvimento no âmbito da Teoria do Processo de 
Trabalho em Saúde, desenvolvido por Mendes-Gonçalves (2017), propiciado pelos estudos de José Ricardo Ayres sobre as relações entre a epidemiologia e as práticas de saúde - em seu mestrado "Epidemiologia e emancipação" (1995) e doutorado "Sobre o risco: para compreender a epidemiologia" (1997). No mestrado, Ayres (1995) realiza uma crítica histórico-epistemológica do conhecimento epidemiológico, dada sua centralidade para o campo da Saúde Coletiva, buscando recuperar suas pretensões emancipadoras, particularmente na problematização acerca da forma como o social foi sendo progressivamente "domesticado" nas relações estabelecidas entre a epidemiologia e as tecnologias da saúde ao longo da história dessa ciência. Em seu doutorado, em estreito diálogo com as filosofias de Habermas e Gadamer, dedica-se ao estudo do conceito epidemiológico de risco, buscando compreender as condições históricas para sua emergência e as suas implicações práticas para a medicina e a saúde pública. Nestes estudos, procedeu a uma importante guinada epistemológica, no sentido de compreender o caráter discursivo e hermenêutico dos discursos científicos e das práticas de saúde que nele se fundamentam.

É assim que se pode entender o investimento e as apostas feitas no conceito de vulnerabilidade $^{16}$, definido por Ayres como "um conjunto de aspectos individuais $e$ coletivos relacionados à maior suscetibilidade de indivíduos e comunidades a um adoecimento ou agravo e, de modo inseparável, menor disponibilidade de recursos de todas as ordens para sua proteção" (Ayres, 2009, p. 446). Neste sentido, os diagnósticos fundamentados pelo conceito de vulnerabilidade buscam caracterizar, de forma particularizada, os determinantes sociais e políticos dos processos e relações multicausais que levam a diferentes conformações da epidemia, desde a ocorrência diferencial da infecção, como do curso do desenvolvimento da doença e seus possíveis desfechos. Por seu potencial de construir totalidades compreensivas de natureza aplicada, explicitando as dimensões éticas, políticas e relacionais das práticas de saúde,

\footnotetext{
16 Logo após o doutorado, em meados dos anos 1990, Ayres iniciou um programa de pesquisa intitulado "Identidade sociocultural e saúde na adolescência: auto-representação e vulnerabilidade ao HIV/Aids entre meninas e meninos da periferia de São Paulo", por meio de um projeto financiado pela Fundação MacArthur - Chicago, USA - de 1995 a 1998. Foi neste momento que me inseri no grupo - logo após participar do Curso de Aprimoramento em Saúde Coletiva (1994) - formado também por Ivan FrançaJunior e que veio, posteriormente, a incluir Haraldo César Saletti Fo., Ângela Freitas e Marco Antonio Santos, à época estudantes da graduação em medicina na FMUSP. Para conhecer tal projeto: https://www.macfound.org/media/files/FLD Report Final Case Studies September 2017.pdf.
} 
fortalece o diálogo, no campo da saúde, entre as disciplinas biomédicas, sociais e as humanas; assim como estreita e legitima os saberes tidos como leigos - a sabedoria prática.

Os trabalhos de Ayres (2001) buscaram também rever a concepção de sujeito predominante no pensamento da saúde, com base no diálogo com autores da filosofia contemporânea, como Gadamer, Ricoeur e Habermas, buscando ressaltar "o caráter imediatamente relacional e irremediavelmente contingente de nossas identidades e historicidades como indivíduos e grupos". Assim, em sua apropriação no âmbito da Saúde Coletiva brasileira, e somando-se a contribuições vindas do campo da psicologia social, o conceito de vulnerabilidade ancora-se numa concepção relacional da subjetividade, entendida como constituída nos (e constituinte dos) contextos intersubjetivos que conformam as experiências dos sujeitos e o campo de possibilidades para os mesmos (Ayres, 2001; 2002; 2011a; Ayres et al., 2012).

O quadro da vulnerabilidade, ao estabelecer três diferentes dimensões de compreensão dos processos saúde-doença - individual, social e programática - inova de forma significativa o entendimento dos determinantes sociais e políticos dos processos saúde-doença por compreender as próprias ações e o conjunto de saberes, tecnologias, instrumentos e serviços como determinantes das condições de saúde que se busca conhecer e transformar. De forma que as próprias intervenções - preventivas e assistenciais - são compreendidas como constitutivas da determinação das infecções e do adoecimento por aids, por sua disponibilidade, acessibilidade, sua organização técnica, sua orientação moral, entre outras características. É, neste sentido, que se propõe adotar a expressão "processos saúde-doença-cuidado" como a mais pertinente para nomear a inseparabilidade desses momentos na apreensão e intervenção das questões de saúde (Ayres, 2009; Ayres, Paiva e França-Jr, 2011). A vulnerabilidade caracteriza-se, assim, como uma categoria diagnóstica com pretensões de orientar 0 desenvolvimento de ações preventivas em diferentes planos (dos interpessoais aos estruturais), incorporando a perspectiva dos sujeitos afetados e seus contextos de intersubjetividade. Trata-se de um construto de caráter pragmático, uma construção imediatamente interessada em "saber o que fazer" (Ayres, 2011, p.172). 
Uma tal mudança de perspectiva na forma de construir "diagnósticos de situação" para a ação em saúde reclama também esforços reconstrutivos no plano dos pressupostos, recursos e estratégias dessas próprias ações. É nesse sentido que se coloca o conceito reconstrutivo de Cuidado (Ayres, 2004).

Ao longo da história da epidemia podemos encontrar uma grande variedade de tecnologias em saúde voltadas para a prevenção de HIV/aids: campanhas de mídia de massa ou segmentada; discursos públicos; aconselhamento individual; oficinas de sexo mais seguro; materiais educativos impressos; fechamento de saunas e boates; vídeos educativos; educação para sexualidade em escolas (com base na promoção de direitos sexuais, assim como na promoção da abstinência, da fidelidade e da redução do número de parceiros sexuais); uso de preservativo; indicação de Profilaxia Pós-exposição (PEP) em pronto-atendimento; recomendação de Profilaxia Pré-Exposição (PrEP); organização de serviços específicos; oferta de autoteste em farmácia comercial; entre outros. Reconhecendo que as tecnologias não se configuram, simplesmente, como aplicações do conhecimento científico ou de recomendações de "como fazer", embora também o sejam, é fundamental compreendermos que há uma série de escolhas, decisões e mediações, feitas por profissionais e gestores de saúde, que implicam na ampliação ou redução das possibilidades para as vidas daqueles a quem se dirigem tais tecnologias. Poder compartilhar tais escolhas e decisões com aqueles efetivamente implicados nas mesmas, abrindo-nos como mediadores entre desejos e possibilidades, é o que se coloca como pretensão do conceito de Cuidado (Ayres, 2011).

A perspectiva do Cuidado, no campo das práticas de saúde, tem sido mais comumente associada à dinâmica das relações interpessoais entre profissionais e usuários dos sistemas e serviços de saúde no âmbito das discussões sobre integralidade e sobre humanização da prática médica e em saúde (Ayres, 2011a). Aceitando, no entanto, o convite de Ayres (2004), entendo ser possível e promissor apropriar-me do conceito de Cuidado na esfera pública da saúde e, particularmente, no campo de discussões desta tese, no aprimoramento da compreensão sobre as políticas públicas de prevenção. 
O Cuidado apresenta-se, neste sentido, como categoria reconstrutiva em sua pretensão de reconciliar as práticas em saúde - persistentemente marcadas por caráter individual-universalista (Ayres, 2004) - e a vida, com seus sentidos existenciais e singulares. Caracterizado por Ayres como a "designação de uma atenção à saúde imediatamente interessada no sentido existencial da experiência do adoecimento, físico ou mental, e, por conseguinte, também das práticas de promoção, proteção ou recuperação da saúde" (Ayres, 2004, p. 89).

Os dois conceitos, vulnerabilidade e Cuidado, articulam-se retroalimentando-se na efetivação das práticas em saúde coletiva. Enquanto a vulnerabilidade efetiva diagnósticos buscando construir sínteses que articulem conhecimentos teóricoconceituais, técnico-operativos e práticos das dimensões comportamentais, sociais e político-institucionais com relação às suscetibilidades individuais e coletivas com vistas a orientar "o que fazer", o Cuidado deve ofertar a indivíduos e grupos os saberes e as práticas mais convenientes para suas necessidades singulares, com vistas à efetiva redução de suas vulnerabilidades - por meio de ações de promoção, proteção e recuperação de sua saúde.

Em sua dimensão reconstrutiva, o Cuidado almeja à transformação dos horizontes normativos das ações de saúde, abrindo a escuta aos sentidos existenciais do que significa bem viver aos indivíduos e grupos para os quais se voltam as ações - seus projetos de felicidade (Ayres, 2008). Para isso, articula aos conhecimentos biomédicos, os conhecimentos das ciências sociais e humanas, assim como saberes práticos derivados dos saberes do cotidiano.

Para orientar a construção deste fazer em saúde "sabendo o quê", Ayres (2011, p. 139) identifica duas esferas de interesse que se articulam no Cuidado em saúde: o êxito técnico e o sucesso prático. A noção de êxito técnico refere-se ao sentido instrumental da ação em saúde, articulando os meios necessários para alcançar os fins pretendidos. O que pode ser exemplificado, tomando em conta nosso objeto de estudo, pelo uso da profilaxia pós-exposição ${ }^{17}$ (PEP) quando houver rompimento, ou não uso,

\footnotetext{
17 A PEP consiste no uso de medicamentos antirretrovirais, tomados por um período de 28 dias consecutivos, por pessoas sabidamente soronegativas, com vistas a evitar a infecção, quando houver possível ou sabida exposição ao vírus.
} 
da camisinha em uma relação sexual penetrativa com pessoa de quem não se conheça o status sorológico, até 72 horas após a exposição. A noção de sucesso prático, por sua vez, diz respeito aos sentidos experimentados por indivíduos e populações em função das implicações simbólicas, relacionais e materiais dessas ações em suas vidas cotidianas. Considerando a situação hipotética identificada acima, a experiência do uso da PEP terá diferentes significados para um homem homossexual que vive com os pais que não sabem sobre sua sexualidade; para um homem heterossexual casado que teve uma relação desprotegida com um parceiro desconhecido em um cinema de pegação; ou, ainda, para um jovem gay, que conta com o suporte de pais e amigos, cujo preservativo rompeu em uma transa eventual.

O conceito de Cuidado apresenta como pretensões a possibilidade de:

(...) fazer aparecer sujeitos onde antes havia apenas objetos (doenças, órgãos afetados, funções alteradas, ações limitadas); de promover o diálogo onde antes só havia monólogos dirigidos (pelo profissional) e prescrições (do profissional); de integrar em totalidades de sentido o que estava disperso em fragmentos objetivos (Ayres, 2011a).

Compreende-se com Ayres (2010) que há sempre no processo de trabalho em saúde uma dimensão hermenêutica. Ou seja, um processo de interpretação e compreensão de uma determinada situação com vistas a identificar do que se trata e o que se deve fazer diante da mesma. O processo de produção de sentido num movimento de interpretação e compreensão ocorre numa dialética entre uma totalidade que dirige nossa atenção para as partes, que no mesmo processo dão inteligibilidade à totalidade (Ayres, 2010). Ao referir-se ao cuidado integral em saúde, Ayres (2010) diferencia o que chamou de uma hermenêutica no sentido fraco de uma hermenêutica no sentido forte. Em sentido fraco, a hermenêutica no cuidado em saúde se orienta, como totalidade, pelo polo tecnocientífico das práticas de saúde e implica em "uma aplicação técnica de leis gerais a situações particulares de intervenção" (Ayres, 2010, p. 128). A hermenêutica em sentido forte, por sua vez, toma como referência o “(...) encontro entre sujeitos, que visa construir objetos e instrumentos capazes de produzir o que as pessoas precisam, em cada situação, para alcançarem seus projetos de felicidade" (Ayres, 2010, p. 128). Neste sentido, o cuidado em saúde na perspectiva 
específica da formulação e implementação de políticas, tal como visado no presente estudo, a partir de agora, chamarei de cuidado público. Este também se orienta sempre por uma hermenêutica em sentido fraco, na medida em que tome o estado da arte tecno-científica como padrão para definição de suas estratégias, métodos e recursos. Mas o cuidado público pode ser objeto de reflexão crítica na medida em que, orientados pela referência de uma hermenêutica em sentido forte, o indaguemos quanto à sua capacidade de ter em conta os significados das intervenções (ou não intervenções) propostas frente à situação sociocultural, econômica, política e existencial de populações e indivíduos por elas visados.

É neste sentido que, nesta tese, me volto, especificamente, para um diagnóstico da dimensão programática da vulnerabilidade de gays e outros HSH à infecção pelo HIV, a partir da perspectiva dos sujeitos diretamente implicados. Busco compreender o diálogo que vem se efetivando, desde o início da epidemia, na forma de políticas, ações e serviços - como vêm (ou não vêm) sendo desenhados e implementados - que pretendem oferecer medidas de proteção do HIV e da aids para gays e HSH. Parto do pressuposto de que o cuidado público que vem sendo ofertado integra leituras acerca da doença e da epidemia, diferentes abordagens preventivas, calcadas em distintos conceitos operativos, recursos tecnológicos e modalidades de gestão, configurando distintas possibilidades e respostas em diálogo com necessidades, desejos e anseios dos sujeitos gays e HSH.

Nossa experiência social com a aids já nos mostrou como algumas proposições técnicas da saúde pública se mostraram profundamente desrespeitosas e inadequadas em relação às vidas de gays e de suas comunidades, tais como recomendações de castidade, celibato ou monogamia estrita (preferencialmente heterossexual), como descritas por Edward MacRae (1987) no artigo "AIDS - prevenção ou novo tipo de segregacionismo?". Neste artigo, MacRae (1987) clamava por formas não-repressivas de prevenção e alertava para que nos atentássemos, como sociedade, "para que a atual crise de saúde não sirva de pretexto para aqueles que, sem se incomodar com os direitos civis da população, procuram constituir novas formas de estigmatização e segregação" (p. 80). 
Neste sentido, penso que se pode compreender este diálogo como imerso em uma disputa de horizontes normativos acerca do que se entende como necessário, em termos da saúde pública, e o que se entende desejável, ou pelo menos aceitável, pelos destinatários das políticas. É neste ponto, que nos parece promissor o diálogo do quadro da vulnerabilidade-cuidado com a Teoria da Luta por Reconhecimento (Honneth, 2009).

\section{Reconhecimento}

Em suas teorizações mais recentes, Ayres (2011a) propõe compreender os processos de vulnerabilização em saúde como decorrência de processos de (não)reconhecimento, ou desrespeito, a partir do diálogo com a Teoria do Reconhecimento de Axel Honneth (2009).

Axel Honneth (2009), discípulo de Habermas, coloca em questão a Teoria da Ação Comunicativa do mestre, ao interrogar as condições dos sujeitos para participar em condições simétricas de um diálogo com vistas à construção dos consensos racionais, ideia reguladora de emancipação social no quadro habermasiano. Em resposta a tal questionamento, Honneth desenvolve sua obra retomando o tema do reconhecimento proposto originalmente por Hegel, buscando fundamentar em teorias empiricamente baseadas uma concepção de subjetividade construída de forma relacional num mundo em conflito (em que vigoram relações assimétricas de poder entre os sujeitos individuais e coletivos). Partindo da centralidade do conflito moralmente motivado no processo de formação das identidades (pessoal e coletiva) e das transformações sociais, Honneth compreende que o motor das relações sociais na esfera pública é a luta por reconhecimento. Dito de outra forma, a teoria do reconhecimento coloca no centro do entendimento sobre a patologia social que limita o processo emancipatório "as causas sociais responsáveis pela violação sistemática das condições de reconhecimento" (Honneth apud Voirol, 2008, p. 51; Ayres, 2011a).

Neste sentido, Voirol (2008) argumenta que Honneth, ao contrapor-se ao entendimento habermasiano sobre a esfera pública, amplia seu quadro de análise sobre 
as relações sociais incorporando, para além das relações linguísticas e das competências comunicativas, dimensões extralinguísticas, integrando elementos como a corporeidade e as pretensões morais.

Por sua vez, Ayres (2011a) propõe uma redefinição do conceito de vulnerabilidade em saúde, nas bases da gramática moral proposta por Honneth, como "violação sistemática das condições de reconhecimento dos sujeitos relacionadas a experiências indesejáveis de saúde e doença" (p. 16) e contrapõe à vulnerabilidade no espaço público da saúde a ideia reguladora de um Cuidado Público, "como conjunto de políticas, serviços e ações que busquem identificar situações de desrespeito aos sujeitos e prover meios de superá-los" (p. 16).

Neste sentido, parece-me particularmente potente para o objeto de estudo desta tese o recurso à compreensão de processos de mudança social motivados por "pretensões normativas estruturalmente inscritas na relação de reconhecimento recíproco" (Honneth, 2003, p. 155).

Como se articulam, na Teoria do Reconhecimento, conflito e mudança social? Segundo Melo (2014), Honneth desenvolve uma teoria acerca dos conflitos sociais em que privilegia a motivação moral ou normativa em detrimento da concepção predominante no âmbito da sociologia, da ciência política e da filosofia política de luta pela autoconservação ou pelo aumento de poder. Com isso, não despreza a dimensão da autoconservação e do poder, mas os considera complementares à dimensão normativa das relações sociais. As lutas sociais moralmente motivadas são decorrentes de experiências de desrespeito social que mobilizam a ação política, vindo a reivindicar a instauração de relações de reconhecimento mútuo, ampliando normativamente o entendimento acerca do humano. Tais lutas tensionam a normatividade social vigente, impulsionando desenvolvimentos sociais, políticos e institucionais. Sendo assim, as transformações no âmbito das relações de reconhecimento mútuo são explicadas por Honneth como:

processos no interior da práxis social: são lutas moralmente motivadas de grupos sociais, sua tentativa coletiva de estabelecer institucional e culturalmente formas ampliadas de reconhecimento recíproco, aquilo por meio do qual vem a se realizar a transformação normativamente gerida das sociedades (Honneth, 2003, p. 156). 
A chave interpretativa para compreender os conflitos sociais são as experiências sociais de desrespeito decorrentes de violações da identidade - pessoal ou coletiva que mobilizam a ação política voltada à expansão das relações de reconhecimento mútuo (Melo, 2014). Em sua gramática moral dos conflitos sociais, Honneth articula desrespeito, identidade coletiva, luta por reconhecimento e mudança social. De forma que, segundo Melo (2014), para Honneth “a ideia básica é a de que sentimentos morais, quando articulados numa linguagem comum, podem motivar as lutas sociais" (p. 24).

$\mathrm{Na}$ teoria do reconhecimento de Honneth, a formação e constituição das identidades individuais se dá a partir do reconhecimento intersubjetivo. Desta forma, uma "autorrelação prática positiva" é dependente do reconhecimento do sujeito por parte dos demais membros de sua comunidade. Nas situações em que o reconhecimento não é bem-sucedido - por sua ausência ou por um falso reconhecimento - pode se desenvolver uma luta por reconhecimento, a partir da experiência do desrespeito, em que indivíduos que compartilham aquela experiência de reconhecimento denegado buscam instaurar condições para o reconhecimento recíproco (Melo, 2014).

Honneth distingue três formas de reconhecimento, com base na reconstrução do argumento hegeliano: o amor, o direito e a solidariedade. Cada modalidade de reconhecimento assegura ao sujeito o potencial de uma "autorrelação prática positiva": nas relações interpessoais de amor e amizade, a autoconfiança; nas relações jurídicas, o autorrespeito; na comunidade social de valores, a autoestima (Melo, 2014). De forma a ressaltar, como destaca Melo $(2014$, p. 22) "tanto o vínculo entre liberdade e autonomia individual quanto vínculos comunitários e societários".

As experiências de desrespeito correspondem às três formas de reconhecimento: experiências de maus tratos e violação à integridade física e psíquica comprometem a autoconfiança no âmbito das relações interpessoais; experiências de privação de direitos e exclusão afetam o autorrespeito, de forma a atingir a integridade social do sujeito como integrante de uma comunidade político-jurídica; e, por fim, 
experiências de degradação e ofensas ameaçam os sentimentos de honra e dignidade do sujeito como membro de uma comunidade cultural de valores (Melo, 2014).

Em sua perspectiva crítico-normativa, o conceito de reconhecimento, por meio de seus padrões, evidencia o caráter normativo intrínseco às relações sociais e aos conflitos sociais, oferecendo uma mediação à teoria para o ponto de vista dos atores sociais em conflito (Melo, 2014).

Assim, por meio da análise da dinâmica social produzida pelas experiências de desrespeito e pela luta por reconhecimento, pode-se depreender uma concepção formal de eticidade - pós-tradicional, democrática (Honneth, 2003, p. 274-275) compreendida como os pressupostos normativos que expressam as condições intersubjetivas que servem à autorrealização individual. Com isso, o autor estabelece a vinculação do propósito crítico de sua teoria à práxis política e social que promove a reconstrução das categorias normativas, de forma a assegurar os pressupostos intersubjetivos que podem garantir processos exitosos de autorrealização (Melo, 2014).

Melo (2014) defende, no entanto, que a compreensão desse processo deva ser politicamente contextualizada, o que implica em partir do entendimento das dimensões sociais em conflito, para posteriormente avaliar a fecundidade do conceito de reconhecimento como categoria explicativa e interpretativa. Neste sentido, o autor aponta que a melhor forma de evitar os riscos de psicologização ou antropologização, implicados na adoção do conceito de reconhecimento, é atribuir centralidade ao diagnóstico dos conflitos sociais e políticos em contraposição à centralidade da perspectiva ética de uma teoria fundada na autorrealização individual.

Uma última nota é importante ao adotar o conceito de reconhecimento: compreender as implicações teórico-metodológicas de sua localização no âmbito da teoria crítica. A teoria crítica funda-se, segundo Melo (2014), na pretensão de identificar e compreender as situações sociais de desigualdade, injustiça, opressão e desrespeito, ao mesmo tempo em que se busca identificar possibilidades concretas de superação prática, com vistas à emancipação. O que se deve fazer por meio da realização de diagnósticos de tempo que permitam identificar tendências - "tanto dos potenciais emancipatórios quanto dos obstáculos à emancipação" - e prognósticos (Nobre, 2011, 
p. 8). Busca-se, assim, uma relação dialética entre teoria e prática, sem o primado de uma sobre a outra, como explicita Nobre $(2011$, p. 8):

\begin{abstract}
Sendo assim, a teoria crítica não pode se confirmar senão na prática transformadora das relações sociais vigentes. As ações a serem empreendidas para a superação dos obstáculos à emancipação constituem-se em um momento da própria teoria. Nesse sentido, o curso histórico dos acontecimentos - como resultado das ações empreendidas contra a estrutura de dominação vigente - dá a medida para a confirmação ou refutação dos prognósticos da teoria. Note-se, entretanto, que a prática não significa aqui uma mera aplicação da teoria, mas envolve embates e conflitos que se costuma caracterizar como "políticos" ou "sociais". A prática é um momento da teoria, e os resultados das ações empreendidas a partir de prognósticos teóricos tornam-se, por sua vez, um novo material a ser elaborado pela teoria, que é, assim, também um momento necessário da prática.
\end{abstract}

Desta forma, busco empreender, neste estudo, um diagnóstico acerca das políticas de prevenção do HIV voltadas a gays e HSH, na perspectiva daqueles diretamente implicados. Pretendo, com isso, identificar, na trajetória histórica de tais políticas no campo da luta contra a aids, conflitos, tensões e experiências de desrespeito que ajudem a compreender o momento atual do enfrentamento da epidemia entre gays e HSH, assim como os limites e possibilidades para sua superação.

\title{
Objetivo
}

Compreender de que forma processos de (não)reconhecimento, ou desrespeito, no âmbito do cuidado público de saúde, compreendido como conjunto de políticas, serviços e ações voltadas à prevenção do HIV e da aids, contribuem para os processos de vulnerabilização de homens que fazem sexo com homens (HSH) ao HIV e à aids no contexto da epidemia e das respostas produzidas no Brasil e no estado de São Paulo, em particular. 


\section{CAPÍTULO 2}

\section{ASPECTOS METODOLÓGICOS E ÉTICOS}

Este estudo pode ser caracterizado como uma análise de políticas públicas na perspectiva proposta por Mattos e Baptista (2015). Alia-se, assim, às inquietações de outros pesquisadores e estudantes da área da Saúde Coletiva que tem estudado e buscado compreender o modo singular de construção de políticas de saúde no Brasil. Articula-se, ainda, aos esforços e à recomendação de pesquisadores do campo da aids que têm se dedicado à análise e compreensão das respostas políticas à epidemia (Parker, 1997; Parker, Galvão e Bessa, 1999; Mattos, 1999; Berkman et al., 2005; Buse, Dickinson e Sidibé, 2008). Assim como se associa aos estudos que tratam dos diálogos socioestatais, particularmente aqueles voltados às articulações no campo dos direitos sexuais, envolvendo os movimentos de aids, LGBT e feminista (Facchini, 2005; Vianna e Carrara, 2007; Carrara, 2016; Alvarez, 2014; Daniliauskas, 2016; Bulgarelli, 2017).

Trata-se de estudo qualitativo, que adota uma perspectiva interdisciplinar, em uma composição que integra diferentes técnicas de pesquisa. Houve produção de material empírico original por meio de entrevistas semiestruturadas com gestores de políticas públicas de prevenção e ativistas dos movimentos de aids e LGBT. A produção e interpretação desse material empírico, orientado pelo quadro teórico acima apresentado, foram cotejadas com documentos das políticas, serviços e ações de saúde, cuidado e prevenção do HIV e da aids voltadas às populações de gays e HSH; observação de caráter etnográfico de eventos presenciais e de atividades no âmbito das redes sociais atinentes à prevenção do HIV e da aids entre gays e outros homens que fazem sexo com homens; conversas informais com informantes-chave; e análise de resultados de outras pesquisas, quantitativas e qualitativas, disponíveis em bases públicas.

Atendendo ao convite de Mattos e Baptista (2015), acerca dos desafios no desenvolvimento dos estudos de análise de política de saúde no Brasil, espero que este estudo contribua com: 1) o desafio de reconhecer nossa trajetória político, social e cultural e suas interferências no processo político nacional; 2) o desafio de desenvolver 
e adaptar conceitos e abordagens que abarquem nosso modo de construção das políticas; e, por fim, 3) o desafio de explorar metodologias de análise que potencializem a reflexão sobre os objetivos e alcances dos estudos sobre política públicas de saúde.

Pretendi, assim, empreender uma reflexão crítica sobre as políticas de prevenção para melhor compreensão de como as decisões técnicas e políticas acerca da prevenção contribuem para determinar a maior ou menor vulnerabilidade à infecção pelo HIV entre HSH e quais determinantes políticos favorecem ou dificultam a implantação de políticas mais apropriadas.

\section{Percurso metodológico}

Realizei entrevistas em profundidade, orientadas por roteiro (Anexo A), com gestores de políticas públicas de prevenção e ativistas dos movimentos LGBT e de aids. Nas entrevistas, investiguei as trajetórias de engajamento dos depoentes com os campos de políticas para aids e LGBT e como estes atores caracterizam e avaliam as políticas públicas de prevenção do HIV e da aids voltadas para gays e outros HSH, buscando reconstruir historicamente esse campo da prevenção no país. Os/a entrevistados foram convidados/a a fazer uma reflexão crítica sobre momentos marcantes, sucessos, êxitos, fracassos, conflitos e tensões, assim como alianças e articulações com vistas ao estabelecimento destas políticas, com vistas a identificar seus limites e possibilidades. Também busquei, nas entrevistas, explorar os diferentes entendimentos acerca do papel do ativismo, dos problemas enfrentados nesta ação e as estratégias que vislumbram para o seu enfrentamento.

O conjunto de entrevistados/a foi composto por pessoas que mantêm ou mantiveram um envolvimento significativo com o enfrentamento da epidemia de HIV/aids no país, com foco particular nas políticas públicas de prevenção de HIV/aids voltadas a gays e HSH no estado de São Paulo e no país. Os/a participantes foram selecionados/a por sua experiência na elaboração, condução e acompanhamento e/ou controle social de políticas públicas de prevenção voltadas a gays e HSH. 
Uma lista inicial, com estimativa de oito participantes, foi elaborada com a ajuda de pares e do orientador, tomando como parâmetro a obtenção de uma totalidade compreensivo-interpretativa de sentidos sobre a questão investigada. Priorizei dar voz aos ativistas, tendo em vista o recorte teórico adotado, que prevê dar voz àqueles mais diretamente implicados e afetados pelo tema. Tomando em consideração as quase quatro décadas de enfrentamento da epidemia de aids, busquei assegurar a participação de ativistas que tenham se engajado neste campo de ação em diferentes momentos, com prioridade para a nova geração de ativistas. Sendo assim, ao longo da produção das narrativas, foram acrescentados dois novos nomes, a partir de minha observação acerca do campo de debates sobre prevenção em eventos e nas redes sociais. Não houve recusas expressas ao convite para participação nesta pesquisa. Foram incluídos/a, no total, dez participantes (apresentados no Quadro 1), tendo esse conjunto se mostrado suficiente para a elaboração de um quadro compreensivo capaz de propiciar a reflexão acerca da questão que orientou esta investigação.

Os/a depoentes foram convidados/a a participar desta pesquisa pessoalmente ou por meio de mensagem pessoal e as entrevistas foram realizadas em locais apropriados que permitiram assegurar o sigilo dos/as participantes, de acordo com a sua disponibilidade e conveniência, em uma ou duas tomadas.

Todas as entrevistas foram realizadas presencialmente, o que implicou em meu deslocamento para Brasília e o Rio de Janeiro, no período de julho a outubro de 2017. As entrevistas tiveram em média duração de 2 horas e 20 minutos, variando de 1 hora e dez minutos a três horas e dez minutos. As entrevistas foram gravadas e, posteriormente, transcritas. Uma exceção aconteceu na entrevista com Jorge Beloqui, que aconteceu em dois momentos: o primeiro, uma conversa informal, que não foi gravada, mas registrada em um caderno e posteriormente autorizada para ser considerada como fonte nesta pesquisa; e, posteriormente, na entrevista, seguindo o roteiro. A maior parte dos participantes provêm da região Sudeste do país ou tem aí sua atuação, principalmente no estado e na cidade de São Paulo - região em que foram notificados os primeiros casos de aids do país, assim como onde se deram as primeiras respostas comunitárias e governamentais para a epidemia de HIV/aids e que ainda concentra a maior parte dos casos e importante protagonismo nas respostas. 
Entre janeiro e fevereiro de 2018, enviei mensagens pessoais a cada um dos/as entrevistados/as agradecendo sua contribuição e compartilhando as entrevistas transcritas e o TCLE digitalizado. Neste momento, os/as entrevistados/as foram consultados acerca de aspectos das entrevistas que haviam deixado dúvidas. Metade dos entrevistados responderam aos questionamentos, alguns deles leram a transcrição e pediram para fazer algumas revisões, tais como desconsiderar alguns trechos que, posteriormente à entrevista, avaliaram não refletir sua experiência ou não ter elementos para fazer determinadas afirmações. No caso de Veriano Terto Jr., acabamos realizando uma segunda tomada, em uma vinda dele a São Paulo, pois eram muitas as dúvidas. Alguns dos entrevistados não responderam à mensagem.

O tratamento das entrevistas enfocou a identificação de regularidades e particularidades nas narrativas dos interlocutores desta pesquisa buscando compreender como se conforma o campo discursivo de ação em que se localizam: atores, articulações, discursos, conflitos e paradoxos. Atribuindo particular atenção à conformação de relações de desrespeito, compreendidas como relações de nãoreconhecimento das expectativas intersubjetivas de diferentes sujeitos. Um dos objetivos da análise foi exatamente identificar compartilhamentos significativos de experiências reconhecimento/desrespeito entre os entrevistados.

\section{Construindo uma totalidade interpretativa e compreensiva}

A primeira etapa de análise consistiu em uma breve recuperação histórica das políticas públicas de prevenção do HIV voltadas para gays e HSH vigentes no país nas décadas de 1980, 1990 e 2000, com base nas narrativas produzidas e seus cotejamentos (com: a literatura atinente ao tema da pesquisa; os documentos das políticas, serviços e ações de saúde, cuidado e prevenção do HIV e da aids voltadas às populações de gays e HSH; a observação de caráter etnográfico de eventos presenciais e de atividades no âmbito das redes sociais atinentes à prevenção do HIV e da aids entre gays e outros homens que fazem sexo com homens; e as conversas informais com informanteschave). Elaborei, assim, uma história narrativa (Epstein, 1996; Galvão, 2000) dos diferentes momentos das respostas políticas à epidemia de aids entre gays e outros 
homens que fazem sexo com homens no Brasil com vistas a compreender e constituir o cenário das políticas públicas de prevenção do HIV voltadas para HSH.

Esta narrativa histórica converge, na segunda e última parte do estudo, para uma análise da situação atual e, sempre tomando como base as entrevistas, buscando interpretá-la, ainda que de modo bastante tateante e preliminar, sob a perspectiva do conceito de reconhecimento. Este cenário constitui-se, assim, como uma totalidade de sentido mais rica, que subsidia a realização de um diagnóstico de tempo (Nobre, 2011; Melo, 2014), ao buscar reconstruir o histórico das políticas, serviços e ações de prevenção preconizados para as populações em estudo. Dessa forma, abarca informações como: contexto sociocultural, político e das políticas de saúde; caracterização/leitura (Girard, 2012) da epidemia; categorias e conceitos mobilizados para orientar as ações de prevenção; estratégias mobilizadas para a prevenção; respostas sociais; atores envolvidos na resposta; e políticas formalizadas em cada período.

Para tal empreendimento, as políticas públicas foram compreendidas tal como definido por Teixeira (1997):

o conjunto de diretrizes e referenciais ético-legais adotados pelo Estado para fazer frente a um problema que a sociedade lhe apresenta. Em outras palavras, política pública é a resposta que o Estado oferece diante de uma necessidade vivida ou manifestada pela sociedade (p. 41).

A proposição de Teixeira (1997) sobre as políticas públicas como resposta do Estado a um problema social está em conformidade com a noção de respostas à epidemia tradicionalmente usada no campo da aids (Mattos, 1999; Galvão, 2000). Jane Galvão (2000), em seu livro "AIDS no Brasil: agenda de construção de uma epidemia", referiu que considerava o termo "respostas" estar, ainda, em processo de elaboração. Segundo a autora, uma das poucas contribuições sobre o termo, até aquele momento, encontrava-se no livro "AIDS in the World II". Partindo do entendimento proposto ali por Mann e Tarantola (1996), de que as respostas institucionais são caracterizadas como um "mosaico complexo" de reação coletiva à epidemia, Galvão (2000) atribui destaque à parte IV, intitulada "respostas institucionais" em que são abordadas respostas como: 
os programas governamentais de Aids, direitos humanos, organizações nãogovernamentais, setor privado, agências das Nações Unidas e agências internacionais de financiamento (Mann e Tarantola, 1996).

Galvão (2000), que buscou contribuir, em seu livro, para ampliar as análises sobre as "respostas brasileiras à epidemia de aids" (p.15), defende a tese de que as respostas institucionais configuram uma "AIDS brasileira" (p. 17). Seguindo tal tradição, a própria autora desenvolveu análises específicas em que abordou as respostas das organizações não-governamentais (Galvão, 1997; 2000), as respostas religiosas frente à epidemia no Brasil (1997), assim como outros autores trabalharam com a ideia de respostas políticas à epidemia (Parker, 1997; Mattos, 1999); respostas jurídicas (Raupp, 2004), entre outras.

Com vistas a operacionalizar, na pesquisa, o que tem sido chamado de campo da aids (Parker, 1997; Câmara, 2002), no qual se dão as respostas à epidemia, o enquadrei como campos discursivos de ação, tal como proposto por Alvarez (2014) para analisar os feminismos. Entendo, assim, que as respostas à epidemia de aids configuram-se como respostas coletivas que se estendem para além da sociedade civil, não sendo produtivo, portanto, levar em consideração a distinção entre sociedade civil e Estado. À medida em que se mostrou conveniente, adotei a linguagem conceitual, o aparelho interpretativo e a nova unidade de análise cunhados por Alvarez (2014) para repensar as dinâmicas e mudanças no âmbito das articulações entre os movimentos sociais de aids e homossexual, gay ou LGBT - a depender dos diferentes momentos históricos, também o Estado e os outros setores envolvidos na resposta.

Tal proposição conceitual permitiu entender que os movimentos sociais, convencionalmente compreendidos como elementos, mais ou menos centrais, da sociedade civil, "se expandem para além da sociedade civil" (Alvarez, 2014, p. 17). Podem, assim, estar ancorados na sociedade civil, mas também estender-se "lateralmente" abrangendo várias outras instâncias organizativas da mesma, assim como expandir-se "verticalmente" para a chamada sociedade política, em direção ao Estado e a outras esferas de ação públicas dominantes, nacionais e transnacionais. 
É neste sentido que Alvarez (2014) afirma ser necessária uma unidade de análise diferente, para que possamos abandonar perspectivas de estudo que visem, por exemplo, pesquisar as articulações entre os movimentos sociais e o Estado ou a sociedade política, como segmentos estanques; mas que possamos examinar se, em um dado campo movimentista, existem atores ou vetores atuantes que se relacionam verticalmente, no interior do Estado ou das agências transnacionais, em um determinado contexto histórico e as implicações disso para o campo como um todo.

Para tal análise, pode-se discernir como alguns dos elementos que conformam um campo discursivo de ação: (a) atoras/es mais ou menos visíveis, hegemônicos, marginalizados; (b) malhas/teias/redes articuladoras; (c) pontos nodais; (d) dimensões verticais, horizontais, e talvez densidade; (e) discursos definidores; (f) lutas interpretativas/conflitos constitutivos; e (g) paradoxos transformadores.

Posteriormente, a partir das narrativas produzidas nas entrevistas, particularmente, daqueles trechos que se referem às tensões e aos conflitos no que tange à prevenção, procedi a duas naturezas de leitura interpretativa: 1) com vistas a caracterizar o cuidado público, busquei identificar: como as leituras acerca da doença e da epidemia são usadas para justificar políticas de prevenção; como se dão as diferentes abordagens preventivas, calcadas em distintos conceitos operativos e recursos tecnológicos; e, por fim, como se dão as diferentes modalidades de organização da gestão (recursos financeiros e humanos, as formas de participação e diálogo com a comunidade, continuidade das ações, avaliação, transparência, accountability); e 2) destaquei, nestes aspectos, aquelas respostas que expressam manifestações de indignação e experiências de desrespeito, de forma a mirar sob a perspectiva do reconhecimento e das capacidades e possibilidades de respostas das políticas no diálogo com necessidades, desejos e anseios dos sujeitos gays e HSH.

Para operacionalizar esta dimensão da análise das políticas de prevenção adoto o conceito de políticas sexuais (Carrara, 2015). Segundo Carrara (2015), o valor do conceito de política sexual (Weeks, 1989) se dá por permitir 
decisões judiciais, diferentes ativismos ou movimentos sociais etc. (p. 324).

Tal abordagem conceitual possibilita a análise de processos sociais que se dão em múltiplos planos articulando realidades nacionais ao plano internacional, por meio da mediação de organismos multilaterais que integram o sistema das Nações Unidas, tal como já mostraram Vianna e Lacerda (2004), como é o caso do Programa das Nações Unidas para a Aids, o UNAIDS, e da Organização Mundial da Saúde (OMS). Propicia, ainda, a abordagem do caráter heterogêneo e complexo das formas de regulação das práticas erótico-sexuais e das expressões de gênero, dado que tais formas de regulação se estabelecem com base no enfrentamento ou na coalizão de diversos atores ou forças sociais e expressam produções simbólicas de natureza muito diversa, tais como: concepções científicas, crenças religiosas, valores morais, princípios jurídicos, posições políticas, entre outras (Carrara, 2015).

A adoção do conceito de política sexual proporciona, ainda, a investigação simultânea dos distintos estilos de "gestão social do erótico e do sexual" (Carrara, 2015, p. 325), assim como a exploração da coexistência, muitas vezes conflituosa, de variados e frequentemente contraditórios modos de regulação moral, entendidos como conjuntos distintivos de técnicas de produção de subjetividades, ou seja, de sujeitos dotados de uma concepção de si e de uma corporalidade singulares (Carrara, 2015).

A análise no plano das políticas sexuais torna possível tratar o próprio dispositivo da sexualidade, compreendido como regime de gestão da sexualidade dotado de racionalidade, moralidade e política singulares, de forma a indagar acerca de suas fissuras, tensões e perspectivas de transformação, enfim, de sua historicidade (Carrara, 2015).

Em articulação com o referencial teórico do reconhecimento (Honneth, 2003), a análise das políticas sexuais permite compreendermos a hermenêutica que orienta as ações de prevenção, entendidas como cuidado público em saúde (Ayres, 2011a) e inseridas no plano das instituições e da política como espaço da construção de direitos. Baseia-se, assim, numa atribuição diferencial de significados e sentidos aos diferentes 
grupos populacionais aos quais se imagina que se dirigem tais ações e políticas, assim como a diferentes construções simbólicas sobre a epidemia, a infecção e a doença. Dessa forma, pode-se considerar que a população formada por gays e $\mathrm{HSH}$, à qual se dirigem políticas e serviços de prevenção, pode ser tomada como uma abstração - uma "comunidade imaginada", nos termos de Anderson (2008), como indica Facchini (2008) em relação à totalidade dos homens e travestis inseridos num contexto bastante fragmentado. Sendo assim, ao compreender as políticas como oportunidade para a construção de direitos, pode-se analisar a forma como seu conteúdo se relaciona a diferenciais no modo como esses direitos são legitimados (ou não) e reivindicados (ou não) pelo grupo em estudo por meio das demandas por reconhecimento.

\section{Tratamento analítico-interpretativo}

O trabalho compreensivo-interpretativo seguiu os pressupostos da hermenêutica contemporânea, buscando significados e sentidos identificados nas entrevistas e documentos (configuração) a partir do confronto com os "pré-conceitos" de que se partiu (pré-figuração), atentando para o modo como as conformidades e rupturas produzidos nesse confronto dialogam com as motivações práticas do estudo (refiguração), ou, sua aplicação (Ricoeur, 1994; Gadamer 1997).

O processo hermenêutico percorreu os seguintes passos: (a) leitura compreensiva dos depoimentos dos gestores e ativistas, visando impregnação, visão de conjunto e apreensão de suas particularidades; (b) identificação e problematização das ideias explícitas e implícitas; (c) busca de sentidos mais amplos subjacentes às falas dos informantes; e (d) construção de síntese interpretativa, articulando objetivo do estudo, base teórica adotada e dados empíricos.

\section{Aspectos Éticos}

O protocolo desta pesquisa foi submetido à avaliação do Comitê de Ética em Pesquisa da Faculdade de Medicina da Universidade de São Paulo (CEP/FMUSP), em cumprimento aos preceitos da Resolução CNS n 466/2012 do Conselho Nacional de 
Saúde - Comissão Nacional de Ética em Pesquisa (CONEP), tendo sido registrado sob o no 140/16. Tal avaliação se deu em dois momentos. Inicialmente, foi avaliado o projeto inicial desta pesquisa, tendo sido aprovado em maio de 2016 (Anexo B). Ao longo do aprofundamento do estudo e de discussões sobre a condução da pesquisa, foram realizadas pequenas modificações no título e na metodologia do projeto, indicando a necessidade de uma reavaliação. Depois de apresentadas e justificadas, as alterações foram aprovadas em janeiro de 2018, por meio de novo parecer (Anexo C).

Com base nesses preceitos, foram respeitados os princípios éticos de sigilo e anonimato dos informantes e prestadas todas as informações necessárias sobre a realização da pesquisa, os recursos metodológicos utilizados e as questões investigadas, assim como sobre o caráter voluntário da participação. Com fins de garantir o fornecimento e clareza dessas informações, foi apresentado a cada informante um Termo de Consentimento Livre e Esclarecido (TCLE; Anexo D), devidamente aprovado pelo CEP/FMUSP, tendo a concordância e assinatura do informante como condições para a realização das entrevistas. No momento da entrevista, foi oferecido aos/à participantes o acesso às transcrições e a possibilidade de revisão dos depoimentos.

Inspirada em procedimento desenvolvido por Pinheiro (2015), que realizou investigação que se aproxima à desta tese - tanto no tema abordado, como na metodologia adotada - foi oferecido aos/à entrevistados/a a possibilidade de serem ou não identificados na pesquisa, a partir de item com as alternativas de identificação de autoria ou garantia de anonimato. Esse arranjo procedimental não isenta a pesquisadora dos cuidados éticos de não-exposição e proteção dos entrevistados/a, mas permite sua identificação, levando em conta que se tratam de pessoas implicadas e posicionadas pessoal e politicamente no campo de luta contra a aids. Todos os/a entrevistados/a consentiram com sua identificação como entrevistados desta pesquisa.

\section{Caracterização dos entrevistados}

Procedo, a seguir, a uma breve apresentação dos entrevistados e de suas trajetórias de engajamento com o campo, que trazem, em meu entender, perspectivas 
singulares de entendimento acerca da aids e da prevenção que contribuem para compor o cenário apresentado por mim. Destaco, no entanto, que as contribuições não serão analisadas em função das trajetórias individuais. Na composição do cenário, aqui apresentado, o tratamento foi dado ao conjunto das narrativas produzidas pelos entrevistados, sujeitos que participam de uma mesma luta, ainda que a partir de posições diferentes. Posições que não são diferentes e demarcadas a todo o tempo, como indicado acima.

Alguns aspectos foram levados em consideração na escolha dos entrevistados. Busquei assegurar ter entre os/a interlocutores/a desta pesquisa, pessoas: 1) com experiência e envolvimento no campo com as políticas de prevenção de HIV, seja pela perspectiva da gestão ou pela do movimento social; 2) com engajamento no campo em diferentes momentos da resposta à epidemia; 3) com diferentes modalidades de atuação no campo - tendo em vista as diferentes formas de atuação das organizações de base comunitária em resposta à aids: cuidado e apoio, prevenção e educação e pressão política (Altman, 1995); 4) assim como, com capacidade de reflexão e elaboração sobre o campo e sobre sua experiência.

\section{Quadro 1 - Apresentação e caracterização dos/a interlocutores/a na pesquisa}

\begin{tabular}{|l|l|}
\hline Interlocutor & Engajamento e atuação no campo \\
\hline Paulo Roberto Teixeira & $\begin{array}{l}\text { Participação no movimento homossexual (déc. 1980) e gestor } \\
\text { de políticas de aids (décs. 1980 em diante) }\end{array}$ \\
\hline Maria Clara Gianna & Gestora de políticas de aids (déc. 1980 em diante) \\
\hline Ivo Brito & Gestor de políticas de aids (déc. 1990 em diante \\
\hline Jorge Beloqui & $\begin{array}{l}\text { Ativista movimento homossexual (déc. 1980) e de aids (1980 } \\
\text { em diante) }\end{array}$ \\
\hline Veriano de Souza Terto Júnior & $\begin{array}{l}\text { Ativista movimento homossexual (déc. 1980) e de aids (1980 } \\
\text { em diante) / pesquisador }\end{array}$ \\
\hline Beto de Jesus & Ativista movimento LGBT (déc. 1990 em diante) / Consultor \\
\hline Matheus Emilio Pereira da Silva & Ativista movimentos LGBT e de aids (déc. 2010 em diante) \\
\hline Gabriel Estrela & $\begin{array}{l}\text { Ativista LGBT e aids (déc. 2010 em diante) / Ator, YouTuber, } \\
\text { consultor }\end{array}$ \\
\hline Carué Contreiras & $\begin{array}{l}\text { Ativista LGBT e aids (déc. } 2010 \text { em diante) / Educador } \\
\text { comunitário em pesquisas sobre PrEP }\end{array}$ \\
\hline Ramón Soares & Ativista LGBT e aids (déc. 2010 em diante) \\
\hline
\end{tabular}




\section{Gestores}

Paulo Roberto Teixeira, 68 anos $^{18}$, gestor

Paulo Roberto Teixeira vinculou-se, inicialmente, ao incipiente movimento homossexual em sua "primeira onda" (Facchini, 2005) no final dos anos 1970. Começou participando em um grupo de discussão organizado por João Silvério Trevisan, em 1976, que precedeu o grupo Somos de São Paulo, tendo se vinculado também a este grupo por pouco tempo. Em paralelo, como estudante de medicina e residente de dermatologia, vinculou-se ao movimento sanitarista. Em 1979, saiu do grupo Somos e vinculou-se ao processo de formação do Partido dos Trabalhadores (PT) em São Paulo. Desde 1978, atuou como médico dermatologista na Divisão de Hanseníase e Dermatologia Sanitária do Instituto de Saúde, da Secretaria de Estado da Saúde de São Paulo (SES-SP). Em 1983, quando houve a primeira eleição direta para governador, na qual Franco Montoro (PMDB) foi eleito, foi convidado a assumir a direção desta Divisão. Assim que surgiram as primeiras informações sobre a aids no Brasil e a mobilização de ativistas homossexuais junto à SES-SP, Teixeira assumiu a coordenação das ações no âmbito do incipiente Programa Estadual de DST/Aids da Secretaria de Estado da Saúde de São Paulo. Foi Coordenador do Programa Estadual de DST/Aids de São Paulo (1983 a 1987; 1990 a 1991; 1995 a 1996), Coordenador do Programa Nacional de DST/Aids do Ministério da Saúde (2000 a 2003) [atual Departamento Nacional de Infecções Sexualmente Transmissíveis, Aids e Hepatites Virais - DIAHV] e Diretor do Programa de Aids da Organização Mundial da Saúde (OMS, em 2003). Desenvolveu trabalhos de consultoria para a Organização Pan-Americana da Saúde (OPAS) em 1994, e foi consultor técnico do Programa Conjunto das Nações Unidas sobre HIV/Aids (UNAIDS) para a América Central e Cone Sul (1996 a 1999).

Paulo foi o único entrevistado que solicitou o roteiro da entrevista antes de sua realização e, com base neste roteiro, organizou sua fala para a entrevista. Ao contar sobre sua participação no movimento homossexual e sobre a história das políticas públicas para a aids, indicou-me livros e capítulos de livros onde eu poderia obter informações já sistematizadas sobre estes assuntos, sendo que aqueles referentes às

\footnotetext{
${ }^{18}$ As idades dos entrevistados referem-se ao momento em que foi realizada a entrevista com cada um deles.
} 
políticas de aids eram de sua autoria (Teixeira, 1997 e Laurindo-Teodorescu e Teixeira, 2015). Enfatizou em sua fala uma avaliação crítica sobre as políticas de prevenção da aids, demonstrando particular preocupação com os jovens e os desafios da efetivação de políticas de educação para a sexualidade e de prevenção no âmbito das escolas. 0 ponto de vista privilegiado por Paulo, em sua entrevista, foi o da gestão das políticas públicas, dando destaque aos valores que orientam e marcam a resposta política à epidemia de aids no Brasil, fortemente articuladas à história de lutas do movimento sanitarista brasileiro.

\section{Maria Clara Gianna, 56 anos, gestora}

Maria Clara teve contato com os primeiros casos de aids, ainda durante o curso de medicina nos anos de 1984 e 1985, quando estava no $5^{\circ}$ e $6^{\circ}$ anos da Faculdade de Ciências Médicas da Santa Casa de São Paulo e fazia estágios no Hospital Emílio Ribas. Posteriormente, na Residência em Medicina Social na mesma instituição, entre os anos de 1986 e 1987, teve contato intenso com os pacientes, entrevistando-os para o preenchimento das fichas de Investigação Epidemiológica para a Seção de Epidemiologia do mesmo Hospital Emílio Ribas. Terminando a Residência, em 1988, foi indicada para trabalhar na Secretaria de Estado da Saúde de São Paulo (SES-SP) para participar da estruturação do Centro de Referência e Treinamento em Doenças Sexualmente Transmissíveis e Aids ${ }^{19}$ (CRT-DST/Aids). Lá, trabalhou como médica sanitarista no setor de Vigilância Epidemiológica (VE) e, posteriormente, assumiu sua direção de 1994 até o momento, revezando-se entre a Diretoria e a Diretoria-Adjunta com Artur Kalichman e, mais recentemente, também com Rosa Alencar. Mostrou-se profundamente marcada pelos depoimentos dos pacientes internados colhidos ao longo de sua formação e nos primeiros anos de atuação na VE, assim pelo contato que ainda mantém com muitos deles, que são acompanhados no Ambulatório de Aids do

\footnotetext{
${ }^{19}$ Criado, originalmente, em 1988, como Centro de Referência e Treinamento em Aids (CRT-A) tinha como função servir de referência assistencial para a rede de serviços, formar recursos humanos e elaborar normas técnicas, com a finalidade de apoiar o processo de descentralização das ações de saúde voltadas ao HIV e à aids. Em 1993, fundiu-se aos programas estaduais de aids e DST, tornando-se o Centro de Referência e Treinamento em Doenças Sexualmente Transmissíveis e Aids, CRT-DST/Aids. Integra vários serviços especializados em um único complexo, reunindo: ambulatório de aids, ambulatório de DST, ambulatório de saúde integral para travestis e transexuais, centro de testagem e aconselhamento. Atua, assim, como serviço de referência técnica, bem como sede da Coordenação do Programa Estadual de DST/Aids.
} 
CRT-DST/Aids. Ressalta que atuou em uma VE muito diferenciada, sob a coordenação de Paulo Roberto Teixeira e a supervisão de sociólogas como Rose Munhoz e Lindinalva Laurindo da Silva (atualmente, Laurindo-Teodorescu). Lá se envolveu em projetos como o estudo sobre o impacto do HIV na vida das pessoas, assim como o desenvolvimento dos primeiros boletins epidemiológicos ${ }^{20}$. Nesta experiência, que desenvolveu com o também jovem sanitarista Artur Kalichman, tiveram como desafio efetivar análises sobre a epidemia, assim como falar sobre as mesmas, quando enfatizou o processo de transição de conceitos que orientaram tais análises e embasaram as ações de prevenção: grupo de risco, situação de risco, comportamento de risco e vulnerabilidade. Os projetos desenvolvidos na VE a aproximaram muito das pessoas vivendo com HIV e aids, dos desafios da assistência à saúde para estas pessoas, assim como dos desafios da rede de atenção à saúde, que foi se formando tendo a aids como foco, pois viajavam pelo estado para falar sobre os dados epidemiológicos e o cuidado às pessoas vivendo com HIV e aids. Muitas das pessoas com quem teve contato neste início da epidemia vieram a participar, posteriormente, das primeiras organizações da sociedade civil sobre o tema. Suas primeiras experiências com a questão da homossexualidade se dão também a partir destes primeiros casos de aids.

Em seu depoimento, Maria Clara falou longamente sobre seu processo de formação profissional e enfatizou o caráter militante de sua atuação à frente da gestão do programa. Falou estritamente do lugar de quem participou da resposta brasileira à epidemia de aids a partir da gestão de políticas públicas e de quem reconhece que há diferentes grupos, discursos e práticas neste campo, demarcando sempre a perspectiva do grupo de atores que integra - o que, quem sabe, possa ser entendido como uma "escola" de gestores e profissionais de saúde que atuam no campo da aids, o grupo que se formou a partir de sua atuação no CRT-DST/Aids.

Ivo Brito, 63 anos, gestor

Ivo Brito é sociólogo com longa experiência na universidade, inicialmente na Universidade Federal da Paraíba e, posteriormente, na Universidade de Brasília,

\footnotetext{
${ }^{20}$ Os boletins epidemiológicos são documentos técnicos que tratam sobre a distribuição dos casos de aids na população para divulgação junto a profissionais de saúde da rede pública, imprensa, sociedade civil organizada e universidade e subsidiam análises sobre as mudanças da epidemia.
} 
atuando, predominantemente, no campo da Saúde Coletiva. Inicialmente, vinculou-se ao campo da aids desenvolvendo pesquisas sob encomenda do Programa Nacional de Aids do governo federal e, posteriormente, vindo a inserir-se institucionalmente no Programa. Atuou na área de Prevenção de 1996 até 2010, sendo coordenador da área de 2004 a 2010, tornando-se, posteriormente, Assessor de Ações Estratégicas. Ficou um breve intervalo fora do Programa na transição das gestões de Alexandre Grangeiro e Paulo Teixeira, entre 2003 e 2004, quando saiu do Departamento para atuar em uma cooperação internacional. Atuou, então, como consultor técnico no Projeto para o Fortalecimento do Sistema Angolano de Educação para o Enfrentamento do HIV/AIDS, a serviço da agência local do Programa das Nações Unidas para o Desenvolvimento (UNDP) em Angola, junto ao Ministério da Educação.

Em sua entrevista, Ivo focou, predominantemente, a linha do tempo das políticas de prevenção a partir de seu espaço privilegiado de atuação no âmbito da gestão de dentro do Ministério da Saúde. O fez a partir de um olhar crítico de quem viu de perto as dinâmicas que interferem na tomada de decisão e os limites para o seu avanço. Sendo também um pesquisador, Ivo sugeriu, generosamente, em diferentes momentos da entrevista, documentos que poderiam ser utilizados como fonte de pesquisa e perspectivas que Ihe pareciam ricas para esta análise. Infelizmente, dado o exíguo prazo para a conclusão desta tese quando do momento da entrevista, não foi possível incorporar a maior parte das suas sugestões, mas estas foram registradas para a continuidade de tais investigações no futuro. Ivo utiliza, predominantemente, em seu relato a categoria LGBT, fazendo referência, em muitos momentos da entrevista, a lésbicas, travestis e pessoas transexuais, assim como às políticas de equidade na área da saúde para a população LGBT, mas trazendo também a comparação, com base na sua interlocução como gestor junto ao movimento de mulheres e ao movimento negro, assim como outros grupos populacionais que trazem suas especificidades para as políticas de prevenção. 


\section{Ativistas}

Jorge Beloqui, 67 anos, ativista ONG/aids

Jorge Beloqui teve experiência nos primórdios do movimento homossexual e foi um dos fundadores do movimento de aids em São Paulo. Iniciou sua militância no Grupo Somos do Rio de Janeiro, em 1979, e em 1981 vinculou-se ao Grupo Somos/SP. Refere ter participado de algumas atividades dispersas relacionadas à aids ao longo da década de oitenta, mas foi em 1989, pouco depois de ter sido diagnosticado com HIV, que efetivamente se vinculou ao movimento, sendo um dos fundadores do Grupo Pela Vidda/SP. .Desde 1995, está no Grupo de Incentivo à Vida (GIV). Nestas quase quatro décadas de respostas à epidemia, Jorge já participou de diversos espaços de participação socioestatal no campo da aids, nas três esferas de governo.

Jorge foi o único dos entrevistados que estabeleceu um limite de tempo para a entrevista, e nele não possível abordar todo o roteiro. Optei por focar, então, na linha do tempo sobre as políticas de prevenção de aids para HSH e aos seus momentos mais marcantes, positiva ou negativamente

Em sua entrevista, Jorge enfatizou dois aspectos do universo das políticas de prevenção voltadas a HSH: as perspectivas adotadas no campo da prevenção no que tange à sexualidade e às mudanças trazidas ao campo da prevenção pela incorporação de novas tecnologias de prevenção, tais como os preservativos masculino (ou peniano, como prefere nomear) e feminino (ou vaginal, como prefere); a redução de danos relacionada ao uso de drogas; a progressiva adoção de medicamentos com vistas à prevenção, que se inicia com a prevenção da transmissão vertical (ou materno-infantil), a profilaxia pós-exposição (PEP), a profilaxia pré-exposição (PrEP) e o tratamento como prevenção (TcP, ou como mais frequentemente nomeado, adotando a sigla em inglês TasP); as tecnologias chamadas comportamentais, como o soroposicionamento, que visam condutas sexuais que implicam na redução de riscos para a infecção; e a testagem como prevenção.

Jorge tem uma posição de destaque na militância da aids por acompanhar intensamente, desde os primórdios do movimento, os debates acerca das pesquisas de vacinas contra o HIV, estando envolvido, desde 1991, com o tema. Participou do Comitê 
Nacional de Vacinas Anti-HIV/Aids, desde a sua instituição em 1992 até o seu término em 2011. Esteve entre os responsáveis, junto a ativistas de outras ONG, pela edição do Dossiê Vacinas, em 1992, e, posteriormente a partir de 1995, do Boletim Vacinas, publicações que têm como objetivo informar ativistas acerca das pesquisas de vacinas, mas que, com as transformações no campo da prevenção, foram gradualmente incorporando o desafio de informar sobre as chamadas novas tecnologias de prevenção (NTP). É também um dos responsáveis pela realização de Encontros nacionais e regionais de Vacinas Anti-HIV com a finalidade de formar e informar ativistas de todo o país.

Veriano Terto Júnior, 56 anos, ativista ONG/aids

Veriano Terto Júnior começou sua trajetória como ativista político no movimento homossexual brasileiro, em 1980, no grupo Somos/RJ e permaneceu vinculado ao grupo até seu término em 1984 - quando este já estava junto ao Auê, que foi anteriormente uma dissidência do Somos - tendo sido o último responsável pela administração e resposta às cartas recebidas por esta organização em uma caixa postal, "o último sinal de institucionalidade do grupo" (Veriano Terto Jr., entrevista). Teve alguma participação no movimento homossexual em São Paulo também no grupo Somos. Foi por meio desta militância em São Paulo que teve contato com os primeiros casos de aids, junto aos amigos e colegas de militância em São Paulo. Em um primeiro momento do contato mais próximo com os primeiros casos de aids, percebe resistência em se aproximar desta discussão pela leitura de que a aids "vinha pra reprimir [as liberdades], pra acabar com a festa" e de que a proposição da camisinha constituía "uma espécie de freio [...] e repressão". Em poucos anos, ao perceber o agravamento da situação, sente que precisa fazer algo, ouve sobre a Associação Brasileira Interdisciplinar de Aids (ABIA), que identifica como uma proposta mais simpática, e começa a se aproximar. A partir dessa aproximação com a ABIA, em 1989, participa da fundação do Grupo Pela Vidda no Rio de Janeiro, "primeiro grupo fundado no Brasil por pessoas vivendo com HIV e aids, seus amigos e familiares" ${ }^{21}$. No mesmo ano, se integra à ABIA, primeiramente por meio de uma pesquisa, depois em uma consultoria, até integrar-se ao seu staff permanente em 1990. A ABIA é primeira organização não-governamental

\footnotetext{
${ }^{21}$ http://aids.org.br/grupo pela viddasp.html
} 
do país, fundada em 1987, que atua na mobilização da sociedade civil para o enfrentamento da epidemia de HIV e da AIDS no Brasil, com ênfase em "advocacy, com foco no acompanhamento das políticas públicas, na formulação de projetos de educação e prevenção ao HIV e à AIDS e no acesso à informação em HIV e AIDS"22. Veriano assumiu a coordenação-geral da ABIA em 1999 e ficou até 2002, quando saiu para se mudar de cidade e experimentar a vida na universidade. Retornou à coordenação-geral da $A B I A$, em 2004 e ficou até 2012, quando a instituição vivia uma crise de financiamento e de modelo de atuação, e decidiu sair para abrir espaço para a renovação institucional. Em 2015, retornou à coordenação de projetos na ABIA e, em 2016, assumiu sua VicePresidência. Nos dois períodos em que se afastou da $A B I A$, teve experiências no âmbito da universidade: entre 2002 e 2004, foi pesquisador-visitante no Núcleo de Pesquisas em Antropologia do Corpo e da Saúde do Programa de Pós-Graduação em Antropologia Social da Universidade Federal do Rio Grande do Sul (NUPACS/PPGAS/UFRGS) e, posteriormente, entre os anos de 2013 a 2015, foi professor-visitante do Instituto de Estudos em Saúde Coletiva da Universidade Federal do Rio de Janeiro (IESC/UFRJ).

Psicólogo, Veriano fez seu mestrado em psicologia clínica na PUC-RJ (1986-9) onde desenvolveu estudo intitulado "No Escurinho do Cinema... Socialidade Orgiástica nas Tardes Cariocas", estudo sobre sexualidade de orientação etnográfica no qual investigou encontros sexuais homoeróticos que aconteciam em um cinema do Rio de Janeiro, o que também considera uma forma de militância. Posteriormente, fez seu doutorado em medicina social sobre histórias sobre homossexualidade e AIDS no Brasil (1993-7) no qual abordou uma geração de homossexuais que viveu o antes e o depois da aids, buscando compreender como reorganizaram suas vidas e sua sociabilidade.

Em sua entrevista, Veriano enfocou as políticas de prevenção falando do lugar de quem está no ativismo da aids há quase 30 anos, mas sempre se manteve atento e dedicado às discussões sobre sexualidade e homossexualidade, sendo uma referência no campo para esta articulação temática. A ênfase de seu depoimento recaiu sobre as experiências não-governamentais no campo da prevenção. Ele diferencia, claramente, dois ou mais campos em intersecção no debate das políticas de prevenção voltadas para

\footnotetext{
22 http://abiaids.org.br/sobre-nos
} 
gays e outros HSH: as ONG/Aids e o chamado, num primeiro momento, movimento homossexual, posteriormente, gay; e, mais recentemente, a emergência do movimento de pessoas trans, constituindo-se como um novo campo. Como pesquisador no campo das humanidades e profundo conhecedor dos movimentos de aids e gay, trouxe informações cuidadosas sobre os diferentes atores, seus posicionamentos, discursos e experiências em diferentes momentos da resposta à epidemia no Brasil. Aponta questões e tensionamentos nesta interseç̧ão, mas também o cuidado de quem não quer desenterrar antigas polêmicas, mas aposta na construção de novas pontes e alianças.

Beto de Jesus, 56 anos, ativista LGBT

Beto de Jesus é formado em filosofia e teologia pela Faculdade de Filosofia, Ciências e Letras vinculada ao Instituto Educacional Seminário Paulopolitano (IESP, atual Centro Universitário Assunção - UNIFAI), instituição subordinada à Igreja Católica. Iniciou o curso de filosofia como seminarista, mas saiu do seminário quando estava no segundo ano e continuou a faculdade como leigo, tendo feito, posteriormente, o curso de teologia, também como leigo.

Proveniente da zona leste de São Paulo, do bairro de Ermelino Matarazzo, Beto sempre teve grande envolvimento com os movimentos sociais locais, desde a juventude, tendo se articulado com os sanitaristas, com a construção de hospital, creche, escola, movimento dos trabalhadores sem terra. Apesar de referir sempre ter vivido sua homossexualidade abertamente, refere nunca ter escutado sobre o movimento homossexual, não tendo se articulado, portanto, à primeira onda do movimento homossexual brasileiro. Ouviu as primeiras notícias sobre a aids na época em que estava na faculdade, em 1983, e foi, com um amigo do seminário, também gay, ao Hospital Emílio Ribas, onde passou a integrar o primeiro grupo de apoio aos pacientes de aids que lá se organizou. Posteriormente, passou um tempo afastado da "luta da aids". Trabalhou como educador, de 1990 até 2001 aproximadamente, tendo trabalhado em um projeto social com crianças e adolescentes, como diretor de um circo-escola, o que se iniciou durante a gestão de Alda Marco Antônio na Secretaria do Menor (nos governos peemedebistas de Orestes Quércia e Luís Antônio Fleury Filho, no governo do estado de São Paulo). Iniciou sua participação no movimento homossexual em 1996, já 
na chamada segunda onda do movimento homossexual brasileiro (Facchini, 2005). Em 1995, teve conhecimento do 170 Encontro da International Lesbian and Gay Association (ILGA) que aconteceria no Rio de Janeiro e participou individualmente, sem vinculação a nenhum grupo ou organização. Nesta ocasião, teve a oportunidade de conhecer ativistas do movimento gay de São Paulo e, no encerramento do encontro, participou com os demais integrantes do evento - de uma Parada na Avenida Atlântica. O grupo de São Paulo comprometeu-se a organizar algo semelhante na cidade. Em torno de 1996, conheceu Ideraldo Beltrame, ativista do grupo CORSA, e começou a participar deste grupo. Participou, com diversos grupos do processo de organização do embrião da primeira Parada de São Paulo: CAHEUSP, CORSA, Etcétera e Tal, Identidade de Campinas e o NGLPT - o Núcleo de Gays e Lésbicas do PT: ainda em 1996, organizaram um ato na Praça Roosevelt e, em 1997, a primeira Parada.

Depois de 2001, começou a trabalhar com consultorias na área de diversidade sexual junto aos Ministérios da Saúde e da Educação, entre outros. Refere nunca ter se vinculado, como ativista, à nenhuma organização de aids, tendo mais frequentemente se vinculado às organizações do movimento LGBT. Atualmente, atua como Gerente de Prevenção e Testagem na AIDS Healthcare Foundation (AHF), organização de aids estadunidense que atua na provisão de cuidados médicos e serviços em 38 países. Além de manter atividades como ativista independente pelos direitos sexuais e reprodutivos.

A entrevista de Beto traz novas tensões para o debate. É o primeiro entrevistado a posicionar-se no campo da aids reivindicando seu posicionamento no movimento LGBT. Tendo em vista sua atuação profissional como consultor e responsável por projetos de expansão do acesso à testagem em organizações não-governamentais que atuam no campo da aids refere ter sido fortemente criticado por ativistas do movimento de aids que discordam da realização de testes por ONG.

Matheus Emilio Pereira da Silva, 21 anos, ativista ONG/aids e LGBT

Matheus Emílio Pereira da Silva, 21 anos, é estudante de direito. Nascido em São Paulo, mudou-se com os pais aos dez anos para o interior de Minas Gerais, onde começou sua trajetória de ativismo com questões LGBT ainda adolescente ao dar início a uma página no Facebook chamada Menino Gay, na qual relatava sobre seus 
sentimentos e vivência como jovem homossexual. Inicialmente, a página funcionava como um diário pessoal, mas, à medida em que foi crescendo, tornou-se, nas suas palavras, "um diário de várias pessoas", conformando-se como um espaço de ativismo e empoderamento coletivo. Aos 17 anos, Matheus voltou do interior de Minas Gerais para a cidade de São Paulo, para poder viver abertamente sua homossexualidade. Neste momento, começou a se vincular com alguns grupos LGBTI, como a Família Stronger ${ }^{23}$ que é um grupo de jovens LGBT da periferia - e logo em seguida também se vinculou ao Grupo de Pais de Homossexuais $\left(\mathrm{GPH}^{24}\right)$, que é uma ONG de pais de LGBT. Atuou como um dos coordenadores-jovens do Projeto Purpurina ${ }^{25}$ - projeto para adolescentes e jovens LGBT do GPH cujas reuniões acontecem no Centro de Referência e Defesa da Diversidade - $\mathrm{CRD}^{26}$ - por mais de um ano, vindo a conhecer o CRD e o Pelo Vidda/SP 27 - ONG/Aids que gerencia o CRD).

No CRD, fez o teste e tomou conhecimento de sua soropositividade para o HIV. Foi se aprofundando nas questões relativas ao HIV e à aids, atuou como agente de prevenção no projeto Viva Melhor Sabendo Jovem, voltado à ampliação do acesso à

\footnotetext{
${ }^{23}$ As "famílias LGBT" constituem-se em redes formadas por adolescentes e jovens LGBT com o objetivo de assegurar suporte e proteção aos seus integrantes. Os membros, não necessariamente LGBT, ocupam diferentes funções conforme sua identidade de gênero, o período de sua entrada e seu engajamento na rede, inspirando-se nas famílias consanguíneas, como "pais", "mães" e "filhos". Há famílias voltadas exclusivamente aos momentos de lazer e outras mais presentes no cotidiano dos jovens (Perillo, 2017). Para saber mais: http://www.familiastronger.com, http://revistageni.org/03/quem-manda-na-noite/ e https://www.unicamp.br/unicamp/ju/noticias/2017/09/06/orgulho-respeito-e-militancia-no-role-dejovens-gays-da-periferia.

${ }^{24} \mathrm{O}$ GPH consiste em um grupo de ajuda que se propõe a oferecer acolhimento e ambiente seguro para que mães e pais de LGBTI possam compartilhar informações e experiências sobre seus filhos e solidariedade no "processo de aceitação" (http://www.gph.org.br).

${ }^{25} \mathrm{O}$ projeto Purpurina é um dos projetos desenvolvidos pelo GPH que se organiza como um grupo de ajuda mútua coordenado e oferecido para adolescentes e jovens, na faixa etária de 13 a 24 anos. Originalmente, mantinha encontros presenciais mensais, mas indica em sua página da internet que a internet passou a ocupar este espaço. Constitui-se, então, no momento como um grupo virtual (http://www.gph.org.br/purpurina.asp).

${ }^{26} \mathrm{O}$ Centro de Referência e Defesa da Diversidade caracteriza-se como um serviço público conveniado voltado ao acolhimento e à inclusão social da população LGBT: lésbicas, gays, homossexuais, bissexuais, travestis e transexuais. O CRD é gerenciado pela ONG/Aids Pela Vidda em convênio com a Secretaria Municipal de Assistência e Desenvolvimento Social da Prefeitura de São Paulo, integrando-se à política de pública municipal de Assistência Social (http://www.aids.org.br/quem somos 27.html, https://www.facebook.com/CentrodereferenciadefesadadiversidadeCRD/) e http://www.prefeitura.sp.gov.br/cidade/secretarias/assistencia_social/noticias/?p=175918).

${ }^{27}$ O Grupo Pela Vidda ((Valorização, Integração e Dignidade do Doente de aids) ) é uma ONG/Aids, fundada em 1989 em São Paulo, articulando pessoas vivendo com HIV e aids, amigos, familiares e pessoas interessadas, com base no grupo de mesmo nome fundado, meses antes, no Rio de Janeiro (http://www.aids.org.br/index.php).
} 
testagem realizado em parceria da Prefeitura de São Paulo com a ONG Viração e a UNICEF e, posteriormente, como agente de prevenção no CRD. Desta forma, veio a se vincular ao Pela Vidda/SP. Atualmente, representa o Pela Vidda/SP na Vice-Presidência do Fórum de ONG/Aids do Estado de São Paulo e gerencia a página Menino Gay no Facebook. No Fórum, entre outras atividades, participa do Grupo de Trabalho (GT) Adolescências e Juventudes, que reúne as ONG/Aids que têm trabalho com jovens. Na página Menino Gay, há hoje uma "comunidade" com mais de 160 mil curtidas e seguidores, parceiros no gerenciamento e no propósito do empoderamento LGBT, falar sobre HIV e incluir pessoas com deficiência (há um grupo fechado vinculado à página com mais de 8 mil membros para e sobre LGBT com deficiências). Por sua inserção no Menino Gay, integra também o Grupo de Trabalho (GT) da Juventude da Associação da Parada do Orgulho de Gays, Lésbicas, Bissexual e Transgêneros (LGBT) de São Paulo (APOGLBT).

Em sua entrevista, Matheus contou sobre suas experiências de engajamento e atuação militante, mostrando intensa articulação com diferentes grupos e atores nos campos de luta contra a aids e pelos direitos LGBT. Refletiu sobre diferentes dinâmicas de discriminação nestes campos e, ao debater políticas, serviços, ações e campanhas de prevenção, enfatizou a importância da adequação da linguagem, da cumplicidade e da especificidade para atingir os jovens.

\section{Gabriel Estrela, 25 anos, ativista em HIV/aids}

Gabriel Estrela iniciou sua carreira como ativista nas redes sociais, em 2015, falando publicamente da sua soropositividade. Anteriormente, em 2013, havia escrito e encenado de forma amadora uma peça de teatro que trata da sua experiência com o HIV. Residente em Brasília até o ano de 2016, iniciou, em 2015, contato com Diego Callisto - ativista da Rede Nacional de Adolescentes e Jovens Vivendo com HIV e Aids (RNAJVHA) e técnico da área de Prevenção do DIAHV - e, por seu intermédio, teve a oportunidade de participar, informalmente, das três versões do "Curso de Formação de Jovens Lideranças - ativismo e mobilização social para a resposta e controle do HIV/aids"28, assim como representou o Distrito Federal no VII Encontro Nacional de

\footnotetext{
${ }^{28}$ Estratégia desenvolvida, nos anos de 2015 e 2016, em parceria pelo DIAHV e o UNAIDS com o objetivo de engajar jovens nas respostas à epidemia, contando com o apoio de outros organizamos multilaterais
} 
Adolescentes e Jovens Vivendo com HIV/Aids. Iniciou, ainda em 2015, seu projeto social que visa articular arte, educação e acolhimento para abordar a temática do HIV. Até o momento, inserem-se neste projeto sua peça de teatro - também intitulada "Boa sorte", um canal no YouTube, consultorias, desenvolvimento de atividades educativas e perfis no Instagram e no Twitter. Quando começou a falar sobre HIV e sua experiência com a soropositividade na grande mídia, recebeu o apoio do UNAIDS que ofereceu a ele atividades de media training. Por meio dessa articulação com o UNAIDS, tornou-se consultor da Rede Globo para apoiar o desenvolvimento de episódios da série voltada ao público juvenil Malhação, na qual havia um personagem soropositivo. Gabriel contribuiu com o roteiro de um produto derivado da série, o webdocumentário "Eu só quero amar", sobre casais sorodiferentes. Participou, ainda, a convite do UNAIDS, da Reunião de Alto Nível sobre o Fim da Aids, no âmbito da Assembleia Geral das Nações Unidas, em 2016, de um evento paralelo que abordou a proposta de adoção do entretenimento, ou mais precisamente do "edutainment ${ }^{29 "}$ como estratégia do UNAIDS "to fast track the response and reach young people". Desde 2017, mudou-se para São Paulo com o objetivo de impulsionar sua carreira e desenvolver de forma mais profissionalizada o projeto Boa Sorte. Aqui, participa do Comitê de Acompanhamento Comunitário dos estudos sobre PrEP desenvolvidos na Faculdade de Medicina da Universidade de São Paulo, coordenados pelo professor Esper Kallás. Tem buscado se articular com o movimento social de aids local e as instâncias de governo, mas tem claro que sua atuação nestes espaços se deve menos à incidência política, e mais por considerar essencial estar informado para atender melhor ao seu público. Neste sentido, entende sua atuação como a de um artista engajado e conectado com as questões contemporâneas com a proposta de promover representatividade de

\footnotetext{
Como UNICEF, UNESCO e UNFPA. Cada versão do curso selecionou 50 jovens de 18 a 26 anos, envolvidos em projetos em suas comunidades. Sendo que as duas primeiras versões privilegiaram a inclusão de jovens provenientes das chamadas populações-chave, tidas como prioritárias no enfrentamento da epidemia pelo DIAHV: gays, outros homens que fazem sexo com homens (HSH), travestis, transexuais e profissionais do sexo. Foram incluídos, ainda, alguns negros e indígenas, que se inserem em populações categorizadas como vulneráveis pelo DIAHV e outros com trabalhos com pessoas que usam drogas e redução de danos. Na terceira versão, foram privilegiados jovens profissionais de saúde.

${ }^{29}$ Edutainment é descrito, no programa do evento, como "purposely designs characters and storylines in mass media dramas to provide viewers with positive role models to relate to, often at a personal and emotional level, than through information alone". Disponível em:

http://www.unaids.org/en/resources/documents/2016/2016 HLM side events [acesso em 17 de abril de 2018].
} 
soropositivos, LGBT e outros grupos afetados pela aids, assim como de educar e comunicar.

Sua entrevista esteve marcada por contar e refletir sobre o seu processo de engajamento e de construção de uma carreira ativista, que se dá articulada a uma causa e não exatamente a um movimento social. Nesta reflexão, questões como discriminação, preconceito e restrições associadas ao HIV e à Aids no universo do entretenimento e das mídias e redes sociais estiveram muito marcadas. Assim como, as questões da linguagem e da comunicação na abordagem sobre o HIV, diversidade sexual e sexualidade e o como sobreviver do ativismo.

\section{Carué Contreiras, 38 anos, ativista aids e LGBT}

Carué Contreiras é médico sanitarista e pediatra. Sua inserção no ativismo se dá por meio do conhecimento acerca da sua soropositividade. Começou se aproximando do campo do HIV, fazendo contatos e buscando se inteirar das discussões. Progressivamente, foi migrando e aproximando-se do movimento LGBT. Tem como marco para sua entrada no ativismo LGBT, a participação na Conferência Municipal LGBT, em 2016. Refere ter se surpreendido nessas aproximações, ao perceber que não se fala do HIV no âmbito do movimento LGBT, o que está descrito em um capítulo de livro de sua autoria. Colabora com a Agência de Notícias da Aids ${ }^{30}$, desde 2014, escrevendo artigos e fazendo a cobertura de eventos comunitários e científicos, como as $20^{a}$ e 21 a Conferências Internacionais de AIDS, realizadas em Melbourne e Durban respectivamente, e o Congresso Brasileiro de Aids, realizado em 2017. Atua, desde 2016, como educador comunitário em um estudo sobre PrEP injetável que é desenvolvido no CRT-DST/Aids, onde tem tido a experiência de se aproximar da formulação de políticas, da oferta de ações e serviços de prevenção, assim como tem ampliado a articulação com diferentes modalidades de grupos e coletivos da comunidade LGBT e serviços voltados a tal comunidade na cidade de São Paulo. Atualmente, integra, no âmbito do movimento

\footnotetext{
${ }^{30}$ Portal de notícias sobre a aids que divulga dados sobre a epidemia, notícias sobre políticas e serviços, resultados de pesquisa e artigos de especialistas e de pessoas vivendo com HIV/aids. Lançado em 2003 por iniciativa da jornalista Roseli Tardelli, tem como objetivo distribuir informações qualificadas para as redações da mídia nacional por meio de sua homepage: www.agenciaaids.com.br.
} 
de aids, a Rede Nacional de Pessoas Vivendo Com HIV/Aids - RNP+-SP, e, no movimento LGBT, o Coletivo A Revolta da Lâmpada ${ }^{31}$ e a Coletiva Médica LGBT ${ }^{32}$.

Em sua entrevista, Carué abordou fortemente a questão da discriminação das pessoas vivendo com HIV e aids por meio da mobilização da categoria "sorofobia", enfatizando fortemente as experiências experimentadas no âmbito da comunidade e do movimento LGBT. Outra especificidade de seu depoimento se dá em função de sua formação técnica em medicina e saúde coletiva, o que aguça seu olhar para as especificidades das necessidades em saúde destes grupos e a percepção de negligência por parte das abordagens técnicas. Por fim, sua experiência, como ativista crítico no âmbito da máquina do Estado também lhe confere a possibilidade de identificar importantes limites nas capacidades de resposta do setor governamental.

\section{Ramón Soares, 23 anos, ativista em HIV/aids}

Ramón Soares é estudante de pedagogia. Em seu processo de formação durante a graduação, aproximou-se do corpo docente e teve forte aproximação com o movimento de educação. Integrando-se ao ativismo, veio também a se aproximar, posteriormente, do movimento LGBT e, por esta via, do movimento estudantil, tendo atuado de forma organizada nestes campos movimentistas e, posteriormente, se afastado. Nesta experiência, integrou o Rua Juventude Anticapitalista, coletivo que, segundo Ramón, tem forte conexão com a Corrente Insurgência do PSOL, e por meio dessa atuação ajudou a fundar a Frente LGBT da USP e atuou nela por dois ou três anos. É filiado à $A B G L T$ e atuou junto a esta organização, tendo a representado nas Conferências Nacional e Estadual de Educação. Passou a atuar autonomamente por aproximadamente dois anos, até vir a participar da fundação do Coletivo Loka de Efavirenz, que entende ser uma forma de reinserção no movimento LGBT. Veio a ter contato mais intenso e próximo com o tema da aids, há dois anos atrás, por meio de um

\footnotetext{
${ }^{31}$ Coletivo ativista que "luta pelo corpo livre e acredita que fervo também é luta", como descrito em sua página no Facebook. Caracterizado por Carué como tendo atuação a partir de uma perspectiva interseccional, por articular diferentes lutas e hierarquias sociais.

32 Iniciativa recente, de 2017, que reúne além de Carué, um grupo de médicos de família e comunidade, com o objetivo de pautar a saúde integral de LGBT a partir de uma perspectiva que articule as necessidades da população às questões técnicas. Pretendem incidir na educação médica, na elaboração de protocolos e nos órgãos representativos da categoria como o Conselho Regional de Medicina, o Sindicato dos Médicos, a Sociedade de Medicina de Família e Comunidade e a Associação Brasileira de Educação Médica.
} 
roommate positivo, muito engajado no movimento de aids. Em julho de 2016, participou do Curso "Participação Juvenil, Ativismo e Direitos Humanos em HIV-AIDS no Estado de São Paulo"33, no qual conheceu vários outros jovens com os quais se identificou fortemente, bem como compartilhou uma experiência de muitas divergências com a organização do curso. A partir deste compartilhamento, vieram a se organizar no Coletivo Loka de Efavirenz, que criou uma página no Facebook e começou a atuar em agosto de 2016. Desde então, passou a participar de eventos da área da saúde, de atividades do movimento de aids e outros espaços ${ }^{34}$ que se articulam com o campo.

A narrativa de Ramón explorou predominantemente o entendimento que o Coletivo faz da epidemia e de seus determinantes, a forma como entendem sua ação política, as tensões no campo da aids, suas críticas a diversos atores deste campo, suas estratégias e alianças, assim como os limites da atuação do Coletivo, além dos planos de continuidade para a ação do grupo. Há muitas articulações e proximidades entre o Loka de Efavirenz e a Rede de Jovens São Paulo Positivo, mas um dos pontos que os diferenciam é que o Coletivo articula jovens independentemente de sua sorologia, enquanto a formação da Rede de Jovens é baseada na soropositividade de seus integrantes.

\footnotetext{
33 O curso "Participação Juvenil, Ativismo e Direitos Humanos em HIV-AIDS no Estado de São Paulo" voltou-se a adolescentes e jovens, com idades entre 15 e 29 anos. Tinha como objetivo formar lideranças juvenis para o fortalecimento do enfrentamento à epidemia de HIV/Aids. Foi promovido pela Rede de Jovens São Paulo Positivo em parceria com a Coordenação Estadual de DST/AIDS da Coordenadoria de Controle de Doenças da Secretaria de Estado da Saúde de São Paulo, contando com o apoio do DIAHV, do Programa Municipal de DST/Aids da Secretaria Municipal de Saúde de São Paulo, do UNAIDS, da UNICEF, da UNESCO, do UNFPA, do Fórum de ONG/Aids de São Paulo, da Rede Nacional de Pessoas vivendo com HIV e AIDS de São Paulo - RNP +, do Movimento Nacional de Cidadãs PositHIVas de São Paulo - MNCP e do Projeto Viva Melhor Sabendo Jovem.

${ }^{34}$ Conheci pessoalmente Ramón, quando falamos juntos em uma mesa sobre HIV na Semana da Diversidade organizada pelo Centro Acadêmico Oswaldo Cruz, dos alunos da Faculdade de Medicina da USP, que ocorreu em agosto de 2017. Nesta ocasião, Ramón estava acompanhado de outros dois integrantes do Coletivo, Luiz Felipe Garcia e Marcelo Jardim dos Santos. Eu já conhecia, no entanto, a página Loka de Efavirenz, desde pelo menos o início de 2017. Foi observando a atuação da página, antes mesmo de ter conhecimento de que se tratava de um Coletivo organizado, que pensei ser importante incluir ativistas jovens entre os entrevistados desta pesquisa.
} 


\section{CAPÍTULO 3}

\section{RESPOSTAS POLÍTICO-INSTITUCIONAIS À EPIDEMIA DE AIDS VOLTADAS PARA GAYS E HSH NO BRASIL}

Construo neste capítulo uma narrativa histórica sobre as respostas políticoinstitucionais voltadas à prevenção de HIV/Aids para gays e HSH no Brasil, o que concorrerá para a compreensão da situação atual da epidemia e os desafios para o Cuidado Público voltado para esse grupo.

O capítulo está estruturado de forma a apresentar: os antecedentes do contexto de emergência da aids e do campo discursivo de ação que se estrutura para responder à epidemia, a partir da organização do movimento homossexual e do movimento sanitarista no Brasil; e o cenário das respostas político-institucionais no campo da aids, com ênfase na prevenção voltada a gays e HSH, ao longo das quase quatro décadas de nossa experiência compartilhada com a doença.

Para efetuar tal composição, me utilizo das entrevistas realizadas, da literatura acerca das respostas à epidemia de aids e de pesquisa documental não-sistemática acerca dos documentos de formalização e sistematização de políticas, assim como de orientação para a ação de gestores e técnicos envolvidos nas respostas à aids. A fim de compreender os modelos de organização de ações e serviços e de respostas em termos de políticas públicas de prevenção, exploro, particularmente, as respostas dos entrevistados às questões do roteiro que orientou a realização das entrevistas referentes à linha do tempo das políticas de prevenção; ao que é considerado conflitivo na política; e ao fracasso e ao sucesso (no sentido de potencialidades e limites das mesmas). Busquei identificar nos relatos dos entrevistados os seguintes aspectos em cada período estudado: contexto das políticas de saúde; leituras acerca da caracterização da epidemia que orientavam as ações de prevenção naquele momento; categorias e conceitos mobilizados para orientar as ações de prevenção; estratégias mobilizadas para efetivar a prevenção; políticas de prevenção formalizadas no período; respostas sociais à epidemia; e atores envolvidos na resposta. Reconhecendo os limites 
de qualquer periodização, trabalho aqui com as diferentes décadas desde a emergência dos primeiros casos de aids no Brasil até a primeira década dos anos 2000.

Em acordo com a literatura e com os consensos definidores do campo, parto do pressuposto de que o movimento de resposta à epidemia de aids se configura como uma resposta coletiva que se caracteriza, assim como Sônia Alvarez (2014) diz em relação aos feminismos, por estar para além da sociedade civil, ou de uma divisão entre sociedade civil e Estado. Entendo que esta não é uma distinção produtiva para a elaboração desta periodização e para a reflexão que quero fazer, embora, claro, não se pode perder de vista os lugares a partir dos quais os sujeitos falam. Há, dentre os entrevistados, sujeitos que estão na gestão, e que falam como gestores, mas que, eventualmente, podem rememorar algo de um momento em que estavam no ativismo; há pessoas que foram só gestoras e só podem contar da experiência da gestão; e há pessoas do movimento que transitam entre ativismo e algum cargo técnico ou têm uma proximidade muito grande com o governo a partir dos espaços de participação socioestatal; e, finalmente, há aqueles que têm em sua trajetória diferentes formas de inserção na academia.

\section{Antecedentes do campo da aids}

Para compreendermos o contexto social e político do surgimento da epidemia é preciso destacar que as primeiras respostas à epidemia de aids no Brasil acontecem no cenário do processo de redemocratização do país, em um momento de transição da ditadura civil-militar, iniciada em 1964 e encerrada em 1985, para o período democrático.

O movimento homossexual e a politização da sexualidade

A década anterior ao início da epidemia, os anos 1970, foi marcada, em sua primeira metade, pela extrema violência dos órgãos da repressão política, atuando sob a égide do Ato Institucional no 5, promulgado no final de 1968. Paradoxalmente, como apontado por Simões e Facchini (2009), foi também um período de grande efervescência nas artes e de intensa contestação cultural, marcado pela contracultura, pelo tropicalismo, pelo underground e pelo "desbunde". 
Em um livro que trata dos movimentos políticos em torno da homossexualidade, estes autores chamam à atenção que o período anterior, nomeado por eles de “movimentação" homossexual, entre as décadas de 1950 e 1970:

\footnotetext{
"desenhou os contornos gerais do processo que fez que as homossexualidades saíssem do armário e se dirigissem não só para as festas, mas também para as assembleias e reuniões de pauta. Essas mudanças ajudaram a aliviar as condições que mantinham a vida homossexual na clandestinidade." (Simões e Facchini, 2009, p. 79).
}

É neste contexto, que ocorre a chamada primeira onda do movimento homossexual, como tem sido nomeada pelos pesquisadores do tema (Green, 2000; Facchini, 2005). Os marcadores que têm sido utilizados para demarcar o início deste período são a fundação do jornal homossexual Lampião da Esquina, reunindo intelectuais do Rio de Janeiro e São Paulo, e o grupo Somos, em São Paulo, no ano de 1978. Anteriormente, Paulo Teixeira refere ter participado em reuniões na casa de João Silvério Trevisan, no ano de 1976 (Teixeira, 2017). Há referências a este grupo, caracterizado como "de conscientização", no livro de James Green, "Além do Carnaval: a homossexualidade no Brasil do século XX" (2000, p. 427-8).

Esta é uma fase intensa, em que muito acontece em um curto intervalo de tempo. Possivelmente uma marca do período da "abertura", em que intensas mudanças sociais e culturais nas mais diversas áreas resultaram no grande movimento de contestação do regime militar.

Considera-se que esta primeira onda se encerra antes de meados dos anos 1980. Neste curto intervalo de tempo, houve uma grande proliferação de grupos, principalmente no eixo SP-RJ, mas atingindo também as regiões Sul, Centro-Oeste e Nordeste. Ocorrem, em abril de 1980, o I Encontro de Grupos Homossexuais Organizados (EGHO) e o I Encontro Brasileiro de Homossexuais (EBHO), com a presença de aproximadamente 200 pessoas na parte fechada do encontro (EGHO), incluindo convidados de 7 grupos, representantes de 4 cidades, além de uma representação do jornal Lampião. No final do mesmo ano de 1980, é realizada uma reunião preparatória do II EGHO, no Rio de Janeiro, que reúne 16 grupos, já contando com grupos recémformados do Nordeste. Logo em seguida, verifica-se redução do número de grupos, de 
forma que o II EGHO só conseguiu se efetivar em 1984, em Salvador, com a presença de apenas cinco grupos, todos do Nordeste (Simões e Facchini, 2009).

Resultaram destes encontros, algumas deliberações, tomadas por consenso entre os participantes: a alteração relativa a "transtornos sexuais" no Código de Doenças e a incorporação na Constituição brasileira da proteção dos direitos em função da "opção sexual". Ademais, decidiu-se, também, pelo fortalecimento dos grupos organizados, pela proteção dos homossexuais no universo do trabalho e da segurança pública, assim como pelo estímulo ao debate sobre o tema da homossexualidade no âmbito científico (Simões e Facchini, 2009).

A fundação do grupo Somos demarca uma postura de politização da questão da homossexualidade a partir de uma perspectiva libertária. Seu funcionamento se dava pela participação em subgrupos "de identificação", posteriormente chamados "de reconhecimento", nos quais seus integrantes compartilhavam suas experiências pessoais. A politização se dava a partir do pessoal e do cotidiano, como na máxima do feminismo: "o pessoal é político". O grupo é caracterizado como sendo imbuído do ideário da contracultura e do espírito contestatório e antiautoritário daquele momento. Sua atuação visava à transformação cultural e social mais ampla com foco na sexualidade, mas entendendo-a conectada a outras experiências de opressão. Neste sentido, buscou articular sua luta a de outras minorias, como o movimento feminista e negro (Simões e Facchini, 2009).

O ano de 1980 é marcado por cisões no incipiente movimento homossexual. No interior do grupo Somos, há uma primeira cisão, com a saída das lésbicas que criam o Grupo de Ação Lésbica-Feminista (Galf). Poucos meses depois, ocorre uma nova cisão, em função de divergências quanto à participação de parte do grupo na manifestação de apoio aos trabalhadores do $A B C$ paulista em greve. Aqueles que criticaram o comprometimento da autonomia do Somos devido à atuação de membros ligados a organizações político-partidárias, desligaram-se e formaram o Grupo de Ação Homossexualista, posteriormente denominado Outra Coisa. Outra ordem de cisão se dá entre o Lampião e os grupos ativistas. O jornal, que já estava com dificuldades financeiras e vivia divergências internas ao grupo de editores, passa a ter postura mais 
irônica nas matérias voltadas ao ativismo, após as cisões no Somos. Este posicionamento tensiona a relação dos grupos com editores e colaboradores do jornal. Em 1981, o Lampião encerrou suas atividades, o que veio a afetar a manutenção dos grupos ativistas, que perderam um significativo espaço de trocas e de acompanhamento das atividades entre seus pares. O Somos, por sua vez, chegou a estabelecer uma sede, em 1982, e manteve suas atividades até 1983, quando, com dificuldades financeiras e um número menor de participantes, vem a se dissolver (Simões e Facchini, 2009).

Simões e Facchini (2009) apontam uma diminuição acentuada na quantidade de grupos organizados no período de 1981 a 1991. Paralelamente, no entanto, o novo cenário político e social da redemocratização e o surgimento da epidemia de aids propiciam, segundo Facchini (2005), uma nova forma de atuação política, por uma nova geração de militantes.

Esta nova geração de militantes caracterizava-se, predominantemente, por não ter engajamento político-ideológico anarquista ou de esquerda e por ser menos resistente à ação de caráter institucional. O movimento, por sua vez, neste momento, apresenta uma nova conformação: mais orientada para o estabelecimento de organizações mais formalizadas e focadas na garantia do direito à diferença (Simões e Facchini, 2009).

Segundo Simões e Facchini (2009), as histórias de dois grupos organizados e de suas lideranças são expressivas da segunda onda do movimento homossexual no Brasil. Tratam-se de Luiz Mott, fundador, em 1980, do Grupo Gay da Bahia ${ }^{35}$ (GGB) em Salvador, e de João Antônio Mascarenhas ${ }^{36}$, um dos fundadores do grupo Triângulo Rosa, que existiu de 1985 a 1988, na zona sul carioca. Estas lideranças diferenciam-se das lideranças da primeira onda do movimento por terem uma atuação mais pragmática, direcionada a assegurar direitos civis e a combater a discriminação e a

\footnotetext{
35 O GGB é o grupo homossexual organizado mais antigo ainda em atuação, desde 1980.

36 João Antônio Mascarenhas teve papel importante na articulação do grupo que originou o jornal Lampião da Esquina e participou de seu conselho editorial no primeiro ano de atuação do jornal. Saiu no final de 1978, por defender, de forma isolada, uma linha editorial mais articulada à defesa dos direitos civis. O que se contrapunha à defesa do direito "a uma existência não mistificada, limpa, confiante, de cabeça levantada", nos termos expressos em artigo de Darcy Penteado, intitulado "Homossexualismo, que coisa é esta" no número 2 (junho/julho de 1978) do Lampião, mencionado por Simões e Facchini (2009, p. 94).
} 
violência contra homossexuais. Distanciam-se, também, das ideias da contracultura e de projetos de transformação social. Destacam-se, entretanto, por levarem adiante as propostas deliberadas no I EGHO e EBHO e nas atividades preparatórias ao II EGHO.

O GGB assumiu a coordenação e deu encaminhamento à campanha para alterar o Código de Doenças do Instituto Nacional de Assistência Médica e Previdência Social (INAMPS) com vistas a "despatologizar" a homossexualidade. A campanha, que se iniciou em 1981, mobilizou políticos e associações científicas, tendo resultado positivo, em 1985, com a sanção da mudança pelo Conselho Federal de Medicina. Antecipando alteração que só veio a ser realizada pela Organização Mundial da Saúde (OMS) em 1990, quando esta publicou a 10a versão da Classificação Internacional de Doenças (CID10). Simões e Facchini (2009) ressaltam a importância desta iniciativa:

\footnotetext{
"Foi uma campanha marcante por ter mirado uma das raras instâncias em que se discriminava oficialmente a homossexualidade no Brasil e, dessa forma, ter questionado a associação entre homossexualidade e doença que voltava com força devido à Aids." (Simões e Facchini, 2009, p. 121).
}

Este fato foi lembrado por Matheus Emilio Pereira da Silva, em sua entrevista ao ser convidado a me ajudar a traçar uma linha do tempo das políticas de prevenção. Matheus destaca o valor da despatologização da homossexualidade como uma condição para o desenvolvimento de políticas públicas, demarcando que é somente na condição de cidadãos que os homossexuais podem vir a tornar-se destinatários de tais políticas.

\footnotetext{
"Uma linha do tempo de políticas, vamos ver, é que tem diversos assuntos transversais que acredito que colaboram muito, como, por exemplo, quando a homossexualidade deixa de ser considerada uma doença. A partir do momento que você... que a homossexualidade deixa de ser considerada uma doença e passamos a ser vistos como pessoas e cidadão normal. Aí, eu acho que a partir desse momento de forma mais específica começam a surgir políticas... Começa a ter um olhar, olhares mais detalhados nos boletins epidemiológicos para essa população, e etc... Antes é, é doente... É doente, deixa para lá. Não se levava tanto a sério, eu acho..." (Matheus Emilio Pereira da Silva, entrevista).
} 
Posteriormente, os dois grupos, Triângulo Rosa e GGB, lideraram campanha para a inclusão, na nova Constituição brasileira, da proibição da discriminação por "opção sexual", renomeada depois como "orientação sexual" (Simões e Facchini, 2009). Esta campanha não foi bem-sucedida, mas teve resultados processuais dignos de nota. Em suas mobilizações, João Antônio Mascarenhas falou a duas subcomissões de parlamentares no âmbito do Congresso Nacional, como representante do movimento homossexual, tendo conseguido que ambas as subcomissões indicassem a inclusão desta forma de discriminação, o que não foi aceito, posteriormente, pela Comissão de Sistematização da Constituinte (Howes, 2003).

Há características distintivas desses dois grupos da segunda onda do movimento, em relação às organizações que tiveram mais destaque no período anterior, que são relevantes para o objeto desta tese. Tratam-se de grupos coesos em torno de uma liderança que se destaca por ser reconhecida, articulada, carismática e provida dos recursos materiais e simbólicos que as capacitavam para o alcance dos objetivos traçados. Além disso, são grupos que se formalizaram, na qualidade de entidade associativa de homossexuais, como sociedade civil sem fins lucrativos. Tendo, também, valorizado a conquista de infraestrutura física e material para sua ação, bem como o estabelecimento de relações com o movimento internacional (Simões e Facchini, 2009). Diferentemente dos grupos anteriores, caracterizados por sua pequena institucionalidade e infraestrutura, como se pode ver no relato de Veriano Terto Jr. sobre o grupo Somos/RJ:

\footnotetext{
"Só que com as dificuldades estruturais, naquele momento, porque antigamente não tinha sede própria, não tinha computador, não tinha endereço, nada disso. Era tudo, funcionava as reuniões na casa das pessoas e quem dispunha de um mimeógrafo em escola rodava os materiais, cartas, panfletos, cartilhas e, quem tinha uma máquina de escrever, datilografava. Eu mesmo, que fiquei responsável pelas cartas num momento, respondia as cartas a mão, não é? As cartas que vinham pro Somos. E tinha uma, e como eu te falei, no final era uma caixa postal. $\mathrm{O}$ último sinal de institucionalidade, que tinha aquele grupo. E assim era naquela época, né?" (Veriano Terto Jr., entrevista, 2017).
}

Neste novo contexto político-institucional do movimento, membros dos grupos da segunda onda atribuem sentidos diferentes à política. Tendem a descaracterizar o 
caráter político dos primeiros grupos ao contrapor a ação destes como "autoajuda", enquanto seus grupos fariam "política". Demarcando contraposição entre a politização do cotidiano, da primeira fase, e a política com fins pragmáticos por meio da atuação institucional com objetivos estabelecidos, do segundo momento do movimento (Simões e Facchini, 2009).

Ademais, estes grupos tenderam a conceber a identidade sexual como algo dado. Decorre desta atuação de caráter mais pragmático, um processo de depuração da homossexualidade de seus aspectos mais marginais em favor de uma respeitabilidade pública. Excluindo, assim, parte significativa das vivências relacionadas à homossexualidade e demarcando, por exemplo, diferenças entre homossexuais e travestis e michês (Simões e Facchini, 2009).

Diante da novidade trazida pela aids, no entanto, a atuação destes dois grupos diferenciou-se. No esforço de assegurar respeitabilidade à causa, o Triângulo Rosa decidiu não associar suas atividades de militância às questões trazidas pela epidemia. 0 GGB, por sua vez, assim como o grupo Atobá ${ }^{37}$, tiveram a aids como tema relevante em suas agendas. Explorarei, nas partes subsequentes deste capítulo, o impacto do surgimento da aids no movimento, assim como seus momentos posteriores, no que dialogam com as respostas à epidemia (Simões e Facchini, 2009, Câmara, 2015, Terto Jr., 2017, 2018).

\section{O movimento sanitarista}

No campo da saúde, os anos 1970, também são marcados por paradoxos. Naquele momento, no Brasil, o sistema de saúde era cindido estando as ações assistenciais de saúde individual subordinadas à lógica da medicina previdenciária tendo como foco os trabalhadores formais, predominantemente no meio urbano, sob o comando do Ministério da Previdência e Assistência Social, enquanto as ações de saúde pública estavam subordinadas ao Ministério da Saúde, voltadas aos setores mais pobres da população, com ênfase prioritária às ações preventivas e de vigilância epidemiológica. Os governos militares incentivavam a expansão do setor privado por

\footnotetext{
37 Fundado em Realengo, na zona oeste, subúrbio do Rio de Janeiro, em 1986 (Veriano Terto Jr., entrevista, 2017; Câmara, 2015; Simões e Facchini, 2009).
} 
meio da compra de serviços pela previdência e de incentivos fiscais às empresas que ofertassem convênios médicos aos seus funcionários; enquanto isso as políticas de saúde expandiam a cobertura da assistência médica previdenciária estatal a categorias e condições anteriormente descobertas, tais como acidentados no trabalho, trabalhadores rurais, empregados domésticos e trabalhadores autônomos, em um movimento de estatização privatizante da atenção à saúde (Cohn, 2003).

Paralelamente, no campo das práticas, desde os anos 1960 e mais intensamente nos anos 1970, há experiências de reforma dos sistemas locais de saúde com vistas a ampliar a cobertura das ações de saúde, descentralizar e aprimorar a gestão, formar recursos humanos em saúde pública e desenvolver ações de prevenção de doenças e de promoção da saúde. No âmbito do Ministério da Saúde, iniciam-se programas verticalizados voltados a algumas doenças, como hanseníase, tuberculose e câncer, assim como são desenvolvidos, no governo federal, novos arranjos institucionais, com vistas a fortalecer órgãos de gestão e administração centralizados para assegurar ações de saúde pública e de assistência individual (Escorel, 1999, Grangeiro e cols., 2009, Paiva e Teixeira, 2014).

O pensamento crítico, herdeiro das discussões originadas nos anos 1950 e 1960 no âmbito do projeto preventivista, que se dirigia ao modelo biomédico e havia se consumado na criação dos departamentos de medicina preventiva e social nas escolas médicas e de disciplinas que ampliavam a perspectiva clínica, se consolidava nas proposições da medicina social ${ }^{38}$. Paralelamente ao endurecimento da ditadura militar no país, aprofundam-se os debates teórico-conceituais e a produção de conhecimentos críticos acerca dos determinantes econômicos da saúde e da doença e dos sistemas de saúde, concatenados à proposição de modelos alternativos ao sistema de saúde vigente. Ao longo dos anos 1970, o campo da medicina social brasileira consolidou-se na proposição de cursos de pós-graduação em medicina social e saúde pública, que passarão, em 1979, a ser enquadrados sob a denominação de Saúde Coletiva. Este processo influenciou a formação de atores e instituições que foram fundamentais para

\footnotetext{
38 O quadro teórico da "escola" representada pelas obras de Maria Cecília Donnangelo, Ricardo Bruno Mendes Gonçalves e José Ricardo de Carvalho Mesquita Ayres, no qual se insere esta tese, constitui-se como produto e produtor deste campo.
} 
a mudança das políticas de saúde no país (Nunes, 2006; Grangeiro e cols., 2009, Paiva e Teixeira, 2014).

Com o aumento das iniciativas no campo da saúde, foi necessária a incorporação de novos quadros técnico-científicos nos diferentes órgãos estatais, o que gerou um afluxo de profissionais na burocracia estatal. Eram, em sua maioria, caracterizados como progressistas, ideologicamente de esquerda, defensores da prestação de serviços estatais de saúde e identificados ao que foi se constituindo como movimento pela reforma sanitária, integrando também o movimento de contestação do regime militar (Escorel, 1999; Paiva e Teixeira, 2014).

O campo movimentista da reforma sanitária englobou diferentes atores sociais de base progressista, destacando-se aqueles que tinham na academia sua base institucional; os movimentos dos médicos, como o Movimento de Renovação Médica e o Movimento dos Médicos Residentes; o movimento estudantil; o movimento popular de saúde; instituições da sociedade civil, como o Centro Brasileiro de Estudos de Saúde (CEBES); assim como projetos institucionais que experimentavam novos arranjos de organização do sistema de saúde, como o PIASS e o Projeto Montes Claros (estudados por Sarah Escorel), e iniciativas - no interior de espaços institucionais do Estado, porosos à ação da esquerda -, como o Programa de Estudos Socioeconômicos em Saúde (PESES), desenvolvido no âmbito da Fundação Oswaldo Cruz (FIOCRUZ) com financiamento da Financiadora de Estudos e Projetos (FINEP) (Escorel, 1999; Paiva e Teixeira, 2014).

A progressiva institucionalização do campo da Saúde Coletiva é fortemente identificada à constituição de duas entidades associativas: o CEBES, em 1976, e a Associação Brasileira de Pós-graduação em Saúde Coletiva (ABRASCO), em 1979. O CEBES foi formado por um grupo de sanitaristas - provenientes de diferentes escolas médicas de São Paulo, que vieram a se conhecer no curso de especialização em saúde pública da Faculdade de Saúde Pública da USP (Escorel, 1999) - com a intenção de publicar um periódico especializado, o Saúde em Debate, que pudesse disseminar as ideias do movimento. A ABRASCO, por sua vez, constituiu-se como uma articulação dos programas de pós-graduação em saúde pública, medicina social e saúde coletiva, naquele contexto que era também marcado pela desconexão entre os sistemas de 
formação de recursos humanos para a saúde e as necessidades do sistema nacional de saúde (Escorel, 1999; Paiva e Teixeira, 2014).

Os princípios da reforma sanitária foram sintetizados em texto aprovado do I Simpósio de Política Nacional de Saúde, realizado na Câmara dos Deputados no final de 1979, tomando por base um documento produzido pelo CEBES e por pesquisadores do Instituto de Medicina Social da Universidade Estadual do Rio de Janeiro, que preconizava: a saúde como direito universal de todo cidadão; a determinação intersetorial da saúde; a regulação do mercado de saúde pelo Estado; a instituição de um sistema de saúde regido pelas diretrizes de descentralização, regionalização e hierarquização, assim como pela participação popular e pelo controle democrático; e, sobretudo, a necessidade de integração entre ações curativas e preventivas, de forma a romper com a cisão entre saúde previdenciária e saúde pública (CEBES, 1980, Paiva e Teixeira, 2014).

Os atores do movimento da reforma sanitária tiveram ação intensa na primeira metade da década de 1980 , culminando na realização da $8^{\circ}$ Conferência Nacional de Saúde, ocorrida em 1986, e nas disputas ao longo da Assembleia Nacional Constituinte, realizada em 1987. A promulgação da Constituição Federal de 1988 estabelece a saúde como direito de todos e responsabilidade do Estado e orienta a criação do Sistema Único de Saúde, assentado sob os princípios de universalidade, igualdade, integralidade e controle social. Após essa importante conquista, identifica-se um processo de enfraquecimento do campo movimentista da luta pela reforma sanitária e, concomitantemente, o engajamento de parte de seus integrantes no processo de institucionalização do novo sistema nacional de saúde (Escorel, 1999; Grangeiro e cols., 2009; Paiva e Teixeira, 2014).

\section{Década de 1980}

A emergência da aids no Brasil se deu em um contexto de enorme sensacionalismo, gerando alarde e pânico na comunidade homossexual. As primeiras notícias sobre a aids chegaram ao Brasil antes que os primeiros casos tivessem sido identificados, como contam Carrara e Moraes (1985 apud Galvão, 2000, p. 20) em artigo 
no qual caracterizaram a aids no Brasil no início dos anos 1980 como um "mal de folhetim" (Galvão, 2000). Jane Galvão, em seu livro "Aids no Brasil: a agenda de construção de uma epidemia" (2000), aborda a configuração de uma "Aids brasileira" por meio das respostas institucionais à epidemia entre 1981 a 1996. Ao traçar uma periodização das respostas, a autora descreve o período de 1981 a 1982 como marcado pela abordagem da imprensa, enquanto não havia respostas governamentais e das organizações da sociedade civil. A partir da descrição feita pela autora, destaco alguns aspectos da abordagem da mídia sobre a aids naquele período: a) enfatizava-se a associação entre homossexualidade e aids, que foi nomeada naquele primeiro momento como "peste gay", "câncer gay", "doença de homossexuais", "praga gay", reforçando a dinâmica de atribuir a doença e suas determinações a um "outro"; b) reportava-se de forma desqualificadora ao contexto libertário do sexo e do uso de drogas da década de 1970, sem fazer referência ao contexto político do país; c) muitas das matérias jornalísticas traziam profissionais de saúde e, em particular, médicos, na qualidade de especialistas, expressando suas hipóteses e explicações sobre as conexões entre aids e homossexualidade, embasados, predominantemente, em opiniões pessoais. Esta abordagem contribuiu fortemente para informar o público geral sobre a aids, assim como para reforçar a atitude crítica da militância de resistência ao discurso moralizador da medicina.

Entre o final de 1982 e o início de 1983, foram diagnosticados os primeiros casos de aids no Brasil, em São Paulo (Laurindo-Teodorescu e Teixeira, 2015, v. 1, p. 33-4). Em junho de 1983, ganhou destaque na imprensa a morte do estilista Marcus Vinícius Resende Gonçalves, o Markito, a primeira morte de um brasileiro por aids tornada pública, impactando fortemente a comunidade homossexual, especialmente pela forma como foi retratada pela imprensa (Perlongher, 1987; Moriconi, 2002 ${ }^{39}$ ).

\footnotetext{
${ }^{39}$ Caio Fernando Abreu, escritor brasileiro que retratou a geração brasileira urbana impactada pela contracultura e pelo desbunde, homossexual, que veio a morrer de aids em 1996, menciona em suas cartas o advento da morte do estilista Markito, citando-a pela primeira vez na carta enviada para a amiga Jacqueline Cantore, em 05 de junho de 1983, dia seguinte ao da morte, na qual Caio conta sobre a reação de outra amiga quando viram a notícia: "ao que se sabe por AIDS, a peste gay, depressão". Ítalo Moriconi, organizador do livro "Caio Fernando Abreu: cartas", adiciona a este trecho uma nota de rodapé em que descreve a relevância desta morte como um marco: "A morte do estilista Markito ficou como uma espécie de marco: a primeira morte por Aids reconhecida publicamente como tal. Foi por esta época, ano de 1983, que o tema da Aids adquiriu maior relevo na imprensa, que falava de um
} 
O antropólogo e poeta argentino Néstor Perlongher, falecido de aids em 1992, nos conta em seu "O que é AIDS" - publicado em 1987 - sobre o contexto da chegada da aids no Brasil, no calor no momento:

"A doença chegou ao Brasil nos braços da moda. Se coube à dermatologista Valéria Petri o mérito de detectar, em fins de 1982, os dois primeiros casos brasileiros de AIDS (rapazes de 30 e 32 anos, com sarcoma de Kaposi, que tinham ido aos Estados Unidos), foi com a morte do costureiro Markito que começou a espetacular ressonância da praga. Sua agonia, detalhada minuciosamente pelos meios de divulgação, desencadeia a primeira onda de pavor local.

$[\ldots]$

A irrupção da AIDS surpreende os gays brasileiros numa situação paradoxal: a fraqueza orgânica dos já quase desestruturados grupos (apenas sobreviveria com ímpeto o Grupo Gay da Bahia) coexistia com uma expansão publicitária do espetáculo gay. O desbunde - versão tropical do out of the closet (literalmente, "fora do armário") dos gays americanos - não tinha apenas favorecido os portadores do novo modelo de homossexual assumido (aquele que mantém uma relação de igual para igual com outro homossexual, também assumido, sem precisar nenhum dos dois se efeminarem). Os travestis, que pouco tinham a ver com o programa de igualdade sexual, aproveitaram também a fresta aberta para invadir maciçamente as avenidas das megalópoles. A sugestiva sagração do travesti Roberta Close como "modelo de mulher nacional" pode bem simbolizar certa deglutição capciosa do homossexualismo que se insinuara, por volta de 1984, pela mídia. Com a emergência do mal, todo esse quadro mudaria: a sensual ambivalência de Roberta Close seria substituída pelo brilho severo de Dona Risoleta.

Há, na crise da AIDS, todo um cheirinho de restauração. Chegou-se longe demais, paga-se agora a culpa pelos excessos libidinosos! Um retorno ao casal, uma volta à família, a morte definitiva do sexo anônimo $e$ impessoal...

A morte do teatrólogo Roberto Galizia - isolado atrás dos vidros da enfermaria, passou seus últimos dias quase cego, ditando poemas à enfermeira -, no verão de 1985 , marca o início da segunda onda de pânico. Os rituais de agonia seriam, doravante, reciclados insistentemente pela mídia.

A televisão desempenha um papel decisivo no procedimento, que chega a beirar o obsceno de espetacularização da morte: mostram-se, por exemplo, cenas de dois rapazes gays de mãos dadas, e logo depois um paciente carcomido pelo sarcoma de Kaposi; panorâmicas do gueto gay, seguidas de martírios de hospital. A imagética própria da medicina é terrorista. Nas reuniões de informação convocadas pelo recém-criado

\footnotetext{
"câncer gay", levando pânico aos libertários de todas as cores e idades, egressos da contracultura dos anos 60/70, como o próprio Caio. A partir desse marco cronológico, tanto a vida quanto a obra de Caio e de outros escritores do fim-de século brasileiro seriam profundamente marcadas pela vivência da Aids. Vide os estudos de Marcelo Secron Bessa, nos ensaios de Histórias positivas (Ed. Record, 1997)."
} 
Grupo de Apoio e Prevenção à AIDS, o público assistente - basicamente homossexual - era bombardeado com transparências de rapazes de nádegas corroídas e rostos desfigurados. Já em 1986, o pintor Darcy Penteado retira-se aos gritos de "Terrorismo médico!" de uma conferência do então secretário municipal de Saúde de São Paulo, onde era exibido na tela um homem deformado pela doença. A reação de Darcy não é apenas emocional: segundo ele, "o problema da AIDS não é a doença em si, mas a paranóia que os meios de comunicação estão criando", e denunciava que "os veículos estão veladamente atrelados a poderosos esquemas médico-farmacológicos multinacionais que certamente pretendem faturar altíssimo às custas da AIDS; a medicina desonesta aliada a grupos conservadores, radicais e ferozes, pretende restaurar horrores em cima desse horror todo" (ISTOÉ, 22.1.1986).

Nem todos os porta-vozes dos chamados "grupos de risco" tinham, num primeiro momento, as coisas tão claras. A redução da promiscuidade e da penetração nos encontros homoeróticos foi conclamada sem rodeios, ainda ao preço da abstinência: "Entre transar e viver, minha opção é viver", declarava, em maio de 1985, o porta-voz do GAPA.

Enquanto isso, a AIDS ia abandonando o dourado reduto do jet-set; aclimatando-se e nacionalizando-se, iria adquirir características propriamente brasileiras na sua difusão. Não somente quebrou com rapidez as barreiras de classes (em fins de 1986, 95\% dos pacientes de AIDS provinham de classes populares), mas também as do gueto homossexual onde fora fechada revelaram-se paulatinamente frágeis. Embora os homossexuais contaminados constituam ainda a vasta maioria, a proporção de homens "bissexuais" contaminados sofre um progressivo aumento.

$[\ldots]$

A defasagem entre as prevenções sexuais promovidas e as práticas homossexuais concretas não é retórica. Assim, em Campinas, a equipe médica da AIDS sentia, no próprio campo, essa inadequação: "O que você recomenda não tem nada a ver com o sexo que eu faço", queixavam-se os homossexuais populares no ambulatório.

No caso do Brasil, os conselhos preventivos dirigidos a homossexuais integraram-se numa estratégia progressista - que visaria salvaguardar, mesmo ao preço do autocontrole, alguns tênues direitos humanos conquistados pelas minorias eróticas. Enquanto o "progressismo" médico advoga certa reforma das práticas corporais, diminuindo assim as probabilidades matemáticas de transmissão do vírus, outros setores, menos compreensivos, propugnam métodos mais ríspidos (do tipo "acabar com o doente para acabar com a doença") (Perlongher, 1987, p. 51-7; destaques do autor).

A primeira resposta governamental à epidemia de aids no Brasil ocorreu no âmbito da Secretaria de Estado da Saúde de São Paulo (SES-SP) e foi provocada por uma demanda expressa, em junho de 1983, por ativistas dos grupos Somos e Outra Coisa à 
SES-SP. Este grupo de militantes cobrava uma posição diante do novo problema de saúde enfrentado pela comunidade homossexual. Inicialmente, se deu pela constituição de um grupo de trabalho reunindo técnicos da SES-SP sob a coordenação da Divisão de Hansenologia e Dermatologia Sanitária do Instituto de Saúde (DHDS) - que já tinha, naquele momento, a intenção de ampliar suas ações trabalhando com doenças sexualmente transmissíveis - e pela elaboração de um documento técnico que delineou a proposta das principais diretrizes e ações a serem implementadas ${ }^{40}$ (Teixeira, 1997; Parker, 1997; Galvão, 2000; Grangeiro e cols., 2009; Laurindo-Teodorescu e Teixeira, 2015, p. 25-51).

Há consenso, dentre os autores que trataram da história das respostas políticas e institucionais à epidemia, de que o pronto acolhimento e resposta por parte da SESSP se deveu ao fato de que o estado de São Paulo, naquele momento, era governado por Franco Montoro, primeiro governador do estado eleito democraticamente, após a ditadura militar, e a SES-SP era dirigida por quadros progressistas vinculados ao movimento da reforma sanitária (Teixeira, 1997; Parker, 1997; Galvão, 2000; Grangeiro e cols., 2009).

Também é digno de nota na construção da primeira resposta governamental à epidemia de aids, como evidenciam Grangeiro, Silva e Teixeira (2009), as influências trazidas pela equipe da Divisão de Hansenologia e Dermatologia Sanitária, sob a coordenação de Paulo Roberto Teixeira, com a política de controle da hanseníase doença que também é fortemente marcada pela experiência do estigma, do preconceito e da discriminação. Nos anos anteriores, esta política havia sido profundamente reformulada de forma a: desinstitucionalizar os doentes, anteriormente isolados compulsoriamente do convívio social; enfatizar estratégias de redução do estigma; incorporar os determinantes sociais nas ações de promoção da saúde.

Desta demanda trazida pelas lideranças do movimento homossexual e de seu reconhecimento por parte de técnicos e dirigentes da SES/SP nasceu, em agosto de 1983, o Programa Estadual de DST/Aids de São Paulo, o primeiro estabelecido no Brasil.

\footnotetext{
${ }^{40}$ Este documento, que me foi apresentado e cedido por Paulo Roberto Teixeira na entrevista realizada em setembro de 2017 como o marco zero das políticas de prevenção de aids no Brasil, será apresentado com mais detalhes a seguir.
} 
Foram centrais, no estabelecimento do novo programa, as diretrizes de nãodiscriminação - incorporada a partir da experiência da política de controle da hanseníase - e de participação social - derivada da experiência do movimento sanitário. O programa foi organizado em torno de quatro estratégias: ações de vigilância epidemiológica (por meio do estabelecimento da notificação compulsória); serviços de referência assistencial e laboratorial; ações e serviços informativos e educativos; participação social. O programa paulista tornou-se rapidamente uma referência importante para as ações dos outros estados e do governo federal (Teixeira, 1997, Galvão, 2000, Simões e Facchini, 2009, Grangeiro e cols., 2009).

Para os gestores entrevistados já atuantes no campo desde a década de 1980, Paulo Teixeira e Maria Clara Gianna, há a compreensão de que as referências éticas e políticas para o estabelecimento dos programas de aids foram definidas nesse momento sob a influência do movimento sanitarista, do movimento pela democratização do país e contra a ditadura, com ênfase na proteção e garantia de direitos dos homossexuais. Há, para estes entrevistados, a compreensão do caráter político e valorativo intrínseco à ação em saúde. Pode-se, assim, identificar que um dos discursos definidores dos programas brasileiros de aids é fundamentado na promoção e proteção dos direitos de cidadania daqueles que integram os grupos afetados pela aids, assim como o combate à sua discriminação, como se pode observar no depoimento de Paulo Teixeira:

Então, existem alguns elementos de toda política brasileira de controle, de combate ao HIV, que foram estabelecidas ali em 1983. Que era o direito à cidadania, a proteção dos direitos do grupo afetado, a prevenção do estigma, o combate à discriminação, né? $\mathrm{E}$, então, com alguns equívocos, pela ignorância, pelo desconhecimento, não é? As referências éticas e políticas foram adotadas ali naquele período e, como está escrito aqui no livro ${ }^{41}$, num contexto do movimento sanitarista, do movimento pela democratização do país, contra a ditadura, etc. Então, essa é a marca do ponto zero, né? Depois, como está descrito aqui no livro, vem a história. Mas essas referências nunca deixaram de ser adotadas, né? Como você vai ver aqui nesse documento, né? Nos primeiros anos, tanto em São Paulo como, anos depois, em âmbito nacional, a política em relação aos homossexuais, $\mathrm{HSH}$, se referiam, repito, muito mais aos direitos e à proteção do que especificamente à prevenção. A prevenção era

\footnotetext{
${ }^{41}$ Paulo Teixeira refere-se aqui ao capítulo intitulado "Políticas públicas em AIDS", de sua autoria, publicado no livro "Políticas, instituições e AIDS: enfrentando a epidemia no Brasil", organizado Richard Parker, no qual conta a história das políticas públicas voltadas à epidemia de aids no Brasil.
} 
abordada genericamente, né? E é quando começam, após os primeiros anos, a surgir as dificuldades na abordagem (Paulo Roberto Teixeira, entrevista).

Naquele momento, a epidemia era caracterizada predominantemente como homossexual. Os saberes tecnocientíficos hegemônicos à época eram fundados sobre a categoria epidemiológica de "grupo de risco". O instrumental epidemiológico do risco teve grande utilidade no contexto da emergência da epidemia nos Estados Unidos, quando profissionais de saúde em hospitais e consultórios depararam-se com uma nova entidade clínica com causa desconhecida. Sua notificação aos profissionais da saúde pública foi seguida de investigação epidemiológica para a identificação dos grupos mais afetados e o estudo descritivo acerca dos aspectos individuais associados ao desenvolvimento da doença - os chamados fatores de risco. Com isso, foi possível conhecer as rotas de transmissão - antes mesmo da identificação do vírus -, sabendo que a doença estava associada ao comportamento sexual e a troca de fluídos (Mann e Tarantola, 1996). No entanto, como apontam Ayres e colaboradores (2003), se observa um deslocamento discursivo com graves consequências na origem do conceito operativo de grupo de risco. Isso se dá quando o risco - categoria analítica que orienta o raciocínio causal nos estudos epidemiológicos - é convertido em conceito operativo para orientar as ações de prevenção. De categoria analítica, converte-se em uma verdadeira categoria "ontológica", designando os grupos "arriscados" como identidades intrínsecas. O que teve resultados limitados em termos de prevenção, mas sérias consequências para os grupos mais afetados pela doença em termos de preconceito, estigmatização e discriminação (Kalichman, 1993; Ayres et al., 2003).

Por aqui, esta discussão já chega fortemente mediada tanto pelas características já apontadas daqueles que estavam à frente das respostas governamentais, como pela proximidade e crítica constante por parte do movimento social. Um dos esforços de imprimir o valor da não-discriminação à ação técnica no campo da saúde se deu na resistência à adoção do conceito de grupo de risco, evitando assim atribuir caráter substantivo à associação entre aids e homossexualidade. É neste sentido que podemos compreender o esforço em adotar outros conceitos operativos na caracterização da 
epidemia que fossem menos impregnados por valores conservadores no campo da sexualidade:

\begin{abstract}
"Eu acho que quando a gente sai de grupo de risco... Porque grupo de risco quando a gente começa a trabalhar com HIV, eram os $\mathrm{Hs}^{42}$, né? Hemofílico, haitiano... Usuários de drogas, né? A questão da heroína e homossexuais, né? Eram estes. E quando a gente começa a trabalhar com a questão do HIV e, aí é anos 1980, a gente começa a perceber que não é isso. Acho que a gente, de cara, a gente olha para grupo de risco e fala: "Não. Não é grupo de risco." Acho que o Paulo Teixeira foi muito importante para a gente naquela época. Artur $^{43}$ e eu, Paulo. Acho que talvez no primeiro boletim epidemiológico que era um boletim amarelinho, a gente já traz a questão de situação de risco. Em que a gente sai de grupo, vai para situação.

[...] Vem [tanto juízo de valor], eu acho que quando a gente sai de grupo de risco e a gente vai pra situação de risco, essa questão do juízo de valor, ela muda. [...] Quando você sai, você vai para situação de risco, você vai para, talvez, comportamento, isso já vai mudando na forma como se olha a epidemia, né? Você vai pra múltiplas relações, relações sexuais desprotegidas [ao invés de se referir à categoria "promiscuidade" ou "relações promíscuas"], né?" (Maria Clara Gianna, entrevista).
\end{abstract}

Em mestrado, defendido em 1993, Artur Kalichman fez uma recuperação histórica do conteúdo e das estratégias de utilização dos conceitos que instrumentalizam o trabalho da Vigilância Epidemiológica (VE) da aids no reconhecimento da epidemia e de seus determinantes. Neste estudo, em que recuperou a forma como o Centers for Disease Control (CDC) estadunidense "contou a história" da nova epidemia, realizou uma análise em que buscou localizar o caráter descritivo/prescritivo com que os conceitos da VE se configuraram em expressão de uma realidade e, ao mesmo tempo, constituíram-se em conhecimento técnico com o propósito de intervir produtivamente sobre essa mesma realidade. Com isso, mostrou como o CDC forjou, como conceitos operativos da VE, no início das respostas técnico-

\footnotetext{
42 Referindo-se à forma como inicialmente o Centers for Disease Control (Centros para Controle de Doenças - CDC) estadunidense caracterizou os grupos mais afetados pela nova doença. Os "4Hs" referiam-se aos homossexuais (homosexuals), usuários de droga injetável (heterosexuals who abuse intravenous drugs), haitianos (Haitians), hemofílicos (hemophiliacs).

${ }^{43}$ Artur Kalichman, médico sanitarista da mesma geração que Maria Clara Gianna, também começou a trabalhar no CRT-DST/Aids assim que terminou a residência médica, em seu caso em Medicina Preventiva na FMUSP. Ambos trabalharam no setor de Vigilância Epidemiológica (VE) nos primórdios do programa estadual de São Paulo, sob a gestão/coordenação de Paulo Teixeira.
} 
científicas à epidemia, a contraposição entre "população geral americana" e os "grupos de risco aumentado para a AIDS", nos quais foram incluídos os homossexuais, os usuários de drogas endovenosas, os haitianos e os hemofílicos. Cotejando, de um lado, uma generalidade homogênea e, de outro, sujeitos específicos, também homogeneizados nas suas "novas identidades 'arriscadas'" (Kalichman, 1993, p. 25). Contraposição que reforçou a ideia da aids como uma doença do "outro", daquele que não é "normal", no que tange à orientação sexual, ao uso de substâncias psicoativas, à ilicitude das drogas, à nacionalidade estrangeira, à cor da pele/raça, à condição de saúde (Kalichman, 1993).

Assim, havia por aqui, como se pode notar no depoimento de Maria Clara Gianna, a preocupação em explicitar a compreensão de que o risco não era uma exclusividade somente de alguns grupos populacionais, mas que todos poderiam potencialmente se infectar.

\begin{abstract}
Nos anos 1980 e nos anos 1990, a gente tem uma epidemia marcadamente gay. Mas que a gente precisava desconstruir o conceito de grupo de risco. A gente precisava ampliar, porque a gente tinha um crescimento de casos entre mulheres, crescia o número de casos entre usuários de drogas injetáveis, crescia o número de casos, também, entre heterossexuais, a gente tinha a transmissão vertical chegando. Então, acho que num primeiro momento que é esse primeiro momento, que ele é meio estratégico, de desconstrução desse conceito de grupo de risco, em que a gente vai pra situação de risco, onde a gente vai pra comportamento de risco e depois quando a gente chega na questão da vulnerabilidade (Maria Clara Gianna, entrevista).
\end{abstract}

Como apontado anteriormente, a mídia e as "autoridades médicas" foram dos principais responsáveis pela disseminação dos discursos assentados sobre a noção de grupos de risco. Essa perspectiva, apesar dos vários esforços dos envolvidos, ainda se manteve por muito tempo, como se vê na menção de dois dos entrevistados sobre incidente no início da década seguinte:

Então pra se ter algumas coisas como... Quando foi? Nos anos 1990, 1991, 1992, aquelas declarações do David Uip falando que ele nunca teve um paciente heterossexual com HIV. Ele falou isso duas vezes pra revista de grande circulação. [...] Que foi muito ruim, eu me lembro, porque outra vez forçava aquela questão, por um lado de gays, por outro lado é uma imagem, passa uma mensagem de segurança falsa, né? Bom, tanto pros 
homens heterossexuais como para as mulheres, né? (Jorge Beloqui, entrevista)

Lembre-se da entrevista do David Uip pra Veja que causou tanto impacto, que é de 1993? Dois? É de 1992. Que, editada ou não, David até dá um depoimento pra mim, aqui, dizendo que não era intenção principal dele. Querendo ou não, traz de novo aquela ideia de que a mulher não adquire, não transmite. Não transmite o HIV. Então, você veja a dificuldade da incorporação da transmissão da mulher pro homem, da transmissão heterossexual. (Paulo Teixeira, entrevista).

Data de 1983, o documento que pode ser considerado como marco zero das políticas de aids no Brasil (São Paulo (Estado), 1983). Elaborado em um momento em que ainda não se sabia sobre a existência do HIV44, este documento buscou reunir e sistematizar as poucas informações disponíveis, que o grupo de técnicos coordenado por Paulo Roberto Teixeira conseguiu reunir, acerca da epidemiologia, clínica, etiologia, modos de transmissão, diagnóstico diferencial, exames complementares e laboratoriais, tratamento, ações educativas, notificação e investigação, bem como contatos de serviços e dos departamentos regionais de saúde da SES-SP. Destinado a profissionais de saúde, foram impressas 5.000 cópias mimeografadas e distribuídas aos serviços de saúde do estado de São Paulo.

Trata-se de um documento bastante sofisticado em vários sentidos. Chamam a atenção alguns cuidados tomados na elaboração do documento, já se usava a sigla AIDS e não foi feita nenhuma referência a GRID (Gay-Related Immune Deficiency) ou outra denominação que atribuísse exclusividade da doença à comunidade gay. No tópico relativo à epidemiologia, houve cuidado em não reforçar a ideia de "grupos de risco", mesmo ao informar que haviam grupos identificados como mais expostos à doença: homossexuais e bissexuais, usuários de drogas e hemofílicos. É por meio deste documento que se passa a estimular e orientar a notificação dos casos de aids e sua investigação epidemiológica no estado de São Paulo. Ao tratar dos modos de transmissão, o documento faz menção à transmissão heterossexual e à transmissão endovenosa (por transfusão e por uso de drogas por via endovenosa, com referência ao

\footnotetext{
44 Já havia a hipótese de que se tratava de um vírus, possivelmente relacionado ao HTLV, o documento faz referência às primeiras notícias acerca dos vírus estudados pelo Instituto Pasteur e dos EUA.
} 
abuso de drogas), assim como alerta para a análise de comunicantes dos doentes, indicando a possibilidade da existência de pacientes assintomáticos. Como naquele momento, ainda não se havia localizado o vírus, ainda não existia possibilidade de diagnóstico, mas algumas indicações de diagnóstico diferencial para as doenças, hoje chamadas, oportunistas. Indicava-se a importância de integrar ações educativas às medidas de controle do novo agravo com vistas à "formação ou mudança de atitudes e comportamentos, capazes de estimular as pessoas a participarem na efetivação das medidas propostas" (São Paulo (Estado), 1983, p. 11). Enfatizando o entendimento de que a saúde da comunidade não depende somente das ações oferecidas pelos serviços de saúde e que muito pode ser feito a partir do compartilhamento dos conhecimentos científicos disponíveis. Neste sentido, destacava-se a relevância do papel dos profissionais de saúde - principal receptor deste documento - na minimização de dúvidas e ansiedades ocasionadas pela divulgação de informações distorcidas e orientava-se informar aos doentes, aos seus comunicantes e aos grupos de maior risco sobre: modo de transmissão, sinais e sintomas, tratamento e locais para o encaminhamento de casos suspeitos.

As medidas educativas propostas são vagas e avaliadas, na atualidade por Paulo Teixeira em sua entrevista, como equivocadas por terem proposto "evitar a troca constante de parceiros sexuais, principalmente parceiros anônimos", bem como "evitar contato sexual com pessoas sob suspeita de 'AIDS'". Dentre as medidas profiláticas propostas, não se mencionava ainda a camisinha como recurso preventivo, o que só veio a ser realizado no estado de São Paulo em 1984. Segundo Pinheiro (2015), as primeiras referências ao uso da camisinha como medida que poderia oferecer alguma proteção à aids datam deste mesmo ano de 1983, o que se dá em meio ao processo de construção da ideia de sexo seguro por parte da comunidade gay nos Estados Unidos (EUA). Tampouco propunha-se, no referido documento, a abstenção sexual, ou medidas mais restritivas da vida social como se tem notícia nos EUA - tais como o fechamento de saunas.

O principal grupo afetado pela epidemia de aids, nos anos 1980, foi o de homossexuais masculinos. Simões e Facchini (2009) chamam a atenção que a aids reacendia a conexão entre homossexualidade e doença, reforçando uma abordagem 
social sobre as sexualidades que produz estigma, sofrimento e opressão. Como escreveram os antropólogos e militantes Peter Fry e Edward MacRae no livro "O que é homossexualidade", da Coleção Primeiros Passos, em 1983 - momento em que o incipiente movimento homossexual atuava e que a comunidade homossexual começava a lidar com a chegada da doença por aqui: "O fato é que a homossexualidade continua sendo tratada, na prática, como uma indigesta mistura de pecado, sem-vergonhice e doença" (Fry e MacRae, 1985, p. 117-8; grifos dos autores).

O movimento gay tem, como a literatura e os depoimentos mostram, uma reação que não é uma reação única e que vai progressivamente se transformando ao longo da década. Há, de imediato, uma reação de questionamento dos discursos que associavam homossexualidade e aids, considerando que a doença poderia estar sendo imputada à homossexualidade de um modo equivocado, configurando-se em mais um modo de controle da sexualidade dos homossexuais e em retrocesso das liberdades recém-conquistadas. Gradualmente, mais e mais pessoas, por diferentes processos, tomam o assunto para si, preocupando-se muito com a epidemia, com as pessoas morrendo, o que mobiliza a construção de respostas. Desde a pressão sobre o governo com vistas a buscar o reconhecimento das consequências da aids na comunidade homossexual, como a constituição de iniciativas variadas - no campo da assistência aos doentes, da prevenção dirigida à comunidade, mais ou menos institucionalizadas (Galvão, 2000; Simões e Facchini, 2009; Câmara, 2015).

O temor de reforço da associação entre homossexualidade e aids e de perda das conquistas sociais e culturais recentes gerou resistências a lidar com a aids no interior da comunidade e do movimento homossexual, como se pode observar na fala de Veriano Terto Jr. (entrevista):

Mas, assim, eu era daqueles que olhava pra aids com uma certa desconfiança, né? Era aquela, aquela, aquele juízo, aquele valor que existia naquele momento que a aids tinha vindo para reprimir as liberdades que a gente teria, né? Os homossexuais e que o movimento homossexual tinha conseguido nos anos 1970. Essa questão de propor camisinha, enfim, como uma espécie de freio, né? E repressão. E até porque, naquela época, os grupos gays, eles não, a agenda de direitos humanos não pertencia aos grupos. A gente trabalhava muito mais com a ideia, de palavras como ir contra a repressão, a favor da liberação, pela emancipação. Se tu ver o nome dos grupos naquele período é tudo: grupo de Emancipação, grupo de Liberação, grupo de, não sei o que, 
antirrepressão. Não tinha essa coisa de grupo por direitos, né? Isso vem depois da Constituinte, em 1987, 1988. Acho que a Cristina Câmara, outros autores, o João Antônio Mascarenhas, eles documentam isso melhor. Mas era, eram essas as palavras. Então, eu era daquela turma que achava que a aids, ela vinha pra reprimir, pra acabar com a festa, enfim. Então, tinha uma certa resistência em trabalhar com essa questão, né? Em incorporar essa questão. E eu mesmo só comecei a usar a camisinha lá por volta de 1987, por aí. Foi entre 1986 e 1987. Quer dizer, já com a aids bem, bem avançada, né? Porque tinha esse tipo de juízo. A gente fazia outras coisas pra não usar camisinha. Tipo, parar de fazer, de ter penetração em relação sexual, parar de ter contatos, quer dizer.... Diminui o número de transas. Começa a ter alguma outra coisa que, né? Pra não... Mas chega uma hora que teve que usar a camisinha, não tinha jeito (Veriano Terto Jr., entrevista).

Apesar das fundamentadas resistências, o relato de Edward MacRae a Cláudio Roberto da Silva, apresentado por Simões e Facchini (2009), nos ajuda a compreender as mudanças subsequentes na resposta do movimento homossexual à aids, que tiveram impacto importante no âmbito das respostas governamentais:

Em 1983, passei uma semana nos Estados Unidos. Quando cheguei a Nova York, toda a defesa em nome do desbunde que li a respeito já não estava mais do mesmo jeito. As pessoas estavam preocupadas com obras assistenciais, acontecia o oposto. Na imprensa gay americana se lia "A Festa Acabou". O movimento gay estava todo voltado à questão da Aids. Então percebi que era uma coisa séria.

Nesse período, uma das grandes posições defendidas pelo movimento homossexual era questionar o discurso médico e a ideia do homossexual como doente mental. Os médicos eram os propagadores de uma nova moral, não mais com base teológica, mas com uma base médica que no final das contas percebíamos como totalmente preconceituosa. Havia um questionamento constante da postura médica e não tínhamos a menor paciência para o seu discurso. No Somos nunca chamavam médicos para falar, no máximo as pessoas visitavam o médico para curar uma gonorreia ou uma sífilis.

Quando voltei ao Brasil, a ideia era que se tratava de mais um complô médico. A questão da Aids era vista como outra fórmula pseudocientífica para oprimir os homossexuais, fazê-lo retornar à margem. Muitos dos antigos militantes defendiam esse parecer. Certamente, também teria tomado esta posição, mas havia estado nos Estados Unidos e visto que o caso era sério. Os norte-americanos não estavam mais defendendo as antigas posições, então comecei a ver a questão sob outro prisma. Assim, houve momentos em que ocorreram algumas discordâncias, mas eles eram pessoas inteligentes e logo começaram a perceber os perigos que estavam correndo. 
É a partir de tais mudanças de perspectiva, que a sociedade civil se organiza para pressionar o governo a responder à epidemia de aids, como apresentado anteriormente.

A primeira ação comunitária de prevenção desenvolvida no Brasil de que se tem referência na literatura foi uma ação do grupo homossexual Outra Coisa de produção e distribuição de material informativo sobre aids em espaços de sociabilidade homossexual já em 1983, uma ação focada na disseminação de informações e de um alerta à comunidade sobre a aids (Perlongher, 1987, p. 51; Galvão, 2000, p. 56-7; Grangeiro e cols., 2009, p. 90). Como apresentado anteriormente, o Outra Coisa era uma dissidência do grupo Somos - inicialmente denominado Grupo de Ação Homossexualista. Segundo depoimento de Regina Facchini à Thiago Pinheiro (Pinheiro, 2015, p. 82), uma das questões que distinguia e tensionava a relação entre o Somos e sua dissidência, o Outra Coisa, era o posicionamento em relação ao que se nomeava, naquele momento, na comunidade homossexual como "peste gay". O depoimento de Veriano Terto Jr., em entrevista a Thiago Pinheiro (2015, p. 82), ajuda a compreender as diferenças de abordagem entre os dois grupos:

Eu acho que os grupos que começaram a falar de prevenção - eu acho, na minha cabeça e é o que eu cito nos artigos - é o grupo Outra Coisa, que (...) foi uma dissidência do Somos, que aconteceu lá pelo início dos anos 80. (...) O famoso racha do Somos de São Paulo, ele acontece por uma (...) acusação, vamos dizer assim, a crítica de que ele era um grupo que prestava menos atenção às coisas da homossexualidade ou jogava as questões da homossexualidade dentro de uma luta mais ampla das esquerdas. (...) Enquanto que o pessoal do Outra Coisa reivindicava que, em vez de olhar pras questões mais, vamos dizer assim, amplas e fora na sociedade, olhassem para as questões da homossexualidade, entende? De coisa de sexualidade, de amor, de afeto, de família, amigos; as coisas mais, vamos dizer assim, não sei se seria a palavra, "intestinas" da vida cotidiana da homossexualidade. Não tanto essa coisa do lugar político da homossexualidade. (...) E, aí, eu acho que, por isso, eles [do Outra Coisa] são quem talvez assumem mais rápido a questão de aids e de DST e as coisas de saúde, porque, vamos dizer assim, essa assim seria uma das questões, sabe? (...) A gente coloca assim, isso é quase meio que um consenso, que a prevenção teria começado com o Outra Coisa, que é esse grupo, por essa relação, por chamar a atenção, vamos dizer assim, das boates... Parece que os primeiros panfletos, enfim, são produzidos pelo Outra Coisa, lá por volta já de 83, 84, 85. (...) [O material] talvez podia falar de camisinha, assim, alguma recomendação. Mas nunca foi uma campanha. Não tinha dinheiro naquela época, não tinha como imprimir material, tudo era muito difícil. Então, não acho que tenha sido, assim, algo muito sistemático e com um discurso bem estruturado sobre o que 
seria a prevenção. Acho que a gente tem que dar o crédito porque foi a primeira tentativa. Mas qual foi o seu impacto, qual foi, em que medida, eu não saberia te dizer. (...) Tanto é que o Outra Coisa, apesar de ter iniciado esse trabalho, vamos dizer assim, que a gente chamaria [de] uma prática comunitária em prevenção, esse grupo não sobreviveu muito tempo depois (Veriano Terto Jr., entrevista).

Ação semelhante à realizada pelo grupo Outra Coisa foi desenvolvida também em Salvador pelo Grupo Gay da Bahia (GGB). Segundo depoimento de Luiz Mott a Thiago Pinheiro (2015, p. 84), desde 1982, quando houve os primeiros relatos de casos de aids no Brasil, o grupo iniciou a divulgação de materiais de alerta à comunidade gay sobre "o risco de relações sexuais com pessoas que vinham de grandes cidades ou do exterior, que era onde era o foco original da aids". Advertiam, que: "Namorar pode, mas manter relação sexual não". O primeiro material informativo do GGB a fazer menção e estimular o uso da camisinha é referido ao ano de 1984 (Mott, $1988^{45}$ apud Pinheiro, 2015, p. 84).

Como destaca Pinheiro (2015), há nesta orientação preventiva uma incorporação da perspectiva do isolamento sanitário demarcando no interior da própria comunidade aqueles "arriscados". A identificação do risco, neste caso, se dá no estabelecimento de uma associação da doença ao que o autor nomeia como um roteiro geográfico-moral, que atribui a chance de infecção àqueles integrantes da comunidade homossexual associados ao circuito que articulava o Brasil ao cenário internacional onde se iniciaram as políticas de liberação sexual (Pinheiro, 2015).

Em 1985, é produzido pelo GAPA-SP - a primeira ONG voltada especificamente à aids - o cartaz "Transe numa boa", que tem grande destaque nos relatos sobre as primeiras respostas à epidemia. Há vários aspectos que explicam tal destaque: é o primeiro material educativo a ter impressão profissional, distinguindo-se daqueles produzidos de forma caseira em mimeógrafos; sua produção gráfica é de autoria de Darcy Penteado, artista de renome, que integrou o grupo Somos, foi um dos integrantes do jornal Lampião da Esquina e participou da fundação do GAPA; é dos primeiros materiais, de que se tem registro ${ }^{46}$, a propor a camisinha como método preventivo; por

\footnotetext{
45 Mott L. A penetração do preservativo no Brasil pós-AIDS. Publicações Técnicas, BEMFAM. 1988;14(fev).

46 O cartaz "Transe numa boa - sexo é bom não deixe a aids acabar com isso" está acessível na exposição virtual "AIDS Education Posters Collection", da Rare Books and Special Collections da
} 
fim, houve no momento de seu lançamento repercussão na grande mídia (Contrera, 2000; Galvão, 2000; Grangeiro e cols., 2009; Pinheiro, 2015).

Apesar do destaque recebido por ser um dos primeiros materiais educativos a mencionar a camisinha (Pinheiro, 2015), este cartaz foi lembrado por um de meus entrevistados pelo destaque às práticas não-penetrativas tais como "evite contato com esperma" ou "masturbação a dois é gostoso e oferece menos risco" e à percepção de estímulo à abstinência sexual, possivelmente associada à recomendação de diminuição do número de parceiros. Pode-se entender, no entanto, menos pela precisão da recordação do próprio cartaz, mas pela experiência de mudança no cenário cultural e valorativo, vivido, naquele momento, como o fim da liberação sexual defendida anteriormente pelo movimento homossexual. Como já expresso, em depoimento apresentado anteriormente, se "olhava pra aids com uma certa desconfiança, [... com] aquele juízo, aquele valor que existia naquele momento que a aids tinha vindo para reprimir as liberdades que a gente teria" (Veriano Terto Jr., entrevista).

Gradualmente, começa a se observar uma transformação das práticas preventivas orientadas pelo conceito operativo de grupos de risco para um novo conceito operativo articulado às noções de práticas sexuais e comportamentos de risco, ainda fragilmente estabelecidos por aqui nos anos 1980. De forma que as medidas de prevenção passam a ser guiadas, não mais pela lógica do isolamento sanitário e da abstenção, mas pela lógica do sexo seguro, orientando, assim, práticas sexuais seguras. Como destacado por Pinheiro (2015), a proposição do uso do preservativo como medida de prevenção se dá neste contexto. Encontra no cenário brasileiro, no entanto, um contexto político menos organizado e cindido no âmbito do movimento homossexual, como apresentado anteriormente. Pode-se pensar também, que tais mudanças se dão na articulação entre alguns profissionais da saúde pública e segmentos dos movimentos homossexual e de aids, mas em um cenário sociocultural com restrições significativas à sua incorporação. Isso pode ser observado neste trecho do artigo de Edward MacRae, no qual o autor articula a necessidade de uma prevenção que não segregue ou 
estigmatize os homossexuais, mas leve em conta suas características socioculturais

(1987):

Surge, então, um outro grupo de propostas que enfatiza o fato de que a AIDS não resulta diretamente do fato de se ter um grande número de parceiros, e sim de práticas específicas. Procura-se, portanto, difundir o conhecimento sobre certas técnicas que retirariam o perigo de contágio das relações sexuais, não importando com quantos parceiros diferentes se dessem. Recomenda-se, assim, usar a camisa-de-vênus e evitar a troca de fluidos orgânicos em geral. Essa abordagem mais positiva esbarra, porém, em muitos obstáculos. O maior deles é a concepção moralista que ainda comanda posições de grande poder dentro de nossa sociedade e que até agora tem tornado quase impossível uma discussão da sexualidade de forma ampla e isenta de preconceitos. A questão da homossexualidade em específico ainda é tratada como um tabu pelos meios de comunicação de maior difusão, apesar do grande interesse manifestado por este assunto pelo grande público. Quando abordado, o tema tem sido tratado de forma oblíqua e eufemística, ou então em tom caricatural e ridicularizador.

Imagine-se, dentro desse contexto, o escândalo provocado quando se pretende fazer recomendações detalhadas sobre como o indivíduo deve proceder para continuar a manter relações homossexuais com prazer e segurança. Obviamente, campanhas desse tipo dificilmente conseguem veiculação adequada e recebem pouquíssimo apoio. Nem mesmo os fabricantes de camisas-de-vênus se dispõem a alardear o seu uso como principal maneira de evitar o alastramento da AIDS. Tampouco existe muito interesse em realizar pesquisas com novos produtos, como preservativos de borracha resistente, mais apropriados ao coito anal, ou então o desenvolvimento de certos espermicidas com a capacidade de neutralizar o vírus propagador da síndrome. ALTMAN (1). Os médicos também se mostram frequentemente incapazes ou então indispostos a atender uma clientela homossexual preocupada mas desejosa de manter sua[s] práticas sexuais, e raramente são capazes de fornecer recomendações detalhadas sobre como fazer isso, preferindo simplesmente apelar para um chamado à castidade ou à monogamia (heterossexual, de preferência).

Outro obstáculo à adoção dessas normas chamadas pelos americanos de safe sex, "sexo seguro" encontra-se entre a própria população homossexual masculina que, ao contrário dos heterossexuais, sempre preocupados com as possibilidades de gravidez, nunca se havia deparado com a necessidade de usar qualquer tipo de preservativo. Até recentemente, essa era até alardeada como uma das grandes vantagens da homossexualidade. Além disso, muitos homossexuais constroem sua identidade desviante em torno da noção de que seriam presas de um instinto ou desejo "selvagem", que não admite controles sociais e que, portanto, tem que ser obedecido, mesmo às custas do opróbio da sociedade maior. Esses indivíduos, portanto, escudados atrás desse conceito de uma homossexualidade imposta pela natureza, recusam-se a abrir mão de práticas perigosas como o coito anal e, frequentemente, repetem o velho chavão sobre o uso de preservativos ser a mesma coisa que "chupar bala sem tirar o papel" (MacRae, 1987, p. 76-7). 
As práticas de prevenção desta primeira década da epidemia são fortemente marcadas, em um primeiro momento, por propostas de alerta e advertência em que são divulgadas as poucas informações disponíveis, repletas de desinformação. Tanto por integrantes da sociedade civil, como pelo governo. Neste contexto, as medidas de proteção são identificadas às recomendações de abstinência sexual, castidade, celibato, monogamia estrita (preferencialmente heterossexual), redução do número de parceiros - em articulação com a noção de promiscuidade, como central para os sentidos sobre a doença - e de recomendação de práticas não-penetrativas - mais fortemente articuladas às formas de gestão comunitária da epidemia.

Somente em um segundo momento, já fortemente impactados pela experiência da soropositividade e dos reflexos da experiência pessoal e coletiva com a própria aids que a comunidade homossexual - neste momento já organizada no âmbito do incipiente movimento de aids - começa a desenvolver tecnologias de prevenção que buscam articular informações sobre prevenção ao universo singular das práticas sexuais do próprio grupo.

Na maior parte desta primeira década, as poucas iniciativas de prevenção eram predominantemente de base comunitária e, como mencionado por Paulo Teixeira, voltadas para homossexuais, tendo em vista a rápida e imediata implicação de segmentos da comunidade em responder à epidemia, assim que os primeiros casos começaram a surgir (Grangeiro e cols., 2009, Galvão, 2000).

Galvão (2000) nomeou este período, de 1985 a 1989, como os "anos heroicos" das respostas à aids. Diante da situação de emergência trazida pela aids, foi mobilizada grande pluralidade de iniciativas, muitas delas com caráter mais pessoal do que institucional. No âmbito das organizações que já atuavam ou que começam a se organizar neste período, dispunha-se de poucos recursos financeiros - nacionais ou internacionais -, o trabalho era predominantemente voluntário, ainda estava pouco estabelecida a noção de "projeto de intervenção" e as trocas entre as poucas entidades existentes eram frequentes (Galvão, 2000, Simões e Facchini, 2009). Como se pode perceber na descrição feita por Veriano Terto Jr.: 
Naquele momento, acho que o único grupo gay, no final dos anos 1980, que funcionava era [...] acho que era Lambda, o nome. Que era coordenado pelo Ubiratan da Costa e Silva. Esse grupo trabalhava com homossexualidade. [...]

O Lambda assume a questão da aids, mas numa perspectiva mais assistencialista. Tanto é que a casa do Ubiratan, uma casa que ele conseguiu, era uma espécie de casa de apoio, onde pessoas homossexuais ficavam. Vinham e iam. Ele, inclusive, tinha um programa, eu me lembro, assim de passagem. [...] Conseguir passagem pra essas pessoas voltarem pra suas casas. Pra quem morava fora de São Paulo. Mas era uma perspectiva mais assistencialista. O Ubiratan morreu, depois, no início dos anos 1990, também. Mas era um grupo, vamos dizer assim, importante (Veriano Terto Jr, entrevista, 2017).

A primeira organização a se estruturar especificamente para desenvolver atividades voltadas à aids, no Brasil, foi o Grupo de Apoio à Prevenção da Aids (GAPA$\mathrm{SP})$, que reuniu entre seus fundadores militantes que haviam atuado no Somos e em outros grupos homossexuais da cidade de São Paulo e funcionários da SES-SP, entre outros. O GAPA-SP é considerado a primeira ONG/Aids brasileira e da América Latina (Teixeira, 1997; Galvão, 2000; Simões e Facchini, 2009; Laurindo-Teodorescu e Teixeira, 2015, v. 2).

Em sua entrevista, Paulo Roberto Teixeira compartilha um aprendizado acerca das respostas comunitárias à epidemia que se deu na escrita do livro "Histórias da Aids no Brasil, volume 2: a sociedade civil se organiza pela luta contra a aids"47: nos estados onde havia movimento homossexual, a criação das ONG/Aids se deu mais rapidamente partindo deste movimento; naqueles estados onde não havia movimento homossexual, o processo de criação das ONG/Aids foi mais tardio e associado aos serviços de saúde voltados à aids.

Em concordância com este entendimento, Veriano Terto Jr. mostra como as primeiras iniciativas comunitárias voltadas a aids configuravam-se como respostas da comunidade homossexual à epidemia:

\footnotetext{
${ }^{47}$ Com o propósito de contar a história da resposta brasileira à epidemia de aids, no período de 1983 a 2003, a partir do relato de seus protagonistas, Paulo R. Teixeira escreveu em coautoria com a socióloga Lindinalva Laurindo-Teodorescu os dois volumes de "Histórias da Aids no Brasil", o primeiro volume voltado às respostas governamentais à epidemia de aids e o segundo às respostas da sociedade civil organizada (Laurindo-Teodorescu e Teixeira, 2015, v. 1 e 2).
} 
E nas ONG/Aids, a maioria delas, capitaneada por pessoas homossexuais que, inclusive, vinham de movimento homossexual. Na ABIA, a gente tinha o próprio Daniel, eu, né? No GIV, na fundação a gente tem o Zezé Melgar, que era, foi do Somos. Morreu logo em seguida, em 1990. No GAPA de São Paulo, a gente tinha o Paulo Bonfim. O GAPA, mesmo, tinha sido fundado por pessoas, como Darcy Penteado, Edward MacRae, entre outros que eram, o próprio Paulo Bonfim, que vinham do movimento homossexual. Então quase que as ONG/Aids eram um braço, vamos dizer assim, instrumental pra intervir na hecatombe da aids, que o próprio movimento homossexual não tinha condições de intervir. E na aids, tinha recurso, coisa que para os grupos gays não tinha. Então não tinha agências que pagavam por trabalhos. O governo, nada. E a cooperação internacional, que era o que financiava o trabalho comunitário, o trabalho de ONG, não financiava homossexualidade. Então, esses grupos, poucos grupos funcionavam sem recursos e nas ONG/Aids tinham recursos, mas que não, acabavam não sendo canalizados para projetos (Veriano Terto Jr., entrevista, 2017).

Como destacado anteriormente, assegurar a participação dos grupos afetados pela epidemia compõe os referenciais ético-políticos defendidos pelos gestores das políticas de aids à época. É no diálogo com a própria comunidade que se expressa uma outra tensão presente na abordagem da epidemia por parte do movimento homossexual. Por um lado, há a demanda por focalização e especificidade nas respostas à epidemia, por outro há o temor de possível estigmatização e fortalecimento da associação entre homossexualidade e doença, decorrente de tal focalização.

Porque ao mesmo tempo que existia uma pressão, por parte dos grupos da comunidade, para que houvesse alguma especificidade nas campanhas, no debate, existia por parte do mesmo grupo, né? Setores da sociedade, uma pressão para que não se especificasse temendo a estigmatização, não é? E os gestores ficavam nessa dúvida, nesse dilema, né? Do quanto deveriam, poderia abordar sem cair no risco e, ao mesmo tempo, sem colocar um véu que minimizasse a situação maior, mais grave, que estava afetando o universo homossexual. Outra razão, e você vai ver nesse pequeno documento ${ }^{48}$, é que embora ainda não se manifestasse nos primeiros anos aqui na população no estado de São Paulo, desde os primeiros dias se sabia que não era exclusiva de homossexuais. Está ali na primeira página do texto: 'atingindo hemofílicos, transfusão de sangue, transmissão vertical, mulheres heterossexuais', etc. Então, esse dilema pairou durante muito tempo. Havia razões dos dois lados. Embora, na prática, as ações fossem específicas. Então, quer dizer, onde se distribuíam os materiais educativos? Onde se priorizou a distribuição de preservativo, quando eles se tornaram disponíveis? Onde procurou se fazer mobilização social e apoio à formação de... Apoio e estímulo ao ativismo, etc.? Era sempre priorizado no grupo de homossexuais, não é?

\footnotetext{
${ }^{48}$ Referindo-se ao Informe Técnico mencionado anteriormente (Secretaria de Estado da Saúde, 1983).
} 
Mas essa tensão nunca deixou de existir e ela existe até hoje, né? (Paulo Teixeira, entrevista)

Esta tensão também é identificada pelos ativistas do próprio movimento homossexual, particularmente por aqueles que migraram do movimento homossexual vindo a fundar o movimento de aids. Simões e Facchini (2009) identificam que o receio de reforçar a associação entre homossexualidade e aids era maior entre aqueles grupos e lideranças menos identificados à cultura do desbunde e da libertação sexual, nos quais as pautas dos direitos eram mais frequentes e vigorosas. $\mathrm{O}$ trabalho de Cristina Câmara (2015) sobre o movimento homossexual na cidade do Rio de Janeiro, relembrado por Veriano Terto Jr. em sua entrevista, também mostra outra faceta desta cisão, ao expor que o grupo Atobá, de origem popular e periférica, priorizou em seu trabalho as experiências homossexuais com a violência e com a aids, enquanto o grupo Triângulo Rosa, originado nas camadas médias intelectualizadas, elegeu a garantia de direitos e a luta contra a discriminação, no âmbito legal.

Porque o pouco que tinha de movimento gay naquela época, ele era, ele tinha uma divisão. Entre aqueles que queriam trabalhar com HIV e aqueles que não queriam trabalhar com HIV, para não associar, não aprofundar a associação entre aids e homossexualidade. Entre eles, acho que estava o grupo Triângulo Rosa. Mas assim, todos os grupos funcionavam em casa de pessoas, na base do mimeógrafo e na base do telefone residencial das pessoas, né? A gente, então, tinha essa certa cisão [...]. O João Antônio Mascarenhas [principal liderança do grupo Triângulo Rosa], também, que tinha sido uma grande liderança, na questão de introduzir a agenda dos direitos no movimento homossexual. O João Antônio se destacou muito no esforço que ele fez, para que na Constituinte, naquele artigo que fala: "É proibido a discriminação por religião, raça, cor", entrasse discriminação sexual. Coisa que não acabou entrando. [...] Então, o movimento homossexual era um tanto cindido nessa questão. Em São Paulo, também era assim cindido.

Essa cisão se expressa não somente em função da decisão de abordar ou não a aids no âmbito do trabalho dos grupos homossexuais. Outra de suas expressões, menos abordada na literatura concernente ao tema, refere-se à forma como a aids e os soropositivos são abordados. Identifica-se, nos relatos coletados nas entrevistas e nos depoimentos informais, um incômodo particularmente nas abordagens de prevenção 
surgidas a partir da disponibilidade do teste diagnóstico para a infecção pelo HIV. Nestas abordagens, se destaca a proposição do teste com a finalidade de demonstrar a ausência do vírus, como atributo demarcador de ser saudável [ou de saúde]. Perspectiva que atribui um estatuto de desvalor às pessoas soropositivas.

Mirando para o campo mais amplo da prevenção da infecção pelo HIV, há a percepção de um paradoxo do campo $^{49}$, quando Jorge Beloqui rememora o início das políticas de redução de danos vinculadas ao uso de drogas injetáveis. A política de redução de danos mostra que, apesar das dificuldades daquele momento, tais como a repressão policial aos agentes públicos, havia abertura para a implantação de políticas ousadas, que chegaram a ser legalizadas e implantadas nacionalmente por municípios, estados e governo federal.

(...) naquela época também veio a questão da redução de danos, acho que foi 1989 ou 1990. Que começou em Santos, né? Porque o uso de drogas injetáveis era muito importante e, bom, me lembro que foi na gestão da Telma de Souza, acho que era o David Capistrano [Secretário Municipal de Saúde à época]. A polícia correndo atrás do prefeito, da prefeita, do secretário. Mas isso, depois, indo como uma política de vários estados, né? Legalizada. $\mathrm{E}$, depois, o Ministério também adotou, né? Então, eram momentos muito complicados para a adoção dessas políticas. Mas havia, muita, por outro lado, muita abertura. [...] Sim. De alguns agentes havia, sim, abertura. Inclusive, Santos era um dos principais, se não o principal, que tinha mais taxa de prevalência do Brasil. Então, era importante. Bom, porto, né? Como é Itajaí, também, tinha. (Jorge Beloqui, entrevista)

Com esta recordação, Jorge Beloqui mostra que, nesta segunda metade da década de 1980, mais um ator entra em cena no campo discursivo de ação da aids: os usuários de drogas injetáveis (UDI). Os UDI, como passam a ser nomeados no campo, são outro grupo fortemente afetado pela epidemia neste primeiro momento, como já chamou à nossa atenção o relato de Maria Clara Gianna apresentado anteriormente.

\footnotetext{
49 O Programa Municipal de DST/Aids de Santos, na gestão da prefeita Telma de Souza, sob a coordenação de Fábio Mesquita, deu início às primeiras ações de redução de danos no Brasil. Em 1997, foi sancionada pelo governador Mário Covas a lei estadual no 9.758, de 17 de setembro de 1997, que autoriza a Secretaria da Saúde a distribuir seringas descartáveis aos usuários de drogas, a partir do projeto de lei no $53 / 96$, do deputado estadual Paulo Teixeira - PT.
} 
Trata-se, também, de um grupo fortemente discriminado e julgado moralmente, seja pela ilicitude do uso de substâncias psicoativas, seja pelo forte julgamento moral feito sobre o uso de drogas.

Há, assim, uma expansão do campo da aids para uma outra rede de atores articulados sob os discursos da redução de danos. Tais discursos compartilham dos valores de defesa dos direitos dos grupos afetados, do respeito à autonomia individual buscando afastar-se dos julgamentos de lassidão moral associado ao uso de drogas. A base deste contradiscurso também se articula, como no caso da defesa da liberdade sexual, aos valores representados pela contracultura.

O surgimento da aids no Brasil, se dá no contexto da ditadura civil-militar, e da cisão, no âmbito das políticas de saúde, entre a medicina individual de caráter assistencial e previdenciária e a saúde pública de ordem coletiva e preventiva. Neste cenário, houve resistências à estruturação de uma resposta institucional organizada, já que se questionava se a doença, ainda que grave, se constituía em um problema de saúde pública (Teodorescu-Laurindo e Teixeira, 2015, v. 1). Além do questionamento técnico, há para os ativistas como marco negativo deste período inicial a percepção de valoração negativa associada à doença e ao grupo afetado, como se pode notar neste depoimento:

Assim, um marco negativo, mas que mostra como que a coisa era, é a declaração de um ministro, isso está documentado, lá no início dos anos 1980? É. Logo que começa a aids, que diz que a aids é um problema de bicha rica, né? (Veriano Terto Jr., entrevista)

Com o atraso na resposta político-institucional na esfera federal, pode-se compreender, como apontam Grangeiro e cols. (2010, p. 15), em artigo sobre a construção da resposta nacional à aids sob a ótica das políticas de descentralização, que a resposta inicial à epidemia, nos anos de 1980, tenha sido caracterizada como essencialmente descentralizada com base na atuação de estados, municípios e organizações não-governamentais (ONG). O Programa Nacional de Aids só veio a ser criado formalmente, em 1985, já na gestão Sarney, no âmbito da Divisão de Hansenologia e Dermatologia Sanitária do Ministério da Saúde, como havia ocorrido em São Paulo e em outros estados. No entanto, é somente em 1986 que começa 
efetivamente a ser implantado, vindo a se consolidar em 1988, sob a gestão de Lair Guerra, já com articulações com organismos internacionais e às vésperas da primeira eleição presidencial direta após o período ditatorial.

Em sua história, o programa nacional de aids teve inúmeras denominações e esteve subordinado a diferentes instâncias do Ministério da Saúde. Sendo, atualmente, designado como Departamento de Vigilância, Prevenção e Controle das IST, do HIV/Aids e das Hepatites Virais (DIAHV) e subordinado à Secretaria de Vigilância em Saúde do Ministério da Saúde. Dada a dificuldade em saber a designação correta a cada diferente momento histórico abordado no estudo, optarei, nesta tese, em utilizar a denominação programa nacional de aids, de forma indiscriminada a partir daqui. Avalio que esta denominação se articula à forma como a literatura internacional se refere às instâncias de coordenação nacional das políticas de aids. Destaco, no entanto, o entendimento, compartilhado amplamente no âmbito do campo discursivo de ação em estudo, de que o programa não se restringe às instâncias governamentais, mas espera-se que possam ter papel de coordenação dos diferentes atores (Teixeira, 1997; Galvão, 2000; LaurindoTeodorescu e Teixeira, 2015).

Em seus 30 anos de existência, o programa nacional teve nove diretores, tendo estado subordinado a um número muito maior de ministros da saúde (22), em dez gestões de sete presidentes da república. Compreendendo a importância de buscar refletir sobre a influência do cenário político mais amplo no âmbito das políticas de aids, trago a seguir um quadro de diretores do programa nacional de aids, ministros da saúde e presidentes da república (Quadro 2).

Quadro 2 - Diretores do Programa Nacional de Aids, Ministros da Saúde e Presidentes do Brasil pós-ditadura civil-militar

\begin{tabular}{|l|l|l|}
\hline Diretor & Ministro & Presidente \\
\hline \multirow{3}{*}{$\begin{array}{l}\text { Lair Guerra } \\
\text { (1985-1990) }\end{array}$} & Carlos Sant'anna & José Sarney \\
& $(1985-1986)$ & \\
\cline { 2 - 2 } & $\begin{array}{l}\text { Roberto Santos } \\
\text { (1986-1987) }\end{array}$ & \\
\cline { 2 - 2 } & $\begin{array}{l}\text { Luiz Carlos da Silveira } \\
\text { (1987-1989) }\end{array}$ & \\
\cline { 2 - 2 } & $\begin{array}{l}\text { Seigo Tsuzuki } \\
\text { (1989-1990) }\end{array}$ & \\
\hline
\end{tabular}




\begin{tabular}{|c|c|c|}
\hline \multirow[t]{2}{*}{$\begin{array}{l}\text { Eduardo Cortes } \\
(1990-1992)\end{array}$} & $\begin{array}{l}\text { Alceni Guerra } \\
(1990-1992)\end{array}$ & \multirow[t]{2}{*}{$\begin{array}{l}\text { Fernando Collor } \\
(1990-1992)\end{array}$} \\
\hline & $\begin{array}{l}\text { José Goldemberg } \\
\text { (Interino, 1992) }\end{array}$ & \\
\hline \multirow[t]{3}{*}{$\begin{array}{l}\text { Lair Guerra } \\
(1992-1996)\end{array}$} & $\begin{array}{l}\text { Adib Jatene } \\
\text { (1992) }\end{array}$ & \multirow[t]{3}{*}{$\begin{array}{l}\text { Itamar Franco } \\
(1993-1994)\end{array}$} \\
\hline & $\begin{array}{l}\text { Jamil Haddad } \\
\text { (1992-1993) }\end{array}$ & \\
\hline & $\begin{array}{l}\text { Henrique Santillo } \\
(1993-1995)\end{array}$ & \\
\hline \multirow[t]{4}{*}{$\begin{array}{l}\text { Pedro Chequer } \\
(1996-2000)\end{array}$} & $\begin{array}{l}\text { Adib Jatene } \\
(1995-1996)\end{array}$ & \multirow[t]{4}{*}{$\begin{array}{l}\text { Fernando Henrique Cardoso } \\
(1995-1998)\end{array}$} \\
\hline & $\begin{array}{l}\text { José Carlos Seixas } \\
(1996)\end{array}$ & \\
\hline & $\begin{array}{l}\text { Carlos Albuquerque } \\
(1996-1998)\end{array}$ & \\
\hline & $\begin{array}{l}\text { José Serra } \\
(1998-2002)\end{array}$ & \\
\hline \multirow[t]{2}{*}{$\begin{array}{l}\text { Paulo R. Teixeira } \\
\text { (2001-2003) }\end{array}$} & $\begin{array}{l}\text { José Serra } \\
\text { (1998-2002) }\end{array}$ & \multirow[t]{2}{*}{$\begin{array}{l}\text { Fernando Henrique Cardoso } \\
(1999-2002)\end{array}$} \\
\hline & $\begin{array}{l}\text { Barjas Negri } \\
(2002)\end{array}$ & \\
\hline $\begin{array}{l}\text { Alexandre Grangeiro } \\
(2003-2004)\end{array}$ & $\begin{array}{l}\text { Humberto Costa } \\
(2003-2005)\end{array}$ & \multirow{4}{*}{$\begin{array}{l}\text { Luiz Ignácio Lula da Silva } \\
\text { (2003-2006; } \\
\text { 2007-2010) }\end{array}$} \\
\hline $\begin{array}{l}\text { Pedro Chequer } \\
(2004-2006)\end{array}$ & $\begin{array}{l}\text { José Saraiva Felipe } \\
(2005-2006)\end{array}$ & \\
\hline \multirow[t]{2}{*}{$\begin{array}{l}\text { Mariângela Simão } \\
(2006-2010)\end{array}$} & $\begin{array}{l}\text { Agenor Álvares } \\
(2006-2007)\end{array}$ & \\
\hline & $\begin{array}{l}\text { José Gomes Temporão } \\
(2007-2010)\end{array}$ & \\
\hline $\begin{array}{l}\text { Dirceu Greco } \\
(2010-2013) \\
\end{array}$ & $\begin{array}{l}\text { Alexandre Padilha } \\
(2011-2014)\end{array}$ & $\begin{array}{l}\text { Dilma Rousseff } \\
\text { (2011-2014; }\end{array}$ \\
\hline \multirow[t]{3}{*}{$\begin{array}{l}\text { Fábio Mesquita } \\
\text { (2013-2016) }\end{array}$} & $\begin{array}{l}\text { Arthur Chioro } \\
(2014-2015)\end{array}$ & \multirow[t]{3}{*}{ 2015-2016) } \\
\hline & $\begin{array}{l}\text { Marcelo Castro } \\
(2015-2016)\end{array}$ & \\
\hline & $\begin{array}{l}\text { Agenor Álvares } \\
(2016)\end{array}$ & \\
\hline \multirow[t]{2}{*}{$\begin{array}{l}\text { Adéle Benzaken } \\
\text { (2016-Atual) }\end{array}$} & $\begin{array}{l}\text { Ricardo Barros } \\
(2016-2018) \\
\end{array}$ & \multirow[t]{2}{*}{$\begin{array}{l}\text { Michel Temer } \\
\text { (2016-Atual) }\end{array}$} \\
\hline & $\begin{array}{l}\text { Gilberto Occhi } \\
\text { (2018-Atual) }\end{array}$ & \\
\hline
\end{tabular}

A articulação com a sociedade civil foi uma das primeiras iniciativas no âmbito do programa nacional de aids. Ainda em 1986, foi estabelecida a Comissão de Assessoramento em Aids, com caráter técnico-consultivo, posteriormente denominada Comissão Nacional de Aids (CNAIDS) (Galvão, 2000). Teixeira (1997) relata o processo 
progressivo de incorporação de representações de diferentes setores e segmentos no âmbito da CNAIDS, buscando traduzir o entendimento de que a aids representa um problema que transcende a área da saúde, constituindo-se em um problema nacional.

No âmbito do governo federal, é só no final da década, já em 1989, que se estabelece a primeira política de prevenção mais estruturada por meio do projeto Previna ${ }^{50}$. Sua proposição se dá em um momento de mudança nas relações interfederativas, em função do maior fortalecimento institucional do programa nacional, que contava naquele momento com o suporte de iniciativas de cooperação técnica e financeira de organismos internacionais. Com isso, o programa nacional passa a agir centralizadamente, estabelecendo normas e propostas de ações a serem implementadas por estados e municípios. Nas palavras de Paulo Teixeira (1997), "de parceiros ou interlocutores, os programas estaduais passam a ser considerados executores das propostas elaboradas e coordenadas em Brasília". O Previna, nesta sua primeira versão, visava desenvolver ações de prevenção voltadas a profissionais do sexo (prostitutas, travestis e michês), homossexuais masculinos, usuários de drogas injetáveis e internos do sistema prisional. Suas ações fundamentavam-se na estratégia de educação entre pares (peer education) na qual membros dos próprios grupos - os multiplicadores, como se convencionou - são formados para desenvolver ações educativas sobre prevenção da infecção pelo HIV (Teixeira, 1997; Galvão, 2000).

É no contexto do Previna, que o Instituto de Estudos da Religião ${ }^{51}$ (ISER) desenvolveu o projeto Prostituição e Direitos Civis, no qual esteve envolvido o grupo Atobá, em que foram desenvolvidos materiais educativos voltados a prostitutas,

\footnotetext{
50 Jane Galvão (2000) e outros autores consultados fazem referência a documentos das duas versões do projeto Previna, de 1989 e 1994. Estes documentos não são disponibilizados, no entanto, no site do DIAHV ou na Biblioteca Virtual em Saúde - BVS MS, "divisão da Biblioteca do Ministério da Saúde, responsável pela veiculação do site da BVS MS, no qual são publicadas as informações bibliográficas produzidas pelo Ministério da Saúde (...) [constituindo-se no] principal canal de acesso para essa produção" (disponível em: http://bvsms.saude.gov.br [acesso em 09 abr 2018]).

51 "O Instituto de Estudos da Religião, ISER, é uma organização da sociedade civil, de caráter laico, comprometida e dedicada à causa dos direitos humanos e da democracia. Surgida no contexto brasileiro dos anos 1970, objetiva promover estudos, pesquisas e também intervenção social a partir de eixos temáticos plurais da sociedade brasileira, como a defesa e a garantia de direitos, segurança pública, meio ambiente, diversidade religiosa, entre outros.", disponível em: http://www.iser.org.br/site/o-iser/ [acesso 09 abr 2018].
} 
travestis e michês, como a cartilha intitulada Damas da Noite (Câmara, 2015; Veriano Terto Jr., entrevista).

Cabe destacar, aqui, que Galvão (2000) mostra, nesta segunda metade dos anos 1980, a entrada da aids na agenda de outras instituições como é o caso do ISER, que desenvolve os projetos com vistas a mobilizar o envolvimento de diferentes tradições religiosas no âmbito das respostas à epidemia, além de envolver-se também em projetos voltados à garantia de direitos no sistema penal. Outros projetos e instituições também se voltam à promoção de respostas religiosas à epidemia. Observa-se, ainda nos anos 1980, esforços no sentido de articular respostas institucionais junto à área de educação e ao sistema penitenciário (Teixeira, 1997).

O projeto Previna contribui, também, para a inserção de mais um ator e sua rede articuladora ao campo: as prostitutas e as associações de profissionais do sexo (Galvão, 2000). É notável, neste sentido, o papel da epidemia de aids em dar visibilidade a grupos cujas identidades são marcadas pela sexualidade dissidente da normatividade hegemônica, como é o caso dos homossexuais e dos trabalhadores sexuais.

A segunda metade da década de 1980 traz à cena um novo ator: as pessoas soropositivas para a infecção pelo HIV. Isso porque, até 1984, conhecia-se a aids e, gradativamente, foi ficando claro para profissionais de saúde e pesquisadores que se tratava de uma doença infecciosa, mas somente neste ano há a confirmação de que se tratava de um vírus que é nomeado neste momento Human Immunodeficiency Virus (HIV, ou vírus da imunodeficiência humana). Com isso, se tornou possível o desenvolvimento de um teste diagnóstico que permitiu identificar pessoas portadoras do vírus, tecnologia que se tornou disponível no mercado em 1985. Em sua entrevista, Veriano Terto Jr. destaca que o teste é uma tecnologia de classificação que distingue infectados e não-infectados, demarcando uma diferença entre as pessoas e comunidades afetadas pela epidemia.

Outros dois importantes marcos na resposta das organizações nãogovernamentais à epidemia foram a fundação, em 1987, da Associação Brasileira Interdisciplinar de Aids (ABIA) no Rio Janeiro, que foi a primeira organização fundada e presidida por uma pessoa soropositiva - Herbert de Souza, o Betinho - e a fundação, 
em 1989, por Herbert Daniel do grupo Pela Vidda-RJ (Valorização, Integração e Dignidade do Doente de Aids), que integrava pessoas soropositivas e soronegativas em sua direção. É digno de nota, para compreender este primeiro momento de resposta à aids, que algumas das primeiras lideranças, no âmbito da sociedade civil, no que veio se chamar movimento de aids, estiveram envolvidas na luta contra a ditadura, como foi o caso de Herbert Daniel e Betinho (Galvão, 2000).

Com o objetivo de compreender o impacto da aids na vida homossexual no Brasil, Terto Jr. (1997), em sua tese de doutorado, tratou de histórias de vida da primeira geração de homens homossexuais soropositivos para o HIV. Ao abordar a emergência das identidades positivas, o autor identifica duas diferentes concepções de identidade soropositiva que conformam dois perfis de respostas comunitárias: a concepção específica e a universalista.

A concepção universalista seria a predominante entre as ONG/Aids no Brasil naquele momento, tendo sido concebida por Herbert Daniel (Daniel, 1989 apud Terto Jr., 1997) e originária de um momento ainda marcado pelos movimentos de luta contra a ditadura. Parte do pressuposto de que soropositivos não seriam somente aqueles que têm o vírus no sangue, pois englobaria, no limite, à toda a humanidade. Nesta perspectiva, a soropositividade é uma marca que afeta não somente àqueles infectados pelo HIV, ou aos doentes e mortos pela aids, mas também aos seus maridos, esposas, companheiros, filhos, pais, amigos, assim como às pessoas que trabalham voluntária ou remuneradamente com a aids. Fortemente ancorada na noção de solidariedade, esta concepção busca mobilizar uma resposta social de envolvimento de toda a sociedade, com seus diferentes atores e setores, para enfrentar os desafios impostos pela epidemia. Teria sido o fundamento dos grupos Pela Vidda, nos quais inspiraria, ainda, uma estratégia de proteção da privacidade dos soropositivos, em que todos os membros deveriam apresentar-se como soropositivos (Terto Jr., 1997).

A concepção específica, por sua vez, refere-se exclusivamente às pessoas infectadas pelo vírus e pela identidade compartilhada por estas pessoas. A construção da soropositividade, neste sentido, se dá pela transformação da condição diagnóstica em categoria política e social. O que dá relevo a experiências, sentimentos, necessidades 
e interesses compartilhados pelas pessoas em função do seu status sorológico, que configuram uma nova identidade pessoal e coletiva. Destaca-se, nesta concepção, a experiência do assumir-se soropositivo, que estaria estreitamente conectada, na experiência homossexual, às experiências de assumir-se homossexual - subjacentes aos discursos de "coming out", "sair do armário", revelação da soropositividade/homossexualidade. Assim como, valoriza o fortalecimento possibilitado pela quebra do isolamento e pela experiência do compartilhamento. Enfatiza, neste sentido, a agência dos soropositivos e sua resposta coletiva. Uma marca distintiva das organizações originadas desta concepção específica de soropositividade se daria na composição de seus quadros diretivos formados exclusivamente por pessoas soropositivas. Além disso, a proposição de grupos e atividades exclusivas para soropositivos no interior de outras organizações, assim como as redes de pessoas vivendo com HIV e aids também seriam caudatárias desta concepção, como é o caso da Rede Nacional de Pessoas Vivendo com Aids, a RNP+, fundada em 1995, e a sua contraparte internacional, a Global Network of People Living with AIDS ${ }^{52}$ (GNP+), fundada em 1992. No Brasil, a fundação do Grupo de Incentivo à Vida (GIV) foi um exemplo deste tipo de organização, que se originou a partir do compartilhamento de experiências no âmbito do Centro de Referência e Treinamento em Aids (CRT-Aids) da SES-SP, tendo como proposta inicial constituir-se como um grupo de ajuda mútua (Galvão, 2000; Terto Jr., 1997; Laurindo-Teodorescu e Teixeira, 2015, v. 2, p. 54).

No cenário internacional, em 1986, foi estabelecido, no âmbito da Organização Mundial da Saúde (OMS), o Programa Especial de Aids - posteriormente chamado de Programa Global de Aids (Global Programme on AIDS, GPA), em 1987 - encarregado por implementar uma estratégia global de combate à epidemia, tendo como seu primeiro diretor Jonathan Mann (Merson e cols., 2008). Merson e colaboradores (2008) apontam que:

[...] graves tensões entre as agências da ONU e especialistas em HIV/aids - que ainda existem hoje - em relação à prioridade relativa que deve ser dada a diferentes abordagens estratégicas para a

\footnotetext{
52 A Global Network of People Living with AIDS origina-se dos Comitês Diretivos Internacionais das Conferências Internacionais de Pessoas Vivendo com HIV realizadas desde 1986 e passa a ser denominada $\mathrm{GNP+}$, quando começa a desenvolver programas e projetos próprios (https://www.gnpplus.net/who-weare/about-us/).
} 
prevenção do HIV também tiveram um papel [no encerramento das atividades do GPA]. Alguns indivíduos sentiram que o HIV/AIDS deveria ser tratado principalmente como um problema de saúde pública com ênfase em intervenções comportamentais de curto prazo, como promoção de preservativos e marketing social, educação sexual de jovens dentro e fora da escola, testagem voluntária e aconselhamento e tratamento de doenças sexualmente transmissíveis. Outros acreditavam que a pandemia poderia ser melhor controlada com uma abordagem de desenvolvimento de longo prazo que abordasse os determinantes estruturais que aumentam a vulnerabilidade à infecção pelo HIV, como gênero, direitos humanos, pobreza e desenvolvimento geral da comunidade. Essa dicotomia de pontos de vista impediu a capacidade das agências da ONU e de doadores bilaterais de harmonizar seus esforços no âmbito nacional e serviu para polarizar a comunidade de HIV/AIDS. (Merson e cols., 2008 , p. 482, tradução livre)

\section{Década de 1990}

Em 1990, após as primeiras eleições diretas para presidente da República, se inicia a gestão de Fernando Collor de Mello, que será marcada por grande conturbação política. A gestão do Ministério da Saúde, sob o comando de Alceni Guerra, também foi marcada por escândalos.

Esta década marca, no âmbito das políticas de saúde, a implantação do Sistema Único de Saúde (SUS) no país e com isso transformam-se, gradualmente, as relações interfederativas para assegurar sua efetivação. Em 1990, foram sancionadas as Leis Orgânicas da Saúde (8.080/90 e 8.142/90). A Lei 8.080/90 que regulamenta os artigos Constitucionais 196 ao 200 da CF/88 e dispõe sobre "as condições para a promoção, proteção e recuperação da saúde, a organização e o funcionamento dos serviços correspondentes" e a Lei 8.142/90 que "dispõe sobre a participação da comunidade na gestão do Sistema Único de Saúde (SUS) e sobre as transferências intergovernamentais de recursos financeiros na área da saúde". Com vistas a assegurar o processo de descentralização da gestão das ações e serviços de saúde na perspectiva de construção do SUS, o Ministério da Saúde foi estabelecendo uma série de quatro normas operacionais, chamadas Normas Operacionais Básicas (NOB), editadas no período de 1991 a 1996, que progressivamente ampliaram as responsabilidades dos municípios no 
que tange às políticas de saúde e vieram à promover transferências de recursos e de atribuições anteriormente alocadas em âmbito federal e estadual para este ente. (Grangeiro et al., 2010).

No que se refere à gestão das políticas de aids, este período, é marcado pela concentração do poder decisório e de financiamento no governo federal, o que se dá, paradoxalmente, em um momento de fortalecimento dos estados e municípios no âmbito das políticas de saúde e de expansão da resposta à epidemia por todas as regiões brasileiras (Grangeiro et al., 2010).

Entre os anos 1990 e 1991, o programa nacional foi coordenado por Eduardo Cortes. Suas ações nesta gestão, promoveram o isolamento do programa nacional nas relações com a sociedade civil organizada, as universidades, os outros entes federativos na gestão das políticas para a aids e os organismos internacionais. Alguns dos entrevistados e a literatura consultada destacam a inadequação de uma campanha promovida neste momento que se baseava no que se pode nomear como uma pedagogia do medo, como descreve Teixeira (1997, p. 63):

\footnotetext{
Neste período, é desencadeada uma campanha nacional sob o tema 'Se você não se cuidar, a AIDS vai te pegar', que retirava toda a esperança das pessoas infectadas e pretendia estimular atitudes e práticas seguras, entre os não-infectados, utilizando a ameaça: a AIDS mata.

Apoiado por um pool de prestigiadas e premiadíssimas agências de publicidade brasileiras, e contando com a colaboração dos mais importantes veículos de comunicação do país, a coordenação do programa afirmava que a opção do governo deveria ser pelos indivíduos ainda não atingidos pela epidemia, mesmo que isto significasse decretar a morte civil das pessoas já infectadas.
}

A referida campanha contrariava frontalmente o discurso defendido pelo movimento social de aids que defendia a solidariedade, nos diferentes planos, como o discurso mobilizador das respostas à epidemia (Teixeira, 1997; Galvão, 2000). A perspectiva do medo, como analisa Vera Paiva (1992) estabelece uma fronteira cultural e um padrão coletivo de comportamento que demarca limites de normalidade e legitimidade, deixando do lado de lá da fronteira o diferente, a aids atribuída ao outro, àquele que não se enquadra. 
Uma reação equivocada, por parte do ministro, à proposta da OMS de realização de pesquisas de vacinas contra o HIV no Brasil, dizendo que o país não serviria de cobaia, tensiona ainda mais a relação com a sociedade civil e com os organismos internacionais.

Apesar deste isolamento, é neste período que se dá início a uma das marcas distintivas das respostas brasileiras à epidemia de aids, que foi a garantia do acesso aos medicamentos (Teixeira, 1997; Nunn, 2009). Tal medida - pouco recordada pelos ativistas como responsabilidade dessa gestão - se contrapunha, de certa forma, ao discurso preventivo manifesto anteriormente na campanha, de exclusão dos soropositivos, e contrariava as diretrizes dos organismos internacionais, como OMS e OPS, que recomendavam que os países pobres só destinassem os recursos financeiros disponíveis à prevenção (Teixeira, 1997; Galvão, 2000).

Em 1992, após a mudança do Ministro da Saúde, Lair Guerra volta à coordenação do programa nacional e retoma negociações com o Banco Mundial para a obtenção de um empréstimo para que o governo brasileiro possa desenvolver atividades em HIV/Aids. Neste processo, é promovida uma reaproximação com a sociedade civil e uma articulação para elaboração do projeto para empréstimo do Banco contando com a participação de representantes dos governos estaduais e da sociedade civil, como Paulo Teixeira e Jane Galvão (Teixeira, 1997; Galvão, 2000; Nunn, 2009). Este é, segundo Paulo Teixeira, o primeiro momento em que o conceito de vulnerabilidade é adotado nas políticas de aids no Brasil:

A primeira discussão onde está incorporado, que eu me recordo, [em que] está incorporado o conceito de vulnerabilidade é o documento que nós preparamos para o Banco Mundial, em 1992, que é o documento sobre intervenção para prevenção. Ele foi elaborado pela Jane Galvão. Eu era o encarregado desse componente. Eu fui encarregado pelos componentes técnicos do Programa. Então a Lair fez a parte gerencial. Eram quinze documentos. E nesse documento de prevenção, nós não fizemos projeto para homossexuais, projetos para profissionais do sexo... Nós fizemos, foi elaborado pela Jane Galvão, com assistência do [Richard] Parker, intervenção por fator de vulnerabilidade (Paulo Teixeira, entrevista).

No total, foram três, os empréstimos do Banco Mundial ao governo brasileiro com vistas ao desenvolvimento de ações em HIV/Aids. Neste primeiro projeto intitulado AIDS I, vigente de 1993 a 1997, o Banco emprestou U\$ 160 milhões de dólares e o 
governo brasileiro deu em contrapartida U\$ 90 milhões. O projeto concentrava-se em 4 grandes áreas programáticas: prevenção; assistência, vigilância epidemiológica e desenvolvimento institucional. Na área de prevenção, tinha como principais objetivos: implementar campanhas de mídia de massa, desenvolver intervenções direcionadas e ações comunitárias para populações de alto risco; realizar estudos de uso de drogas endovenosas; e desenvolver programas de testagem e aconselhamento (Nunn, 1999, p. 175).

A literatura que trata das respostas políticas à epidemia no Brasil atribui enorme importância aos acordos de empréstimo propiciados pelo Banco Mundial, apesar de não desconsiderar que houve recursos de outras agências internacionais (Galvão, 2000). Isso se dá pelas mudanças propiciadas pelos mesmos nas respostas governamentais e nãogovernamentais. Galvão (2000) destaca a ampliação significativa dos recursos financeiros e o incremento no número de ações decorrentes de tais recursos; a liderança do programa nacional na região; e a visibilidade alcançada pelo programa no país e no cenário internacional. Nunn (2009) chama a atenção para a delicada interrelação entre sociedade civil organizada e o programa nacional, no que nomeia como um momento crítico em sua análise acerca da política e da história do tratamento da aids no Brasil. Segundo a autora, com esta decisão, a coordenação do programa nacional direciona a formação de novas instituições no âmbito do movimento e, a partir deste momento, o movimento não estava mais fazendo pressão de fora do governo, mas estava trabalhando no governo federal e recebendo apoio financeiro para constituir novas instituições no campo (Nunn, 2009). Grangeiro et al. (2009), por sua vez, avaliam que se fortaleceu uma experiência de organicidade propiciada por uma rede de interlocuções entre profissionais e instituições, já existente desde a formação do programa nacional, a partir dos recursos propiciados por tal acordo.

Nesse contexto, também, o programa nacional retomou o diálogo com a OMS para o estabelecimento de acordo para o desenvolvimento de pesquisas preparatórias aos ensaios clínicos de vacinas anti-HIV. Foram implantados três estudos de coorte de HSH com comportamentos de alto risco para a infecção pelo HIV: Projeto Bela Vista em São Paulo; Projeto Horizonte em Belo Horizonte; Projeto Praça Onze no Rio de Janeiro. Esses projetos foram financiados pelo governo federal com recursos provenientes da 
OMS de 1994 até 1999/2000 (Brasil, 2001). Em seu relato, Maria Clara Gianna destaca a experiência do Bela Vista em São Paulo como estratégica para o programa estadual. Isso por ter fortalecido as relações com a comunidade homossexual, ter fomentado o desenvolvimento de estratégias de aproximação dentro e fora do serviço e ter formado profissionais que até hoje trabalham no CRT-DST/Aids.

Na área da prevenção, é retomada uma nova versão do projeto Previna, com o nome de "Projeto de prevenção de DST/AIDS para populações sob maior risco", a partir de 1994. Este projeto que havia sido iniciado pelo governo federal em 1989, foi interrompido na gestão de Eduardo Cortes. Em sua nova versão ${ }^{53}$, o Previna volta-se aos seguintes segmentos populacionais: $\mathrm{HSH}$, trabalhadores sexuais (homens, mulheres e travestis), internos do sistema penal e, agora, garimpeiros da Amazônia Legal. Como se pode notar também, no depoimento de Ivo Brito, o programa nacional utiliza a articulação entre as análises de risco e de vulnerabilidade para definir os grupos a serem abrangidos pelos projetos de prevenção a serem financiados com os recursos do acordo:

Então, na década de 1990 nós, com o Previna, que era uma estratégia, por incrível que pareça, né? Era uma estratégia que as pessoas, às vezes "Ah, nós não estamos focalizando hoje." Não. A resposta brasileira sempre foi uma resposta que, de algum modo, ela foi conduzida com um certo direcionamento pra aqueles segmentos que são mais afetados pela epidemia. Então, desde a década de 1990, você tem, por exemplo, um olhar das estratégias de prevenção voltadas para esses segmentos. O que acontece? Na década de 1990, você teve um olhar muito pela perspectiva do movimento social. Você não tinha - mesmo o Previna - as estratégias de prevenção.... Na verdade, não eram nem estratégia, porque eu não chamo isso de estratégia. Era muito mais de financiamento das organizações não-governamentais para a execução de ações junto a esses segmentos. Então, na verdade, você tinha um plano de ação, chamado Previna, em que você traçava algumas diretrizes voltadas para esses segmentos. Foi quando, dentro do Previna, se constituiu, pela primeira vez, se construiu a matriz, trazendo para o âmbito da abordagem da prevenção, o conceito de vulnerabilidade. Se você tiver um papel aí.... Eu te mostro, mais ou menos, como que era. É um documento que não foi publicado. Lamentavelmente, não foi publicado. Mas é um documento que.... Depois eu posso tentar ver se até eu localizo ele para você. Então, você tinha uma matriz que era, basicamente, ela era feita alto risco, baixa vulnerabilidade. Você tinha alto risco e alta vulnerabilidade. Você tinha baixo risco, alta vulnerabilidade. Você tinha baixo risco, baixa vulnerabilidade. Era assim que se trabalhava a prevenção na época do projeto Previna. Então, aqui dentro, você classificava as populações. Então, alto risco, você tinha um elenco de populações, que você listava, que tinha o risco. E você, depois, trabalhava

\footnotetext{
${ }^{53} \mathrm{Na}$ primeira versão, também incluía usuários de drogas injetáveis (Galvão, 2000, p. 82).
} 
para ver quais dessas populações tinha alto risco e tinha baixa vulnerabilidade. Ou quais dessas que tinha alto risco e tinha alta vulnerabilidade. Portanto, você tinha aqui focalização. [...] E aqui a mesma coisa. Você tinha baixo risco, você tinha alta vulnerabilidade. Então assim que você trabalhava população indígena, trabalhava ribeirinhos, mulheres, tã-rã-rã, tã-rã-rã, tã-rã-rã. [...] Então, você ia fazendo uma série de combinações aqui, pra fazer uma, para a definição de algumas diretrizes, do ponto de vista operacional, pra você desenvolver as ações de prevenção. Então, para as populações, vamos dizer, de alto risco e alta vulnerabilidade: HSH, usuários de drogas injetáveis, na época, nos anos 1990, profissionais do sexo, tal. Nessa variante aqui, por exemplo, eu diria muito pouco foi feito dentro do âmbito, por exemplo, governamental. Então, isso aqui o Departamento apoiava, financiava um conjunto de projetos. Muitos desses projetos numa perspectiva mais de como o Departamento estava olhando os números e os dados do ponto de vista epidemiológico, para essa matriz aqui. E orientava os editais, no sentido "Ah, vamos fazer estratégias de interpares. Vamos fortalecer isso. Vamos fortalecer aquilo. Vamos fortalecer..." Então, você tinha um conjunto de medidas que eram adotadas, mas amarrando os editais para que os projetos, com esse segmento... [...] fossem focalizados nessa população (Ivo Brito, entrevista).

Considerando os modos de gestão da epidemia neste momento, podemos destacar da fala de Brito que temos uma política de prevenção focalizada nos grupos populacionais mais afetados pela epidemia, definidos em função de análises que articulam os conceitos operativos de risco e de vulnerabilidade, que se dá por meio de projetos de prevenção desenvolvidos por organizações da sociedade civil, com a adoção da estratégia de educação entre pares (peer education), financiados, de forma centralizada, pelo programa nacional. O que foi caracterizado por Jane Galvão (2000) e relembrado por Ivo Brito em sua entrevista - como o período da "ditadura dos projetos". A ação governamental se dava por meio da realização dos diagnósticos para indicar quais os segmentos populacionais deveriam ser abarcados pelas ações de prevenção; pela definição das diretrizes da política; e pelo financiamento das ações que eram efetivadas pelas ONG em espaços diversos. Brito destaca em seu depoimento, que esta forma de gestão implicava em uma divisão interna também na forma de organização do próprio programa. De forma que a gestão das políticas de prevenção voltadas aos grupos mais afetados pela epidemia se dava pelo setor de Articulação com ONG, enquanto a gestão das políticas de prevenção voltadas aos demais segmentos populacionais ocorria no setor de Prevenção. 
Simões e Facchini (2009) apontam que, na perspectiva do movimento homossexual, tal modo de gestão assegurou recursos a grupos que, até aquele momento, tinham dificuldade em obter financiamento. Chamam à atenção para a reversão da dinâmica de discriminação dos homossexuais, propiciada pela classificação como "grupo de risco", que vem a se converter - favoravelmente diante das reações contrárias do próprio movimento e do campo - em justificativa para o estabelecimento de políticas focalizadas de prevenção e cuidado dirigidas a este segmento. O que Galvão (2000) já havia indicado anteriormente, destacando o papel da epidemia de HIV/aids em atribuir inegável visibilidade a segmentos populacionais tradicionalmente estigmatizados - como os grupos de gays e de trabalhadoras(es) sexuais. O que podemos nomear como um dos paradoxos transformadores do campo (Alvarez, 2014). O paradoxo dos "grupos de risco" que reverte abordagem discriminatória em visibilidade, a partir da resposta social do próprio grupo à forma desrespeitosa de tratamento. O que fica evidente na descrição de João Silvério Trevisan (2006, p. 462-3):

Ao contrário do que muita gente diz, a meu ver, o vírus da Aids realizou em alguns anos uma proeza que nem o mais bem-intencionado movimento pelos direitos homossexuais teria conseguido, em muitas décadas: deixar evidente à sociedade que homossexual existe e não é o outro, no sentido de um continente à parte, mas está muito próximo de qualquer cidadão comum, talvez ao meu lado e - isto é importante! dentro de cada um de nós, pelo menos enquanto virtualidade. Graças à característica de estigma que a Aids historicamente adquiriu, já não se pode mais esconder o desejo: ele está lá, sendo identificado, flagrado e denunciado por intermédio da doença. [...] Há que lembrar também um extraordinário efeito colateral dessa epidemia sexualizada. Ela ofereceu de presente às sociedades modernas elementos inestimáveis para educação da sexualidade e, eu acrescentaria, da sensibilidade, para não dizer do desejo. Graças a ela, as escolas, as famílias, a mídia, os políticos e, pasmem!, até as igrejas mais reticentes foram obrigados a se engajar com maior ou menos energia, numa generalizada (porque compulsória, sem escolha) campanha em busca dos meandros da sexualidade, essa esfinge que insolentemente exigia: "decifra-me, ou te devorarei." A sociedade passou a debater amplamente argumentos a favor e contra sexo anal, sexo oral, perversões, quantidade de parceiros/as, uso da camisinha, sexo seguro e doenças venéreas, métodos anticoncepcionais, casamento entre pessoas do mesmo sexo, conveniência ou não da adoção de crianças em família não-padronizadas etc. etc. Deflagrou-se uma epidemia de informação, que não tem retorno porque deixará marcas nas próximas gerações. Nesse mesmo sentido, reafirmo que nunca se discutiu tanto a realidade homossexual como nos tempos de Aids 
O incremento ao financiamento de projetos de prevenção das ONG com recursos dos acordos efetivados pelo governo federal contribuiu para a institucionalização do movimento homossexual (Facchini, 2005) e ampliou significativamente o desenvolvimento das ações de prevenção ao longo da década de 1990. Além disso, como assinalam Simões e Facchini (2009), há um novo florescimento do movimento por direitos dos homossexuais com a realização mais frequente e continuada dos encontros nacionais, a formação de redes e associações - como a Associação Brasileira de Lésbicas, Gays, Bissexuais e Travestis ${ }^{54}$ (ABGLT), em 1995, e a Associação para a Saúde e Cidadania Integral na América Latina e Caribe ${ }^{55}$ (ASICAL), em 1997 (ABGLT, 2003) -, vinculação a redes e associações internacionais e o início da organização das Paradas do Orgulho LGBT. Estas transformações no cenário são retratadas por Veriano Terto Jr.:

E nos anos 1990, a coisa muda. Porque com o empréstimo que o Banco Mundial faz ao Brasil, há recursos para as ONGs desenvolverem trabalho de prevenção. Inclusive pelos índices epidemiológicos. Pelo alto impacto nessa população, o governo reconhece a importância de desenvolver mais trabalhos ou, pelo menos, apoiar trabalhos com a população $\mathrm{HSH}$. E com a população trans, que a partir daquela metade dos anos 1990, também começa a se organizar politicamente. E há recursos da aids para isso. Então, há um aumento do número de projetos de prevenção para a população HSH desenvolvido tanto por ONG como, também, pelos grupos gays. E muitos grupos gays ressurgem ou são fundados, a partir do momento em que também há uma possibilidade de recurso razoável e contínuo por parte do Ministério. Então, as paradas gays retomam, a partir de 1995. Elas já aconteciam, de uma maneira extremamente incipiente, lá na época do Somos. A ABGLT, que era uma proposta dos anos 1980, ela se concretiza em 1995. Naquela reunião da ILGA $^{56}$ aqui no Brasil, que conta com apoio da Lair Guerra, que era

\footnotetext{
${ }^{54}$ A ABGLT - atualmente, Associação Brasileira de Lésbicas, Gays, Bissexuais, Travestis, Transexuais e Intersexos - veio, posteriormente, a incluir em seu nome transexuais e, mais recentemente, intersexos, mantendo, no entanto, a mesma sigla. Simões e Facchini, 2009. Disponível em:

https://www.abglt.org/quem-somos [acesso em: 28.04.2018].

${ }^{55}$ A Associação para a Saúde e Cidadania Integral na América Latina e Caribe (ASICAL) é uma rede regional de grupos e organizações, criada em dezembro de 1997, em Lima, Peru com a missão de constituir-se em uma resposta que promova e desenvolva estratégias e ações de prevenção, atenção e apoio em HIV/Aids e Direitos Humanos com gays e outros homens que fazem sexo com homens (HSH), de modo a contribuir para a melhoria da qualidade de vida na América Latina e no Caribe. Apesar de referida até recentemente em documentos e parcerias institucionais, o domínio do website que se encontra nessas divulgações dá acesso a outra instituição (ABGLT, 2003).

${ }^{56}$ Entre 18 e 25 de junho de 1995, foi realizada, no Rio de Janeiro, a 17ạ Conferência Mundial da International Lesbian and Gay Association (ILGA). Organizada pelos grupos Arco-Íris, Atobá, Caras e Coroas, Coletivo das Feministas Lésbicas (São Paulo), Coletivo de Lésbicas do Rio de Janeiro, Instituto Superior de Estudos da Religião (ISER) e Triângulo Rosa, teve como tema a "Cidadania completa para lésbicas e gays!". Nesta conferência, as metas da ILGA foram expandidas para incluir a promoção do respeito universal por e a observância dos "direitos humanos e liberdades fundamentais". Por ocasião
} 
coordenadora - ela põe dinheiro do governo brasileiro na reunião da ILGA. O Richard também promove uma reunião no ISER - e eu acho que com dinheiro governamental, também - com as lideranças homossexuais daquele período. Aí, são marcos que vão indicando um outro caminho, que as coisas vão tomando (Veriano Terto Jr., entrevista).

Os projetos de prevenção - que ganham centralidade na agenda das ONG que prestam serviços no campo da aids - são orientados pelo conceito operativo de comportamento de risco. Intencionam, assim promover mudanças de comportamentos que favoreçam a exposição ao vírus (Galvão, 2000). Este conceito operativo deriva das críticas ao conceito de grupos de risco e destaca que as chances de infecção não são atributos de identidades ou grupos identitários, mas devem ser atribuídas a comportamentos ou práticas sexuais. No âmbito comunitário, onde se origina esta discussão, é central o processo de construção da noção de sexo seguro por parte da comunidade homossexual estadunidense (Pinheiro, 2015). Processo este que se articula, na produção de conhecimentos técnico-científicos com os esforços das teorias cognitivo-comportamentais (Parker, 1998).

Tendo em vista os limites borrados de qualquer periodização, é importante demarcar que, no final dos anos 1980 e início dos anos 1990 - o que pode ser considerado um segundo momento das abordagens no campo da prevenção -, é que se dá a "vinda" do sexo seguro e do preservativo, identificados como medidas provenientes da comunidade homossexual de São Francisco, Estados Unidos. A apropriação inicial desta nova perspectiva de prevenção, traz novo fôlego ao recémformado grupo Pela Vidda que, começa a realizar oficinas de sexo seguro em casas noturnas. Nestas atividades, conjugam informações e educação acerca das formas de transmissão do HIV às dinâmicas anteriormente utilizadas no âmbito dos grupos homossexuais de compartilhamento acerca da política da vida cotidiana:

E então, naquela época, inclusive, no Pela Vidda, começamos a fazer oficinas de sexo seguro, né? Sexo mais seguro. A gente fez em boate. Antes de que a boate abrisse para o público. [...] Levando em conta quais eram os fluidos, quais eram as rotas, quais eram as situações que envolviam mais ou menor ou nenhum risco. [...] Então, 
aí, a gente falava, claro, obviamente de práticas sexuais, né? (Jorge Beloqui, entrevista).

As estratégias que passam a ser adotadas, neste momento, são fortemente articuladas às práticas sexuais e à exploração do universo erótico dos sujeitos. Apostavase na construção do vínculo, no estabelecimento de relações de confiança e cumplicidade para que, a partir do conhecimento e conscientização sobre o próprio erotismo se pudesse identificar, de forma singular, como seria possível incorporar a prevenção, como algo possível. As oficinas de sexo seguro abarcavam - além de experiências mais vivenciais e de promoção da reflexão - o compartilhamento de informações e a entrega de "insumos", como passaram a ser nomeados preservativos ${ }^{57}$ e gel lubrificante - quando este foi incorporado - podendo incluir, ainda, kit de redução de danos (agulhas e seringas; cachimbo; canudo; material para higienização). As oficinas ocorriam predominantemente entre grupos de pares, mas não necessariamente. Dependiam, no entanto, do estabelecimento de acordos, em que se soubesse que as pessoas ali não estavam para julgar umas às outras. Há relatos de experiências muito criativas neste momento, usando como subsídios: vídeos pornográficos, relatos eróticos, filipetas com as informações do que dá tesão para cada um. Em alguns serviços de saúde, inspirados pelo aprendizado comunitário das oficinas de sexo seguro, procurou-se incorporar atividades grupais de caráter educativo e reflexivo em atividades de sala de espera ou em grupos para entrega de resultados de exame de Papanicolau. Em muitas destas atividades, ensinar a colocar a camisinha podia ser um elemento disparador da cumplicidade para lidar com as dificuldades e desafios singulares. As atividades de aconselhamento - realizado antes e depois da testagem para o HIV - também procuraram investigar e explorar o universo das práticas sexuais, abordando individualmente as possibilidades de incorporação da prevenção.

\footnotetext{
57 O preservativo, ou camisinha, é incorporado como tecnologia no discurso preventivo a partir de 1984; é distribuído de forma eventual e em projetos esparsos, a partir de 1987, sua distribuição sistemática só passa a ocorrer a partir de 1994 (Gianna et al., 2012).
} 
É interessante, neste sentido, observar as ações de um projeto desenvolvido no início dos anos 1990 pela ABIA em ambientes de trabalho, que não eram voltados a gays, mas tinham uma abordagem ousada das práticas sexuais:

Em 1990, o Betinho e o Daniel inventam um projeto para trazer dinheiro pra ABIA que era o projeto "A Solidariedade é uma Grande Empresa". E eles me chamaram para meio que coordenar esse projeto. $\mathrm{E}$ eles um pouco na frente, iam abrindo as portas e eu ia executando. $O$ projeto, que era um projeto bastante ousado, porque a ABIA não tinha nada a oferecer para as empresas, em termos de técnica. Não era uma empresa de consultoria. $O$ que a gente oferecia era é uma espécie de animação política e a empresa para ela - já era um privilégio assim, por causa do Betinho - dar dinheiro pra ABIA. Em troca, a gente fazia horrores dentro da empresa na verdade. Coisas que, hoje em dia, a gente não faria. A gente desenvolvia oficinas. Tinha uma questão de montar uma política de HIV/Aids dentro da empresa na qual se garantia o respeito aos direitos trabalhistas e direitos humanos das pessoas vivendo com HIV/Aids, ou seja, não demissão, não testagem compulsória, apoio.

Os trabalhos de prevenção, a gente fazia com material pornográfico. Imagina, dentro de empresas como a Vale do Rio Doce, BNDES, Caixa Econômica. Oficinas de sexo seguro. Inclusive em regiões uma das conveniadas era a Vale do Rio Doce. Então, a gente fazia isso no interior do Pará, em Carajás, em Santa Inês, no Maranhão, no interior de Sergipe, no interior de Minas Gerais, na linha do trem. Tudo com essa linguagem da solidariedade. $E$, assim que o projeto se firmou um pouquinho, eu pude chamar dois colegas, que era o José Carlos e o Rubem Almeida, que eram soropositivos e trabalhavam e tinham se aproximado do Pela Vidda, por serem pessoas soropositivas e doentes de aids. E ali, nós formamos um trio. Eu, o Zé Carlos e o Rubem. Betinho e Daniel na dianteira, abrindo as portas das empresas e a gente junto com as equipes, os profissionais das empresas, fazendo oficina de prevenção, ajudando a montar folhetos das próprias empresas, realizando palestras de SIPAT, dando treinamento. Mas nada técnico, tudo muito político. E foi um período, foi um projeto muito legal, porque os profissionais... A gente dizia: "A ABIA não pode ser uma empresa de consultoria de aids no local do trabalho, técnica. Porque nenhum de nós é especialista nessa área $e$ não é isso que a $A B I A$ vem a oferecer. $A$ ABIA vem fazer um trabalho político na empresa para despertar a solidariedade". $E$, então, a gente queria que as empresas tivessem as suas políticas de HIV, fizessem eventos de HIV. Nós juntamos uma rede de profissionais das empresas que trabalhavam no projeto, de empresas amigas, que se reuniam na ABIA com uma certa periodicidade. Nós juntamos, sentamos, fizemos as empresas sentarem com um representante de comunidades, em algumas áreas que elas atuavam. Por exemplo, aqui no Rio, ali na área de Vargem Grande, as Ceras Johnson, que era uma empresa contratada, sentava com a comunidade. Tinha uma favela ali perto. Desenvolvia atividades. A gente animava, levava material, trabalhava junto. Mas, mais no sentido de incentivar. E eu acho que [era] isso que os profissionais precisavam, realmente. Alguém que tivesse do lado deles, não para ensinar [a] eles o que eles já sabiam. Porque pesquisa, a parte toda de saúde no local do trabalho eles já tinham. O que precisava era esse apoio meio de fora, da 
sociedade, que fazia eles trabalharem. Eles vinham pra ABIA. Eles começaram a participar até dos velórios das pessoas que morriam, sabe? Foram incorporando esse ethos, vamos dizer assim, de solidariedade que a gente queria passar. E, realmente, trabalhamos com pessoas incríveis... por exemplo, as atividades que a gente fez em Carajás foram fantásticas. $\mathrm{Na}$ verdade, nessa época eu fui sozinho e... Mas, depois, as pessoas, os empregados lá da Vale em Carajás, eles vinham ao Rio, eles passavam pela ABIA. Vinham visitar e queriam saber como é que estavam as coisas. [...] O Rubens morreu em 1992. As pessoas das empresas acompanharam, vários dos profissionais, a doença do Rubens, os momentos finais dele. $\mathrm{O}$ Zé Carlos morreu em 1994 e, também o pessoal das empresas, todo, a Caixa Econômica, eu me lembro, o BANERJ, as assistentes sociais, os médicos, todo mundo foi no velório, no enterro. Então, foi um projeto que deu, assim, muita satisfação. Muita alegria. E, apesar, daquele momento que a gente vivia. Mas isso que eu te digo, a gente, como é que tu ia usar um vídeo pornográfico gay, hoje em dia, eu não sei, não. Para trabalhar a camisinha e sexo seguro no interior do Pará, sabe? E a gente fazia isso. Em Minas. E nunca, nunca deu escândalo, nunca foi uma questão. Héteros também. Mas os gays ainda causavam mais choque, porque muitas dessas pessoas no interior nunca imaginavam. E eram vídeos europeus, com essa estética de couro, leather, sadomasoquismo. $\mathrm{E}$, assim a gente fazia umas oficinas muito legais, muito loucas. E esse negócio, também, algumas empresas depois organizavam os eventos de aids no local de trabalho. Eu me lembro que São Paulo teve um. Vários aqui no Rio, também. Mas um de São Paulo foi no Hotel Cad'oro que, na época, era um hotel bastante chique. E nós dissemos, disse "Não, o evento não é pros profissionais?" "Não. De jeito nenhum. Tem que trazer os maquinistas, os caldeireiros, os operários, os mineiros têm que vir." Né? E aí trouxemos os operários. Então, muito legal ver dentro do hotel Cad'oro, aquela coisa formal de empresa. Mas, ao mesmo tempo, aqueles, aquele pessoal rude, duro, né? Que trabalhava nas minas da Vale, operário da empresa, enfim, falando junto. Criando essa... A ideia da interdisciplinaridade, da solidariedade. Foi muito legal esse negócio. Eu fiquei muito feliz." (Veriano Terto Jr., entrevista)

Contrapondo-se à experiência da morte civil, termo cunhado por Herbert Daniel (1989) para referir-se à experiência vivida pelas pessoas soropositivas de estigmatização, discriminação, preconceitos e silenciamento em torno da doença, este projeto trabalhava com a perspectiva da transformação dos contextos de intersubjetividade, embasado no discurso da solidariedade e no trabalho político para mobilizá-la. Estabelecendo, assim, uma gramática que subverte não somente a abordagem da sexualidade, mas também outras dinâmicas relacionais implicadas nas condições de saúde e de vida dos trabalhadores.

Ainda no início dos anos 1990, a ABIA inicia um projeto especificamente dirigido aos HSH, que articula pesquisa e reflexão acadêmica, produção de materiais 
informativos e educativos e o desenvolvimento de intervenções fundamentadas na proposta de ativismo cultural. Richard Parker (1998) justifica tal proposição ao explicar que havia crescente consenso na literatura científica da época de que a redução do risco de infecção pelo HIV em comunidades homossexuais se devia a processos de mobilização comunitária associados à transformação dos contextos intersubjetivos por meio do fomento de uma cultura comunitária de sexo mais seguro. Defendia, assim, a associação entre ativismo cultural, mobilização comunitária e transformação social como base para a reformulação dos programas de intervenção em HIV/Aids. Nesta proposta, há, segundo Parker (1998, p. 107), um deslocamento do foco da atenção do comportamento de risco para "as representações sociais associadas à homossexualidade, vulnerabilidade ao HIV/AIDS, cidadania sexual e diversas questões conexas". Em minha interpretação, muda-se aí do conceito operativo de comportamento de risco para vulnerabilidade, tendo como contraponto não mais os comportamentos seguros, mas as respostas sociais de transformações das relações sociais que conformam os contextos de vulnerabilidade.

Veriano Terto Jr. contou sobre este projeto em sua entrevista:

Mas aí o Richard, então, já na coordenação da ABIA e com os contatos que ele tinha com agências americanas, o Richard teve a ideia de fazer um projeto para a população homossexual. Que, até aquele momento, não existia no Brasil. Existia, assim, uma ou outra ação direcionada. [...] dentro desse cenário, o Richard tem essa ideia e consegue um financiamento para fazer, aí sim, um projeto, né? Com atividades, objetivos e atividades sistemáticas, organizadas de prevenção. O Richard, naquele momento, já desenvolvia pesquisas, CAP ${ }^{58}$. Pesquisas comportamentais, lá no IMS, onde ele estava, que ele era professor. E, vamos dizer assim, a ideia era que o projeto de intervenção, de alguma maneira, dialogasse também com o projeto, as pesquisas, os projetos de pesquisa que o Richard desenvolvia. E aí, o Richard me chamou coordenar esse projeto na ABIA. Então aí, eu me afastei do Projeto de Aids no Local de Trabalho e fui trabalhar no projeto HSH, como a gente começa a falar. Que começa, de fato, em 1993. E aí, eu fui, vamos dizer assim, eu costumo dizer que esse projeto - ele, na verdade, virou um programa porque até hoje a ABIA desenvolve projetos para a população $\mathrm{HSH}$, tendo trabalhado com diferentes metodologias e diferentes, vamos dizer assim, subpopulações, ao longo dessa trajetória, com jovens, homossexuais soropositivos, homossexuais em geral. Misturando pesquisa e

\footnotetext{
${ }^{58}$ Referindo-se a pesquisas sobre conhecimentos, atitudes e práticas - do inglês knowledge, attitudes and practices (KAP) - relacionadas ao HIV/aids, mas também em associação com as iniciativas de pesquisa comportamental do The Center for AIDS Prevention Studies, da Universidade da Califórnia, San Francisco, que era um dos subcontratantes do programa AIDSCAP da USAID, explicado em seguida.
} 
intervenção. Trabalhando com perspectiva de ativismo cultural, e isso ao longo dos anos, são 25 anos que a ABIA desenvolve esse tipo de programa.

A partir de 1992, tem agências ${ }^{59}$ mais simpáticas à questão da homossexualidade. Como AIDSCAP ${ }^{60}$ e AIDSCOM ${ }^{61}$, que eram programas da própria USAID ${ }^{62}$, que tinham - ainda que com uma ênfase muito comportamentalista - eles apoiavam trabalhos com as prostitutas e, por exemplo, apoiaram um programa da ABIA. Foi com o AIDSCAP, primeiro. O projeto HSH da ABIA.

[Neste projeto,] A gente tinha a produção de material informativo, o IEC ${ }^{63}$, como a gente chama. Tinha a realização de oficinas. Tinha o desenvolvimento de pesquisa comportamental. E a parte toda de publicações, boletins, enfim, não era bem um material de IEC. Era basicamente esse o trabalho do primeiro $\mathrm{HSH}$.

\section{$[\ldots]$}

[A distribuição do IEC] era a intervenção, justamente. Que aí, esse projeto foi feito em parceria com o grupo Pela Vidda do Rio de Janeiro e o grupo Pela Vidda de São Paulo. Onde, então, o material produzido pelo projeto era distribuído nos locais gays de São Paulo e do Rio. E ele trabalhava em consonância, vamos dizer assim, em diálogo, usando, às vezes, materiais, enfim... numa parceria não tão institucionalizada, mas, vamos dizer assim, numa parceria política com grupos como GAPA Ceará - que naquela época era forte - e o grupo Nuances, em Porto Alegre. Que a gente chegou até a editar um livro chamado Entre Homens ${ }^{64}$, onde esses projetos colaboravam, onde esses grupos colaboravam no livro. Então, esse era o desenho do projeto $\mathrm{HSH}$, naquele momento. Mas trabalhando com a perspectiva de ativismo cultural, né? De trabalhar sexo seguro, com imagens eróticas, de reforçar esse lugar da sexualidade e do sexo nas mensagens de prevenção, de valorizar as culturas, vamos dizer assim, a produção cultural das homossexualidades, Arco-Íris, Triângulo Rosa, enfim... Participar das Paradas, dos eventos. E aí, tinha treinamentos de jovens, principalmente. Que eram as equipes que iam para as boates, para

\footnotetext{
59 Entre elas, a United States Agency for International Development (USAID), a agência do governo dos Estados Unidos voltada ao desenvolvimento e à ajuda humanitária internacionais, que estabeleceu uma política de AIDS em 1987. Neste ano, iniciou as atividades do projeto AIDSCOM, com o objetivo de apoiar campanhas de mídia de massa, iniciativas de marketing social de preservativos e ações de educação de pares para jovens. Posteriormente, em 1991, deu início ao programa AIDS Control and Prevention (AIDSCAP), com o objetivo de apoiar o desenho, a implementação e a avaliação de programas de prevenção por parte de governos e organizações não-governamentais internacionais. Disponível em: https://www.usaid.gov/sites/default/files/documents/1864/OHAtimeline.pdf [acesso em 27.04.2018].

${ }^{60}$ Sobre o programa AIDS Control and Prevention (AIDSCAP). Disponível em: https://pdf.usaid.gov/pdf docs/PNACE650.pdf [acesso em 27.04.2018].

${ }^{61}$ Sobre o projeto AIDSCOM. Disponível em: https://www.usaid.gov/sites/default/files/documents/1864/OHAtimeline.pdf [acesso em 27.04.2018]. 62 Sobre a USAID. Disponível em: https://www.usaid.gov [acesso em 27.04.2018].

63 Materiais para Informação, Educação e Comunicação (IEC), mais um termo derivado da articulação com o financiamento das agências internacionais. Disponível em:

http://siteresources.worldbank.org/INTEAPREGTOPTRANSPORT/Resources/5738021163017279494/3138417-1239142047073/6 IEC Materials.pdf [acesso em 27.04.2018].

64 Parker Richard, Terto Jr. Veriano (organizadores). Entre homens: homossexualidade e aids no Brasil. Rio de Janeiro: ABIA; 1998.
} 
as saunas, para os parques, para distribuir camisinha e distribuir o material, nesses locais.

\section{$[\ldots]$}

Então, o conceito de prevenção não era só intervir no comportamento. Era, também, promover uma rede de articulação e solidariedade entre a ONG, os serviços e os próprios locais de encontro, comerciais principalmente. Então, um envolvimento com os donos das boates, das saunas, até mesmo de cinemas de pegação, vídeo locadoras que pudessem, de alguma maneira, ser solidários e facilitar e trabalhar junto. Para aquela questão, como também serviços. Estabelecer parcerias para criar, facilitar um pouco mais o acesso e diminuir a homofobia dentro dos serviços. Que, naquela época, se hoje em dia é forte, naquela época, ainda, era mais forte. Então, essa era um pouco da ideia. $E$, também, claro, produzir pesquisa que era produzir dados, informações que pudessem orientar as políticas públicas voltadas para a população homossexual. Coisa que só vai acontecer, no âmbito governamental, na década seguinte. Mas era isso que orientava e orienta até hoje, a ideia de intervenção mesmo. Não era a nossa ideia cobrir a cidade inteira do Rio e São Paulo, nem criar... A ideia era como a palavra fala, intervenção, mostrar que era possível, medir, conhecer o impacto dessa intervenção. E esperar que o que fosse dali produzido, em termos de experiências, fossem evidências e informações para orientar políticas públicas mais amplas. Para a população e outras ações que pudessem ser copiadas ou ser referências para outras populações, para outras cidades também. Isso acho que continua, basicamente, até hoje. O que vai mudando, dentro da $A B I A$, é o financiador e, um pouco, a metodologia, mas os princípios gerais são os mesmos. É intervir nessa questão, vamos dizer assim, programática, com os serviços de saúde, também cultural, de promover ambientes mais favoráveis para que se faça prevenção, para que dentro das boates, dentro das saunas, se tenha um espaço para um acesso fácil, rápido à camisinha. Então, são coisas assim, que a gente trabalhou e trabalha, desde sempre nos projetos. O projeto da Schorer65 foi um projeto que ele enfatizou muito essa questão de criar parcerias com os serviços, outras ONGs. E, também, de produção cultural, né? Juntando cultura e saúde, oficinas de fotografia, atividades usando cinema, trabalhando junto com o Festival de Cinema do Pela Vidda de São Paulo. Quer dizer, via essa valorização das manifestações culturais, também passar as mensagens de prevenção e saúde. Então, isso são linhas, assim, políticas que o projeto sempre trabalhou. E que eu acho que acabaram, de alguma forma, sendo adotadas em alguns... Eu acho que esse discurso mais solidário, enfim... o primeiro texto do Plano de Enfrentamento da Aids na População Homossexual e População Trans, ele é bastante influenciado por essas experiências da sociedade civil. Não só da ABIA, mas também de outros grupos que, naquele momento, nos anos 1990, também começam a trabalhar com homossexualidade, a partir do momento que tem financiamento nacional (Veriano Terto Jr., entrevista).

\footnotetext{
65 Referindo-se ao projeto SAGAS desenvolvido pela ABIA, entre 2007 e 2012, em parceria com as ONG Somos (Porto Alegre/RS), Arco-Íris (Rio de Janeiro/RJ), GRAB (Fortaleza/CE), com financiamento da Fundação Schorer (Amsterdam, Holanda). A Fundação Schorer é uma ONG holandesa que trabalha na promoção de direitos LGBT e no enfrentamento da epidemia de aids e realiza ações de cooperação internacional (Castro e Pedrosa, 2012).
} 
Ao analisar o fenômeno, descrito acima, que denominou como "ditadura de projetos", Galvão (2000, p. 111) distingue dois paradigmas de prevenção em HIV, fundados em ação política e cultural ou em intervenção comportamental. No primeiro paradigma, as ONG tinham maior autonomia sobre os projetos, buscavam desenvolver estratégias articuladas à linguagem e aos códigos culturais dos grupos com os quais estavam trabalhando, de forma a promover uma tradução localizada e singularizada das prescrições de mudança de comportamento. No segundo paradigma, há uma tendência maior à padronização, imposta pela própria forma de gerenciamento imposta pelos financiadores. Como consequências desse segundo paradigma, a autora aponta uma delimitação mais restrita entre ações e resultados esperados, maior rigor no gerenciamento dos recursos, de forma que se estabelece uma relação com a epidemia "mais asséptica e menos ativista".

Aqui, se instaura um novo paradoxo do campo, na medida em que se dá o incremento no financiamento das ações de prevenção e a maior institucionalização das organizações com atividades em HIV/aids, ocorre também maior despolitização, com reforço ao tecnicismo das ações, como se pode ver no relato de um dos entrevistados:

Então, o uso do preservativo, eu acho que foi muito importante porque teve uma coisa liberadora a respeito da penetração, né? Então, não importava onde, não importava quando e como, né? Porque não sei se você lembra, naquela época, nos Estados Unidos, que fecharam saunas, fecharam lugares... Bom, então, aqui não. Então, aqui, era uma coisa mais de - que bom - de fazer chegar esses preservativos aos lugares onde tem que ser usados e tudo isso. $E$ isso, acho que tinha que ser feito pelas ONG, fundamentalmente - o que é muito insuficiente, né? Então, teve esse negócio liberal, se falava muito mais de sexualidade, com isso essas oficinas de sexo seguro, que falavam de rota, de fluidos, de tudo isso. Necessariamente falavam de sexualidade, né? De prática sexual, né? Então... E, aos poucos, a sexualidade, a prática sexual e tudo isso, foi saindo de cena e ficou aquele mote de 'use camisinha'. Ou seja, não se sabia... [...] em que situação. E se omitia, eu acho, fundamentalmente, a situação. Por um lado, tem o seu o lugar isso, talvez numa campanha maciça: 'Use camisinha'. Mas na prática pra você, pra abordagem, eu não acho que fosse adequado.

Para estimular o desenvolvimento de projetos assentados sob a estratégia de educação entre pares, em 1996, o programa nacional de aids publicou o Manual do 
Multiplicador - Homossexual ${ }^{66}$ (Brasil, 1996). Para a elaboração desse manual, o programa contou com a colaboração de dois ativistas do movimento gay, Luiz Mott (Grupo Gay da Bahia, Salvador) e David Harrad (Grupo Dignidade, Curitiba). Dirigido a multiplicadores e monitores que seriam "membros do próprio grupo" (p. 5) atuando por meio da educação através de pares, para desenvolver intervenções comportamentais junto a "'homossexuais com comportamento de risco', visa[ndo] exatamente substituir tais condutas perigosas por comportamentos de baixo ou nenhum risco" (p. 31). O que indica um esforço inicial de massificação dos projetos de intervenção e mostra um deslocamento discursivo do conceito de risco epidemiológico, presente na categoria de comportamento de risco, para um sentido do senso comum de risco como perigo.

Em meados de 1996, a então coordenadora do programa nacional sofreu um acidente grave e houve uma mudança na coordenação. É neste momento que Pedro Chequer, que já atuava no setor de Vigilância Epidemiológica, assumiu a gestão pela primeira vez.

Nesse mesmo ano, na Conferência de Aids de Vancouver, foi relatada a eficácia da terapia antirretroviral altamente ativa (Highly Active Antiretroviral Therapy, HAART) - conhecida no Brasil como terapia tríplice ou "coquetel" - e iniciou-se a distribuição gratuita e universal dos antirretrovirais (ARV) que compõem tal terapêutica no SUS (o que foi assegurado pela Lei $n^{\circ}$ 9.313, de 13 de novembro de 1996) (Galvão, 2002). A terapia tríplice propiciou mudança significativa na qualidade de vida das PVHA, diminuição da mortalidade e transformação da experiência com a aids. Como já destacado acima, os organismos internacionais discordavam da política nacional de oferta de tratamento para a aids. Nesse contexto, o lançamento do livro "Confronting AIDS" pelo Banco Mundial, em 1997, provocou enorme reação e mal-estar por parte dos atores do campo no Brasil. Um de meus entrevistados, ao contar sobre este incidente fazendo um paralelo com uma política da atualidade - referiu-se ao livro dizendo que

\footnotetext{
${ }^{66}$ Esta publicação integrava um conjunto de manuais sobre educação através de pares. Sendo que o primeiro volume o Manual do Multiplicador - Prevenção às DST e AIDS (Brasil, 1996) caracterizava a estratégia e era acompanhado de outros quatro manuais complementares. Dirigiam-se ao treinamento de multiplicadores e monitores com vistas a atender às necessidades e características específicas das populações, tidas como grupos de maior risco para a infecção pelo HIV: profissionais do sexo, homossexuais masculinos, presidiários e adolescentes (Brasil, 1996, 1996, 1996, 1997). Havia, ainda, o compromisso de publicar manuais semelhantes para usuários de drogas e garimpeiros (Calazans, 2012).
} 
seria mais apropriado que se chamasse "Confronting people with AIDS". Isso porque ao advogar que países em desenvolvimento só deveriam investir em prevenção, com base em argumentos fundamentalmente epidemiológicos e econômicos, este livro enfatizava a ideia de "controle da epidemia" como norte central de uma política de aids. Desconsiderando, assim, as vidas daqueles vivendo com o HIV e a aids:

This book provides information and analysis to help policymakers, development specialists, public health experts, and others who shape the public response to HIV/AIDS to design an effective strategy for confronting the epidemic. It draws upon three bodies of knowledge: the epidemiology of HIV; public health insights into disease control; and especially public economics, which focuses on assessing tradeoffs in the allocation of scarce public resources.

The report offers persuasive evidence that, for the 2.3 billion people living in parts of the world where the epidemic is still nascent, an early, active government response encouraging safer behavior among those most likely to contract and spread the virus has the potential to avert untold suffering and save millions of lives. Even where the virus has spread widely in the general population, prevention among those most likely to contract and spread it is still likely to be the most cost-effective way to reduce infection rates. [...]

But only the government has the means and mandate to provide what economists call public goods. In the case of HIV/AIDS, these include information about the distribution of infection and behaviors that spread it and knowledge of the costs and effectiveness of prevention and mitigation programs. Similarly, governments have a unique responsibility to reduce the negative externalities from risky behavior, by encouraging safer behavior among those most likely to pass the virus to others.

Although sound, these policies can be politically difficult. Indeed, because the spread of HIV involves private behaviors that many people deplore--multiple sexual partners and injecting drug use-governments that attempt to reduce the spread of HIV by these activities may appear to their constituents to condone immoral acts. Governments must make clear that the best way to protect everyone from HIV is to help people who engage in the riskiest behavior to avoid infection.

Because resources are scarce, one must think through how best to allocate them. The consequences of these decisions for particular individuals can be enormous. And there are painful dilemmas. In countries where HIV has spread widely, the epidemic will greatly increase the demand for health care and the need for poverty assistance. Governments of poor countries face the challenge of responding to the new needs of the AIDS-affected poor while not neglecting the needs of the poor who suffer from other illnesses and other causes of poverty. Drawing on the experience of countries that have faced these dilemmas, the report suggests responses that are both humane and affordable. 
A reação mobilizou e uniu aos diferentes atores que compõem a resposta nacional à epidemia - ativistas, técnicos e gestores de políticas públicas e pessoas da universidade - em defesa da indissociabilidade entre tratamento e prevenção. O que veio a definir um dos discursos definidores do campo da aids. A elaboração deste discurso foi tributada por entrevistados à adoção do conceito operativo de vulnerabilidade, tendo por referência os direitos. Nessa perspectiva, ter acesso à prevenção é direito dos soronegativos, enquanto ter acesso ao tratamento é direito dos soropositivos, assegurando-se a todos o direito à saúde.

Aqui você tem um período, acho que é 1996, não só do acesso universal que o medicamento entra, tal, mas você tem uma discussão aqui, que é uma discussão que é muito interessante, porque essa matriz [de vulnerabilidade] aqui. Ao mesmo tempo que ela delega ao outro para fazer a prevenção nas populações de maior risco, através de projetos, mas ela traz para dentro do Departamento uma concepção muito interessante que é não separar prevenção de assistência. Então é nesse período em que.... Não é agora [por referência à atualidade da entrevista]. "Ah, vamos fazer." Não. É de lá. Sempre esteve, sempre carregou essa marca, que prevenção e assistência são indissociáveis. Isso estava claro nessas discussões, nesse documento, desde o início. A partir de 1996, torna-se mais evidente ainda, quando você tem o acesso... E essa polêmica, é uma polêmica que se dá com o Banco Mundial. Porque o Banco Mundial puxava a gente para a focalização. Queria que a gente só fizesse prevenção focalizada. Nós dizíamos "Nós não podemos fazer prevenção só focalizada." Nós temos que, ao mesmo tempo que temos que focalizar, nós temos que ter ações para focalizar, nós temos também que ter ações para quem não está afetado. Tem que fazer prevenção para os soronegativos. Nós temos que ter um foco nisso. E mais, o Banco dizia: "Mas vocês tão investindo muito em tratamento." Falei: "Não. Porque tratamento e prevenção é indissociável." Então, desde essa época, já começa essa discussão de construção desse conceito de vulnerabilidade, de associar esse conceito de vulnerabilidade com conceito de risco. Fazer essa matriz. E ver como você lidava com essa, com essa concepção (Ivo Brito, entrevista).

Também em 1996, foi criado o Programa Conjunto das Nações Unidas sobre HIV/AIDS ${ }^{67}$ (UNAIDS), integrando, além da OMS, outras cinco agências do sistema das Nações Unidas: Banco Mundial, Fundo de População das Nações Unidas (FNUAP), Fundo das Nações Unidas para a Infância (UNICEF), Organização das Nações Unidas para a Educação, Ciência e Cultura (UNESCO) e o Programa das Nações Unidas para o Desenvolvimento (PNUD). Atualmente, o UNAIDS envolve ainda o Alto Comissariado das

\footnotetext{
${ }^{67}$ https://unaids.org.br
} 
Nações Unidas para os Refugiados (ACNUR), Programa Mundial de Alimentos (PMA), Escritório das Nações Unidas sobre Drogas e Crime (UNODC), Entidade das Nações Unidas para a Igualdade de Gênero e o Empoderamento das Mulheres (ONU Mulheres), Organização Internacional do Trabalho (OIT), reunindo os esforços de 11 organizações (Galvão, 2000). A criação do UNAIDS se deu com base em três justificativas explícitas: 1) a crítica formal da liderança da OMS à atuação do GPA; 2) a proposta de maior coordenação entre as agências do sistema das Nações Unidas, particularmente com a intenção de reforçar a autoridade coordenadora dos Conselhos Econômicos e Sociais; e, por fim, 3) a crença de que a criação do UNAIDS seria a melhor forma de articular uma resposta multissetorial que incluísse as iniciativas na área da saúde e os programas que abordassem os determinantes estruturais da epidemia (Merson e cols., 2008)

No final da década, no programa sob o comando de Pedro Chequer e no contexto de elaboração de um projeto para novo acordo de empréstimo - o AIDS II teve vigência de 1999-2000, mas as negociações iniciaram-se em 1997 (Galvão, 2000; Nunn, 2009) começa a se falar de novas tendências da epidemia, tais análises epidemiológicas impactam significativamente as políticas de prevenção até a próxima década.

A partir de 1998, você tem uma mudança. Você tem uma disseminação - não sei se você lembra - da caracterização que vigorava à época, a aids tá interiorizando, a aids tá feminizando, a aids tá juvenizando, a aids não sei o que... Pauperizando. [...] Quer dizer, já havia um pouco antes, dentro do Previna. Porque o Previna deixa de existir aí, a partir de 1998. O Previna vai até, mais ou menos, 1998.

Depois de 1998, você tem uma nova reorientação, já com o Pedro assumindo, a Lair saindo, tem umas mudanças e isso faz com que haja uma primeira, vamos dizer assim, uma primeira abordagem aonde a prevenção, ela passa a ser, ela passa a incorporar o conceito de direitos humanos, passa a trazer... Ela olha a população sobre a perspectiva mais geral. $O$ conceito de vulnerabilidade torna-se mais potente. Começa a se fazer uma discussão mais abrangente com envolvimento do movimento sem terra, movimento de barragem, população negra. Você tem uma difusão maior das articulações com outros segmentos que não apenas movimento aids. A partir de 1998, você amplia as articulações da resposta brasileira com outros segmentos e outros movimentos que não exclusivamente aqueles movimentos que atuam no campo do HIV. Isso que marca 1998, mais ou menos, até... Tô tentando fazer uma periodização que você me pediu (Ivo Brito, entrevista). 
Há um forte consenso entre os gestores entrevistados de que, a partir da década de 1990, se adotou o conceito operativo de vulnerabilidade para orientar o desenvolvimento das políticas de prevenção. Observo, no entanto, que seria importante efetivar análise aprofundada para compreender a forma como tem sido operado o conceito no delineamento e desenvolvimento de tais políticas. Isso é questionado também por Brito, em articulação à necessidade de aprofundar tal debate no campo com o movimento social e com técnicos e gestores - sobre distinções e articulações entre as análises de risco e de vulnerabilidade. Teixeira aponta a dificuldade de sua incorporação ao longo da história, tanto por sua complexidade, como por resistências de setores mais conservadores - como aqueles que motivaram o afastamento de Jonathan Mann do GPA-OMS no início dos anos 1990. Do que se nota nos relatos articulados à caracterização das políticas desse momento, o conceito de vulnerabilidade é identificado como associado à promoção do diálogo, participação e fortalecimento dos movimentos sociais; à incorporação do vocabulário dos direitos; e à abordagem dos determinantes sociais. Percebo, entretanto, a possibilidade - que precisaria ser melhor investigada - de que os determinantes sejam "encarnados" acriticamente em grupos populacionais - de forma que gênero se converta em mulheres; classe em pobreza; idade em juventude - ao invés de guiar o olhar para relações de poder que conformam diferenciações e hierarquias. Assim como se depreende a tendência somente à substituição de termos, dos grupos de risco para os grupos vulneráveis, continuando a conformar identidades.

No que tange às tendências de feminização, pauperização, juvenização, interiorização e heterossexualização da epidemia, os gestores fazem ressalvas e reconhecem alguns equívocos. Por um lado, reconhecem que a ampla disseminação dessas tendências pode ter encoberto a relevância da epidemia entre grupos desproporcionalmente afetados, como os homossexuais masculinos. De outro, também ponderam que, no âmbito dos programas, não se deixou de desenvolver ações focalizadas dirigidas a esse segmento populacional. Como se pode notar no depoimento de Paulo Teixeira:

É um pouco polêmico. Por quê? Porque esse discurso tinha razão e não tinha razão, né? Então, ele tinha razão porque era verdadeiro. Mas não tinha razão porque, de uma certa forma, ele encobria, um pouco, o 
fato de que os homossexuais continuavam sendo os mais atingidos. Ele tinha razão porque, de fato, pipocava em todo Brasil, mas não tinha razão porque continuavam sendo os grandes centros, os mais atingidos. Então, dependia da aproximação que você fazia. Então, eu mesmo quando assumi [a coordenação do programa nacional], em 2000, eu usava esse discurso, mas tentando colocar "Pessoal, quando eu falo interiorização, não quero dizer que a epidemia está se deslocando dos grandes centros para o interior. O que eu quero dizer é que mais de três mil municípios já conhecem os casos de aids. Eles, de fato, acontecem em todo Brasil. Mas, veja, eles estão concentrados nos grandes centros. Eu não estou dizendo que tem mais mulheres do que homens. Mas o que eu quero dizer é que um grande número de mulheres está sendo afetada. Não quero dizer que a transmissão é, principalmente, heterossexual. Não. Os gays são os mais afetados." Entendeu? Então, tinha muita polêmica em torno desse discurso. Então eu usava esse discurso que o Pedro formulou, mas relativizando e não colocando como a verdade que pudesse encobrir esse fato que era os grandes centros urbanos. Mas havia algumas verdades, dependendo de como você analisasse.

\section{Anos 2000}

Buscando garantir maior integração da resposta brasileira à epidemia de aids ao SUS, iniciam-se discussões, desde o final dos anos 1990, visando o fortalecimento da agenda da descentralização no âmbito do programa nacional. O que veio a se efetivar, a partir de 2002, com a portaria 2.313/2002 que instituiu uma política de incentivo financeiro a estados e municípios para o desenvolvimento de ações voltadas a HIV, aids e outras DST, que previa a transferência de recursos federais por meio de mecanismo fundo-a-fundo, ${ }^{68}$ condicionada à qualificação desses sítios a partir da apresentação de um plano de ação e metas (PAM). Nesse processo, o programa nacional transferiu atribuições e recursos financeiros federais para os governos locais (Grangeiro et al., 2010).

Apesar de se configurar em um movimento importante para a sustentabilidade da resposta política à epidemia, essa mudança causou conflitos com os movimentos sociais. Os questionamentos da sociedade civil se deram por dois motivos. Primeiramente, por colocar as organizações não-governamentais em "confronto direto com os dirigentes, os políticos, no âmbito local" (Ivo Brito, entrevista), ficando

\footnotetext{
${ }^{68}$ Transferências diretas de recursos financeiros do Fundo Nacional de Saúde para os Fundos Estaduais e Municipais.
} 
submetidos a maior controle moral. A resistência também se deu pela dificuldade dos governos locais de executar operacionalmente o processo de repasse de recursos para as organizações da sociedade civil.

O que se confirmou em um estudo de caso sobre o efeito da descentralização das transferências para os programas de redução de danos no Rio de Janeiro, no qual se observou redução dos recursos transferidos aos programas e do número de programas financiados (Fonseca et al., 2007). Assim como em estudo exploratório realizado com ONG do Rio Grande do Sul sobre a Política de Incentivo, que indicou redução dos recursos acessados pelas ONG para a realização de ações de prevenção dirigidas aos segmentos populacionais mais afetados pela epidemia (Duarte, 2008).

Em análise efetivada a partir dos dados dos PAM estaduais e municipais do ano de 2006, observou-se que, ainda que a política de incentivo tenha abrangido as regiões que concentram o maior número de casos de aids, a resposta local induzida se mostrou dissociada do perfil da epidemia nacional. Somente um terço dos municípios (31,1\%) e metade dos estados (51,9\%) incluíram as populações prioritárias nas ações de prevenção e de assistência. Considerando-se especificamente os HSH, estes foram incluídos em somente $18,7 \%$ dos planos, representando somente $1,5 \%$ do valor total dos recursos previstos nos mesmos (Grangeiro et al, 2012).

Com isso, ao longo dos anos 2000, como ressaltado por muitos dos entrevistados, observou-se progressiva crise do financiamento das ONG. Além das dificuldades de repasses de recursos financeiros pelos governos locais para as organizações da sociedade civil, como apontado acima, houve também diminuição do financiamento internacional. Essa contração se deu por mudanças nas prioridades de investimento internacional ${ }^{69}$, esteve associada à política conservadora da gestão Bush como será tratado mais adiante -, mas na segunda metade da década também esteve associada tanto às consequências da crise econômica mundial, como pela transformação da posição da economia nacional - impacto das políticas nacionais de redução da desigualdade.

\footnotetext{
69 Segundo Merson (2008), muitos governos europeus ampliaram o financiamento para a prevenção, mas o foco de tais esforços foram os continentes africano e asiático.
} 
Paradoxalmente, um aspecto que também influiu no refluxo de recursos internacionais foi a avaliação positiva das agências internacionais sobre as respostas políticas brasileiras à epidemia, particularmente os resultados da garantia do acesso aos medicamentos antirretrovirais. Aquelas mesmas agências, que a princípio contrapuseram-se a tais políticas, confrontadas com os dados apresentados pelo programa nacional - utilizando-se dos mesmos parâmetros epidemiológicos e econômicos - gradualmente reconhecem seus resultados de redução da mortalidade, da prevalência de doenças oportunistas e das internações, representando economia significativa em assistência à saúde.

A agenda da descentralização e da integração das políticas de aids ao SUS implicava - na esfera da prevenção - além da transferência de recursos e da atribuição da contratação das ONG pelos governos locais, em incorporar ações de prevenção à rotina dos serviços de saúde da atenção básica (Doneda et al., 2002). Isso porque a política de aids no Brasil desenvolveu-se, no âmbito do SUS, por meio de serviços de atenção especializada à saúde, como os centros de referência, os serviços de atenção especializada e os centros de testagem e aconselhamento (Paiva et al., 2006). Tal agenda tornou-se especialmente desafiadora no caso das populações mais afetadas pela epidemia, tradicionalmente estigmatizadas e consideradas de difícil acesso ou invisibilizadas pelos serviços de saúde.

É no bojo desse desafio que se pode compreender a publicação, em 2002, pelo programa nacional - sob a gestão de Paulo Teixeira - do "Guia de Prevenção das DST/Aids e Cidadania para Homossexuais" (Brasil, 2002) com a proposta de "resgatar a experiência acumulada pelos vinte anos de combate à epidemia pelo HIV/aids junto aos gays, lésbicas, travestis e transgêneros" (p. 4) e o objetivo de oferecer subsídios técnicos e conceituais para programas e ações voltadas à saúde sexual, cidadania e prevenção das DST/aids junto a homossexuais.

A leitura epidemiológica que justificou a produção desse guia e corroborou que o segmento populacional de homossexuais e bissexuais era "um dos mais prioritários para a implantação de ações de prevenção das DST/HIV/aids no País" (Brasil, 2002, p. 109), avaliava que a despeito das tendências de crescimento da epidemia "entre os 
jovens, as mulheres, no interior do País e entre pobres" (p.24), esta continuava "estabilizada em patamares elevados entre homossexuais e bissexuais" (p. 24), sendo que, naquele momento, "a probabilidade de um homossexual estar infectado pelo HIV é cerca de 11 vezes maior do que a de um homem heterossexual" (p. 109)

As práticas e discursos preventivos, neste documento, foram tramados em torno dos conceitos operativos de comportamento de risco e vulnerabilidade - com ênfase na vulnerabilidade social. Assim, ressaltava o que foi chamado "empoderamento" descrito como associado ao bem-estar, à autoestima, ao respeito aos direitos de cidadania e ao estar bem na família, trabalho, amor e comunidade - como aspecto que influencia diretamente no uso sistemático do preservativo. Adotava a noção de "intervenção comportamental", salientando o respeito à autonomia diante da orientação sexual das pessoas e de suas práticas sexuais e à livre expressão do afeto e do desejo. A perspectiva da prevenção apresentada no documento é fortemente marcada pela modelagem do comportamento, estando a referência da vulnerabilidade - tal como adotada nesse documento - associada ao respeito à autonomia, à "garantia da segurança e da cidadania das minorias sexuais", ao acesso à informação, ao combate ao estigma e ao preconceito e à promoção da aceitação social e da autoestima. Para isso, orientava o desenvolvimento de um processo de mapeamento e conhecimento acerca da comunidade, de pesquisa comportamental, estabelecimento de parcerias e alianças na comunidade e a realização de oficinas de sexo mais seguro. É digno de nota que apresentava diagrama voltado a informar sobre a hierarquia de risco de infecção pelo HIV segundo os diferentes tipos de práticas sexuais, favorecendo a abordagem das práticas.

O Guia (Brasil, 2002) procurava fornecer repertório acerca da construção social da sexualidade e da homossexualidade, da vulnerabilidade ao HIV/AIDS de homossexuais, das expressões das homossexualidades, de metodologias de intervenção, dos direitos humanos, da articulação entre movimento homossexual e a aids, assim como sobre a história da aids e a história da homossexualidade no Brasil, incluindo informações sobre a declaração universal dos direitos humanos, os direitos fundamentais das pessoas que vivem com HIV/AIDS, os direitos sexuais e contatos de grupos homossexuais em todo o Brasil. Tinha como pretensão a ampliação das ações, 
conformando-se, como diz o nome, em um orientador, técnico e conceitual, para a elaboração de programas e ações por parte dos mais variados atores, tais como:

profissionais das áreas de saúde, de direitos humanos e de assistência social, lideranças homossexuais, agentes de saúde, multiplicadores de informação e todas as pessoas que trabalham na prevenção das DST e aids, em organizações governamentais ou nãogovernamentais (Brasil, 2002, p. 8)

Durante os anos de 2001 e 2002, a ABIA desenvolveu o projeto "Aprimorando o debate: respostas frente à AIDS no Brasil", no qual promoveu uma série de quatro seminários, em diferentes capitais brasileiras, com o objetivo de fomentar o debate entre os diversos atores do campo - ONG, organismos governamentais, universidades, agências internacionais - sobre caminhos e tendências das respostas frente à epidemia nos campos da prevenção, pesquisa, direitos humanos e assistência. No evento voltado à prevenção, teve como tema "Prevenção à AIDS: limites e possibilidades na terceira década". Nele, buscou-se refletir criticamente sobre os marcos conceituais que orientam as ações de prevenção, considerando como um dos dilemas do campo: a pouca teorização que impede a adequada avaliação das ações e os modelos de intervenção muito intuitivos e pouco reflexivos. O contexto de proposição da reflexão era o de viabilizar o financiamento das ações de prevenção no SUS e recolocar o tema na pauta das agências internacionais que avaliavam que a resposta brasileira à epidemia havia atingido "patamares de excelência" (Passarelli, 2002).

As perspectivas críticas no campo da prevenção, procuravam: 1) problematizar conceitualmente a concepção de sujeito - em termos de intersubjetividades e de alteridade - e o caráter das práticas de saúde - como diálogo cuidador orientado pelo sucesso prático - para embasar propostas de prevenção com caráter emancipador (Ayres, 2002); 2) "discutir a necessidade de politizar os espaços psico-educativos $e$ propor a noção de 'emancipação psicossocial'”' (p. 20) como contraponto operacional à vulnerabilidade, contrapondo-se ao modelo de indivíduo pensado como consumidor que deve seguir prescrições preventivas e aprender a usar adequadamente os produtos (camisinha; scripts de sexo seguro; medicação), assim como criticar a ideia de “empoderamento" como “'compensação hidráulica' da autoestima” (Paiva, 2002, p. 24) 
e resultante da vontade individual; 3) questionar as respostas técnicas - e, portanto, predominantemente impessoais, rotinizadas, sem criatividade no enfrentamento de novos desafios e situações, esvaziadas dos conteúdos políticos envolvidos nas questões abordadas, centradas em concepções medicalizadas e biologizadas - na abordagem da prevenção, enfatizando seu caráter político político-pedagógico (Seffner, 2002).

Em consonância com os esforços de descentralização das ações de prevenção e respondendo à percepção de que a epidemia se interiorizava, o programa nacional lançou mão de uma estratégia de fomento à interiorização da cobertura das ações dirigidas aos $\mathrm{HSH}$, por meio do "desenvolvimento institucional e fortalecimento de organizações da sociedade civil, que atuam no campo da luta pela cidadania do público GLT" (Brasil, 2005, p. 5). Trata-se do Projeto Somos, que se iniciou em 1999 - ainda no âmbito da implementação do Aids II (1999-2002) - e chegou a durar até pelo menos $2006^{70}$. Concebido pela ASICAL ${ }^{71}$ e efetivado pela ABGLT, o Somos ${ }^{72}$ tinha como objetivo reduzir a incidência de HIV/Aids e de outras DST entre a população de HSH, por meio do fortalecimento institucional dos grupos que trabalham com esta população. Tinha como linhas de atuação o desenvolvimento organizacional, o advocacy e a intervenção, com vistas à promoção de "mudanças sociais favoráveis aos gays e outros HSH e o combate à Aids" (Brasil, 2005, p. 14).

O projeto Somos começou como um projeto piloto, com duração de três anos, no qual quatro grupos capacitaram outros 24 , abordando os temas de desenvolvimento organizacional e prevenção. Segundo dados apresentados no sítio da $A B G L T^{73}$, o projeto foi considerado relevante para a organização do movimento LGBT em âmbito nacional, corroborando as avaliações de que as políticas de aids favoreceram a institucionalização

\footnotetext{
70 Ver: http://drtonireis.blogspot.com.br/2015/09/um-pouco-da-historia-da-abglt.html e https://www.abglt.org/quem-somos [acesso em 02.05.2018].

${ }^{71}$ Referida anteriormente, a ASICAL é a Associação para a Saúde e Cidadania Integral na América Latina e Caribe (ASICAL) é uma rede regional de grupos e organizações, criada em dezembro de 1997, em Lima, Peru com a missão de constituir-se em uma resposta que promova e desenvolva estratégias e ações de prevenção, atenção e apoio em HIV/Aids e Direitos Humanos com gays e outros homens que fazem sexo com homens (HSH), de modo a contribuir para a melhoria da qualidade de vida na América Latina e no Caribe. Segundo Veriano Terto Jr., em sua entrevista, foi uma iniciativa patrocinada e incentivada por Pedro Chequer, quando Diretor do programa nacional de aids.

${ }^{72}$ Nomeado em homenagem ao grupo Somos-SP, da primeira onda do movimento homossexual no Brasil.

${ }^{73}$ Disponível em: https://www.abglt.org/quem-somos [acesso em02.05.2018].
} 
do movimento LGBT (Facchini, 2005; Simões e Facchini, 2009). Chegou a abranger 270 grupos, presentes em 220 municípios, por meio da atuação de Centros de Capacitação e Assessoria distribuídos nas cinco regiões do país (Norte, Nordeste, Centro-Oeste, Sudeste e Sul). Segundo o Ministério da Saúde, entre 2004 e junho de 2005, o financiamento dessa estratégia mobilizou R\$ 860 mil (Pela Vidda, 2006).

Em 2005, o programa nacional publicou o manual "Projeto Somos Desenvolvimento Organizacional, Advocacy e Intervenção para ONGs que trabalham com GAYS e outros HSH", publicação que sistematizou a experiência da ABGLT no projeto Somos, com o objetivo auxiliar as instituições que trabalham com populações de gays e outros homens que fazem sexo com homens (HSH).

Esse projeto mobilizava o conceito operativo de vulnerabilidade, articulando a ideia de que o "exercício pleno da cidadania" seria "elemento essencial para a prevenção da DST/Aids" (ABGLT, 2003, p. 74); assim como destacou a defesa e a promoção de direitos humanos como recurso para enfrentar a exclusão social, o estigma e a discriminação que contribuem para a vulnerabilidade e reforçam o risco de infecção pelo HIV (Brasil, 2005).

Apesar do referido manual (Brasil, 2005) mencionar que uma definição de vulnerabilidade da OMS referia-se também à "maior possibilidade de sofrer conseqüências desnecessárias da infecção pelo HIV e Aids", toda a ênfase no que se apresenta do projeto é focada na prevenção da infecção pelo HIV. O manual refere que, à medida em que a organização venha a crescer, também poderá abordar o apoio para pessoas vivendo com HIV/aids. Não se dá destaque ao fato de que parcela significativa dos gays vivem com HIV e aids e são discriminados e estigmatizados por isso, inclusive dentro da própria comunidade homossexual - um aspecto que me foi chamado à atenção ao longo das entrevistas, especialmente pelos ativistas.

Houve neste momento - final dos anos 1990 e início dos anos 2000 - no programa nacional, o Comitê Assessor para Ações de Prevenção das DST/Aids junto aos Homens que Fazem Sexo com Homens ${ }^{74}$, e no programa estadual, o Fórum de

\footnotetext{
${ }^{74}$ A existência deste Comitê foi mencionada por Beto de Jesus em sua entrevista. Depois disso, confirmei esta informação com Denise Serafim, técnica aposentada do MS que trabalhou no programa
} 
Organizações com Trabalhos de Prevenção das DST/Aids para Homens que Fazem Sexo com Homens do Estado de São Paulo (Fórum HSH/SP). Há registro sobre esse último no "Guia de Prevenção das DST/Aids e Cidadania para Homossexuais" (Brasil, 2002), na seção sobre o movimento homossexual e a aids, na qual foi caracterizado como uma iniciativa pioneira cuja experiência estava sendo replicada em outros estados. Criado em 1999, o Fórum HSH/SP reunia instâncias governamentais locais, grupos e ONG homossexuais e do movimento de aids e constituiu-se em espaço de discussão e de deliberação para questões relacionadas à homossexualidade e à prevenção das DST/HIV/aids. A lembrança desses espaços institucionais e de sua produção mobilizou a avaliação de Beto de Jesus, em entrevista, de que "já fomos melhores do que nós somos". Foi nestes espaços institucionais que foram produzidos campanhas e materiais educativos dirigidos a diferentes públicos segmentados e contextos para abordar a prevenção entre gays, alguns deles muitíssimo ousados para os dias de hoje - mais de 15 anos depois.

Há registros na área dedicada às campanhas do programa nacional em seu website da realização de uma campanha voltada aos HSH que envolveu diferentes ações articuladas e materiais informativos no ano de 2002. Chama a atenção - especialmente retrospectivamente, observando o contexto atual das chamadas "guerras culturais" e “onda de conservadorismo" - que entre 2001 e 2002, o programa nacional, à época sob a gestão de Paulo Teixeira, no governo de Fernando Henrique Cardoso, tendo como ministros da saúde José Serra ${ }^{75}$ e Barjas Negri, tenha produzido uma sequência de

nacional desde 1989. Segundo ela, em 1989, haviam dois comitês assessores - um dirigido a prostitutas e outro a gays - que se reuniam para discutir estratégias: campanhas, projetos, organização social. Pouco depois, ela referiu ter havido desmobilização das ONG e, com isso, ter ficado um longo período sem reuniões. Os comitês foram reativados, em torno de 1999, na época em que Rose Munhoz coordenou o setor de Prevenção do programa. Identifiquei também que em uma publicação do Projeto Somos há menção de que Marcelo Nascimento, do Grupo Gay de Alagoas e presidente da ABGLT à época, era membro do referido Comitê. Consultado, Veriano Terto Jr. referiu ter havido um número imenso de Comitês e GT na história do programa, o que dificultava sua lembrança.

\footnotetext{
75 José Serra esteve na gestão do Ministério da Saúde de 31 de março de 1998 a 20 de fevereiro de 2002, tendo sido substituído por Barjas Negri, quando saiu para candidatar-se à Presidência da República, nas eleições presidenciais de 2002, pelo PSDB. Em sua atuação à frente do MS, fez grande propaganda dizendo-se responsável pela criação do bem-sucedido programa brasileiro de aids beneficiando-se dos resultados positivos da adoção em 1996 dos medicamentos antirretrovirais - e da iniciativa dos medicamentos genéricos (Figueiredo e Coutinho, 2003). Disponível em:

https://pt.wikipedia.org/wiki/Lista de ministros da Saúde do Brasil https://www.folhadelondrina.com.br/politica/serra-deixa-ministerio-da-saude-no-dia-20-381174.html
} 
campanhas abordando alguns dos grupos populacionais mais afetados pela epidemia e mais fortemente estigmatizados: travestis $^{76}$ (em agosto de 2001); profissionais do sexo ${ }^{77}$ (em março de 2002); gays e $\mathrm{HSH}^{78}$ (em junho de 2002); preconceito contra as pessoas vivendo com HIV e aids ${ }^{79}$ (dezembro de 2002).

A campanha para os HSH tinha como objetivo incentivar o uso do preservativo e diminuir o preconceito e a discriminação relacionados "às diferenças sexuais". O texto de descrição e justificativa da campanha articula: 1) a posição de grupos de homossexuais e de pesquisadores de que o preconceito e a discriminação dificultam o acesso à informação; 2) dados de um estudo do Ministério da Saúde que aponta o risco acrescido em onze vezes de que um homossexual contraia o HIV comparativamente aos homens que tem relações sexuais somente com mulheres; e 3) dados da ABIA e do MS que mostram crescimento no número de casos de aids entre homo e bissexuais; 4) além de uma explanação sobre as diferentes ações da campanha. Diferentemente da maioria das demais campanhas divulgadas no website, consta na página um ofício circular do coordenador do programa com informações técnicas que justificam a campanha, as linhas estratégicas adotadas, os materiais informativos produzidos e o reforço à participação das diferentes instâncias governamentais e não-governamentais em sua realização. Havia, ainda, uma ressalva informando sobre atraso na distribuição e adaptações nos materiais em função do período eleitoral. Segundo este ofício:

[...] o Ministério desenvolveu a campanha nacional de informação em três linhas estratégicas: (i) aumento da auto-estima e redução do preconceito, a partir da promoção da aceitação das diferenças

\footnotetext{
https://eleicoes.uol.com.br/2010/pre-candidatos/conheca-a-trajetoria-de-jose-serra-pre-candidato-apresidencia-pelo-psdb.jhtm https://jornalggn.com.br/blog/luisnassif/serra-admite-nao-ser-pai-dos-genericos [acesso em 02.05.18].

${ }^{76}$ Com produção de cartazes, cartilha para travestis e transgêneros, folders para educadores e para profissionais de saúde. Disponível em: http://www.aids.gov.br/pt-br/campanha/campanha-travestis2002 [acesso: 02.05.18].

${ }^{77}$ Com produção de folder, cartilha para profissionais do sexo, manual para profissionais de saúde, adesivos para banheiros, bottons e spot de rádio. Disponível em: http://www.aids.gov.br/ptbr/campanha/campanha-profissionais-do-sexo-sem-vergonha-garota-voce-tem-profissao-2002 [acesso em 02.05.18].

${ }^{78}$ Descrita a seguir, no corpo do texto. Disponível em: http://www.aids.gov.br/ptbr/campanha/campanha-homens-que-fazem-sexo-com-homens-hsh-2002 [acesso em 02.05.18].

${ }^{79}$ Com produção de cartaz, folder para profissionais de saúde e filme para TV. Disponível em: http://www.aids.gov.br/pt-br/campanha/campanha-do-dia-mundial-aids-o-preconceito-tem-cura-2002 [acesso em 02.05.18].
} 
por meio de campanha de mídia massiva; (ii) promoção do uso do preservativo e do gel lubrificante nas relações sexuais com estímulo da responsabilidade individual, por meio da disponibilização de materiais informativos específicos que possam subsidiar intervenções educativas diretas com o público-alvo e, (iii) aceitação das diferenças e acolhimento humanizado, além do estímulo ao aconselhamento para uso do preservativo e ao diagnóstico precoce do HIV, a partir da sensibilização de profissionais de saúde e de educação.

Essas linhas de ação originaram diferentes tipos de materiais informativos, a saber: peça para TV dirigida para a população em geral (Respeitar as diferenças é tão importante quanto usar camisinha); peça para cinema (Fantasia); anúncio em revistas de grande circulação ("Use camisinha com seu namorado" também é uma conversa de pai para filho); cartazes, folderes e filme educativo para profissionais da educação; cartazes e folderes para profissionais de saúde; filme para estabelecimentos comerciais freqüentados por homossexuais (Exibicionista); cartazes e filipetas para homossexuais. Esses materiais informativos foram distribuídos pelo Programa Brasileiro de DST e Aids às organizações não-governamentais, às universidades, aos Programas Estaduais e Municipais de DST e Aids e às Secretarias de Educação e Saúde, visando tanto sua divulgação como subsidiar ações educativas locais no âmbito da prevenção das DST/Aids.

Parte dos materiais adotados na campanha haviam sido produzidos no âmbito da ação articulada do programa estadual de São Paulo com o Fórum HSH, tais como o filme intitulado "Exibicionista" - produzido para salas de cinema de pegação frequentadas por homossexuais - e um filme para cinema voltado à chamada população geral nomeado "Fantasias". Estes dois filmes não estão disponibilizados no website e não consegui localizá-los. O filme "Exibicionista" - relembrado por Beto de Jesus e também descrito em entrevistas feitas por Thiago Pinheiro (2015) - aborda uma cena de "banheirão", termo êmico usado para caracterizar situações de sexo anônimo em banheiros públicos. O folder distribuído em espaços de sociabilidade homossexual foi intitulado "darkroom" e foi minuciado por Cristiane Gonçalves - em entrevista a Thiago Pinheiro (2015) -uma das técnicas responsáveis pela produção desses materiais nas áreas de prevenção dos programas, inicialmente, no estadual e, posteriormente, no nacional:

A gente fez uma campanha super explícita, que era um folderzinho com um monte de meninos de pau duro, em situações [de sexo] ou no darkroom ou no parque ou na sauna, que eram esses lugares de encontro rápido. E a gente já sabia que, em algumas condições, especialmente parque e darkroom, é difícil botar o preservativo, pelas próprias condições aí do ambiente. Então, a gente focou essa campanha 
pra esses lugares. (...) E foi uma campanha ótima. Fez um baita sucesso porque era especificamente voltada pra isso. Quem ia fazer campo em boate, quem ia fazer campo nesses lugares, tinha um material que dialogava diretamente com a população. Eram homens bonitos e diferentes. Teve todo um processo de seleção, de colocar bonitos, mas não necessariamente no padrão, naquele padrão estético e tal. Foi bem legal essa campanha. E eu gostei muito do resultado ${ }^{80}$ (Cristiane Gonçalves, entrevista).

Estes materiais educativos são tidos por Beto de Jesus, nos dias de hoje, como inconcebíveis, em função do que ele descreveu como a experiência de "pânico moral" que vivemos nos dias de hoje.

Integrou, ainda, a referida campanha o vídeo educativo "Pra que time ele joga" distribuído para escolas para ser apresentado para adolescentes. Esse vídeo foi produzido, entre 2001 e 2002, também na parceria do Fórum HSH com o programa estadual com o objetivo de abordar o tema da homofobia nos ambientes escolares. Foi utilizado no estado de São Paulo, na parceria com o programa "Prevenção também se ensina", da Fundação para o Desenvolvimento da Educação (FDE), vinculada à Secretaria de Estado da Educação, tendo sido distribuído a escolas estaduais. Posteriormente, foi reproduzido pelo programa nacional ${ }^{81}$ para ser distribuído aos programas estaduais e municipais de DST e Aids, a organizações de encontros e, sob demanda, a escolas (Brasil, 2007). Está, ainda, disponível no YouTube 82 e é abordado em plano de aula disponibilizado do Portal do Professor do Ministério da Educação ${ }^{83}$. O filme aborda a homossexualidade a partir da história de Pedro, um adolescente, tratando das relações do jovem com seus colegas, seus questionamentos, as reações e questionamentos de seus colegas, o acolhimento por parte dos professores e dos pais. Em meio à trama da história, a partir da expressão de preconceitos, o filme aborda informações sobre aids e sobre diferentes expressões da sexualidade.

\footnotetext{
80 "O folder intitulado 'darkroom', referido nos [...] depoimentos, carrega as logomarcas do Projeto Bela Vista e do Fórum de ONGs \& OGs DST/AIDS - HsH de SP" (Pinheiro, 2015, p. 128).

${ }^{81}$ Segundo informações do Ministério da Educação (MEC), o MS reproduziu o vídeo também em espanhol, para ser divulgado na América Latina (Brasil, 2007).

${ }^{82}$ Disponível em: https://www.youtube.com/watch?v=3qUaurijFOY [acesso em 02.05.18].

${ }^{83}$ Disponível em: http://portaldoprofessor.mec.gov.br/fichaTecnicaAula.html?aula=12723 [acesso em 02.05.18].
} 
Entre os entrevistados, há a lembrança de um dos vídeos da referida campanha intitulado "Campainha" ${ }^{84}$, reconhecida como uma conquista. Ivo Brito lembrou-se também de seu veto pelo Conselho Nacional de Autorregulamentação Publicitária ${ }^{85}$ (CONAR). Este vídeo foi desenvolvido como filme publicitário e foi exibido em televisão aberta pelo período contratado pelo programa nacional. Atualmente, consta da página em que são apresentadas as campanhas do programa nacional em seu website, mas nomeado como "sem título". O vídeo inicia-se com cenas cotidianas de uma família em sua casa - o pai lê na sala, a filha adolescente estuda na mesa de jantar - quando toca a campainha, a mãe entra na sala e avisa: "É ele". O pai levanta-se, atende à porta onde está um rapaz que diz: "Oi, eu preciso falar...", ao que é interrompido pelo pai que afirma: "Ele não quer falar com você", pedindo ao rapaz para não insistir. Ao fechar a porta, o pai vai ao quarto, o filho pergunta se ele foi embora, o pai confirma e sai. No quarto, a mãe diz ao filho: "Filho, você vai encontrar um rapaz que te mereça", e o narrador encerra dizendo: "Usar camisinha é tão importante quanto respeitar as diferenças".

À despeito da ingenuidade da situação retratada e da ausência de qualquer conteúdo de caráter erótico, o CONAR afirma ter recebido duas denúncias de consumidores que motivaram sua análise pelo Conselho de Ética da instituição. O relator deste processo foi o médico Pedro Kassab, que foi presidente e uma das principais lideranças da Associação Médica Brasileira ${ }^{86}$ (AMB) - sendo caracterizado, em históricos da Reforma Sanitária, como fortemente liberal e conservador. As denúncias feitas por

\footnotetext{
${ }^{84}$ Disponível em:

http://www.aids.gov.br/sites/default/files/campanhas/2002/38288/filme sem marca1.wmv [acesso em 02.05.18].

85 O Conselho Nacional de Autorregulamentação Publicitária (CONAR) é uma ONG que se atribuiu a responsabilidade de assegurar o cumprimento do Código Brasileiro de Autorregulamentação Publicitária. Foi fundada em 1980 e formada por profissionais e entidades do setor publicitário e seus associados - anunciantes, agências e veículos de comunicação. Disponível em: http://www.conar.org.br [acesso em: 27.12.17].

${ }^{86}$ Nos históricos da Reforma Sanitária brasileira, a AMB é reconhecida como das instituições mais conservadoras e liberais da categoria médica. Formada, em 1952, com a finalidade de contrapor-se à organização da categoria médica por melhores salários, teve Pedro Kassab como uma de suas principais lideranças. O grupo liderado por Kassab, dirigiu a entidade desde sua fundação até 1981, quando depois de uma eleição fraudulenta em 1979 - foi derrotado por uma chapa vinculada ao Movimento de Renovação Médica (REME).Qual eleição foi fraudulenta?! Sendo o REME - baseado no ideário da crítica à "prática médica principalmente da perspectiva das classes populares, discutindo o direito à atenção médica, a socialização" (Campos, 1987 apud Escorel, 1999, p. 99) - um dos atores importantes do Movimento da Reforma Sanitária (Escorel, 1999).
} 
dois consumidores mobilizam ideias de que o filme publicitário do MS: contradiz os preceitos morais da família; denigre o ser humano; estimula o homossexualismo; não deveria ser visto nunca por um filho/criança, cuja educação deve ser cuidada pela família exclusivamente; degrada a ordem natural das coisas; e ofende pessoas de bem. 0 parecer do relator aborda, como produto, a ideia que o anúncio transmite e, como consumidor, toda a população, criticando-a por não ter se dirigido a um público específico. Utilizando-se dos termos adotados no filme - diferença e respeito -, o relator aborda a homossexualidade como diferença e expressa percepção de que o filme se configura em desrespeito, ataque e choque, pois deformaria a família ao expressar naturalidade, trivialidade, acolhimento e esperança "como se diferença não existisse", de forma a "delinear essa plena indiferença em relação à diferença". Retratado como uma intromissão perturbadora "da maneira de tratar a questão da homossexualidade" - o que seria prerrogativa da família - o anúncio é qualificado como um "jus sperneandi"87 - demanda não-legítima - não merecedor do apoio do referido relator. Ao final do parecer, ainda, o relator mobiliza novamente o imperativo da proteção às crianças e aos adolescentes diante desse assunto, evocando a associação entre homossexualidade e pedofilia (CONAR, 2002). O que se articula ao que Sérgio Carrara (2016) tem descrito como novo dispositivo da sexualidade. Dialogando mais especificamente com o tema deste estudo, o parecer - ao processo intitulado como "RESPEITABILIDADE", nos acórdãos do CONAR - recomenda a suspensão do vídeo da primeira propaganda de prevenção de aids dirigida aos homossexuais - depois de 20 anos de epidemia - e expressa sua discordância da perspectiva de prevenção adotada, neste momento, pelo Ministério da Saúde:

Ninguém, em bom juízo, é contrário à prevenção, nessas e em outras situações, mas encarar homossexualismo como banalidade e introduzir a imagem de solidariedade e aconselhamento quase lírico e esperançoso de futuro romance homossexual, da mãe ao filho, podem contribuir para que se originem numerosos problemas, o que não seria preciso ocorrer para se fazer a profilaxia (CONAR, 2002).

\footnotetext{
${ }^{87}$ Expressão coloquial utilizada no meio jurídico caracterizada como um "falso latinismo" jocoso que "alude ao espernear de uma criança inconformada com uma ordem dos pais". Disponível em: https://stj.jusbrasil.com.br/noticias/112358771/jus-sperniandi-quando-o-inconformismo-natural-setorna-abuso-do-direito-de-recorrer [acesso: 27.12.18].
} 
Segundo consta, o Ministério da Saúde não se manifestou sobre o referido parecer e a suspensão da sua exibição. O que também só veio a se tornar público por iniciativa, anos depois, do Grupo Pela Vidda/SP, que solicitou cópias de campanhas do programa nacional para exibi-las em seu evento Cinema Mostra Aids e foi informado sobre a suspensão. Tendo, a partir daí, buscado se informar e divulgado amplamente a proibição, assim como solicitou a revisão do parecer ao CONAR, tal como outras ONG (Pela Vidda, 2006, p. 20-1).

A partir de 2005, organizações vinculadas aos movimentos de aids e homossexual começaram a apontar tendências ao recrudescimento da epidemia de HIV e aids entre gays, outros HSH e travestis. Foram organizados documentos ${ }^{88}$, seminários $^{89}$ e publicações, entre 2005 e 2007, para expressar tal preocupação e demandar políticas mais estruturantes no campo da saúde (Pecoraro, 2006; Pela Vidda, 2006; Pela Vidda \& ABIA, 2007).

Entre essas iniciativas, estiveram um número especial dos Cadernos Pela Vidda intitulado Homossexuais e Aids, a epidemia negligenciada (Pela Vidda, 2006) e o seminário Homossexualidade Masculina e HIV/AIDS: 25 anos de Epidemia, promovido pela $A B I A$, o Grupo de Incentivo à Vida (GIV) e o grupo Lutando Pela Vida de Diadema, que pretendia refletir sobre as articulações entre homossexualidade masculina e a soropositividade para o HIV, para fortalecer as respostas para o enfrentamento da epidemia.

Uma estratégia mobilizada pelo movimento social de aids para questionar o discurso oficial sobre a epidemia de aids entre homossexuais se deu pela apropriação e

\footnotetext{
${ }^{88}$ Cadernos Pela Vidda (Pela Vidda, 2006) reproduziu documento divulgado, em 2005, pelo programa nacional em resposta às críticas das ONG de que a resposta governamental à epidemia de aids entre homossexuais era deficiente.

${ }^{89}$ Em abril de 2006, o Projeto Somos realizou o Seminário Intervenção, Promoção e Educação em Saúde, no qual foram discutidos os rumos das intervenções preventivas às DST, HIV e aids dirigidas a gays, lésbicas, transgêneros e bissexuais (Pela Vidda, 2006, p. 7; http://www.ggb.org.br/somos 2006.htm [acesso em: 02.05.18]). Em junho do mesmo ano, ocorreu o seminário Homossexualidade Masculina e HIV/AIDS: 25 anos de Epidemia, promovido pela ABIA, o Grupo de Incentivo à Vida (GIV) e o grupo Lutando Pela Vida de Diadema, com o objetivo de avaliar o impacto da aids entre os homossexuais no Brasil (Pecoraro, 2006). Em maio de 2007, parceria entre o Grupo Pela Vidda-SP e a ABIA organizou o seminário Homossexuais e Aids no Brasil: esquecer ou enfrentar? (disponível em: http://abiaids.org.br/pela-vidasp-e-abia-divulgam-propostas-para-enfrentar-a-epidemina-da-aids-entrehomossexuais/26408 Acesso em: 13.06.2017].
} 
a crítica do conhecimento e do instrumental da epidemiologia da aids e da saúde pública. Assim, os Cadernos Pela Vidda (Pela Vidda, 2006) apresentaram um artigo de balanço da situação da epidemia e das respostas preventivas no Brasil, bem como uma revisão de estudos internacionais que indicavam crescimento da epidemia entre homossexuais no mundo e fragilização dos esforços preventivos. Com isso, procuravam alertar para o recrudescimento da epidemia entre gays e outros HSH. Apresentavam, ainda, uma perspectiva crítica sobre a leitura epidemiológica da epidemia de HIV/Aids ao apontar a existência de vidas humanas por trás dos "frios dados estatísticos". Aprofundando a estratégia de apropriação das metodologias de análises epidemiológicas utilizadas pelo programa nacional, Jorge Beloqui (2006) - pesquisador e ativista do movimento de aids - efetuou análise em que demonstrou a desproporção do risco relativo para aids entre homens homossexuais quando comparados com homens heterossexuais, que se tornou uma apresentação nesse seminário, um artigo na edição especial do Cadernos Pela Vidda e, posteriormente, uma publicação científica ${ }^{90}$.

Buscando explicitar a necessidade de reformulação da política, de forma a assegurar aos chamados HSH a devida prioridade nas respostas à epidemia, as propostas do seminário organizado pelo Pela Vidda-SP e a ABIA indicavam que o financiamento para ações e políticas de prevenção voltadas ao grupo deveria ser proporcional à sua participação na epidemia - considerando a alta incidência de casos de infecção por HIV, aids e outras DST entre os HSH. Recomendavam, ainda, a necessidade de novos modelos de vigilância epidemiológica (Pela Vidda \& ABIA, 2007).

No bojo dessas críticas, há algumas constatações críticas às políticas de aids em desenvolvimento naquele momento: 1) as análises epidemiológicas induziam à uma "desomossexualização" da aids: se contribuíram em reverter a noção de "grupos de risco" e a estigmatização associada, acabavam por colocar os homossexuais em segundo plano das políticas de prevenção; 2) o redirecionamento das políticas de prevenção induzido por tais análises, contribuiu para distanciar as ONG que prestam serviços em aids dos projetos voltados aos gays; 3) a ênfase atribuída, no âmbito das

\footnotetext{
${ }^{90}$ Essa análise foi publicada em um artigo na Revista de Saúde Pública (Beloqui, 2008).
} 
políticas de prevenção, à luta contra a homofobia, à ações de visibilidade e à defesa dos direitos humanos - por mais que se mostrassem relevantes e bem-sucedidas - não se constituíam, sozinhas, como uma política de saúde pública de prevenção em HIV/Aids; 4) a política de prevenção centrada, exclusiva ou predominantemente, na execução pelas ONG, além de insuficiente, demonstrava descompromisso, ausência de competência técnica e de vontade política por parte das instâncias governamentais, particularmente de estados e municípios, na efetivação de programas de prevenção para gays (Pela Vidda, 2006).

Pode-se identificar nesse tensionamento, o paradoxo transformador das políticas de prevenção nos anos 2000, que contrapõe políticas de prevenção focada nos direitos e na visibilidade social à especificidade de uma política de prevenção ancorada e estruturante das políticas de saúde.

Num primeiro momento ${ }^{91}$, o programa nacional defendeu sua perspectiva das políticas de prevenção, explicitando suas principais diretrizes: descentralização das políticas de prevenção no SUS e mobilização dos gestores locais; financiamento das paradas do orgulho LGBT e fortalecimento institucional do movimento LGBT, para promover visibilidade e empoderamento; apoio às respostas da sociedade civil, como o financiamento de eventos e projetos; fomento a pesquisas; apoio ao programa Brasil sem Homofobia ${ }^{92}$ (Pela Vidda, 2006, p. 22-5). Posteriormente, foi iniciado um processo de negociações e articulações junto ao movimento social, do qual já fez parte a realização do seminário "Homossexuais e Aids no Brasil: esquecer ou enfrentar?", organizado em parceria pelo Grupo Pela Vidda-SP e pela ABIA, em 2007, com financiamento do programa nacional. Nesse evento, os participantes elaboraram um documento de propostas com vistas à "revisão da agenda governamental de prevenção em HIV/Aids para homossexuais" e o "aprimoramento das ações de prevenção" (Pela Vidda \& ABIA, 2007)

\footnotetext{
${ }^{91}$ Disponível em: http://www.giv.org.br/Not\%C3\%ADcias/noticia.php?codigo=1408 [acesso em: 22.03.17]

92 O programa "Brasil Sem Homofobia: programa de combate à violência e à discriminação contra GLTB e promoção da cidadania homossexual" foi uma iniciativa importante, instituída em 2004, pelo Conselho Nacional de Combate à Discriminação vinculado à Secretaria Especial dos Direitos Humanos (SEDH) (Brasil, 2004).
} 
Como resultado de tais demandas e do processo mobilizado por elas, foi elaborado, em 2007, o Plano Nacional de Enfrentamento da Epidemia de Aids e DST entre Gays, outros Homens que fazem Sexo com Homens (HSH) e Travestis $^{93}$ (Brasil, 2007) com propostas de metas e atividades para serem desenvolvidas no período de 2007 a 2011 e a indicação de que estados e municípios deveriam desenvolver planos congêneres. No entendimento de Ivo Brito - à época coordenador da área de prevenção do programa nacional -, esta foi uma iniciativa inovadora na gestão das políticas de prevenção. Era a primeira vez que se estabelecia uma proposta com uma perspectiva mais estruturante - como era cobrado pelo movimento social - envolvendo a sociedade civil no seu delineamento. O Plano se pretendia transversal e buscava se articular a outras políticas públicas do governo federal - que naquele momento, sob a gestão de Luiz Inácio Lula da Silva, implantava e fortalecia as políticas de equidade -, amparandose ao programa Brasil sem Homofobia.

Considerando análises que tratam de mudanças nas formas de participação socioestatal entre as gestões de Fernando Henrique Cardoso (PSDB) - caracterizada pela colaboração com a sociedade civil - e de Luiz Inácio Lula da Silva (PT) - descrita como de participação -, pode-se aventar a hipótese de que tenha se constituído, na construção do Plano de Enfrentamento, uma experiência mais participativa. Um aspecto, no entanto, deve ser levado em consideração: as articulações entre o movimento LGBT e as instâncias governamentais - que se iniciaram com as políticas de aids - intensificaram-se fortemente ao longo dos anos 2000, especialmente durante as gestões petistas (Bulgarelli, 2017). Com isso, como destacou Ivo Brito em entrevista, o lócus privilegiado de interlocução, atuação e mobilização política do movimento LGBT, no âmbito das relações com o governo federal, deixou de ser o programa de aids. No Ministério da Saúde, a instância responsável pelas políticas de equidade era a Secretaria de Gestão Estratégica e Participativa (SGEP), mas estas relações ampliaram-se, especialmente para a relação com Secretaria de Direitos Humanos da Presidência, criada em 2003, onde foi elaborado o programa Brasil sem Homofobia, e com o Ministério da

\footnotetext{
${ }^{93} \mathrm{Na}$ gestão de Mariângela Simão como diretora do programa de aids.
} 
Educação, por meio da Secretaria de Educação Continuada, Alfabetização, Diversidade e Inclusão (Secadi).

Esperava-se, inicialmente, que ao final do período de sua vigência, o plano fosse avaliado e renovado, assegurando seu caráter estruturante como política pública. Sua avaliação, no entanto, se deu já com a perspectiva do seu encerramento, segundo Brito (em entrevista), tanto por mudanças no âmbito da gestão das políticas de aids no país, como pelo entendimento de que no contexto da implantação, a partir de 2011, da Política Nacional de Saúde Integral de Lésbicas, Gays, Bissexuais, Travestis e Transexuais (Brasil, 2012), a política de prevenção do HIV e da aids estaria subsumida e assegurada. As políticas de cunho mais abrangente, no entanto, como o Programa Brasil sem Homofobia (Brasil, 2004) e a Política de Saúde Integral da População LGBT (Brasil, 2012), não mencionam dados acerca da epidemia de HIV e aids, nem fazem referência à prevenção do HIV.

Na percepção de ativistas, como Veriano Terto Jr., no entanto, o Plano nunca chegou a funcionar efetivamente, pois foi pouco incorporado pelas gestões locais estaduais e municipais. Lembra-se de algumas experiências interessantes nesse marco em alguns governos locais, mas foram poucas e pontuais. Entende, assim, que a articulação aids-homossexualidade ficou progressivamente restrita, configurando-se como um problema das ONG - especialmente das ONG/aids -, de algumas gestões do programa nacional e de um ou outro governo local, predominantemente no início dos anos 2000.

Como a aids se comporta como uma pandemia, as interfaces do programa brasileiro com o cenário internacional são grandes e se intensificaram fortemente entre o final dos anos 1990 e os anos 2000. Configurando-se como um tema importante na agenda do desenvolvimento, foi pauta, no ano 2000, de um debate no Conselho de Segurança ${ }^{94}$ da ONU, acerca de suas implicações no âmbito da paz e segurança - tendo sido a primeira vez que uma questão de saúde foi discutida em sua agenda (Merson, 2008). Em 2001, foi realizada Sessão Especial da Assembleia Geral da ONU sobre

\footnotetext{
${ }^{94}$ Para ver mais: UN Security Council. Security Council Resolution 1308 (2000) on the responsibility of the Security Council in the maintenance of international peace and security: HIV/AIDS and international peacekeeping operations. July 17, 2000.
} 
HIV/AIDS (UNGASS), convocada por seu secretário-geral à época, Kofi Annan, na qual foi firmada uma declaração de compromisso ${ }^{95}$ com o estabelecimento de metas para os países afetados e de níveis de financiamento para os países doadores, articulando os governos de 189 países, incluindo o Brasil (Grangeiro et el., 2006).

Conforme informam Alexandre Grangeiro e colaboradores (2006) a Declaração é produto de um acordo internacional que estabelece princípios essenciais para uma resposta efetiva, tornando-se instrumental para reafirmar a urgência e a necessidade de resposta à pandemia. Ela é constituída em onze capítulos $^{96}$ nos quais se integram compromissos e metas nacionais, regionais e globais. Sua proposição previu, originalmente, a realização de avaliações nos anos de 2003, 2005 e 2010. A primeira avaliação teve muitas limitações em relação à qualidade das informações e à participação da comunidade, o que dificultou a análise dos progressos. Foram sendo gradualmente estabelecidos parâmetros e indicadores para comparação e análise. No Brasil, houve processo intenso de participação da comunidade pelo menos de 2003 a 2010. Posteriormente a 2010, foi estabelecido um relatório de acompanhamento anual da resposta do país. Em sua entrevista, Ivo Brito aponta a importância desse material para futuras análises, especialmente significativos quando cotejados com os relatórios produzidos pela sociedade civil organizada ${ }^{97}$.

\footnotetext{
${ }^{95}$ UN General Assembly. Declaration of commitment on HIV/AIDS and political declaration on HIV/AIDS: focus on progress over the past 12 months. United Nations General Assembly Special Session on HIV/AIDS; June 25-27, 2001.

${ }^{96}$ Liderança; prevenção; cuidados, apoio e tratamento; o HIV/Aids e os direitos humanos; reduzir a vulnerabilidade; as crianças órfãs e as que se encontram em situação vulnerável por causa do HIV/Aids; atenuar o impacto social e econômico; investigação e desenvolvimento; o HIV/Aids nas regiões afetadas por conflitos e catástrofes naturais; recursos; e atividades de seguimento.

97 Grangeiro e colaboradores (2006) informam que, em 2003, por ocasião da primeira avaliação das metas da UNGASS, a ONG Gestos, de Pernambuco e o Fórum de ONG/Aids de São Paulo organizaram o "I Fórum UNGASS Brasil", que se configurou como a instância formal do movimento social para discutir e acompanhar o cumprimento dos compromissos assumidos pelo país ao firmar a Declaração. $\mathrm{O}$ artigo é também assinado por Alessandra Nilo, da Gestos e integrante do Fórum, e descreve as atividades desenvolvidas por este Fórum até aquele momento, explicitando que sua própria publicação se articulava a uma iniciativa da qual o Fórum foi parceiro. Por orientação de Ivo Brito, fiz contato com Alessandra Nilo (da ONG Gestos/PE), e solicitei os relatórios produzidos pela sociedade civil como contraponto aos relatórios de país e fui informada de que já há algum tempo os "shadow reports" não têm sido produzidos. De qualquer forma, ela não conseguiu localizar os que haviam sido elaborados para que eu os pudesse conhecer.
} 
Para os objetivos desta tese, há alguns pontos a destacar sobre a Declaração de Compromisso que nos falam sobre os saberes e conceitos que orientam o desenvolvimento das ações e políticas de prevenção, assim como sobre o horizonte normativo que contextualiza a resposta à epidemia nesse momento. Como em todos os documentos que analisei do UNAIDS, é possível identificar explicitamente a referência aos dois conceitos operativos no campo da prevenção: risco e vulnerabilidade. Consonante com isso, a meta $52^{98}$ do capítulo sobre prevenção - que se refere à garantia da existência de um vasto conjunto de programas de prevenção que levem em consideração aspectos variados das culturais locais - expressa como contraponto à redução dos comportamentos de risco, o incentivo aos comportamentos sexuais responsáveis.

Em editorial do American Journal of Public Health, publicado em março de 2002, sobre a Declaração de Compromisso, Sofia Gruskin ${ }^{99}$ questionava se as lições dos últimos vinte anos haviam sido ignoradas pelas Nações Unidas. A autora aponta no pequeno editorial alguns dos problemas da Declaração. O mais central deles para o tema que mobiliza minha investigação é o fato de que não constam menções aos HSH, nem aos trabalhadores sexuais da declaração final da UNGASS sobre HIV/Aids; o que foi apontado por Gruskin como uma omissão que poderia prejudicar a participação desses grupos como atores plenos nas respostas ao HIV e à Aids. Também indica ter havido um retrocesso na forma como os direitos humanos foram abordados, ao torná-los um componente separado da resposta, ao invés de ser integrado a ela. O que abriu espaço para o que é percebido por Ivo Brito, mais recentemente, como eclipse dos direitos humanos, na forma como têm sido progressivamente abordados nos relatórios de progresso, com ênfase exclusiva às dimensões do estigma e da discriminação. A abordagem dos direitos humanos na Declaração, foca-se exclusivamente nas estruturas legais, excluindo outras ferramentas e mecanismos, e em especial, segundo Gruskin,

\footnotetext{
98 O documento da Declaração de Compromisso tem seus parágrafos numerados, sendo que o capítulo dedicado à prevenção é composto por oito metas, correspondentes aos parágrafos de número 47 a 54 . ${ }^{99}$ Sofia Gruskin é advogada e uma das principais parceiras de Jonathan Mann na proposição das interfaces entre saúde e direitos humanos. Juntamente com Daniel Tarantola veio ao Brasil em 1997 no primeiro curso que organizamos sobre Vulnerabilidade, tendo, depois disso, estabelecido parcerias com vários pesquisadores brasileiros, inclusive com nosso grupo no Departamento de Medicina Preventiva, da Faculdade de Medicina da USP.
} 
fracassa em reconhecer o valor ou mesmo a existência de abordagens baseadas em direitos para a política de HIV/Aids e o trabalho dos programas. Por fim, a autora destaca que o texto que aborda a "redução da vulnerabilidade" enfatiza os indivíduos em risco para infecção - sob a ótica de seus comportamentos de risco ou desprotegidos - dando pouca atenção à vinculação entre estes comportamentos e o ambiente que os rodeia, assim como à dimensão programática da vulnerabilidade, relacionada, portanto, ao necessário cuidado e suporte por parte dos serviços de saúde e de outras instituições.

As críticas de Gruskin (2002) à abordagem das Nações Unidas em sua Declaração de Compromisso sobre o HIV/Aids coadunam com a minha avaliação, assim como de muitos outros autores, de progressiva atribuição aos indivíduos dos riscos de infecção pelo HIV. Isso, a despeito das críticas do movimento feminista à abordagem de prevenção focada nos comportamentos de risco e do fato de que tais abordagens continuem apresentando-se como orientadas pelo conceito de vulnerabilidade.

No Brasil, Vera Paiva, Lígia Pupo e Renato Barboza (2006) fizeram uma análise da resposta brasileira à aids tomando por referência algumas das metas de prevenção estabelecidas pela UNGASS HIV/Aids. Depreenderam que, apesar de dispor de uma ampla variedade de programas de prevenção que atendiam às metas propostas, a resposta brasileira à aids tinha como desafios: a descontinuidade das ações, particularmente no que se refere às populações mais vulneráveis; a constituição e a formação de equipes para trabalhar em prevenção; as desigualdades regionais, de gênero e de raça. O que levou os autores a concluírem que não é dada prioridade, na resposta nacional, ao direito à prevenção, nem pelas instâncias públicas de controle social, nem nas agendas do movimento social - o que me leva a questionar as conclusões dos autores, se os mesmos entendem que haveria prioridade ao direito à prevenção por parte das instâncias governamentais envolvidas na resposta à epidemia.

Em 2003, foi estabelecido pelo governo estadunidense de George Bush ${ }^{100} \mathrm{O}$ President's Emergency Plan for AIDS Relief (PEPFAR), [ou Plano de Emergência do Presidente dos EUA para Alívio da AIDS] com a perspectiva de dispender 15 bilhões de dóares em cinco anos para ofertar prevenção, tratamento e cuidados, tendo como foco

${ }^{100}$ George Bush foi presidente dos Estados Unidos de 2001 a 2009. 
inicial os 15 países em que se concentravam $80 \%$ das pessoas que precisavam de tratamento para aids (Merson, 2008, p. 484). Sua política de prevenção fundava-se na chamada abordagem ABC (Abstinence, Be faithful and Condoms), que focava suas ações na promoção da abstinência sexual, da fidelidade - com a perspectiva da redução do número de parceiros sexuais - e, somente em último caso, do uso do preservativo. Tal abordagem foi altamente contestada e criticada, tanto por sua ineficácia, como pelas questões éticas relacionadas à restrição do direito à informação (Santelli e cols, 2013; Kirby, 2008). A criação do PEPFAR e a política conservadora do governo Bush impôs condicionalidades também à USAID, que incluíam restrições ao trabalho com usuários de drogas e profissionais do sexo. A mais importante delas era a obrigação dos países e organizações assinarem uma "cláusula anti-prostituição", em que se comprometiam a ter uma política explícita contra o trabalho sexual. Isso levou o programa nacional ${ }^{101}$ a recusar uma doação de 40 milhões de dólares da USAID, em 2005, impactando projetos que eram financiados pelo projeto AIDSCAP, da USAID, alguns deles voltados a HSH (Correa et al, 2011). As consequências desse conservadorismo no cenário internacional também impactaram as políticas e as ações no contexto nacional:

Do ponto de vista internacional é o cenário conservador que marca as políticas de prevenção. A influência da política do Bush [20012009]. Então isso, também, reflete internamente. E, nesse período, tem aquele rompimento do governo brasileiro com a PEPFAR [President's Emergency Plan for AIDS Relief, ou Plano de Emergência do Presidente dos EUA para Alívio da AIDS]. O dinheiro ia ser repassado [para o financiamento das ações de prevenção dirigidas às prostitutas] e havia as condicionantes. O governo brasileiro não aceitou as condicionantes e rejeitou o recurso que vinha do PEPFAR pra financiamento de organizações do movimento social. Mas isso não impediu, por exemplo, que PEPFAR atuasse no Brasil, através de acordos ou de financiamentos isolados com algumas organizações não governamentais, inclusive, de HSH. [...] Todos os lemas que estavam contidos na política [sobre a questão, por exemplo, de diminuição de parceria, abstinência], de algum modo, chegaram a nós. [O que demandava fazer] um contra-discurso. Também foi um momento turbulento em termos de você constituir essa estratégia do contra-discurso (Ivo Brito, entrevista).

Dada a sensibilidade das políticas de aids, ou a sensibilidade dos temas abordados no âmbito das políticas de aids, os impactos do conservadorismo que hoje

\footnotetext{
${ }^{101}$ Sob a gestão de Pedro Chequer à época.
} 
estão explícitos já começavam a se deixar notar no campo. Alguns entrevistados, como Paulo Teixeira, identificam o ano de 2004 como um momento de inflexão, mas não mencionam alguma situação específica. Na tese de Thiago Pinheiro, dois entrevistados com experiência na gestão relatam ter sido frequente em suas experiências os questionamentos sobre os materiais e conteúdos abordados nas ações de prevenção, pelo Ministério Público, parlamentares ou cidadãos individualmente. Em minha experiência de atuação no CRT-DST/Aids identifico uma mudança nas possibilidades de atuação a partir da segunda metade dos anos 2000. Nesse momento, reconhecendo que a internet e os websites de encontros haviam produzido mudanças significativas na sociabilidade homossexual, ensaiávamos produzir um website com conteúdos ousados de prevenção dirigido aos HSH. Me lembro de ouvir da Diretoria do CRT-DST/Aids, que, apesar de a proposta ser procedente, não havia condições para uma ação dessa natureza naquele momento. A situação que consigo identificar como demarcadora de uma mudança de postura, índice de alerta sobre os limites dos conteúdos dos materiais voltados à prevenção, ocorreu com um material informativo produzido pela Associação da Parada do Orgulho de Gays, Lésbicas, Bissexual e Transgêneros de São Paulo (APOGLBT). Uma orientação que visava reduzir danos relacionados ao uso de substâncias psicoativas dirigida aos frequentadores da Parada, em um folheto informativo sobre prevenção das DST/Aids, virou destaque na mídia, tendo sido tratada como apologia ao uso de drogas. Gerou também constrangimentos aos programas de aids, pois constava do folheto os logotipos dos programas como financiadores do material. Em contato com Regina Facchini, à época presidente da APOGLBT, recebi a informação de que o "alvo" inicial da investigação do repórter havia sido um logotipo do Ministério do Turismo, naquele momento sob a gestão de Marta Suplicy. Quando informado de que não havia financiamento do governo federal para o referido folheto, mas se tratava de contrapartida oferecida pela APOGLBT ao Ministério em virtude do seu investimento na Parada, o repórter mudou o enfoque de sua matéria. Não havia escândalo envolvendo o governo federal, mas o tema da redução de danos e da aids ofereciam - já nesse momento - o escândalo.

Outra marca importante de mudança no contexto das políticas de prevenção nos anos 2000 , se dá no contexto das organizações multilaterais, com a publicação, em 
2005, do documento referencial Intensificando a Prevenção ${ }^{102}$ pelo UNAIDS, a partir de uma solicitação do seu Conselho Coordenador em 2004. Esse documento se configura como uma resposta político-institucional do UNAIDS à Declaração de Compromisso da UNGASS HIV/Aids. É o que se pode considerar a segunda geração de documentos do UNAIDS sobre prevenção. Na primeira geração ${ }^{103}$, a ênfase ainda se dava na esteira do trabalho desenvolvido anteriormente pelo Banco Mundial e o enfoque era dado para a orientação de que os países desenvolvessem estudos de custos sobre as estratégias de prevenção (UNAIDS, 2000). Nesse documento de 2005, o UNAIDS estabelece a proposição de intensificar a prevenção com vistas a assegurar o acesso universal à prevenção e ao tratamento, por meio da construção de sinergismos entre os dois. Essa proposição fundamenta-se em um estudo baseado em modelagem matemática para demonstrar que a sustentabilidade da resposta à epidemia depende desta integração. O documento utiliza-se da articulação entre os dois conceitos operativos no campo da prevenção: risco e vulnerabilidade. Estabelece como princípios para uma prevenção efetiva: a promoção, a proteção e o respeito aos direitos humanos, incluindo a igualdade de gênero; a diferenciação e adaptação local dos programas de prevenção; a fundamentação em evidências; a ampla abrangência dos programas; a disponibilização de intervenções já existentes e o desenvolvimento de novas tecnologias; a sustentabilidade em longo prazo; cobertura, escala e intensidade; a participação da comunidade, particularmente daqueles mais afetados. Dois anos depois, o UNAIDS publicou um manual com orientações para os países com bases nas bases estabelecidas pelo documento referencial. Nesse documento são apresentadas as medidas de

\footnotetext{
102 Intensificando a prevenção ao HIV - Documento Referencial das políticas de Prevenção UNAIDS, 2005. Disponível em: http://data.unaids.org/publications/irc-pub06/jc585-prevention-paper_pt.pdf [acesso em 07.07.17], traduzido de Intensifying HIV prevention: UNAIDS policy position paper (UNAIDS, 2005) Disponível em: http://data.unaids.org/publications/irc-pub06/jc1165-intensif hivnewstyle en.pdf [acesso em 07.07.17]. É a primeira publicação do órgão, firmando-se em sua atribuição ${ }^{103}$ Costing Guidelines for HIV Prevention Strategies, UNAIDS, 2000. Neste primeiro documento, são abordadas as seguintes estratégias, tidas como estabelecidas: rastreio de sangue para infecção pelo HIV; uso dos meios de comunicação de massa; educação sobre aids nas escolas; marketing social de preservativos; tratamento de doenças sexualmente transmissíveis; educação de pares entre trabalhadoras sexuais comerciais; aconselhamento e testagem voluntária; atividades de prevenção entre usuários de drogas injetáveis; prevenção da transmissão de mãe para filho (transmissão vertical). Não há nenhuma menção a gays, homossexuais ou homens que fazem sexo com homens neste primeiro documento do UNAIDS. Disponível em: http://data.unaids.org/publications/irc-pub05/jc412costguidel en.pdf [acesso em 07.07.17].
} 
prevenção priorizadas para os principais públicos, e os HSH são um dos grupos priorizados (UNAIDS, 2007).

Segundo Ivo Brito (entrevista), a publicação desse documento se configurou como o primeiro anúncio daquilo que foi chamado no campo como as "novas tecnologias de prevenção". O que veio a reforçar uma perspectiva de prevenção mais focada nos indivíduos - em sua adesão responsável a uma nova tecnologia - e com menor ênfase na transformação social. Perspectiva mais adequada aos esforços de aumento de escala (scale-up) para as políticas de prevenção, no que os cenários, nacional - da descentralização - e internacional - da prevenção biomédica -, se encontram. Ao falar desse contexto, Ivo diz notar, a partir desse momento, o que chama de um eclipse da sexualidade nas abordagens de prevenção. Ou o que para outros entrevistados se coloca como o desaparecimento das práticas sexuais.

Em síntese, o que eu quero mostrar é que esse período de 2006 é também quando muda o discurso da UNAIDS. [...] É quase que uma evolução do Confronting AIDS, 1996, dez anos depois, você tem o discurso da UNAIDS chamado Intensificando a Prevenção, é o documento. [...] No intensificar a prevenção é que [se] dá origem aos primeiros elementos e objetos de incorporação de tecnologias, novas tecnologias no campo da prevenção. Aí vem revolução da prevenção. Vem prevenção combinada.... Tudo isso vem um pouco desse documento base, que me parece que é um documento importante que é Intensificando a Prevenção de 2006, [...] que é uma referência importante para a prevenção. É aí que abre essa discussão da possibilidade de que as estratégias biomédicas são estratégias também importantes para o campo, para a prevenção (Ivo Brito, entrevista).

Em acordo com a percepção de Ivo, entre 2005 e 2007, foram divulgados os resultados de estudos clínicos que demonstraram o efeito protetor da circuncisão masculina na prevenção da infeç̧ão pelo HIV (Auvert et al., 2005; Gray et al., 2007; Bailey et al., 2007). Um painel de especialistas, convocado pela Organização Mundial de Saúde (OMS) e pelo Programa Conjunto das Nações Unidas sobre HIV/AIDS (UNAIDS) em março de 2007, passou a recomendar a oferta da circuncisão masculina médica voluntária (MVMC, male voluntary medical circumcision) como parte de uma estratégia abrangente de prevenção do HIV nas regiões com epidemias de HIV/Aids consideradas 
generalizadas, ou seja, com alta prevalência de HIV heterossexualmente transmitido (WHO/UNAIDS, 2007). A despeito da circuncisão não ser uma medida recomendada para as características da epidemia de aids brasileira, o que se viu aqui foi grande resistência à discussão e implementação de novas tecnologias de prevenção, o que discutiremos no próximo capítulo.

É neste momento que o termo epidemia concentrada começa a ganhar relevo no debate sobre as políticas de prevenção no Brasil, apesar de já ser usado desde os primeiros documentos do Banco Mundial. Como a epidemia brasileira é caracterizada como concentrada, a proposição da circuncisão não é recomendada no Brasil, nem as informações sobre esta medida de prevenção foram divulgadas por aqui. A admissão de que a epidemia no Brasil é concentrada também foi um processo repleto de tensões, em especial porque implicava assumir também o crescimento da epidemia entre os HSH, um dos grupos nos quais a epidemia se concentra.

Isso se dá em meio a uma série de transições. No programa nacional, ocorre em meados de 2010, a transição da direção de Mariângela Simão para Dirceu Greco. Há, nesse ano, a primeira eleição da presidenta Dilma Rousseff e com ela se dá a mudança no Ministério da Saúde, de José Temporão para Alexandre Padilha. Segundo Ivo Brito, esta nova configuração da gestão traz consigo uma nova forma de lidar com as populações mais afetadas pela epidemia.

A Mariângela, ela imprime uma gestão, aprofunda a questão da descentralização que vinha na gestão do Grangeiro. [...] O Departamento passa a participar mais, por exemplo, de algumas esferas decisórias como, por exemplo, as articulações com o CONASS, CONASEMS, com a Atenção Básica. Você tem uma mobilidade maior, vamos dizer, do Departamento em várias esferas decisórias do próprio Ministério da Saúde. Para fora do Ministério da Saúde com as políticas transversais. Então, por isso, o Plano ganhou uma força muito grande durante a gestão [...]. Ganharam uma expressão muito grande dentro da gestão da Mariângela. E passa a minguar na gestão subsequente. E nessa gestão, também, já há uma mudança também do perfil do próprio governo. $O$ final do segundo mandato do governo Lula, início do primeiro mandato do governo Dilma. E aí, você tem uma configuração diferente do ponto de vista de como lidar com essas populações em particular. Que são as populações com as quais a gente trabalha. Então tem uma mudança aí. Eu diria que foi um período de muita dificuldade nossa. [...] Talvez [...] maior do que o período da transição do Serra pro Lula, que pegou o período do governo Bush. [...] Muito maior. Muito maior. Muito maior. Muito maior. [...] Por incrível que pareça, muito maior. Quer dizer, você tinha toda a possibilidade... [...] é 
quase que, eu não diria omissão, mas a palavra não tem outra, quase que uma camuflagem, vamos dizer assim, dessas populações. E, por isso, voltou muito forte a questão dos projetos. Eles estão até agora, de novo, a coisa dos projetos, projetos, projetos. Não temos uma estratégia, uma estratégia estruturante para responder a esses segmentos da população. Hoje, nós não temos. Seria muito bem-vinda, ter novamente, repensar um plano, um plano para esse segmento da população (Ivo Brito).

O cenário político a que Ivo se refere, das eleições de 2010, é o que a literatura das ciências sociais tem apontado como um momento de reaglutinação conservadora (Machado, 2012; Facchini e Rodrigues, 2017). Em estudo que abordou o ativismo religioso e a entrada do tema do aborto nas eleições de 2010, Maria das Dores Campos Machado mostrou ter havido naquela ocasião um processo reativo às agendas de direitos dos movimentos feministas e LGBT, de recomposição da política dos segmentos religiosos (Machado, 2012).

Grosso modo, a trajetória das respostas político-institucionais voltadas à prevenção de HIV/Aids para gays e HSH nos mostra um cenário de crescente reconhecimento dos homossexuais como sujeitos políticos, sua maior participação nos espaços socioestatais, ampliação significativa de sua visibilidade social, assim como o maior direcionamento de políticas públicas focalizadas para o grupo. Não obstante, é forçoso admitir vivermos um momento de importantes retrocessos.

Nota-se, pelo acima exposto, ter havido uma confluência favorável de movimentos por busca de reconhecimento: movimento de redemocratização, no plano político; de direitos civis, no plano do movimento homossexual; de equidade em saúde, no movimento sanitário, e, neste, em particular, de construção de novo repertório de conceitos capazes de sustentar, no campo das tecnologias, a busca de equidade; e de direito à "vida antes da morte", no caso da aids.

Por outro lado, há uma resistência que se mostra como mecanismos sistemático de desrespeito (no caso aqui, de origem homofóbica), que torna a resposta, no caso da aids, seletiva e desigual em seu investimento e eficácia. Se há confluência, há também desencontro, e até conflito, entre diferentes movimentos por reconhecimento. Isso aparece já precocemente, seja internamente à própria comunidade gay, na relutância de algumas de suas principais organizações em relacionar a sua luta por direitos civis 
com a agenda da resposta à Aids e, externamente a ela, pela atitude da mídia e de autoridades da saúde, que, em plena fase de redemocratização política e construção do SUS, trata a epidemia com um discurso moralizante e discriminatório.

As agendas dos direitos dos homossexuais e da luta contra a aids em um dado momento se unem, mas não atingem o compartilhamento necessário com o movimento sanitário. Talvez isso explique porque a resposta à aids, embora tributária do SUS, tenha parecido, em certo momento, se apartar dele, quase até ser visto como estranho a ele (pelos agentes da reforma sanitária, por um lado, e pelos técnicos, gestores e ativistas da aids, por outro).

Quando esses diversos movimentos de reação às situações de desrespeito (opressão da ditadura, iniquidade em saúde, preconceito contra homossexuais e estigma e discriminação das pessoas vivendo com aids) se desencontraram em seus ritmos, com a política entrando em uma certa "normalidade" democrática, a reforma sanitária tendo seus quadros absorvidos pela institucionalização do SUS e a aids sendo banalizada no âmbito das políticas de saúde, o processo de busca de reconhecimento na interface LGBT e aids parece perder potência também. 0 movimento de exclusão (não-reconhecimento) se impõe socialmente e com isso permanece intocada, ou piorando, a vulnerabilidade da população LGBT.

Resgatado, em linhas gerais, o conjunto de respostas produzidas para o enfrentamento da epidemia de HIV e aids entre gays e HSH no Brasil até os anos 2000, vou me debruçar, no próximo capítulo, sobre o cenário atual, os últimos cerca de 15 anos, já mais voltada às fragilidades, desafios e potencialidades, tal como identificadas pelos entrevistados e interpretados à luz das teorias do reconhecimento e da vulnerabilidade e Cuidado Público. 
Noite de sábado, dia treze de junho de 2015. Por volta das 20 horas, desço a pé as Ruas Augusta e Frei Caneca, vindo do metrô, excitada e curiosa com o que me esperava. Lá encontraria um grupo de amigos também animados, que me dariam apoio. Apesar de circular bastante pela região, não conhecia o lugar do evento, cujo nome despertava a minha curiosidade "Cemitério dos Automóveis", descrito como um bar e teatro alternativos pela pessoa que me convidou. Chegando lá, encontro um galpão embaixo de um prédio. O lugar ainda fechado. A atividade que antecedia o debate para o qual eu havia sido convidada ainda não tinha se encerrado. Na porta, algumas poucas pessoas, em sua maioria adultos jovens. O motivo da minha ansiedade, eu participaria como mediadora de um debate intitulado "Clube do Carimbo"104 e as práticas bareback ${ }^{105 " ~ n a ~ q u i n t a ~ e d i c ̧ a ̃ o ~ d o ~ f e s t i v a l ~ P o p ~ P o r n . ~ E r a ~ a ~ p r i m e i r a ~ e d i c ̧ a ̃ o ~ d o ~ f e s t i v a l ~ a p o ́ s ~}$ a morte de sua fundadora Suzy Capó ${ }^{106}$, no início daquele ano. Descrito pela imprensa como um evento "para quem gosta de sexo e tem a cabeça aberta"107, sua programação era variada e incluía a exibição de audiovisuais, apresentações burlescas, exposição de diferentes expressões artísticas como fotografia, desenho e pintura, além de diversos

\footnotetext{
104 O termo "Clube do Carimbo" foi utilizado em uma série de duas reportagens sensacionalistas do programa Fantástico da Rede Globo que atribuíam a um grupo de soropositivos a transmissão intencional e deliberada do HIV. A matéria tratava relações sexuais desprotegidas como responsabilidade individual somente das pessoas soropositivas e não informava adequadamente que uma pessoa soropositiva em terapia antirretroviral e carga viral indetectável não transmite o vírus. Houve grande reação do movimento social contrariamente a essa abordagem da mídia com várias notas divulgadas destacando que a abordagem dada ao tema fomentou o pânico moral, incentivou a estigmatização e discriminação das pessoas soropositivas e mobilizou iniciativas de criminalização da transmissão do HIV no Congresso Nacional. O UNAIDS também lançou uma nota, mas o programa nacional não se manifestou.

${ }^{105}$ As práticas nomeadas bareback - em referência ao inglês "em pelo", "sem sela" - referem-se ao sexo anal desprotegido de forma intencional (Silva e Iriart, 2010).

${ }^{106}$ Suzy Capó, jornalista, cineasta, promotora cultural e militante LGBT, foi uma das fundadoras do Festival Mix Brasil e fundou o festival Pop Porn em 2011, inspirando-se no PornFilmFestival de Berlim. Disponível em: https://popporn.com.br/festival// [acesso em: 06.05.18].

107 https://www.huffpostbrasil.com/2015/06/11/pop-porn-2015-vai-misturar-erotismo-pornografia-earte-em-sao-p a $21682634 /$
} 
tipos de oficinas, com temas como sexo tântrico, uso de cordas em fetiches (shibari) e filmagem de filmes eróticos. No convite que eu havia recebido, os organizadores pautavam o debate com as seguintes informações:

Em tempos de Clube do Carimbo sentimos novamente a necessidade de tratar sobre esse tema que nunca deveria ser pausado. 0 índice de pessoas com o vírus da AIDS sofreu grande aumento no Brasil e nunca tivemos tanta informação à disposição. Nesse debate queremos trazer à tona a discussão da cultura de bareback. Existe hoje um grupo de risco tão bem definido quanto já foi em outras épocas?

Estariam comigo no debate, o deputado federal Jean Wyllys (PSOL), Bruna Valin - mulher transexual, soropositiva e militante dos movimentos de AIDS e LGBT -, Henrique Contreiras ${ }^{108}$ - que me foi apresentado, neste convite, como médico e jornalista da área de HIV/Aids para a Agência Aids -, Lucinha Araújo - mãe do Cazuza e presidente da Sociedade Viva Cazuza e Rico Dalasam ${ }^{109}$ - rapper, negro e gay. Na noite anterior, havia acontecido na boate L'Amour, na Rua Bento Freitas, a festa de abertura do festival com várias performances e a promessa de uma "festa de pelados"110. Entre as minhas muitas inquietações antes do início do evento, eu tinha dúvidas sobre se haveria público para um debate sobre aids em uma noite de sábado, mas aos poucos foram chegando meus amigos, mais e mais conhecidos - estavam lá jovens ativistas, gestores de políticas de prevenção de HIV/aids dos programas municipal e estadual de São Paulo, gestoras de políticas LGBT da Secretaria da Justiça de São Paulo - e muitos mais. Uma matéria da Agência Aids sobre o debate descreveu bem a situação: "a sala foi pequena e o tempo, curto, para a roda de conversa".

Os anos 2010 começaram e trouxeram consigo novos atores e novos espaços. Transformações na sociabilidade, nas formas de fazer política e no contexto político do

\footnotetext{
108 Henrique Contreiras é o nome civil de Carué Contreiras, entrevistado nesta pesquisa. Carué só passou a usar publicamente seu nome social depois de "sair do armário" em relação à sua soropositividade.

109 Rico Dalasam acabou não participando do debate.

110 Termo êmico para descrever festas em que os participantes podem ficar nus. Para ver mais:

https://paulosampaio.blogosfera.uol.com.br/2017/04/18/criador-da-festa-do-pelados-sucesso-nocentro-de-sp-diz-que-roupa-e-uma-prisao/ [acesso em: 06.05.18].
} 
país, impactaram o debate público sobre HIV, aids e prevenção. Desde este debate, estive em diversos eventos ${ }^{111}$ cuja presença era predominantemente de jovens e os cenários são muito distintos dos hotéis em que o movimento de aids historicamente realiza seus eventos. Em alguns deles, me chamou a atenção o caráter de depoimento das participações dos jovens soropositivos nas "rodas de conversa"112. O primeiro evento de que participei com essa dinâmica era intitulado "Desconstruindo o HIV em alto e bom som"113 para o qual fui instigada a participar após um chamado de uma amiga e ativista na lista de e-mails da "comunidade onírico-conceitual" do NEPAIDS. A divulgação do evento anunciava:

O futuro já chegou e a indiferença do status de HIV já é uma possibilidade técnica. O que falta é a desconstrução do estigma que recai sobre os corpos com HIV. Essa opressão restringe a emancipação sexual e política de toda a comunidade LGBTQIA+. A única saída é o protagonismo das pessoas vivendo com HIV. Existem lobbies da indústria farmacêutica por trás de tudo isso? Para discutir essas questões estamos convidando especialistas, estudiosos e pessoas soropositivas que adotaram tratamentos alternativos e também tratamento antirretroviral.

Assustou a essa amiga a perspectiva "negacionista" do HIV referida pelos organizadores da atividade, o que fez com que ela nos mobilizasse, assim como a um grupo grande de jovens ativistas, a participar do evento. A observação do debate me mostrou um novo grupo de atores na sociedade civil ocupando a cena pública para falar de sua experiência com o HIV. Os jovens das estatísticas estavam agora encarnados e contando sobre suas experiências. Apesar de minha pesquisa não ser uma etnografia,

\footnotetext{
${ }^{111}$ Me vêm à cabeça: as rodas de conversa "Desconstruindo o HIV em alto e bom som", realizada em 19 de novembro de 2016, na 2a Conferência Internacional SSEX BBOX - que ocorreu no Centro Cultural São Paulo, paralelamente ao festival Mix Brasil - ; "Diagnóstico: vivências da AIDS hoje”, realizada em 03 de fevereiro de 2017, na Casa 1; “HIV é uma questão de gênero?", realizada em 31 de março de 2017, no XII Curso Avançado de Patogênese do HIV 2017, na Faculdade de Medicina da USP e disponível em: https://www.youtube.com/watch?v=PmrW5NTUFaY [acesso: 06.05.2018].

${ }_{112}$ Formato que também se popularizou nos últimos tempos e que, originalmente, busca propiciar maior integração e horizontalidade entre os participantes da atividade. Apesar de todos os eventos descritos acima terem recebido este nome, alguns deles não diferiram de uma mesa-redonda com falas longas dos convidados e pequeno espaço de tempo para a participação do público.

${ }^{113}$ A 2a Conferência Internacional SSEX BBOX, onde ocorreu esta roda de conversa, foi organizada pelo coletivo "[SSEX BBOX] - SEXUALIDADE FORA DA CAIXA" que se apresenta como "um projeto de justiça social que busca oferecer perspectivas plurais sobre sexualidade e gênero a partir do relato das experiências de pensadorxs, educadorxs, ativistas, artistas e outras pessoas que vivem, aprendem e amam 'fora da caix(inh)a'". Para ver mais: http://www.ssexbbox.com e http://www.itaucultural.org.br/ssex-bbox-serie-generos [acesso em 06.05.18].
} 
aos poucos fui observando e entendendo as articulações que iam se estabelecendo entre jovens já inseridos no movimento de aids - muitos deles integrantes da Rede de Jovens São Paulo - e estes que estavam recém-chegados ao campo. Essas observações, assim como o acompanhamento das redes sociais, me fizeram decidir pela inclusão de alguns deles entre os meus entrevistados.

Dentre as transformações da nova década estavam sinais claros de retrocessos nas políticas de aids, o que me havia motivado a desenvolver esta investigação. Em paralelo, no entanto, nas minhas circulações profissionais e pessoais, eu entrava em contato com uma ativa sociabilidade jovem homossexual e feminista, assim como com eventos como os descritos acima, que pautavam o debate público sobre sexualidade e gênero de uma perspectiva libertária.

Há certo consenso no campo acerca de um refluxo das respostas à epidemia de aids a partir de 2011, na primeira gestão da presidenta Dilma. O primeiro evento identificado a tal mudança de rumos se dá quando o governo federal veta o conjunto de materiais educativos vinculado ao projeto Escola sem Homofobia. Seguido, posteriormente, em 2012, do cancelamento de uma campanha de massa na mídia, por ocasião do Carnaval, dirigida aos jovens gays e da substituição de outra campanha voltada às prostitutas em 2013. No campo, tais situações foram caracterizadas como um retrocesso acentuado nas respostas à epidemia baseadas no referencial dos direitos humanos e no combate ao estigma e à discriminação (Beloqui e Terto Jr., 2012; Chequer, Teixeira e Grangeiro, 2013; Malta e Beyrer, 2013; Ferraz et al., 2013; Seffner e Parker, 2016a; Seffner e Parker, 2016b). Adicionalmente, houve uma série de controvérsias e disputas nessa última década envolvendo posicionamentos contrários da sociedade civil e da academia em relação ao governo federal, em torno dos dados acerca do crescimento da mortalidade por aids e do excessivo otimismo em relação à incorporação de tecnologias biomédicas, na assistência e na prevenção (Grangeiro, Castanheira e Nemes, 2015; Seffner e Parker, 2016a).

Busco responder ao objetivo desta investigação de compreender de que forma processos de (não)reconhecimento, ou desrespeito, no âmbito do cuidado público de saúde, contribuem para os processos de vulnerabilização de gays e bissexuais ao HIV e 
à aids no contexto da epidemia e das respostas produzidas no Brasil e no estado de São Paulo, em particular. Entendo, em especial, que este estudo tem duas finalidades, por um lado, a questão prática, de refletir criticamente sobre as políticas de prevenção para compreender melhor como as decisões técnicas e políticas acerca da prevenção contribuem para determinar a maior ou menor vulnerabilidade à infecção pelo HIV entre gays e quais determinantes políticos favorecem ou dificultam a implantação de políticas mais apropriadas. Simultaneamente, há o esforço de refletir sobre a fecundidade do diálogo do quadro teórico da Vulnerabilidade e Direitos Humanos com a Teoria do Reconhecimento para efetivar análises de situação e construção de respostas.

Nesse sentido, expresso o entendimento de que esta tese se configura como um produto - provisório, experimental, limitado e autoral - para compartilhar os achados e ampliar o debate sobre a pertinência e a fecundidade deste diálogo. Procurei organizar este capítulo de forma a adotar o léxico e a gramática propostos pela Teoria do Reconhecimento visando apoiar as pretensões acima apresentadas. Para isso, apresento a seguir quais as dimensões sociais em conflito; quais expectativas normativas violadas foram expressas pelos entrevistados na forma de experiências de desrespeito e, que identificadas por mim, sustentam o diagnóstico empreendido acerca da vulnerabilidade programática; quais as expectativas normativas que - em minha interpretação - se expressaram na interlocução com os entrevistados e devem orientar a perspectiva de construção do Cuidado Público.

\section{Dimensões sociais em conflito}

Para refletirmos sobre a fecundidade da adoção da teoria do reconhecimento para orientar um diagnóstico acerca da vulnerabilidade de gays e bissexuais ao HIV e à aids é necessário que possamos partir do entendimento das diferentes dimensões sociais em conflito (Melo, 2014).

A luta por reconhecimento dos homossexuais como legítimos reclamantes e destinatários de políticas de saúde, e, mais especificamente, de políticas de prevenção do HIV e da aids, se dá no contexto do Brasil após os processos de redemocratização e 
promulgação da Constituição Federal de 1988. Como afirmam Adriana Vianna e Sérgio Carrara (2007), a chamada Constituição Cidadã catalisa demandas sociais por novos direitos. Assegura igualmente direitos políticos e direitos sociais, dentre eles o direito à saúde, "garantido mediante políticas sociais e econômicas que visem a redução do risco de doença e de outros agravos e o acesso universal e igualitário às ações e serviços para sua promoção, proteção e recuperação" (Brasil, 1988). Tais conquistas, no entanto, ocorrem em um cenário intenso de disputas normativas, de forma que a discriminação por orientação sexual não é incluída na Constituição.

Baseando-me na proposição de Sérgio Carrara (2016), entendo que as discussões sobre políticas e ações de prevenção dirigidas a gays e bissexuais se dão no contexto do que o autor denomina processo de cidadanização da homossexualidade. Carrara empresta a noção de cidadanização do trabalho de Luiz Fernando Dias Duarte e colaboradoras (1993), que tratava de ações desenvolvidas em bairros populares por ONG nos anos 1980. Os autores abordavam o processo amplo de incorporação social e política de categorias sociais marginalizadas, por meio das dinâmicas de individualização, racionalização e responsabilização (Duarte et al., 1993; Carrara, 2016). Diferentemente de Carrara (2016), no entanto, entendo que não se trata da cidadanização de "sexualidades e expressões de gênero não-normativas", apesar de concordar com o mesmo no esforço por não ter como referência as categorias médicas ou as novas categorias identitárias em sua perspectiva essencialista. A diferença que reivindico se deve ao entendimento de que há sempre uma normatividade implicada nas práticas sociais (Melo, 2014). Neste sentido me parece mais fecunda a adoção da categoria reconhecimento, em sua perspectiva de uma reivindicação por ampliação da normatividade hegemônica vigente. Defendo, assim, a ideia de que estamos diante de processos de luta por reconhecimento de sexualidades e expressões de gênero dissidentes, o que inclui a dimensão da cidadanização.

Há grande consenso de que a conquista de direitos sexuais é fortemente tributária do feminismo e do movimento LGBT (Vianna e Lacerda, 2004; Vianna e Carrara, 2007; Vaggione, 2017; Biroli, 2018). É neste sentido que Vaggione (2017) expressa que esses movimentos sociais questionam a normatividade masculina e heterossexual subjacente à cidadania, que torna marginais identidades e práticas 
alheias a este corpo hegemônico. Para além disso, reivindicam a ampliação de tal normatividade, de forma a sexualizar a cidadania. Essa aspiração tem provocado uma reação de grupos sociais que se veem ameaçados por tais processos, particularmente grupos religiosos católicos e evangélicos - reação que se dá tanto por meio da ação direta de suas instituições (como a Igreja Católica), como por meio de parlamentares e políticos vinculados a esses grupos que exercem seu poder no Legislativo e pressionando o Executivo, como ainda por meio do que tem sido chamado ativismo religioso conservador $^{114}$ (Machado, 2012; Vaggione, 2017; Almeida, 2017; Facchini e Rodrigues, 2017). Essa é uma primeira dimensão social em conflito que compõe o contexto onde se dão as demandas por reconhecimento identificadas neste estudo.

Uma segunda dimensão social de conflito, trata da reconfiguração de forças sociais no país que vem impondo redução da agenda de direitos sociais: restrições nos direitos humanos e nas condições de vida (Lima, 2018); redefinições nas políticas econômicas e recuos no pacto social estabelecido no âmbito da Constituição de 1988 (Biroli, 2018); a cronificação do subfinanciamento do SUS e o incremento da participação do setor privado no âmbito das políticas nacionais de saúde (Scheffer, 2015).

Por fim, outro conflito estruturante para o nosso campo é o que Susan Kippax e Niamh Stephenson denominaram como a "histórica e problemática distinção entre as dimensões biomédica e social do HIV" (tradução livre, 2012, p. 789). As autoras pautaram esse debate no momento em que se fortalecia e legitimava a ideia de que dispondo das novas tecnologias de prevenção - aquelas que passaram a ser nomeadas no campo como tecnologias de prevenção biomédica - estaríamos, em nossa quarta década de convivência com a epidemia, próximos de seu fim. Essa guinada biomédica esteve articulada à alegação genérica de que a prevenção havia fracassado. Elas chamam a atenção, no entanto, que tal discurso falha em notar que todas as intervenções preventivas - quaisquer que sejam - têm que se articular às vidas cotidianas e serem integradas às relações e práticas sociais. Interessa-me, particularmente, desse debate as duas narrativas que organizam a história da

\footnotetext{
114 Vaggione (2017) informa, por suas análises, que o ativismo católico conservador integra uma rede de atores e organizações, religiosos e seculares.
} 
prevenção: a biomédica e a social, pois nos ajudam a compreender as transformações no campo da prevenção apresentadas no capítulo anterior e as críticas empreendidas pelos entrevistados acerca das políticas.

Na narrativa biomédica, o foco da prevenção são os membros individuais de populações, compreendidos como agentes neoliberais racionais que, aconselhados por especialistas, adotam tecnologias de prevenção ou modificam seu comportamento para reduzir a transmissão do HIV. Em tal narrativa, as falhas são tidas como fraquezas individuais ou ocorrem em função de alguma vulnerabilidade forjada na estrutura social, tais como a pobreza ou o gênero. A narrativa social, por sua vez, ao invés de focar nos indivíduos, está preocupada com as relações entre as pessoas e as formas como práticas sexuais ou outras práticas sociais, que colocam as pessoas em risco, são produzidas ou transformadas. A ênfase, aqui, se dá nas comunidades, redes, coletividades, nas formas como interagem entre si, com o vírus, com a biomedicina, com o Estado, com as instituições, construindo capacidades (ou não) de responder de forma efetiva e, muitas vezes, criativa à ameaça do HIV e da aids. Nessa perspectiva, as respostas sociais ao HIV e à aids almejam promover transformações sociais, sempre compreendidas como localizadas, contextualizadas e lentas - como qualquer processo social. Entende-se, assim, na perspectiva da narrativa social, que o foco da pesquisa e da ação se concentra nas relações sociais e nas normatividades que regulam tais relações. As autoras nomeiam a abordagem social de "saúde pública social", o que penso se relaciona à nossa Saúde Coletiva, a despeito das histórias sociais de constituição de cada campo (Kippax e Stephenson, 2012).

Em nossas formulações iniciais sobre a vulnerabilidade (Ayres et al.,2003; 2006), nomeamos, como seu contraponto, as respostas sociais - entendidos como processos de transformação social forjados no interior das comunidades para responder às ameaças impostas pelo vírus e suas consequências. Entendo que nos aproximamos, no diálogo engendrado com a teoria do reconhecimento, da sua pretensão teóricoexplicativa - no sentido de buscar compreender a gramática dos conflitos sociais e a racionalidade das mudanças sociais com vistas a explicar sua transformação normativa Interessa-nos refletir sobre a pretensão crítico-normativa da mesma teoria, de forma que, ao empreendermos nosso diagnóstico das patologias sociais e analisarmos os 
movimentos sociais, possamos discernir seu caráter - emancipatório ou reacionário com relação à forma como tais movimentos participam de tais processos de mudança social de teor normativo (Melo, 2014).

No que tange à dimensão do conflito que acabo de descrever, é importante destacar que historicamente, nos discursos e nas políticas de saúde e de aids, deu-se maior centralidade às abordagens biomédicas, enfatizando-se a assistência à saúde em detrimento da prevenção, especialmente em sua dimensão social. No momento atual, a ênfase na dimensão biomédica da prevenção se assenta em uma noção equivocada, de que o emprego das tecnologias biomédicas nos poupará de lidar com práticas e relações sociais implicadas nas transformações sociais. Conecta-se, ainda, a uma narrativa biomédica de sucesso do tratamento, o que não é de todo verdadeiro, se considerarmos os dados anteriormente apresentados de mortalidade por aids e as demandas atuais dos grupos ativistas que reclamam falta de medicamentos e inúmeras preocupações com a qualidade da assistência (Kippax e Stephenson, 2012; Grangeiro, Castanheira e Nemes, 2015; Seffner e Parker, 2016a). Nas políticas de aids, o discurso biomédico foi fortalecido a partir de 1996, quando se identificou a terapia tripla ("coquetel"), reforçando as conexões entre testagem e prevenção e re-posicionando a prevenção como assunto privado, que se dá nos consultórios (Kippax e Stephenson, 2012) - e não mais nos compartilhamentos das oficinas de sexo seguro e no debate público e aberto que destaca nossa solidariedade.

\section{Expectativas normativas violadas}

Tendo mapeado os conflitos políticos que marcam nosso tempo, empreendo nesta seção - com base no diálogo com os sujeitos imediatamente concernidos - o diagnóstico acerca da vulnerabilidade programática de gays e bissexuais ao HIV e à aids. Para isso, recorro às narrativas produzidas nas entrevistas, em especial, àqueles trechos que se referem às tensões e conflitos no que tange à prevenção. Busquei identificar expectativas normativas violadas - na forma de experiências de desrespeito e indignação - expressas pelos sujeitos ao caracterizarem e refletirem criticamente sobre o cuidado público a eles ofertado. 
Para caracterizar o cuidado público, busquei identificar de que formas as práticas e discursos no campo da saúde pública são experimentados pelos sujeitos, quando produzem experiências de desrespeito ao confrontarem suas pretensões normativas e necessidades. Para organizar o relato nesta tese, categorizei tais narrativas tendo por referência três grandes categorias de práticas e discursos do campo da saúde pública: as abordagens da epidemiologia, as abordagens preventivas e a gestão e organização dos serviços. É importante destacar que, na abordagem do campo da aids como um campo discursivo de ação - tal como adotada neste estudo - compreendo os diferentes atores como envolvidos na luta em questão, de forma que todos têm um caráter militante e ativista.

\section{Abordagens da epidemiologia}

No campo, as abordagens da epidemiologia costumam ser adotadas para justificar (ou não) o desenvolvimento de políticas. Na ótica dos ativistas, no entanto, são compreendidas como as formas em que a epidemiologia, as políticas de saúde e os governos os categorizam como segmento populacional destinatário de tais políticas.

Há, neste sentido, a percepção de que tais abordagens contribuíram para impor restrições às respostas políticas voltadas aos gays e bissexuais por meio de dois processos: a resistência em admitir a epidemia de aids concentrada nestes grupos e a ênfase nas tendências de interiorização, feminização, juvenilização da epidemia de aids. Essa compreensão é amplamente compartilhada pelos entrevistados - ativistas e gestores-, com exceção dos mais jovens que não se referem a esses fenômenos, possivelmente por engajarem-se no campo quando tais processos já tinham outra configuração. Na perspectiva dos ativistas, no entanto, são experimentados como tendo servido para desfocar e invisibilizar os grupos mais afetados pela epidemia, como se pode notar no trecho abaixo:

[...] teve um discurso da interiorização da aids, da feminilização da aids, da juvenização da aids, né? Não estou dizendo que não houve esse movimento, mas a gente está numa epidemia concentrada. [...] $\mathrm{E}$ quem são as pessoas [em que se concentra a epidemia]? São as pessoas que [são atacadas pelo] pânico moral, né? [...] Então, assim, são as prostitutas, são os prostitutos, são os gays, são as travestis, são as 
transexuais, são as pessoas que usam drogas. Quer dizer, são a escória [...] de quem nos ataca. Não nos fazendo de coitado, mas assim são as populações que estão completamente negligenciadas, né? $E$ que, politicamente, se trabalha contra [elas]. Então, é muito difícil, acho quando você tira a discussão de gênero das escolas, quando você tira o Escola sem Homofobia, o kit da Escola sem Homofobia. Quando você acaba com Prevenção nas Escolas. Então, assim, foi um desmonte sistemático de ações, que são ações de política pública, que não poderiam ter sido desmontadas. Mas aí, assim, não se teve o culhão para dizer "Não. Isso não é uma questão política. Isso é uma questão de saúde pública. [Não é] Política partidária, isso é uma questão de saúde pública. Não é uma questão de moralidade, é uma questão de ética, de garantir que essas pessoas tenham acesso à informação, tenham acesso à testagem, tenham acesso..." (Beto de Jesus, entrevista)

A categoria HSH é, por sua vez, fortemente questionada pelos ativistas. Se em algum momento das respostas à epidemia foi considerada valorosa por assegurar a distinção entre as práticas e as identidades sexuais, tendo algum caráter agregador; na atualidade, é alvo de críticas, pois nubla e homogeneíza diferentes segmentos sociais, assim como denotam as resistências a que a homossexualidade seja objeto de políticas de saúde. Sendo compreendido, assim, como um termo que deveria ser abolido.

Eu acho que o HSH é uma herança da época [...] do comportamento [de risco] [...] Mas, assim, você não tá reconhecendo a identidade das pessoas. Como é que você vai se comunicar, se você não está reconhecendo a legitimidade daquela identidade. Se você está reconhecendo a legitimidade de vários espaços de frequência e tal, mas continua essa herança de você continuar chamando por um termo epidemiológico, da época em que a epidemiologia não era informada pelos direitos LGBT, né? Eu acho que a própria epidemiologia pode mudar. [...] Tanto que houve muita tensão, ainda existe [em função da] inclusão das mulheres trans e travestis nessa categoria. E elas ainda estão, na vigilância epidemiológica. Na categoria de exposição, né? Mas a categoria de exposição também tem que respeitar a identidade. Porque a categoria de exposição vai chamar ela de [homem], né? [...] Você não consegue tirar dados do boletim epidemiológico pra desagregar quantos daqueles HSH que morreram, quantos são - na verdade - mulheres trans e travestis. Então, se você não reconhece a identidade, você não gera dado. Então, essa categoria é problemática, primeiro, pelo trans já é bem problemático, para as pessoas trans. Mas você, também, dentro daqueles que são homens cisgênero, você não reconhece a forma como as pessoas se identificam. Então, você tá chegando na população falando HSH e as pessoas olham e não se reconhecem naquilo. Às vezes, tem momentos que isso gera um estranhamento mesmo. Por que não chamar pela forma que eles se identificam? Sempre essa questão de "Ah, mas vamos... Tem aqueles do armário não sei o que". Entendo que no Marrocos, talvez, a maioria seja $\mathrm{HSH}$ - no sentido de que não se identifica como gay ou 
bissexual. Mas em São Paulo, não é. Então, eu acho que, assim, a gente precisa sempre se dirigir respeitando a categoria. E aí, os outros HSH, para incluir todos aqueles que não se identificam, que precisam também ser objetos de política." (Carué Contreiras, entrevista)

Tanto que eu acho que devia ser abolido o termo HSH; [...] que é um absurdo continuar usando o termo HSH. Porque quando eu falo de HSH, no geral, eu nublo. Quem são os HSH? Eu faço política para os HSH? Não. Eu tenho que fazer pra gay. Eu tenho que fazer política pra gay. Eu tenho que fazer política pra travesti. Eu não posso colocar travesti dentro dos HSH. Vamos cair numa outra discussão da história de gênero e tal. Mas, assim, isso é um termo da epidemiologia que não responde mais. Não dá conta. Não dá conta mais. Nubla. Invisibiliza. "Ah, mas..." Não. É como a palavra, odeio de morte, homoafetivo. Tem heteroafetivo? Não. Não tem. E porque que tem homoafetivo? Porque eu tenho que dizer que a minha relação só pode ser aceita se eu tiver afeto? Eu não posso ter uma relação só pra fuder e as pessoas me respeitarem? Que os heterossexuais podem ter só pra fuder. E não criaram heteroafetivo pra essas pessoas. Então, assim, é ruim quando você vai criando essas caixas e essas, não sei... E, pra mim, [...] HSH é um pouco isso. Assim, é mais palatável. Porque tem governo que não quer falar gay, que não pode falar gay. Que tem lei contra gay. $\mathrm{Ai}$, meu cu. Enquanto a gente não fizer isso, os gays vão... Porque a gente tá com $20 \%$ de prevalência? Porque a gente tá correndo atrás de HSH. A gente tá correndo... Porque a gente deixou de botar o foco. A gente deixou de falar especificamente pra essas populações. A gente deixou de fazer programas específicos pra essa população. A gente deixou de pensar estratégias específicas pra essa... Uma outra organização tá fazendo. A ABIA faz, né? Continua fazendo. Mas, assim, são pouquíssimas. A gente conta na palma da mão, [as] que estão tendo essa preocupação em relação a isso. (Beto de Jesus, entrevista)

Tem primeiro isso, são chamadas de políticas de HSH. Isso acho que diz alguma coisa. Continua, [...] se falando HSH, isso significa que tem algum descontato aí com o LGBT, né? Que acho que vem das duas partes. [...] Primeiro, esse problema que é [...] não tem articulação de movimento social de LGBT com o governo, com os departamentos de aids. Pode ter tido no passado, financiaram tudo do movimento LGBT, as paradas, não sei o que. Mas, agora, não. E tem um outro problema que é de ser, que aí, é a falta da... Que aí, é a questão da heteronorma médico-sanitária, né? Que, assim, não só as políticas...É que, assim, foca no HIV, você quase que lida com os gays pelas circunstâncias. Eu não queria lidar com os gays, não era pra ser objeto da política, mas como eram eles que tão com HIV, aí acaba virando. Mas só esse aspecto que é considerado e outras questões de saúde são totalmente ignoradas. Então há a fragilidade enorme da não existência de uma política de saúde do homem gay, bissexual. Que não é só uma questão da política pública. Isso aí vem muito anterior, começa na pesquisa, passa pelas entidades médicas, por quem faz a disseminação de conhecimento, os protocolos, os livros, a formação dos profissionais de saúde e chega na política pública. Então, quem está lá no Ministério da Saúde é tão heteronormativo quanto qualquer outra pessoa da sociedade. Aí, então, veio dar naquela - eu escrevi um artigo que critica a cartilha de saúde do homem gay, bissexual, que saiu logo antes do golpe. E aí, eu acho que mostra isso, porque o que a cartilha traz? E a própria 
Política Nacional de Saúde Integral LGBT, o que que traz de saúde do homem gay, bissexual? Pouquíssimo. Na própria Política Nacional, quem discute mais saúde são as pessoas trans, que são pessoas que dependem da saúde pra concretizar sua identidade de gênero, de alguma forma. Então, as pessoas trans, que sempre pautam mais saúde. Homens gays e bis não. Você vai numa conferência, pouco pautam. Isso, então, se expressou num capítulo que fala sobre homens gays na Política de Saúde Integral, que é muito pouco. E aí, essa cartilha que será um produto dessa política que é um fiasco. [...] Pra você ver, começa falando que justificando a necessidade de saúde específica - pega um capítulo lá da saúde integral do homem hétero, né? Que é a saúde do homem, mas é a saúde do homem hétero e põe os dados lá pra introduzir. Os dados que eles colocam são a diferença de saúde, de anos, de expectativa de vida entre homens e mulheres. Ao invés de comparar os homens héteros [com] os homens gays e bis, faz essa comparação. Então, os homens vivem menos, os homens gays e bi tão dentro desse bolo. Então, não conseguem nem identificar, assim. E aí, tem uma discussão muito legal que é de violência, violência como agravo em saúde, né? Que é a coisa da não identificação, que até então foi muito importante. Mas quem que trouxe isso? Foi o pessoal dos direitos humanos, não foi o pessoal da saúde. E aí, o problema do documento é esse, não tem contribuição técnica da saúde. E a discussão de HIV super fraca também. Então quem vai, quem fez todo esse movimento e tal, a genealogia dessa política de saúde é dos direitos humanos. E aí, não tem contribuição técnica da saúde. Então não fala, por exemplo, da hepatite A, né? Que agora a gente tá tendo, você acompanhou, né? (Carué Contreiras, entrevista)

\section{Abordagens preventivas}

A própria ideia de prevenção, mobiliza reações de indignação em alguns dos entrevistados, na medida em que - da forma como tem sido convencionalmente referida estritamente à prevenção da infecção pelo HIV - exclui os soropositivos de sua proposição. Além disso, nessa perspectiva, se a noção de prevenção não vier a ser discutida com as necessárias mediações, transforma-se em sinal de alerta apontando: "cuidado com o corpo positivo", de forma a incentivar o estigma e a sorofobia. Indicando como, muitas vezes, sentem-se os soropositivos, diante de determinadas abordagens sobre a doença e os doentes. É neste sentido, que Carué Contreiras tem adotado a construção "prevenção e direitos humanos", com vistas a incluir os soropositivos no horizonte normativo dos direitos humanos.

Eu tenho me irritado muito com o termo prevenção, assim. [...] Necessariamente você tá, quando você fala prevenção, você está excluindo, né? Você tá falando pra plateia, falando de prevenção, aquelas 
pessoas que já vivem com HIV estão assim, né? Não estão. A conversa não está se dirigindo a elas, e você não está chamando a atenção para as pessoas negativas ali, das necessidades e existência das pessoas vivendo com HIV, nem falando da questão de inclusão delas e tal. [...] E aí, chama a gente vivendo com HIV pra falar de prevenção. Vou falar de alguma coisa que me concerne. Mas, então, eu sempre, quando falam em prevenção, eu falo em prevenção e direitos humanos. É uma forma que eu encontrei, por enquanto, pra tentar entender que, assim, não tem como você falar de HIV falando só de prevenção. A gente sempre tem que falar de direitos humanos. E aí, eu entendo que você consegue incluir, falar em direitos humanos inclui vários tipos de direitos e você inclui os direitos das pessoas vivendo com HIV e a discussão de sorofobia. [...] A demanda, acho que é essa, de que a nossa problemática seja discutida, seja apresentada, enfim. Que é uma problemática, claro que tem a problemática de tratamento tudo, também. Mas, principalmente, a problemática de silenciamento e discriminação. Então, quando a gente vê que chega no espaço que é a pura prevenção, a gente está sendo ali... Na verdade, aquilo tá contribuindo para o estigma, né? Porque pra você colocar - como o Loka falou, né? - o "cuidado com o corpo positivo". [...] Se você não faz a mediação, se você não pega a nuance, você vai incentivar o estigma, a sorofobia." (Carué Contreiras, entrevista)

Na percepção de um gestor - que pode ser compreendido aqui também como ativista das reformas no campo sanitário - as políticas de prevenção, na atualidade, têm muito invólucro e pouco conteúdo. Configuram-se como a expressão máxima de uma política de prevenção focada no consumidor e não no sujeito de direitos; menos ainda no reconhecimento de práticas e condutas características de alguns segmentos populacionais, mas potencialmente presente no repertório sexual de todos (como o sexo anal). Nesse sentido, o entrevistado aponta que muitas vezes a adoção dos conceitos operativos se dá como uma bandeira, sendo efetivamente mal operacionalizados. Lembramos, nesse momento da entrevista, sobre algo que muitos de nós - que estudamos e defendemos a adoção do conceito de vulnerabilidade vivemos quando o conceito estava sendo adotado no país ao ouvirmos em alguma situação de alguém - podendo ser ativista ou gestor: "Não se fala mais risco, agora é vulnerabilidade". E a prática continuava a mesma... Isso se associa à crítica feita por um ativista, de que os conceitos operativos eram sujeitos a modas.

Para alguns dos entrevistados, a expectativa sobre uma política de prevenção é a de "empoderar para ter autonomia sobre o corpo, sobre sua sexualidade". 
Aproximando-se da proposta de emancipação psicossocial defendida por Vera Paiva (2002), apesar das críticas feitas pela autora ao termo "empoderamento".

No que se refere aos conceitos operativos das abordagens preventivas, o principal tensionamento no cenário atual se dá com a noção de "prevenção combinada"115. Grande parte dos entrevistados critica tal concepção por entender que ela se reduz a um conjunto de técnicas e tecnologias; a um cardápio de recursos, serviços, técnicas e tecnologias sem levar em consideração os sujeitos que as adotarão e os contextos de adoção. Tal noção, coloca no mesmo plano - em equivalência - as abordagens biomédicas - a chamada "mandala da prevenção" (Figura 1), que oferta técnicas e tecnologias - e as abordagens estruturais - que lidam com representações e construções sociais; leis e normas; instituições sociais; códigos/normatividades socioculturais. Fica ausente, no entendimento de alguns dos entrevistados, um elemento ordenador dos diferentes contextos em que os sujeitos se inserem: no caso da transmissão sexual, exatamente compreender mais sobre como se organiza a sexualidade.

\footnotetext{
${ }^{115}$ A prevenção combinada foi proposta no cenário internacional em 2008 (Piot et al., 2008). Em 2017, o Ministério da Saúde colocou em consulta pública o documento "Prevenção Combinada do HIV: bases conceituais para profissionais, trabalhadores e gestores de saúde" (Brasil, 2017). Neste documento, apresenta-se a Prevenção Combinada como um terceiro paradigma de prevenção do HIV, superando os paradigmas do risco e da vulnerabilidade.
} 
Figura 1 - Mandala da Prevenção

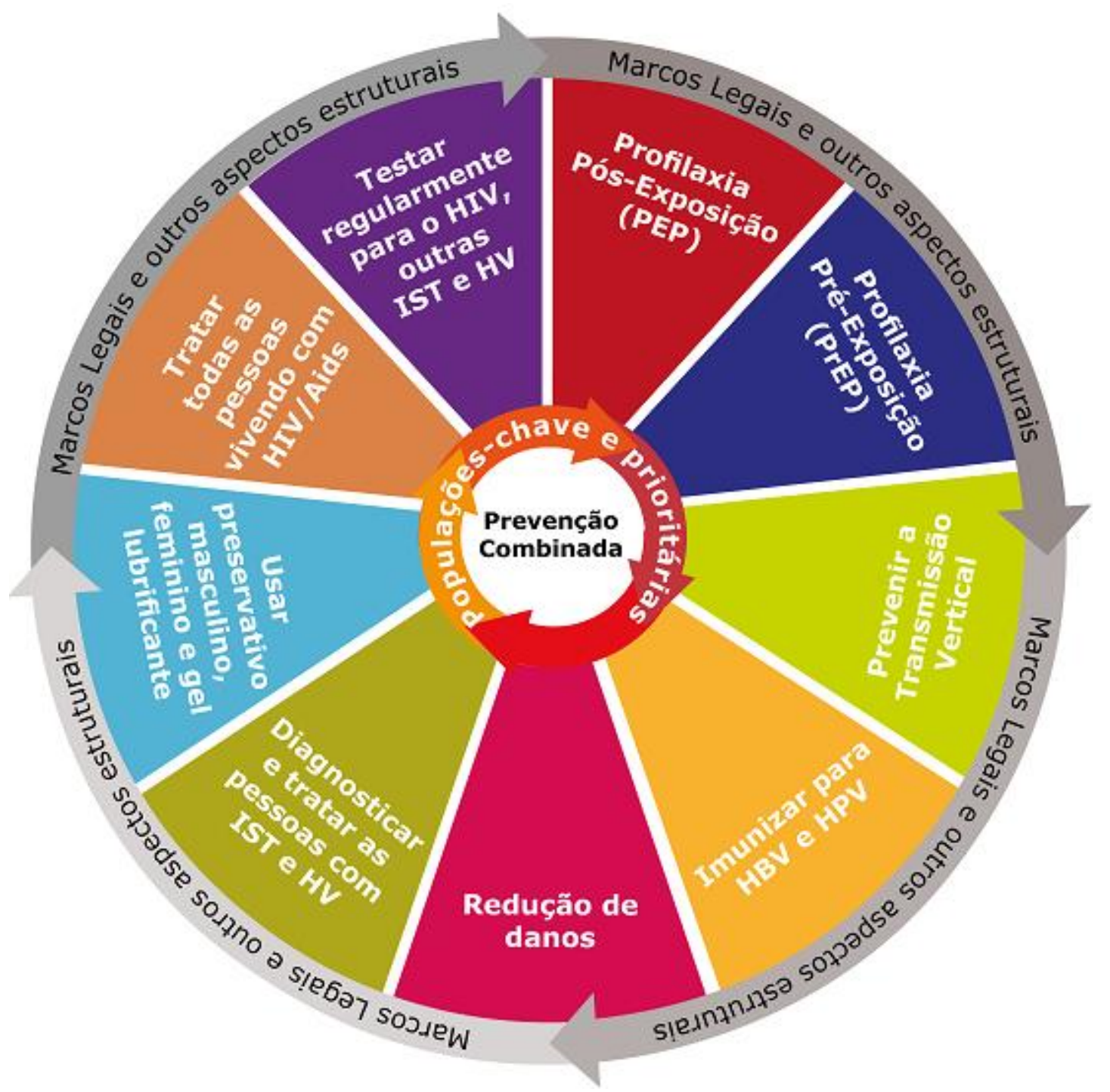

Nessa perspectiva, Veriano considera que pode ser uma oportunidade de voltar a trazer o sexo para o espaço público. Isso, se não for abordado somente como saída individual, tecnicista e prescritiva; há, assim, a necessidade de se abordar as dimensões sociais e políticas; a solidariedade no que tange ao sexo.

[...] as novas tecnologias de prevenção acabam trazendo à tona, né? Retrazer essa questão [...] próprio sexo seguro, que acho que tem que voltar. A partir do momento em que vai romper o sinônimo de que sexo seguro é igual à camisinha - passa a ser outras coisas - então tu vai ter que voltar a relativizar a ideia do sexo seguro e isso é bom porque vai crescer, né? Vai trazer de volta, talvez, o sexo pra dentro das conversas. As pessoas vão dizer "Ó, eu posso fazer... PrEP é bom, porque eu tô numa fase mais galinha da minha vida" ou "Eu posso fazer PrEP, mas eu posso ter o perigo de pegar outras DST, porque eu faço sexo oral. Então, o que 
eu vou fazer? Eu posso usar o PrEP pro HIV, mas como é que eu me previno do...? Porque eu faço outras práticas que..." E aí tem que falar, né? Então, pode ser isso, [...] uma maneira de recolocar. Então, por isso que a gente, na ABIA e em outros lugares, algumas ONGs têm essa ideia de colocar dentro da dimensão social e política, inclusive, as novas tecnologias de prevenção, pra que elas não fiquem restritas somente ao âmbito de que elas cobrem, protegem tantos por cento no sexo anal, protegem tantos por cento do HIV. Só vendo as questões biomédicas, né? Mas o que elas trazem de desafio pra voltar a falar de sexualidade, prevenção, de direitos, de formas de sexo, de locais de sexo, enfim. São importantes pra prevenção, né? (Veriano Terto Jr., entrevista)

Articulando-se com a questão da sexualidade, Gabriel destacou um aprendizado tido no Congresso de Aids ao assistir uma fala de Beto de Jesus, de que "prevenção combinada" tem que ser acompanhada da discussão do gerenciamento de risco.

No entendimento de Gabriel, a grande diferença é enfatizar a educação antes de valorizar a tecnologia. O que ele justifica pela percepção de que há muita valorização da tecnologia, mas não se compartilha informação que propicie o bom manuseio das ferramentas disponíveis.

De forma geral, no entanto, o conceito subjacente à proposição da prevenção combinada - em consonância com a narrativa biomédica e individualizante do HIV - é o de comportamento de risco, de forma que a proposta só vem a ampliar as maneiras no sentido da ampliação da oferta dos recursos tecnológicos - para se comportar responsavelmente, permanecendo a ênfase no indivíduo, tido como agente racional neoliberal, como expressam Kippax e Stephemson (2012), ou o consumidor, como apresentado por Paiva (2002).

Um desafio para o campo da prevenção são os seus sentidos para os sujeitos, o que foi trazido por um ativista entrevistado que contou sobre como recebeu seu diagnóstico da soropositividade e, depois, quando teve um diagnóstico de sífilis. Ele reforçou em seu relato sobre como sentiu-se culpado e errado, tendo demorado a valorar positiva e generosamente a si mesmo pelo fato de ter se cuidado e ter sido diagnosticado rapidamente. Em sua experiência pessoal, a identificação de uma doença foi significada, imediatamente, como fracasso e não como autocuidado. De forma que, a ênfase individualizante das noções de comportamento de risco e de comportamento 
responsável, tendem a mobilizar a culpa e a responsabilização individual, o que torna difícil a valorização da prevenção e do autocuidado.

É uma coisa que a gente sabe como é que... E aí? Acontece, né? E olha que foi foda. Fiquei péssimo, porque eu me sentia errado. Ó que doidera. Como você é forte, eu sentia que eu tinha fracassado. E eu demorei pra entender que não. Muito pelo contrário. Eu vi a sífilis, eu fui tratar. Eu fui tão cedo que a porcaria deu negativo no teste. Eu achei que não era sífilis.

Nas reflexões críticas de alguns dos entrevistados, foi possível compreender que a definição dos conceitos operativos impacta as formas de gestão da epidemia, orientando, e por vezes reorientando, os mandatos dos diferentes atores institucionais, vindo a redirecionar suas ações. Assim, com a crescente ênfase nas tecnologias biomédicas no campo da prevenção, há o entendimento de que se reforçou o mandato da OMS e se deslocou o papel do UNAIDS - criticado por alguns dos entrevistados por ter assumido o que nomearam como papel de ONG nos últimos tempos, no sentido de centrar sua ação no desenvolvimento de projetos, deixando de lado o caráter político de sua ação. Consequência direta das transformações nos conceitos operativos são os indicadores adotados nos relatórios de progresso das respostas do país - não há mais, segundo Ivo Brito, indicadores voltados à sexualidade e aos direitos humanos - estes últimos tendo sido substituídos por indicadores de estigma e preconceito, não mais o direito à saúde.

Penso que, em parte, a propositura do UNAIDS do "entretenimento como forma de engajar a juventude na resposta ao HIV/Aids" (mencionado anteriormente), se coloca - predominantemente - como forma de marketing do comportamento responsável e dos diferentes recursos tecnológicos. Há, no entanto, como me mostraram alguns entrevistados das novas gerações, outras possibilidades no mesmo cenário. Assim, se pensamos na profusão dos jovens YouTubers ${ }^{116}$ que começam a falar sobre HIV e que

\footnotetext{
${ }^{116}$ A partir das informações das entrevistas fui identificando alguns deles, mas não me aprofundei nesta investigação:

Canal do YouTube Canal das Bee. Disponível em: https://www.youtube.com/user/CanalDasBee [acesso em 15.01.2018] (tinha 341.163 inscritos naquele momento)

Canal Põe na Roda. Disponível em: https://www.youtube.com/user/canalpoenaroda
} 
têm recebido um investimento significativo por parte do UNAIDS ${ }^{117}$, podemos reconhecer novas modalidades de ação das novas gerações que abrem espaço para comunicação mais dirigida a segmentos bem particularizados, o que pode facilitar o diálogo e garantir a abordagem de especificidades. Ramón, do Coletivo Loka de Efavirenz, no entanto, expressa crítica, incômodo e questiona o papel de muitos dos seus colegas, jovens YouTubers, pela percepção de que eles seguem uma cartilha, um checklist, da UNAIDS e do MS, faltando-Ihes autonomia e a efetiva abertura de novas formas de lidar com o HIV, a aids e a prevenção. Reivindica, em contraposição, uma perspectiva dos discursos sobre HIV e aids ancorados no pensamento crítico, na ampliação da consciência e da normatividade, para promover a emancipação, e o

[acesso em 15.01.2018] (tinha 705.146 inscritos naquele momento) Canal Mandy para Maiores. Disponível em: https://www.youtube.com/user/mandyparamaiores [acesso em 15.01.2018] (tinha 1.034.558 inscritos naquele momento) Canal Sensualise Moi. Disponível em: https://www.youtube.com/user/sensualisemoiTV [acesso em 15.01.2018] (tinha 455.259 inscritos naquele momento) Daniel Fernandes, Canal do YouTube Prosa Positiva. Disponível em: https://www.youtube.com/channel/UCvORuPRYH92ZGHrxb3OugoQ [acesso em 15.01.2018] (tinha 2.177 inscritos naquele momento) https://www.youtube.com/watch?v=f8cBUJVA-0c Gabriel Comicholli, Canal do YouTube HDiário. Disponível em: https://www.youtube.com/user/Gabrielcomicholi/videos?view=0\&sort=da\&flow=grid [acesso em 15.01.2018] (tinha 30.453 inscritos naquele momento) Canal do YouTube Vida Positiva. Disponível em: https://www.youtube.com/channel/UCKWzX5GOiOLrOGBC8830j-g [acesso em 15.01.2018] (tinha 4.563 inscritos naquele momento) Canal do YouTube Chá dos 5. Disponível em: https://www.youtube.com/user/chados5 [acesso em 15.01.2018] (tinha 38.690 inscritos naquele momento) Canal Bia Nickytinha no YouTube. Disponível: https://www.youtube.com/channel/UCV9inJ9HZyTxTt970xyu4Rg [acesso em 15.01.2018] (tinha 3.987 inscritos naquele momento) Não significa defender pautas progressistas no campo dos direitos sexuais e reprodutivos: Vídeo Diga não ao aborto. Disponível em: https://www.youtube.com/watch?v=GhVZpl4V2H0 [acesso em 15.01.2018]

Canal do Loka de Efavirenz. Disponível em: https://www.youtube.com/watch?v=vv17hpH-s w w [acesso em 15.01.2018] (tinha 201 inscritos naquele momento) Canal Fachki. Disponível em: https://www.youtube.com/channel/UC5xKuc0eOD-ZOekv3V1JPwg [acesso em 15.01.2018] (tinha 31 inscritos naquele momento) Canal Positivo Matheus. Disponível em: https://www.youtube.com/channel/UCrVvcphDBKg5YwZLE3Q0yww/feed [acesso em 15.01.2018] (tinha 1.725 inscritos naquele momento) Canal de Joao Geraldo Netto - Assessor de Comunicação do DIAHV-MS. Disponível em: https://www.youtube.com/watch?v=PBbLKAmF-H0 [acesso em 15.01.2018] (tinha 7.476 inscritos naquele momento)

${ }^{117}$ Sobre a iniciativa do UNAIDS: https://unaids.org.br/2017/03/campanha-esefossecomvoce-do-unaidse-lancada-no-programa-encontro-com-fatima-bernardes-da-rede-globol https://unaids.org.br/2017/01/jovens-talentos-online-trazem-nova-voz-para-resposta-ao-hiv-ediscriminacao/ 
diálogo com os específicos posicionamentos políticos acerca da sexualidade. O que se expressa, na dinâmica das redes sociais, na forma das tretas, porque, segundo Ramón, politicamente já tem muita gente que faça consenso no campo. O Loka reivindica o lugar do dissenso.

E aí, a gente teve um problema que foi, a gente sentou e viu canal de YouTube. Canal de YouTube. Canal de YouTube. A gente falou: "Não. Não. Não. A gente não vai pra esse sentido". [...] Mas, assim, se você pega o script de slogans da UNAIDS e do Ministério, você pode fazer o checklist do script em todos os canais. Em todos. E foi literalmente assim, chegou um determinado momento em que a gente começou a fazer check-list. Falou tal coisa, de novo. Falou tal coisa, de novo. Esse também falou isso. Esse também falou isso. E aí [...], a gente viu "Não vai rolar". Só que não suficiente com o não vai rolar, a gente acabou criando brigas, né? Dizendo "Com essa, com essa e com essa pessoa..." Ou melhor: "com esse, com esse, com esse discurso, a gente vai fazer frente de oposição". Assim, não é que a gente não vai na linha deles, é que a gente vai opor o discurso deles, assim. Acho que politicamente já tem quem faça consenso. $\mathrm{O}$ que mais tem são pares nossos fazendo consensos. Tentando fazer, cumprir ou fazer valer a cartilha do Ministério, a cartilha da UNAIDS, entendeu? Dos seus slogans, das suas proposições - que são importantes. [...] mas a gente tá aqui pra dar conta de uma outra coisa. Pra dar conta de dizer, se tem quem tá lá pra dizer "use camisinha", a gente tá lá pra dizer - não é que não use camisinha-, mas pense na camisinha que você tá usando, né? Que a camisinha não seja só um estorvo na sua vida, mas também não seja só uma obrigação na sua vida. Mas que você consiga entender o que significa o dispositivo da camisinha ali, na sua prática sexual. E aí, fazer esse movimento significava bater em coisas sacralizadas dentro do movimento: um corpo cristão sacralizado, uma noção de manutenção da saúde que era completamente cristalizada, né? Então, por exemplo, a gente faz um debate antiproibicionista na Loka e a gente não consegue fazer um debate antiproibicionista nem com os nossos pares do movimento de HIV, que dirá com a galera que tá sobrevivendo da epidemia desde 1980, entendeu? Que acha que, de fato, debater a interação com outras drogas ou com drogas ilícitas e o medicamento, não é só uma coisa desnecessária, como é uma coisa que tem que ser desestimulada, entendeu? E a gente tá aqui pra dizer "Então, mas calma aí. O que que é nesse momento histórico a droga ilícita, com consumo de açúcar do jeito que é, com consumo de álcool do jeito que é, com consumo de gordura do jeito que é, com consumo de sal do jeito que é, com consumo de medicamentos do jeito que é". Como é que a gente pensa? Por que que é tão preocupante? Mas, assim, conseguir fazer esses debates ou conseguir fazer esse tipo de tensão que é mais na ponta, é o que a gente se preocupa em fazer no movimento de HIV/aids do que ficar comprando briga, entendeu? Com o movimento. Porque a gente sabe que vai ter briga, se a gente focar nisso. Porque a gente tá defendendo coisas muito polarizadas, assim. E, assim, a resposta que a gente tem disso é muito dúbia, né? Porque quase sempre a gente tem experiências mútuas, assim, de a gente ouvir numa mesma situação, de um mesmo conjunto, de um mesmo coletivo. Ou de pessoas de uma mesma área, pessoas de um mesmo evento, desde "Vocês são muito loucos. Vocês são muito 
irresponsáveis", né? Até 'Nossa, é importante o que vocês estão dizendo, mas talvez vocês precisem fazer isso de outra forma."'

Matheus, por sua vez, reclama cuidado, exatamente por parte do UNAIDS e do MS, no sentido de que orientem os YouTubers para que não falem e divulguem informações e posicionamentos que prejudiquem as pautas, mensagens defendidas pelo movimento de aids no campo.

É, e tem uma tensão - e um detalhe quem mexe muito com isso é a UNAIDS, o UNAIDS que impulsiona muito essa onda de YouTubers que levanta muito essa discussão, é uma política da UNAIDS de tentar fortalecer esses YouTubers - e de fato eles são bons, mas precisam ter cuidado naquilo que eles estão falando, porque eles são influenciadores. Aquilo que eu estou falando aqui, que eu falo aqui num grupo no Pelo Vidda, por exemplo, está restrito a um grupo de vinte, trinta pessoas. Eles, na internet, é algo que eles não têm controle. Então, da mesma forma, que pode ter cem acessos, pode ter cem mil. Então, ele tem que ter cuidado com aquilo que ele fala. (Matheus Emílio Pereira da Silva, entrevista)

Um dos entrevistados chama a atenção sobre as formas como as diferentes políticas de enfrentamento da epidemia atribuem sentidos e valores (ou desvalor) às pessoas soropositivas. Assim, metas dos organismos internacionais, anteriores às atuais, visavam ampliar o acesso ao tratamento, já a meta atual intitulada 90-90-90118, visa ao controle da epidemia. De forma que as pessoas vivendo com HIV passam a ser tratadas como doentes que devem ser tratados não por si mesmos - como um valor -, mas porque em estando tratadas se assegura a diminuição da carga viral comunitária e se previnem novas infecções. Como sustentou o entrevistado, tal construção tecnooperativa vulnera a dignidade humana. Nesse sentido, outro entrevistado apontou que

\footnotetext{
118 Meta estabelecida pelo UNAIDS que prevê que $90 \%$ da população deve ser testada, $90 \%$ daqueles identificados como soropositivos devem ser tratados e $90 \%$ dos tratados devem ter carga viral indetectável. Disponível em: http://www.unaids.org/en/resources/documents/2017/90-90-90 [acesso em: 10.05.18].
} 
as pessoas soropositivas não são incluídas na categoria de populações-chave, como se não tivessem uma relevante contribuição e importância estratégica no enfrentamento da epidemia, além de se configurarem em um dos principais compromissos de cuidado das políticas de aids.

\section{Gestão e organização dos serviços}

Uma dimensão central das narrativas dos entrevistados descreve experiências no âmbito dos serviços voltados à prevenção, a relação com os profissionais, os discursos que orientam estas práticas. A expectativa normativa violada, nestes casos, refere-se à desconsideração da singularidade das práticas sexuais e dos arranjos relacionais de gays ao tratar da prevenção.

Mas, assim, não ter gel é um desrespeito, sabe, pra gente assim.

É você não entender o sexo anal, né? E passa batido, assim... Não consegue botar isso no orçamento, sei lá onde é que tá problema. (Carué Contreiras, entrevista)

Uma forte percepção, nesses casos, é de que os discursos dos profissionais não dialogam com suas experiências pessoais. Tratam-se de discursos prescritivos e seus anseios ficam sem respostas:

Porque acho que, até então, o debate que eu tinha era assim "Não pode pegar. Tem que usar camisinha." Mas eu não gosto de usar camisinha... (Ramón Soares, entrevista)

Os arranjos relacionais em que se dão tais práticas, bem como os posicionamentos políticos que as orientam não encontram espaços de escuta no âmbito das políticas e dos serviços de prevenção. O grupo é muito segmentado e tem se transformado significativamente, experimentando, nas novas gerações, padrões bastante fluidos, que reivindicam novos olhares e entendimentos. Diante desses cenários, as políticas e serviços tem alcance muito limitado, pois fundamentam-se em normatividades convencionais.

Porque, por exemplo, se você tem uma política pública que tá pensando prevenção desconsiderando, por exemplo, relações não- 
monogâmicas, né? Ou pensando ou considerando efetivamente... Porque eu acho que uma coisa é levar em consideração que a pessoa vai ter muitos parceiros, a outra é levar efetivamente isso em consideração. E, por exemplo, se você pensa uma política, né? Se você pega uma política pública que consegue fazer um debate sobre isso, você consegue acessar uma determinada parte, por exemplo, do público LGBT, mais especificamente dos HSHs que fazem debates específico político disso, né? Isso pode parecer uma coisa muito longe, mas ela não é, né? Porque uma coisa é eu ser o HSH que tem como perspectiva na vida ter um parceiro estável, ter uma relação estável, que vai durar anos, etc e tal. E uma coisa é pensar, dentro desse esquema de relação, prevenção, saúde, inclusive em sorodiscordância, enfim, etc e tal. E a outra é você pensar isso com um público $\mathrm{HSH}$, por exemplo, que inclusive faz força contra esse discurso monogâmico, né? O que faz discurso ou que vai contra essa lógica. Então, por exemplo, se a gente pensa no conjunto dos HSHs que hoje fazem debate de amor livre, de relações abertas, etc e tal, ou mesmo do conjunto HSH que tá dentro do grupo barebacking, dentro do grupo BDSM, que trabalha de uma outra lógica a prevenção, aí essa extensão conceitual encontra muitas limitações, né? Porque eu acho que ela tem expansão pra abarcar tudo isso, né? Mas é justamente isso, os diferentes departamentos, os diferentes governos, as diferentes pessoas que tão pensando as diferentes políticas, vão afunilando esses conceitos, vão agrupando esses conceitos vão fazendo com que determinadas políticas alcancem ou não alcancem determinadas partes desse conjunto HSH. E que eu acho que, por exemplo, a questão que tem com a juventude, mais especificamente adolescentes HSHs, nesse momento, que todo mundo tá numa tensão... Porque pra além dos HSH é uma faixa etária que tá com toda uma nova realidade de dinâmica sexual, o que a gente tem discutido, muito dentro da Loka, é como acho que enquanto, por exemplo, parte dessa lógica monogâmica, parte dessa lógica cristã de pensar as relações, enquanto isso não for superado, eu acho que dificilmente, por exemplo, essa parcela HSH vai ser alcançada. (Ramón Soares, entrevista)

\section{O desconhecimento sobre as práticas e os arranjos relacionais faz com que os}

profissionais não consigam compreender as demandas colocadas pelo grupo.

Estabelece-se, assim, uma interrupção do diálogo:

Lembrando do desconhecimento da sexualidade, só um caso que eu lembrei do pessoal usando PrEP, da questão da PrEP, lá, que está sendo implementada. E aí, como as pessoas não conseguiam... pra elas, era uma novidade a relação aberta. Isso virou uma... que, aí, tinha um casal que... Isso se colocou, porque, assim, tinha casal que chegava querendo tomar $\operatorname{PrEP}$, né? As pessoas não sabiam, não entendiam. Ah, o que que é relação aberta? (Carué Contreiras, entrevista)

Como que você acha que você pode fazer um trabalho de prevenção singular, achando que você pode ajudar a pessoa a construir 
um projeto de prevenção dela, se eu faço cara super escrota quando ela fala "Ai, eu lambo cu. Eu gosto de leite. Eu sei lá o que mais quero fazer..." Sabe? Então, eu não sei. Pra mim é uma... Eu acho que um pouco a falência, pra mim, da questão da prevenção. A gente tá ligado a pessoas nos centros de saúde que têm... E aí, assim, tô falando no geral. Claro que você tem as exceções. Serviços que são mais friendly, ok, ba-ba-ba. Mas, no geral, são pessoas conservadoras, são pessoas que não têm escuta, que não querem escutar, que tem opinião já super formada sobre as coisas, que vai cagar regra, que vai dizer que você não pode fazer isso, que você não pode fazer aquilo. Mesmo... Assim, pra mim, é um avanço pensar, hoje, que se assume a posição de dizer "As pessoas que estão com carga viral indetectável, elas são intransmissíveis." Porque já se falavam isso quando você quer ter filho. Quando cê quer ter filho, tá dentro de uma situação heteronormativa. Agora, eu não posso falar isso quando eu quero ter prazer?

Na perspectiva da gestão das políticas de prevenção, os entrevistados identificam grande fragilidade das estruturas, o que restringe o alcance das ações:

Tudo perde muito no alcance, na sofisticação, na linguagem, também por falta de orçamento, de pessoal, de você poder contratar profissionais.

O contexto atual, de desmonte das políticas públicas é identificado com enorme preocupação pelos gestores. Há consequências imediatas como a ausência de concursos públicos há anos, de forma que não está assegurada a renovação dos quadros para os serviços públicos.

Tudo o que a gente falou até agora depende de SUS. O próprio SUS, hoje, tá sendo colocado num risco enorme. E risco mesmo, né? Uma outra questão que me preocupa são os profissionais de saúde. Hoje, a gente não tem renovação de quadros pro serviço público. Não tem, praticamente, nenhuma renovação de quadros pro serviço público. Isso em todas as instâncias. Em todas as instâncias, você não tem renovação de quadros. De quadros que possam manter a política, inovar a política. Então é um desafio, talvez o maior. É um desafio. Não ter renovação de quadros e não ter pessoas jovens que possam ser incorporadas a esta discussão, pessoas recentemente formadas, né? Mesmo aqui, a gente hoje tem, fora a parceria com a universidade, a gente hoje carece de renovação de quadros. Eu acho que isso é um problema. Eu acho que isso é um problema enorme, não ter renovação de quadros. Não ter pessoas que possam trazer o novo, né? Eu acho que isso... e se incorporarem nas tarefas do dia-a-dia. As equipes estão cada vez mais reduzidas. (Maria Clara Gianna, entrevista) 


\section{Expectativas normativas em conflito}

A análise das entrevistas expressou dois grandes conflitos no campo que limitam os esforços por prevenção e cuidado. Eles foram tornados visíveis pela abordagem das lutas por reconhecimento. A sistematização das entrevistas permitiu, assim, discernir melhor seus contornos. O primeiro articula-se aos impedimentos crescentes à abordagem da sexualidade, conformando-se como a luta pelo reconhecimento de sujeitos sexuados, com sua diversidade de práticas, identidades e arranjos - abordado anterior e articuladamente às abordagens preventivas. O segundo dos conflitos referese à experiência de rechaço dos soropositivos no universo homossexual e será tratado a seguir.

O argumento central se articula nos termos do estigma da aids que seria atribuído aos homossexuais, como já se pôde notar - anteriormente - na história das respostas à epidemia. O que leva os homossexuais soropositivos a serem duplamente estigmatizados, sendo marcados tanto por sua homossexualidade, como pela soropositividade. De forma que recebem um não-lugar, como se vê no depoimento de Beto de Jesus:

$\mathrm{Na}$ comunidade gay, quando uma pessoa se infecta, ela ganha um não-lugar. A ela é destinado um não-lugar social. Se ela, ainda, consegue manter um corpo sem lipodistrofia, ela ainda consegue... E ela não fala sua sorologia, ela consegue passar. Mas quando você tem qualquer traço de lipodistrofia, é um não-lugar. (Beto de Jesus)

Essa experiência produz enorme dor, afastamento e silenciamento dos soropositivos e uma cisão no âmbito dos movimentos sociais.

Pessoas soropositivas acabam numa tendência, principalmente a medida que vão amadurecendo, isso já é uma coisa normal - mas com o HIV, isso se acelera - de irem se afastando da vida, vamos dizer assim, homossexual, dos locais gays, do estilo de vida, porque não tem lugar, né? Enquanto soropositivo. O nível de rejeição ainda é muito alto, se pessoas soropositivas querem transar com pessoas sabidamente negativas. 
Essa dinâmica esteve presente desde a década de 1980 e permanece em termos muito assemelhados. No trecho a seguir, um jovem militante homossexual conta sobre uma experiência de confronto experimentada em uma reunião com o movimento LGBT

E ele veio com uns papos de "A gente tem que tomar cuidado pra não falar com gay e parecer que a gente tá falando que o HIV tá entre eles, porque não é bem assim". Virei pra ele e falei assim "Cara, eu acho que cê tá bem equivocado com que você tá dizendo. Porque antes de reconhecer o preconceito em qualquer lugar, a gente precisa conhecer o preconceito nessa sala, né?" E aí, uma pessoa que não vê a importância de cuidar da sua comunidade, o orgulho de estar cuidando de sua comunidade, né?

Ao afinar a escuta para as questões trazidas por alguns entrevistados, passei a me questionar sobre o estigma como um conceito operativo. Pois, por ser pouco preciso reforça a dinâmica discriminatória no sentido do que traduzi de Carué como "estigma dos homossexuais" ou como colocado por Ivo como discurso do movimento homossexual: "essa mistura é muito perigosa para nós, porque nós já somos uma população muito estigmatizada, podemos nos tornar mais estigmatizados ainda".

Então, assim, tem isso. Essa coisa que a política de aids é opressora, porque é estigmatizante. Por isso que não é possível usar a palavra estigma dentro do movimento LGBT. Porque quando você fala estigma, quando você fala estigma já é genérico, né? Aí, quando você tenta especificar usando estigma do HIV, eles interpretam como sendo aquilo que eles sofrem, por alguns deles serem promíscuos e terem HIV, entendeu? [risada] Então... Então é isso. Existe esse desconforto.

Observa-se no campo, algumas mudanças em sua configuração. Se o movimento homossexual se institucionalizou fortemente a partir dos anos 1990, mais recentemente, na década de 2010, há diminuição da atuação institucional em um contexto, caracterizado por Facchini e Rodrigues (2017), que passa a valorizar a autonomia e a horizontalidade; o uso da internet e o ciberativismo; ações ativistas de caráter "espontâneo" e lúdico.

Segmentos do movimento institucionalizados neste momento são poucos e focam sua ação na busca da visibilidade e na perspectiva dos direitos. Configuram-se, 
no entanto, em minha avaliação como um movimento social de caráter reacionário se não inclui a dimensão da sexualidade e da soropositividade. 


\section{CONSIDERAÇÕES FINAIS}

Nesta tese procurei responder ao objetivo de compreender de que forma processos de (não)reconhecimento, ou desrespeito, no âmbito do cuidado público de saúde, contribuem para os processos de vulnerabilização de gays e outros homens que fazem sexo com homens (HSH) ao HIV e à aids no contexto da epidemia e das respostas produzidas no Brasil e no estado de São Paulo, em particular.

Para isso, adotei o referencial teórico dos conceitos de vulnerabilidade, cuidado e reconhecimento. Em meu trajeto metodológico, percorri: a realização de entrevistas em profundidade com gestores de políticas públicas de prevenção e ativistas dos movimentos LGBT e de aids; a elaboração de uma breve narrativa histórica sobre as respostas político-institucionais voltadas à prevenção de HIV/Aids para gays e HSH no Brasil gays e HSH, vigentes nas décadas de 1980, 1990 e 2000, com base nas narrativas produzidas e seus cotejamentos; uma análise da situação atual buscando interpretá-la, preliminarmente, sob a perspectiva do conceito de reconhecimento.

Identifiquei na história das políticas que houve momentos de próspera convergência de movimentos sociais, em torno da redemocratização, da crescente cidadanização das sexualidades dissidentes e da progressiva garantia do direito à saúde, articulada à construção de repertório tecno-conceitual para o fortalecimento da equidade em saúde.

No âmbito da comunidade homossexual sempre se observou uma dupla força de aproximação e distanciamento em relação às políticas de aids. Aproximando-se do financiamento que contribuiu com a institucionalização do movimento e com seu fortalecimento no país, mas evitando a inserção substantiva da aids e dos homossexuais soropositivos em sua agenda.

Em diálogo com a teoria do reconhecimento, apontei as principais dimensões em conflito na atualidade e no campo, assim como identifiquei as expectativas normativas violadas, tal como expressas nas narrativas pelos entrevistados, em suas experiências com as políticas de prevenção. 
Ficou claro que políticas de prevenção centradas nos indivíduos e focadas naqueles soronegativos para o HIV fragilizam a construção de respostas inovadoras e significativas por parte da comunidade, pois reforçam a ação tecnicista e individualizam as experiências dos sujeitos diante dos inúmeros desafios colocados pelo HIV e pela aids às suas vidas. Na dimensão individual e interpessoal, produzem experiências de culpa, sensação de fracasso e a cisão da comunidade, dividida entre negativos e positivos, embrenhando solidão, isolamento e silêncio nas vidas de homossexuais masculinos.

Há mudanças significativas nas experiências de ativismo nos movimentos LGBT e de aids, sendo que as movimentações das novas gerações são menos institucionalizadas, o que abre uma perspectiva interessante de ação comunitária, mas também traz desafios importantes que envolvem, inclusive, a possibilidade de que possam efetivamente construir uma ação significativa. Para que isso aconteça, apontase a recomendação de que não sejam instrumentados como reprodutores de discursos tecnicistas, focados em indivíduos soronegativos, na promoção do comportamento responsável, com vistas a promover capacidades de mobilizar sua comunidade.

Algumas questões se colocam para o movimento sobre como lidar politicamente com as demandas colocadas: a sexualidade com suas variadas expressões e a soropositividade.

Gostaria de destacar como contribuição da abordagem das lutas por reconhecimento, a politização e o foco na identificação dos conflitos encobertos no campo que impedem e reclamam transformações. 


\section{REFERÊNCIAS}

ABEP. Critério Brasil de classificação econômica [internet]. São Paulo; 2008 [citado 23 fev. 2014]. Disponível em: <http://www.abep.org/criterio-brasil $>$.

ABGLT. Juntos somos mais fortes. Curitiba; 2003 [citado 2 jul. 2014]. Disponível em: $<$ http://www.abglt.org.br/prog/somosport.zip >.

ABIA [internet]. Pela Vida/SP e ABIA divulgam propostas para enfrentar a epidemina da AIDS entre homossexuais. Rio de Janeiro; 2007 [citado 13 jun. 2018]. Disponível em: $<$ http://abiaids.org.br/pela-vidasp-e-abia-divulgam-propostas-para-enfrentar-a-epidemina-daaids-entre-homossexuais/26408>.

Abreu CF. Cartas. Moriconi I, organizador. Rio de Janeiro: Aeroplano; 2002.

Almeida R. A onda quebrada: evangélicos e conservadorismo. Cad. Pagu [online]. 2017 [citado 5 jun. 2017]; 50(e175001). Disponível em: <http://dx.doi.org/10.1590/18094449201700500001>

Alvarez SE. Para além da sociedade civil: reflexões sobre o campo feminista. Cad. Pagu. 2014; 43: 13-56.

Anderson B. Comunidades imaginadas: reflexões sobre a origem e a difusão do nacionalismo. São Paulo: Companhia das Letras; 2008.

Auvert B, Taljaard D, Lagarde E, Sobngwi-Tambekou J, Sitta R, Puren A. Randomized, controlled intervention trial of male circumcision for reduction of HIV infection risk: the ANRS 1265 trial. PLoS medicine. 2005 [cited 2018 May 8]; 2(11):e298. Disponível em:

<http://journals.plos.org/plosmedicine/article?id=10.1371/journal.pmed.0030226>.

Ayres JRCM. Cuidado: filosofia e humanização da atenção à saúde (2011). Adaptado do artigo original: Ayres, JRCM. O cuidado, os modos de ser (do) humano e as práticas de saúde. Saúde e Sociedade. 2004a ;13(3):16-29.

Ayres JRCM. O cuidado, os modos de ser (do) humano e as práticas de saúde. Saude soc. [Internet]. 2004b [citado 10 mai. 2018]; 13(3):16-29. Disponível em:

$<$ http://www.scielo.br/scielo.php?script=sci_arttext\&pid=S0104-

$12902004000300003 \& \operatorname{lng}=e n>$.

Ayres JRCM. Cuidado: trabalho e interação nas práticas de saúde. Rio de Janeiro: CEPESCUERJ/IMS-ABRASCO; 2009. p. 129-55: Para compreender o sentido prático das ações de saúde. (Clássicos para Integralidade em Saúde).

Ayres JRCM. O cuidado e o espaço público da saúde: virtude, vontade e reconhecimento na construção política da integralidade. In: Pinheiro R; Silva Júnior AG, organizadores. Cidadania no cuidado: o universal e o comum na integralidade das ações de saúde. Rio de Janeiro: IMS/UERJ - CEPESC; 2011. v.1, p. 27-44. 
Ayres JRCM. Cuidado e reconstrução das práticas de Saúde. Interface (Botucatu) [Internet]. 2004c [citado 10 mai. 2018]; 8(14):73-92. Disponível em:

<http://www.scielo.br/scielo.php?script=sci_arttext\&pid=S1414-

32832004000100005\&lng=en>.

Ayres JRCM. Epidemiologia e emancipação. São Paulo: HUCITEC; Rio de Janeiro: ABRASCO; 1995.

Ayres JRCM. Georges Canguilhem e a construção do campo da saúde coletiva brasileira. Intelligere. 2016 [citado 19 dez. 2017]; 2(1):138-154. Disponível em:

$<$ http://revistas.usp.br/revistaintelligere>.

Ayres JRCM. Integralidade do cuidado, situações de aprendizagem e o desafio do reconhecimento mútuo. In: Pinheiro R, Lopes TC, organizadores. Ética, técnica e formação: as razões do cuidado como direito à saúde. Rio de Janeiro: CEPESC-IMS/UERJ-ABRASCO; 2010. v.1, p. 123-153.

Ayres, José Ricardo de Carvalho Mesquita. Para comprender el sentido práctico de las acciones de salud: contribuciones de la Hermenéutica Filosófica. Salud colectiva, v. 4, n. 2, p. 159-172, 2008. Disponível em: http://www.scielo.org.ar/scielo.php?script=sci_arttext\&pid=S185182652008000200007

Ayres JRCM. Práticas educativas e prevenção de HIV/Aids: lições aprendidas e desafios atuais. Interface - Comunic, Saúde, Educ. 2002;6(11):11-24.

Ayres JRCM. Prevenção de agravos, promoção da saúde e redução de vulnerabilidade. In: Martins MA, Carrilho FJ, Alves VA, Castilho CG, Wen CL, organizadores. Clínica médica. Barueri: Manole; 2009. v. 1, p. 437-455.

Ayres JRCM. Repensando conceitos e práticas em saúde pública. In: Parker R, Terto Jr. V, organizadores. Aprimorando o debate: respostas sociais frente à AIDS. (Anais do Seminário Prevenção à AIDS; Limites e Possibilidades na Terceira Década). Rio de Janeiro: ABIA, 2002. p. 12-19.

Ayres JRCM. Sobre o risco: para compreender a epidemiologia. São Paulo: HUCITEC; 1997.

Ayres JRCM. Sujeito, intersubjetividade e práticas de saúde. Ciênc. saúde coletiva [Internet]. 2001 [citado 10 maio 2018]; 6(1):63-72. Disponível em:

<http://www.scielo.br/scielo.php?script=sci_arttext\&pid=S1413-

$81232001000100005 \& \operatorname{lng}=e n>$.

Ayres JRCM. Uma concepção hermenêutica de saúde. Physis [Internet]. 2007 [citado 10 maio 2018]; 17(1):43-62. Disponível em:

$<$ http://www.scielo.br/scielo.php?script=sci_arttext\&pid=S0103-

$73312007000100004 \& \operatorname{lng}=e n>$.

Ayres JRCM. Vulnerabilidade, direitos humanos e cuidado: aportes conceituais. In: Barros S, Campos PFS, Fernandes JJS, organizadores. Atenção à saúde de populações vulneráveis. Barueri: Manole; 2014. p. 1-25. (Enfermagem e Saúde, 4).

Ayres JRCM, Calazans GJ, Saletti Filho HC, França Júnior I. Risco, vulnerabilidade e práticas de prevenção e promoção da saúde. In: Campos GWS, Bonfim JRA, Minayo MCS, Akerman M, 
Drumond Júnior M, Carvalho YM, organizadores. Tratado de Saúde Coletiva. Rio de Janeiro: Fiocruz; 2006. p. 375-417.

Ayres JRCM, França Júnior I, Calazans GJ, Saletti Filho HC. O conceito de vulnerabilidade e as práticas de saúde: novas perspectivas e desafios. In: Czeresnia D, Freitas CM, organizadores. Promoção da saúde: conceitos, desafios, tendências. Rio de Janeiro: Fiocruz; 2003. p. 117-38.

Ayres JRCM, Paiva V, França Júnior I. Conceitos e práticas de prevenção: da história natural da doença ao quadro da vulnerabilidade e direitos humanos. In: Paiva V, Ayres JRCM, Buchalla C. Vulnerabilidade e direitos humanos: prevenção e promoção da saúde: da doença à cidadania. Livro I. Curitiba: Juruá; 2012. p. 71-94.

Ayres JRCM, Paiva V, França Júnior I. From natural history of disease to vulnerability: changing concepts and practices in contemporary public health. In: Parker R, Sommer M, editors. Routledge handbook of global public health. Abingdon: Taylor and Francis; 2011. p. 98-107.

Ayres JRCM, Santos L, organizadores. Saúde, sociedade e história: uma revisita às contribuições de Ricardo Bruno Mendes-Gonçalves. São Paulo: Hucitec; Porto Alegre: Rede Unida; 2017. (Saúde em Debate, 270).

Baggaley RF, White RG, Boily MC. Systematic review of orogenital HIV-1 transmission probabilities. Int J Epidemiol. 2008; 37(6):1255-1265.

Bailey RC, Moses S, Parker CB, Agot K, Maclean I, Krieger JN, Williams CF, Campbell RT, NdinyaAchola JO. Male circumcision for HIV prevention in young men in Kisumu, Kenya: a randomised controlled trial. Lancet. 2007; 369(9562):643-56.

Baral S, Sifakis K, Cleghorn F, Beyrer C. Elevated risk for HIV infection among men who have sex with men in low and middle-income countries 2000-2006: a systematic review. PLoS Med. 2007 [citado 27 abr. 2018]; 4:e399. Disponível em:

<http://journals.plos.org/plosmedicine/article?id=10.1371/journal.pmed.0040339>.

Barbosa-Júnior A, Szwarcwald CL, Pascom ARP, Souza Júnior PB. Tendências da epidemia de AIDS entre subgrupos sob maior risco no Brasil, 1980-2004. Cad. Saúde Pública [online]. 2009 [citado 28 abr. 2018]; 25(4):727-737. Disponível em:

<https://www.arca.fiocruz.br/bitstream/icict/830/2/Landmann_Tend\%C3\%AAncias\%20da\%20 epidemia.pdf>.

Barcellos NT, Fuchs SC, Fuchs FD. Prevalence of and risk factors for HIV infection in individuals testing for HIV at counseling centers in Brazil. Sex Transm Dis. 2003 [cited 2018 Mar 17]; 30(2):166-73. Available from: <https://www.ncbi.nlm.nih.gov/pubmed/12567177>.

Beloqui JA. Risco relativo para Aids de homens homo/bissexuais em relação aos heterossexuais. Rev. Saúde Pública [online]. 2008 [citado 17 mar. 2018]; 42(3):437-442. Disponível em: <http://www.producao.usp.br/bitstream/handle/BDPI/11969/art BELOQUI Risco relativo pa ra Aids de homens homo-bissexuais 2008.pdf?sequence $=1>$.

Beloqui JA. Risco relativo para Aids dos homossexuais masculinos no Brasil. Cadernos Pela Vidda. 2006;16(42):16-9. 
Beloqui Jorge e Terto Jr Veriano. A prevenção à AIDS no governo Dilma e a censura dos vídeos da campanha do Carnaval de 2012. [acesso em 25.09.2017]. Disponível em: http://www.clam.org.br/uploads/conteudo/artigoveriano.pdf http://www.clam.org.br/busca/conteudo.asp?cod=9212.

Berkman A, Garcia J, Munoz-Laboy M, Paiva V, Parker R. A critical analysis of the Brazilian response to HIV/AIDS: lessons learned for controlling and mitigating the epidemic in developing countries. Am J Public Health. 2005;95(7):1162-72. Epub 2005/06/04.

Berquó E, Barbosa RM. Uso do preservativo: tendências entre 1998 e 2005 na população brasileira. Rev. Saúde Pública [periódico da internet]. 2008 [citado 24 fev. 2014]; 42(Suppl1):3444. Disponível em:

$<$ http://www.scielo.br/scielo.php?script=sci_nlinks\&ref=000125\&pid=S0102-

311X201000040002300014\&lng=en->.

Beyrer C, Baral SD, Griensven F, Goodreau SM, Chariyalertsak S, Wirtz AL, Brookmeyer R. Global epidemiology of HIV infection in men who have sex with men. Lancet. 2012 [cited 2017 Mar 17]; 380(9839):367-77. Available from:

<https://www.thelancet.com/journals/lancet/article/PIIS0140-6736(12)60821-6/fulltext>.

Biroli F. Reação conservadora, democracia e conhecimento. Revista de Antropologia (São Paulo). 2018 [citado 10 maio 2018]; 61(1):83-94. Disponível em:

<http://www.revistas.usp.br/ra/article/view/145515/139668>.

Brasil. Conselho Nacional de Combate à Discriminação. Brasil Sem Homofobia: Programa de combate à violência e à discriminação contra GLTB e promoção da cidadania homossexual. Brasília: Ministério da Saúde; 2004.

Brasil. Constituição 1988. Constituição da República Federativa do Brasil. Brasília (DF): Senado; 1988 [citado 2 mai. 2014]. Disponível em:

<http://www.senado.gov.br/legislacao/const/con1988/CON1988 04.02.2010/CON1988.pdf>.

Brasil. Ministério da Saúde. Secretaria de Assistência à Saúde. Programa Nacional de Doenças Sexualmente Transmissíveis/AIDS. Manual do Multiplicador - Homossexual. Brasília: Ministério da Saúde; 1996.

Brasil. Ministério da Saúde. Secretaria Executiva. Coordenação Nacional de DST e Aids. $A$ contribuição dos estudos multicêntricos frente à epidemia de HIV/AIDS entre UDI no Brasil: 10 anos de pesquisa e redução de danos. Brasília (DF); 2001. (Série Avaliação, 8) - (Série C. Projetos, Programas e Relatórios, 58).

Brasil. Ministério da Saúde. Secretaria de Gestão Estratégica e Participativa. Política Nacional de Saúde Integral de Lésbicas, Gays, Bissexuais, Travestis e Transexuais. Brasília: Ministério da Saúde; 2012.

Brasil. Ministério da Saúde. Secretaria de Políticas de Saúde. Coordenação Nacional de DST e Aids. Bela Vista e Horizonte: estudos comportamentais e epidemiológicos entre homens que fazem sexo com homens. Brasília (DF); 2000. (Avaliação, 5). 
Brasil. Ministério da Saúde. Secretaria de Políticas de Saúde. Coordenação Nacional de DST e Aids. Guia de Prevenção das DST/Aids e Cidadania para Homossexuais. Brasília; 2002. (Manuais, 52).

Brasil. Ministério da Saúde. Plano Nacional de Enfrentamento da Epidemia de Aids e DST entre Gays, outros Homens que fazem Sexo com Homens (HSH) e Travestis. Brasília: Ministério da Saúde; 2007.

Brasil. Ministério da Saúde. Secretaria de Vigilância em Saúde. Departamento de DST, Aids e Hepatites Virais. Recomendações para terapia antirretroviral em adultos infectados pelo HIV 2008. Suplemento III - Tratamento e prevenção. Brasília: Ministério da Saúde; 2010.

Brasil. Ministério da Saúde. Secretaria de Vigilância em Saúde. Departamento de DST, Aids e Hepatites Virais. PCAP - Pesquisa de conhecimentos, atitudes e práticas na população brasileira. Brasília (DF); 2011. (Série G. Estatística e Informação em Saúde).

Brasil. Ministério da Saúde. Secretaria de Vigilância em Saúde. Departamento de Vigilância, Prevenção e Controle das Infecções Sexualmente Transmissíveis, do HIV/Aids e das Hepatites Virais. Boletim Epidemiológico - Aids e DST. Brasília (DF): Ministério da Saúde - Secretaria de Vigilância em Saúde - Departamento de Vigilância, Prevenção e Controle das Infecções Sexualmente Transmissíveis, do HIV/Aids e das Hepatites Virais; 2008. Semanas epidemiológicas: 27aa a 52ạ de 2007 e 1a a 26a de 2008.

Brasil. Ministério da Saúde. Secretaria de Vigilância em Saúde. Departamento de Vigilância, Prevenção e Controle das Infecções Sexualmente Transmissíveis, do HIV/Aids e das Hepatites Virais. Boletim Epidemiológico - Aids e DST. Brasília (DF) Ministério da Saúde; 2011. Semanas epidemiológicas: 27aa a 52a de 2010 e 1a a 26a de 2011.

Brasil. Ministério da Saúde. Secretaria de Vigilância em Saúde. Departamento de Vigilância, Prevenção e Controle das Infecções Sexualmente Transmissíveis, do HIV/Aids e das Hepatites Virais. Boletim Epidemiológico - Aids e DST. Brasília (DF): Ministério da Saúde; 2013. Semanas epidemiológicas: até 26ạ semana epidemiológica de dez. 2013.

Brasil. Ministério da Saúde. Secretaria de Vigilância em Saúde. Departamento de DST, Aids e Hepatites Virais. Protocolo Clínico e Diretrizes Terapêuticas para Profilaxia Antirretroviral PósExposição de Risco à Infecção pelo HIV. Brasília: Ministério da Saúde; 2015.

Brasil. Ministério da Saúde. Secretaria de Vigilância em Saúde. Departamento de Vigilância, Prevenção e Controle das Infecções Sexualmente Transmissíveis, do HIV/Aids e das Hepatites Virais. Boletim Epidemiológico - Aids e DST. Brasília (DF): Ministério da Saúde; 2016. Semanas epidemiológicas: 27a a 53a de jul. a dez. de 2015 e 1a a 26a de jan. a jun. de 2016.

Brasil. Ministério da Saúde. Secretaria de Vigilância em Saúde. Departamento de Vigilância, Prevenção e Controle das Infecções Sexualmente Transmissíveis, do HIV/Aids e das Hepatites Virais. Boletim Epidemiológico HIV/AIDS. Brasília (DF): Ministério da Saúde; 2017. Semanas epidemiológicas: 27ạ a 53a de jul. a dez. de 2016 e 1a a 26a de jan. a jun. de 2017a.

Brasil. Ministério da Saúde. Secretaria de Vigilância em Saúde. Departamento de Vigilância, Prevenção e Controle das Infecções Sexualmente Transmissíveis, do HIV/Aids e das Hepatites Virais. Prevenção Combinada do HIV/Bases conceituais para profissionais, trabalhadores(as) e 
gestores(as) de saúde/Ministério da Saúde, Secretaria de Vigilância em Saúde, Departamento de Vigilância, Prevenção e Controle das Infecções Sexualmente Transmissíveis, do HIV/Aids e das Hepatites Virais. - Brasília: Ministério da Saúde; 2017b. 123 p.: il.

Brasil. Ministério da Saúde. Protocolo clínico e diretrizes terapêuticas para Profilaxia Préexposição (PrEP) de risco à infecção pelo HIV. Brasília: Ministério da Saúde; 2017c.

Brasil. Ministério da Saúde. Secretaria de Vigilância em Saúde. Programa Nacional de DST e Aids. PCAP - Pesquisa de conhecimento, atitudes e práticas na população brasileira de 15 a 54, 2004. Brasília (DF); 2005.

Brasil. Ministério da Saúde. Secretaria de Vigilância em Saúde. Programa Nacional de DST e Aids. Projeto Somos Desenvolvimento Organizacional, Advocacy e Intervenção para ONGs que trabalham com GAYS e outros HSH. Brasília; 2005. (Manuais, 65).

Brasil. Presidência da República. Anais da Conferência Nacional de Gays, Lésbicas, Bissexuais, Travestis e Transexuais - GLBT. Brasília: Presidência da República; 2008.

Brasil. Presidência da República. Conselho Nacional LGBT. Anais da 2a Conferência Nacional de Políticas Públicas e Direitos Humanos para Lésbicas, Gays, Bissexuais, Travestis e Transexuais LGBT. Brasília: Presidência da República; 2011.

Brasil. Presidência da República. Relatório final - 3a Conferência nacional de políticas públicas de direitos humanos de lésbicas, gays, bissexuais, travestis e transexuais. Brasília: Presidência da República; 2016.

Brito AM, Sousa JL, Luna CF, Dourado MI. Tendência da transmissão vertical de Aids após terapia anti-retroviral no Brasil. Rev. Saúde Pública [Internet]. 2006 [acesso 28 abr. 2018]; 40 (Suppl): 18-22. Disponível em:

$<$ http://www.scielo.br/scielo.php?script=sci_arttext\&pid=S0034-

$89102006000800004 \& \operatorname{lng}=e n>$.

Bulgarelli L. [Alerta Textão]: estratégias de engajamento do movimento LGBT de São Paulo em espaços de interação online e offline (2015-2016) [dissertação]. São Paulo: Faculdade de Filosofia, Letras e Ciências Humanas da Universidade de São Paulo; 2017.

Buse K, Dickinson C, Sidibé M. HIV: know your epidemic, act on its politics. J R Soc Med. 2008 [cited 2018 Mar 18]; 101(12):572-573. Available from:

<https://www.ncbi.nlm.nih.gov/pmc/articles/PMC2625375/>.

Buss P. Uma introdução ao conceito de promoção da saúde. In: Czeresnia D, Freitas CM, organizadores. Promoção da saúde: conceitos, reflexões, tendências. Rio de Janeiro: FIOCRUZ; 2003. p. 15-38.

Cáceres CF. Epidemiology of HIV/AIDS infection among men who have sex with men in Latin America and the Caribbean: current situation and recommendations for epidemiological surveillance. In: Cáceres CF, Pecheny M, Terto Júnior V, editors. Aids and male-to-male sex in Latin America: vulnerabilities, strengths and proposed measures - perspectives and reflections from the point of view of public health, social sciences and activism. [Lima]: UPCH/UNAIDS; 2002. p. 23-54. 
Cáceres CF, Pecheny M, Frasca T, Rios RR, Pocahy F. Review of legal frameworks and the situation of human rights related to sexual diversity in low and middle income countries. Porto Alegre: UNAIDS; 2009. (Draft report).

Cadernos Pela Vidda. Homossexuais e Aids, a epidemia negligenciada. São Paulo 2006;16(42).

Cadernos SECAD 4 [Ministério da Educação]. Gênero e Diversidade Sexual na Escola: reconhecer diferenças e superar preconceitos. Brasília: Ministério da Educação - Secretaria de Educação Continuada, Alfabetização e Diversidade; 2007.

Cai WD, Zhao J, Raymond HF, Feng YJ, Liu J, McFarland W, Gan YX, Yang ZR, Zhang Y, Tan JG, Wang XR, He ML, Cheng JQ, Chen L. HIV prevalence and related risk factors among male sex workers in Shenzhen, China - results from a time-location-sampling survey. Sex Transm Infect. 2009;86(1):15-20. Epub 2009 Oct 22.

Calazans G. Prevenção ao HIV/Aids, estigmatização e vulnerabilidade. In: Venturi G, Bokani V, organizadores. Diversidade sexual e homofobia no Brasil. São Paulo: Editora Perseu Abramo; 2011. p. 141-154.

Câmara C. Articulações entre governo e sociedade civil: um diferencial na resposta brasileira à AIDS.Impulso (Piracicaba). 2002; 32: 57-67.

Câmara C. Um olhar sobre a história do ativismo LGBT no Rio de Janeiro. Rev do Arquivo Geral da Cidade do Rio de Janeiro. 2015; 9:373-396.

Camargo Júnior KR. Prevenção do HIV: desafios múltiplos [HIV prevention: multiple challenges]. Divulgação Saúde Debate. 2003;70-80:204-14.

Carneiro M, Cardoso FA, Greco M, Oliveira E, Andrade J, Greco DB, Antunes CM. Determinants of human immunodeficiency virus (HIV) prevalence in homosexual and bisexual men screened for admission to a cohort study of HIV negatives in Belo Horizonte, Brazil: project Horizonte. Mem Inst Oswaldo Cruz. 2003;98(3):325-9.

Carneiro M, Figueiredo ACM, Greco M, Oliveira E, Andrade J, Lignani Junior L, Greco DB. Design, implementation, and evaluation at entry of a prospective cohort study of homosexual and bisexual HIV-1-negative men in Belo Horizonte, Brazil: Project Horizonte. J Acquir Immune Defic Syndr. 2000; 25(2):182-17.

Carrara S. A antropologia e o processo de cidadanização da homossexualidade no Brasil. Cad. Pagu. 2016 [citado 5 jan. 2017]; 47. e164717. Disponível em:

$<$ http://www.scielo.br/scielo.php?script=sci_arttext\&pid=S0104-

$83332016000200604 \&$ Ing=en\&nrm=iso>.

Carrara S. Moralidades, racionalidades e políticas sexuais no Brasil contemporâneo. Mana (Rio de Janeiro). 2015 [citado 5 jan. 2017]; 21(2):323-345. Disponível em:

$<$ http://www.scielo.br/scielo.php?script=sci_arttext\&pid=S0104-

93132015000200323\&lng=en\&nrm=iso>.

Carrara S, França IL, Simões JA. Conhecimento e práticas científicas na esfera pública: antropologia, gênero e sexualidade. Revista de Antropologia (São Paulo). 2018 [citado 8 mai. 2018]; 61(1):71-82. Disponível em:

<http://www.periodicos.usp.br/ra/article/view/145514>. 
Carrara S, Simões JA. Sexualidade, cultura e política: a trajetória da identidade homossexual masculina na antropologia brasileira. Cad. Pagu. 2007 [citado 10 out. 2017]; 28:65-99. Disponivel em: <http://www.scielo.br/scielo.php?script=sci_arttext\&pid=S0104$83332007000100005 \& \operatorname{lng}=e n \& n r m=i s o>$.

Castro C, Pedrosa F, organizadores. Rede SAGAS Brasil: interações preventivas com juventudes homossexuais, mulheres lésbicas e pessoas vivendo com HIV/AIDS. Fortaleza: GRAB; 2012.

Celum C, Baeten JM, Hughes JP, Barnabas R, Liu A, Rooyen H, Buchbinder S. Integrated strategies for combination HIV prevention: principles and examples for men who have sex with men in the Americas and heterosexual African populations. J Acquir Immune Defic Syndr. 2013;63(02): S213-20. Epub 2013/06/21.

Celum C, Hallett TB, Baeten JM. HIV-1 prevention with ART and PrEP: mathematical modeling insights into resistance, effectiveness, and public health impact. J Infect Dis. 2013; 208(2):18991. Epub 2013 Apr 9.

Chequer P, Marins JRP, Possas C, Valero JDA, Bastos FI, Hearst N. AIDS research in Brazil [Introduction]. AIDS. 2005;19(4):S1-S3.

Chequer P, Teixeira PR, Grangeiro A. Entre a ousadia e o retrocesso. Folha de S. Paulo, São Paulo. 2013 jun. 16; Opinião.

Cohn A. A saúde na previdência social e na seguridade social: antigos estigmas e novos desafios. In: Cohn A, Elias PEM. Saúde no Brasil: políticas e organização de serviços. 5a ed. São Paulo: Cortez: CEDEC; 2003. P. 13-57.

Contreiras C. O HIV no fundo do armário. In: Cidade Queer, uma leitora. São Paulo: Edições Aurora: Publication Studio SP; 2017.

Contrera WF. GAPAS: uma resposta comunitária à epidemia da AIDS no Brasil. Fortaleza: Encaixe; 2000.

Cornejo-Valle M, Pichardo JI. La "ideología de género" frente a los derechos sexuales y reproductivos. El escenario español. Cad. Pagu. 2017 [citado 5 abr. 2018]; 50(175009). Disponível em: <http://www.scielo.br/scielo.php?script=sci_arttext\&pid=S0104$83332017000200501 \&$ lng=en\&nrm=iso>.

Corrêa S, Pimenta C, Maksud I, Deminicis S, Olivar JM. Sexualidade e desenvolvimento: a política brasileira de resposta ao HIV/AIDS entre profissionais do sexo [Relatório de Pesquisa]. Rio de Janeiro: ABIA; 2011.

Daniel H. Vida antes da morte. Rio de Janeiro: ABIA; 1989.

Daniliauskas M. Não se nasce militante, torna-se: processo de engajamento de jovens LGBT panorama histórico na cidade de São Paulo e cenário atual em Paris [tese]. São Paulo: Faculdade de Educação da Universidade de São Paulo; 2016.

Doneda D, Brito I, Gandolfi D. Interfaces entre a prevenção e a assistência às DST e AIDS na perspectiva do Sistema Único de Saúde: avaliação e crítica das ações desenvolvidas pela Coordenação Nacional de DST e Aids. In: Parker R, Terto Jr. V, organizadores. Aprimorando o 
debate: respostas sociais frente à AIDS. (Anais do Seminário Prevenção à AIDS; Limites e Possibilidades na Terceira Década). Rio de Janeiro: ABIA, 2002. p. 36-8.

Dourado I, MacCarthy S, Reddy M, Calazans G, Gruskin S. Revisitando o uso do preservativo no Brasil. Rev. bras. epidemiol. [Internet]. 2015 [acesso 20 abr. 2017]; 18(Suppl 1):63-88. Disponível em: $<$ http://www.scielo.br/scielo.php?script=sci_arttext\&pid=S1415$790 \times 2015000500063 \& \operatorname{lng}=e n>$.

Duarte CAE. O paradoxo da descentralização no financiamento para as ações de DST/AIDS: visão das entidades representativas do movimento social em municípios do Rio Grande do Sul. [Trabalho de conclusão do curso - Especialização em Saúde Pública). Porto Alegre: Universidade Federal do Rio Grande do Sul; 2008.

Duarte LFD, Barsted LL, Taulois MR, Garcia MH. Vicissitudes e limites da conversão à cidadania nas classes populares brasileiras. Revista Brasileira de Ciências Sociais. 1993; 22(8):24-40.

El-Sadr WM, Serwadda DM, Sista N, Cohen MS. HIV prevention: great achievements, more challenges ahead. J Acquir Immune Defic Syndr. 2013;63(Suppl 2): S115-6. Epub 2013/06/21.

Epstein S. Impure Science: AIDS, Activism, and the Politics of Knowledge. Berkeley: University of California Press, 1996. [cited Jun 17 2017]. Available from: <http://ark.cdlib.org/ark:/13030/ft1s20045x/>.

Escorel S. Reviravolta na saúde: origem e articulação do movimento sanitário [online]. Rio de Janeiro: Editora FIOCRUZ; 1999 [citado 26 mar. 2018]. Disponível em: <http://books.scielo.org/id/qxhc3/pdf/escorel-9788575413616.pdf>.

Facchini R. Entre umas e outras: mulheres, (homo)sexualidades e diferenças na cidade de São Paulo [tese]. Campinas: IFCH - Instituto de Filosofia e Ciências Humanas da Unicamp; 2008.

Facchini R. Sopa de letrinhas? Movimento homossexual e produção de identidades coletivas nos anos 90. Rio de Janeiro: Garamond; 2005.

Facchini R, Rodrigues J. Que onda é essa? Guerras culturais e movimento LGBT no cenário brasileiro contemporâneo. In: Machado FV, Barnart F, Mattos R, organizadores. A diversidade e a livre expressão sexual entre as ruas, as redes e as políticas públicas. Porto Alegre: Editora Rede Unida; 2017. p. 35-60.

Facchini R, Sivori H. Conservadorismo, direitos, moralidades e violência: situando um conjunto de reflexões a partir da Antropologia. Cad. Pagu. 2017 [citado 5 abr. 2018]; 50 (e175000). Disponível em:

<http://www.scielo.br/scielo.php?script=sci_arttext\&pid=S0104-

$83332017000200301 \& \operatorname{lng}=e n \& n r m=i s o>$.

Facchini, Regina et al. "A prevenção não sobe a Augusta": homossexualidade, HIV, "risco" e produção de fronteiras na região central da cidade de São Paulo. Sexualidad, Salud y Sociedad. 2018. $N^{\circ}$ 29. Disponível em <http://dx.doi.org/10.1590/1984-6487.sess.2018.29.16.a>.

Ferraz D, Calazans G, Terto Junior V, Grangeiro A, Paiva V. AIDS In Brazil: What Keep Us Awake? (oral presentation CS43). In: 2nd International HIV Social Sciences and Humanities Conference; 7-10 July. Paris: France; 2013. 
Ferreira AD, Caiaffa WT, Bastos FI, Mingoti SA. Profile of male Brazilian injecting drug users who have sex with men. Cad. Saúde Pública [Internet]. 2006 [cited 2018 Mar 17]; 22(4):849-860. Available from: <http://www.scielo.br/scielo.php?script=sci_arttext\&pid=S0102$311 \times 2006000400023 \& \operatorname{lng}=e n>$.

Ferreira LO, Sabino OE, Raymond HF, Chen SY, McFarland W. Use of time-location sampling for systematic behavioral surveillance of truck drivers in Brazil. AIDS Behav. 2008;12(4):S32-8.

Figueiredo R, Coutinho C. A eleição de 2002. Opinião Pública. 2003;9(2):93-117.

Fonseca EM, Nunn A, Souza-Junior PB, Bastos FI, Ribeiro JM. Descentralização, AIDS e redução de danos: a implementação de políticas públicas no Rio de Janeiro, Brasil. Cad. Saúde Pública. 2007;23(9):2134-44.

Fonseca MGP, Bastos Fl. Twenty-five years of the AIDS epidemic in Brazil: principal epidemiological findings, 1980-2005. Cad. Saúde Pública [Internet]. 2007 [cited 2018 Mar 17];23(Suppl 3):S333-S343. Available from:

$<$ http://www.scielo.br/scielo.php?script=sci_arttext\&pid=S0102-

$311 \times 2007001500002 \& \operatorname{lng}=e n>$.

França IL. Cercas e pontes: movimento GLBT e mercado GLS na cidade de São Paulo. [dissertação]. São Paulo: Faculdade de Filosofia, Letras e Ciências Humanas da USP; 2006.

França IL. Consumindo lugares, consumindo nos lugares: consumo, homossexualidade e produção de subjetividades na cidade de São Paulo [tese]. São Paulo: Programa de Doutorado em Ciências Sociais da Unicamp; 2010.

França IL. Masculinidades em diálogo: homossexualidade, consumo e produção de subjetividades em São Paulo [Relatório de qualificação para o doutorado em Ciências Sociais]. Campinas: IFCH- Instituto de Filosofia e Ciências Humanas da Unicamp; 2008. Mimeo.

França IL. Sobre 'guetos' e 'rótulos': tensões no mercado GLS na cidade de São Paulo. Cad. Pagu. 2007 [citado 17 mar. 2018]; 28:227-255. Disponível em:

<https://periodicos.sbu.unicamp.br/ojs/index.php/cadpagu/article/view/8644804>.

Fry P, MacRae E. O que é homossexualidade. São Paulo: Abril Cultural: Brasiliense; 1985. (Primeiros Passos, 26).

Funari SL. A percepção de risco nas práticas de sexo bucal frente à epidemia do HIV [dissertação]. São Paulo: Instituto de Pesquisa da Secretaria de Estado da Saúde; 2003.

Gadamer HG. Verdade e método: traços fundamentais de uma hermenêutica filosófica. Tradução de Flávio Paulo Meurer. 3a ed. Petrópolis: Vozes; 1997. p. 406-411.

Galvão J. AIDS no Brasil: a agenda de construção de uma epidemia. São Paulo: Editora 34; Rio de Janeiro: ABIA; 2000.

Gianna MC, Kalichman A, Paula I, Cervantes V, Shimma E. Políticas públicas e prevenção das DST/AIDS: ontem, hoje e amanhã. In: Paiva V, Ayres JRCM, Buchalla CM, coordenadores. Vulnerabilidade e direitos humanos: prevenção e promoção da saúde. Livro I: da doença à cidadania. Curitiba: Juruá; 2012. v. 1, p. 43-70. 
Girard G. Risque du sida et structuration des sociabilités homosexuelles: analyse sociologique des normes de prévention en France, 1989-2009 [these]. Paris: Ecole des Hautes Etudes en Sciences Sociales (EHESS); 2012 [citado 5 jan. 2017]. Disponível em: $<\underline{\text { https://tel.archives-ouvertes.fr/tel-00676665/document }>\text {. }}$

Gray RH, Kigozi G, Serwadda D, Makumbi F, Watya S, Nalugoda F, Kiwanuka N, Moulton LH, Chaudhary MA, Chen MZ, Sewankambo NK, Wabwire-Mangen F, Bacon MC, Williams CF, Opendi $P$, Reynolds SJ, Laeyendecker O, Quinn TC, Wawer MJ. Male circumcision for HIV prevention in men in Rakai, Uganda: a randomised trial. Lancet. 2007; 369(9562):657-666.

Grangeiro A, Castanheira ER, Nemes MIB. A re-emergência da epidemia de aids no Brasil: desafios e perspectivas para o seu enfrentamento. Interface (Botucatu) [Internet]. 2015 [citado 6 mai. 2018]; 19(52):5-8. Disponível em:

$<$ http://www.scielo.br/scielo.php?script=sci_arttext\&pid=S1414-

$32832015000100005 \& \operatorname{lng}=e n>$.

Grangeiro A, Escuder MM, Castilho EA, et al. Análise da política de incentivo do Ministério da Saúde para a resposta de estados e municípios à aids [relatório de pesquisa]. São Paulo: Faculdade de Medicina da Universidade de São Paulo; 2009.

Grangeiro A, Escuder MM, Silva SR, Cervantes V, Teixeira PR. Características da resposta à Aids de Secretarias de Saúde, no contexto da política de incentivo do Ministério da Saúde. Saúde Soc. 2012;21(4):954-75.

Grangeiro A, Silva LL, Teixeira PR. Resposta à aids no Brasil: contribuições dos movimentos sociais e da reforma sanitária. Rev Panam Salud Publica. 2009: 26(1): 87-94.

Green JN. Além do Carnaval: a homossexualidade masculina no Brasil do século XX. Fino C, Leite CA, tradutores. São Paulo: Editora UNESP; 2000.

Green JN. Mais amor e mais tesão: a construção de um movimento brasileiro de gays, lésbicas e travestis. Cad. Pagu. 2015 [citado 5 mar. 2018]; 15:271-95. Disponível em: <https://periodicos.sbu.unicamp.br/ojs/index.php/cadpagu/article/view/8635596>.

Griensven F, Varangrat A, Wimonsate W, Tanpradech S, Kladsawad K, Chemnasiri T, Suksripanich $\mathrm{O}$, Phanuphak P, Mock P, Kanggarnrua K, McNicholl J, Plipat T. Trends in HIV prevalence, estimated HIV incidence, and risk behavior among men who have sex with men in Bangkok, Thailand, 2003-2007. J Acquir Immune Defic Syndr. 2010 [cited 2018 Apr 27]; 53(2):234-9. Available from: <https://www.ncbi.nlm.nih.gov/pubmed/19901844>.

Gruskin S. The UN General Assembly Special Session on HIV/AIDS: were some lessons of the Last 20 Years Ignored? Am J Public Health. 2002;92(3):337-338.

Gruskin S, Tarantola D. Um panorama sobre saúde e direitos humanos. In: Paiva V, Ayres JRCM, Buchalla C, organizadores. Vulnerabilidade e direitos humanos: prevenção e promoção da saúde. Livro I: da doença à cidadania. Curitiba: Juruá; 2012. p. 23-41.

Guimarães, Mark Drew Crosland et al. "Comparing HIV risk-related behaviors between 2 RDS national samples of MSM in Brazil, 2009 and 2016". Medicine. 2018.Vol. 97. № 1 Suppl. 
Harrison LH, do Lago RF, Friedman RK, Rodrigues J, Santos EM, de Melo MF, Moulton LH, Schechter M. Incident HIV infection in a high-risk, homosexual, male cohort in Rio de Janeiro, Brazil. J Acquir Immune Defic Syndr. 1999;21(5):408-12.

Hollands R, Chatterton P. Producing nightlife in the new urban entertainment economy: corporatization, branding and market segmentation. Int J Urban Reg Res. 2003;27(2): 361-85.

Honneth A. Luta por reconhecimento: a gramática moral dos conflitos sociais. Repa L, tradutor. São Paulo: Editora 34; 2003.

Howes R. João Antônio Mascarenhas (1927-1998): pioneiro do ativismo homossexual no Brasil. Cad. AEL. 2003;10(18/19):289-311.

Kalichman A. Vigilância epidemiológica de AIDS: recuperação histórica de conceitos e práticas [dissertação]. São Paulo: Faculdade de Medicina da Universidade de São Paulo; 1993.

Kerr LRFS, Mota RS, Kendall C, Pinho AA, Mello MB, Guimarães MDC, Dourado I, Brito AM, Benzaken A, McFarland W, Rutherford G; The HIVMSM Surveillance Group. HIV among MSM in a large middle-income country. AIDS. 2013;27: 427-435.

Kerr, Ligia et al. "HIV prevalence among men who have sex with men in Brazil: results of the 2nd national survey using respondent-driven sampling". Medicine. 2018. Vol. 97, № 1 Suppl.

Kippax S, Stephenson N. Beyond the Distinction Between Biomedical and Social Dimensions of HIV Prevention Through the Lens of a Social Public Health. Am J Public Health. 2012 [cited 2018 Apr 5]; 102(5):789-799. Available from:

<https://www.ncbi.nlm.nih.gov/pmc/articles/PMC3483918/>.

Laurindo-Teodorescu L, Teixeira PR. Histórias da aids no Brasil. Brasília: Ministério da Saúde/ Secretaria de Vigilância em Saúde/Departamento de DST, Aids e Hepatites Virais; 2015. 2 v.

Lima M. A produção de conhecimento em tempos de conflito: o lugar das Ciências Sociais. Revista de Antropologia (São Paulo). 2018 [citado 8 maio 2018]; 61(1):95-102. Disponível em: <http://www.revistas.usp.br/ra/article/view/145516>.

Ma X, Zhang Q, He X, Sun W, Yue H, Chen S, Raymond HF, Li Y, Xu M, Du H, McFarland W. Trends in prevalence of HIV, syphilis, hepatitis $C$, hepatitis $B$, and sexual risk behavior among men who have sex with men: results of 3 consecutive respondent-driven sampling surveys in Beijing, 2004 through 2006. J Acquir Immune Defic Syndr. 2007;45(5):581-7.

Machado LZ. O aborto como direito e o aborto como crime: o retrocesso neoconservador. Cad. Pagu. 2017 [citado 5 abr. 2018]; 50(e17504). Disponível em:

$<$ http://www.scielo.br/scielo.php?script=sci_arttext\&pid=S0104-

$83332017000200305 \& \operatorname{lng}=$ en\&nrm=iso>

Machado LZ. Feminismos brasileiros nas relações com o Estado. Contextos e incertezas. Cad. Pagu. 2016 [citado 5 abr. 2018]; 47(e16471). Disponível em:

$<$ http://www.scielo.br/scielo.php?script=sci_arttext\&pid=S0104-

$83332016000200301 \&$ Ing=en\&nrm=iso>. 
MacKellar D, Gallagher K, Finelayson T, Sanchez T, Lansky A, Sullivan PS. Surveillance of HIV risk and prevention behaviors of men who have sex with men-a national application of venue based, time-space sampling. Public Health Reports. 2007;122(Suppl 1):S39-S47.

MacRae E. AIDS: prevenção ou novo tipo de segregacionismo? Temas IMESC, soc. dir. saúde. 1987;4(1): 73-81.

MacRae E. A construção da igualdade: identidade sexual e política no Brasil da abertura. Campinas: Editora da UNICAMP; 1990. (Coleção Momento).

Malta M, Beyrer C. The HIV epidemic and human rights violations in Brazil. J Int AIDS Soc. 2013; 6:18817. Epub 2013/11/15.

Malta M, Magnanini MMF, Mello MB, Pascom ARP, Linhares Y, Bastos FI. HIV prevalence among female sex workers, drug users and men who have sex with men in Brazil: a systematic review and meta-analysis. BMC Public Health. 2010 [cited 2018 Mar 27]; 10(317): 1-16.

Available from: <https://www.ncbi.nlm.nih.gov/pubmed/20529289>.

Mann JM, Tarantola D, Netter TW. A AIDS no mundo. Rio de Janeiro: RelumeDumará/ABIA/IMS/UERJ; 1993.

Mann JM, Gostin L, Gruskin S, Brennan T, Lazzarini Z, Fineberg HV. Health and human rights. Health Hum Rights. 1994 [cited 2017 Jan 5]; 1(1): 6-23. Available from:

$<$ https://www.ncbi.nlm.nih.gov/pubmed/10395709>.

Mann JM, Grodin MA, Gruskin S, Annas GJ. Health and human rights: a reader. London: Routledge; 2000.

Mann JM, Tarantola D, editors. AIDS in the world II: global dimensions, social roots, and responses. 2nd ed. New York: Oxford University Press; 1996.

Mello MB, Malta M, Pascom ARP, Linhares Y. Revisão sistemática de estudos com HSH, UDI e TS no Brasil: 1998-2008 [relatório técnico encomendado pelo Departamento Nacional de DST/Aids]. Brasília (DF): Ministério da Saúde; 2009.

Mendes-Gonçalves RB. Epidemiologia e emancipação. Hist. cienc. saúde-Manguinhos [Internet]. 1995 [citado 5 jan. 2017]; 2(2): 138-141. Disponível em:

$<$ http://www.scielo.br/scielo.php?script=sci_arttext\&pid=S0104-

$59701995000300011 \& \operatorname{lng}=\mathrm{en} \geq$.

Merson MH, O'Malley J, Serwadda D, Apisuk C. The history and challenge of HIV prevention. Lancet. 2008; 372(9637):475-488.

Mesquita F, Doneda D, Gandolfi D, Nemes MIB, Andrade T, Bueno D, Piconez-Trigueiros D. Brazilian response to the human immunodeficiency virus/acquired immunodeficiency syndrome epidemic among injection drug users. Clin Infect Dis. 2003;37(Suppl 5): S382-S5.

Moore DM, Kanters S, Michelow W, Gustafson R, Hogg RS, Kwag M, Trussler T, McGuire M, Robert W, Gilbert M. Implications for HIV prevention programs from a serobehavioural survey of men who have sex with men in Vancouver, British Columbia: The ManCount Study. Can J Public Health. 2012;103(2):142-6. 
Nunes ED. Saúde coletiva: uma história recente de um passado remoto. In: Campos GWSC, Minayo MCS, Akerman M, Drumond Júnior M, Carvalho YMaria, organizadores. Tratado de Saúde Coletiva. São Paulo: Hucitec; 2006. p. 295-315.

Nunn A. The politics and history of AIDS treatment in Brazil. New York: Springer; 2009.

ONU. Declaração de compromisso sobre o VIH/SIDA (Sessão Extraordinária da Assembleia Geral Sobre o VIH/SIDA de 25-27 de junho de 2001). [S.I.]: Secretaria Geral das Nações Unidas; 2001 [citado 25 mar. 2018]. Disponível em:

<http://www.unfpa.org.br/Arquivos/declaracao compromisso.pdf >.

Padian NS, Buve A, Balkus J, Serwadda D, Cates W Jr. Biomedical interventions to prevent HIV infection: evidence, challenges, and way forward. Lancet. 2008;372(9638):585-99. Epub 2008/08/09.

Paiva CHA, Teixeira LA. Reforma sanitária e a criação do Sistema Único de Saúde: notas sobre contextos e autores. Hist. cienc. saúde-Manguinhos. 2014:21(1). p. 15-35.

Paiva V. Analysing sexual experiences through 'scenes': a framework for the evaluation of sexuality education. Sex Education. 2005;5(4):345-58 (14).

Paiva V. Beyond magic solutions: prevention of HIV and AIDS as a process of Psychosocial Emancipation. Divulg Saúde Debate. 2003; 27: 192-203.

Paiva V. Em tempos de AIDS. São Paulo: Summus; 1992. p. 53-62: 0 simbolismo da aids, alteridade e cidadania.

Paiva V. Sem mágicas soluções: a prevenção ao HIV e à AIDS como um processo de "emancipação psicossocial". In: Parker R, Terto Jr V, organizadores. Aprimorando o debate: respostas sociais frente à AIDS. (Anais do Seminário Prevenção à AIDS; Limites e Possibilidades na Terceira Década). Rio de Janeiro: ABIA; 2002. p. 20-27.

Paiva V, Ayres JRCM, França Júnior I. Expanding the flexibility of normative patterns in youth sexuality and prevention programs. Sex Res Social Policy. 2004;1(1):83-97.

Paiva V, Pupo LR, Barboza R. O direito à prevenção e os desafios da redução da vulnerabilidade ao HIV no Brasil. Rev. Saúde Pública. 2006; 40 (Supl): 109-119.

Parker R. Introdução. In: Parker R, organizador. Políticas, instituições e AIDS: enfrentando a epidemia no Brasil. Rio de Janeiro: Jorge Zahar/ABIA; 1997. p. 7-15.

Parker R. Prefácio à edição brasileira. In: Mann JM, Tarantola D, Netter TW. A AIDS no mundo. Rio de Janeiro: Relume-Dumará/ABIA/IMS/UERJ; 1993. p. XIII-XV.

Parker R, Galvão J, Bessa MS. Políticas sociais, desenvolvimento econômico e saúde coletiva: o caso da AIDS. In: Parker R, Galvão J, Bessa MS, organizadores. Saúde, desenvolvimento e política: respostas frente à Aids no Brasil. Rio de Janeiro: ABIA; São Paulo: Editora 34; 1999. p. 7-28.

Parker R, Terto Jr. V, organizadores. Entre homens: homossexualidade e AIDS no Brasil. Rio de Janeiro: ABIA; 1998. 
Passarelli CAF. Notas sobre o seminário "Prevenção à AIDS: limites e possibilidades na terceira década". In: Parker R, Terto Jr V, organizadores. Aprimorando o debate: respostas sociais frente à AIDS. (Anais do Seminário Prevenção à AIDS; Limites e Possibilidades na Terceira Década). Rio de Janeiro: ABIA; 2002. p. 7-11.

Paulo RT, organizador. Síndrome de Imunodeficiência Adquirida ("AIDS"): informe técnico. São Paulo: Secretaria de Estado da Saúde de São Paulo; 1983. [documento mimeografado digitalizado].

Pecoraro M. AIDS e homossexualidade: 25 anos. Boletim ABIA. 2006, 54: 10-11.

Pelúcio L. Marcadores Sociais da Diferença nas Experiências Travestis de Enfrentamento à AIDS. Saúde Soc. 2011;20(1):76-85.

Perillo M. 'Rolês', 'closes' e 'xaxos': uma etnografia sobre juventude, (homo)sexualidades e cidades [tese]. Campinas: Instituto de Filosofia e Ciências Sociais da Unicamp; 2017.

Perlongher N. Antropologia das sociedades complexas: identidade e territorialidade ou como estava vestida Margaret Mead. Revista Brasileira de Ciências Sociais. 1993; 22: 137-144.

Perlongher N. O negócio do michê: a prostituição viril em São Paulo. São Paulo: Editora Perseu Abramo, 2008.

Perlongher N. O que é Aids. 4a ed. São Paulo: Brasiliense; 1987. (Primeiros Passos, 197).

Pinheiro TF. Camisinha, homoerotismo e os discursos da prevenção de HIV/Aids [tese]. São Paulo: Faculdade de Medicina da Universidade de São Paulo; 2015.

Pinheiro TF, Calazans GJ, Ayres JRCM. Uso de camisinha no Brasil: um olhar sobre a produção acadêmica acerca da prevenção de HIV/Aids (2007-2011). Temas psicol. [Internet]. 2013 [citado 28 out. 2017]; 21(3):815-836. Disponível em:

$<$ http://pepsic.bvsalud.org/scielo.php?script=sci_arttext\&pid=S1413-

$389 \times 2013000300009 \& \operatorname{lng}=\mathrm{pt}>$.

Ricoeur P. Tempo e narrativa. Tomo I. Tradução de Constança Marcondes Cesar. Campinas: Papirus; 1994. p. 85-125;

Royce RA, Sena A, Cates W Jr, Cohen MS. Sexual transmission of HIV. N. Engl. J. Med. 1997; 336(15):1072-8.

São Paulo. Secretaria de Estado da Saúde Boletim Epidemiológico C.R.T. - DST/AIDS. São Paulo: Secretaria de Estado da Saúde; 2012; 29(1).

Schechter M, Lago RF, Mendelsohn AB, Moreira RI, Moulton LH, Harrison LH; Praça Onze Study Team. Behavioral impact, acceptability, and HIV incidence among homosexual men with access to postexposure chemoprophylaxis for HIV. J Acquir Immune Defic Syndr. 2004; 35(5): 519-25.

Scheffer MC. O capital estrangeiro e a privatização do sistema de saúde brasileiro. Cadernos de Saúde Pública [online]. 2015 [citado 9 mai. 2018]; 31(4):663-666. Disponível em: <https://doi.org/10.1590/0102-311XPE010415>. 
Scheffer MC, coordenador. Contribuições para uma agenda de pesquisas sobre o Sistema Único de Saúde: síntese das discussões realizadas no Strategic Workshops USP "A saúde no Brasil após a PEC 241". São Paulo: Departamento de Medicina Preventiva da Faculdade de Medicina da Universidade de São Paulo; 2017.

Scheffer MC, Schraiber LB. Interface, vinte anos: a saúde coletiva em tempos difíceis. Interface [online]. 2017 [citado 9 mai. 2018]; 21(62:487-491. Disponível em:

<https://doi.org/10.1590/1807-57622017.0288>.

Seffner F. Prevenção à AIDS: uma ação político-pedagógica. In: Parker R, Terto Jr V, organizadores. Aprimorando o debate: respostas sociais frente à AIDS. (Anais do Seminário Prevenção à AIDS; Limites e Possibilidades na Terceira Década). Rio de Janeiro: ABIA; 2002. p. 28-35.

Seffner F, Parker R. Desperdício da experiência e precarização da vida: momento político contemporâneo da resposta brasileira à aids. Interface (Botucatu) [Internet]. 2016 [citado 6 mai. 2018]; 20(57):293-304. Disponível em:

$<$ http://www.scielo.br/scielo.php?script=sci_arttext\&pid=S1414-

$32832016000200293 \& \operatorname{lng}=e n>$.

Seffner F, Parker R. A neoliberalização da prevenção do HIV e a resposta brasileira à AIDS. In: Mito vs realidade: sobre a resposta brasileira a epidemia de HIV e Aids em 2016. Rio de Janeiro: ABIA; 2016 [citado 6 mai. 2018]. Disponível em: <http://abiaids.org.br/wpcontent/uploads/2016/07/Mito-vs-realidade_HIV-e-AIDS_BRASIL2016.pdf>.

Silva LAV, Iriart JAB. Práticas e sentidos do barebacking entre homens que vivem com HIV e fazem sexo com homens. Interface (Botucatu) [Internet]. 2010 [citado 6 mai. 2018]; 14(35):739752. Disponível em:

$<$ http://www.scielo.br/scielo.php?script=sci arttext\&pid=S141432832010000400003\&lng=en>.

Simões JA, França IL, Passador LH, Facchini R. Convenções de gênero, raça e idade em lugares de sociabilidade homoerótica em São Paulo. In: Seminário Internacional Debates contemporâneos sobre raça, etnicidade, sexualidade e gênero; 2008; São Paulo. São Paulo: FFLCH-USP; 2008. (Comunicação).

Simões JA, Facchini R. Do movimento homossexual ao LGBT. São Paulo: Editora Fundação Perseu Abramo; 2009.

Simões JA, França IL. Do gueto ao mercado. In: Green JG, Trindade R, organizadores. Homossexualismo em São Paulo e outros escritos. São Paulo: Editora Unesp; 2005. p. 309-333.

Sívori H, Giumbelli E, Rohden F, Carrara S. "Fundamentalismos", sexualidade e direitos humanos: interrogando termos, expandindo horizontes. Sex., Salud Soc. (Rio J.). 2017 [citado 5 abr. 2018]; 26:171-180. Disponível em:

<http://www.scielo.br/scielo.php?script=sci_arttext\&pid=S1984-

64872017000200171\&lng=en\&nrm=iso>.

Sutmöller F, Penna TL, Souza CT, Lambert J; Oswaldo Cruz Foundation STD/HIV Prevention Group. Human immunodeficiency virus incidence and risk behavior in the 'Projeto Rio': results of the first 5 years of the Rio de Janeiro open cohort of homosexual and bisexual men, 1994-98. Int J Infect Dis. 2002;6(4):259-65. 
Szwarcwald CL, Andrade CL, Pascom AR, Fazito E, Pereira GF, Penha IT. HIV-related risky practices among Brazilian young men, 2007. Cad. Saúde Pública. 2011;27(Suppl 1): S19-S26. Epub 2011/04/29.

Szwarcwald CL, Barbosa Junior A, Souza Junior PRB, Lemos KRV, Frias PG, Luhm KR, Holcman MM, Esteves MAP. HIV testing during pregnancy: use of secondary data to estimate 2006 test coverage and prevalence in Brazil. Braz J Infect Dis [Internet]. 2008 [cited 2018 Mar 27]; 12(3): 167-172. Available from:

$<$ http://www.scielo.br/scielo.php?script=sci_arttext\&pid=S1413-

$86702008000300002 \& \operatorname{lng}=$ en>.

Szwarcwald CL, Carvalho MF, Barbosa Junior A, Barreira D, Speranza FA, Castilho EA. Temporal trends of HIV-related risk behavior among Brazilian military conscripts, 1997-2002. Clinics. 2005;60(5):367-74. Epub 2005/10/29.

Teixeira PRP. Políticas públicas em AIDS. In: Parker R, organizador. Políticas, Instituições e AIDS: enfrentando a epidemia no Brasil. Rio de Janeiro: Jorge Zahar: ABIA; 1997. p. 43-68.

UNAIDS. 90-90-90 An ambitious treatment target to help end the AIDS epidemic. Geneva; 2014 [cited 2018 May 9]. Available from:

<http://www.unaids.org/sites/default/files/media_asset/90-90-90_en.pdf>.

UNAIDS. Costing guidelines for HIV prevention strategies. Geneva; 2000 [cited 2018 Mar 17]. Available from: <http://data.unaids.org/Publications/IRCpub05/JC412-CostGuidel_en.pdf>.

UNAIDS. Practical Guidelines for Intensifying HIV Prevention: Towards Universal Access. Geneva; 2007.

UNAIDS. Programa Conjunto das Nações Unidas sobre HIV/Aids 2011. Boas práticas de participação: diretrizes para ensaios clínicos de prevenção biomédica do HIV. Geneva; 2011.

UNAIDS. UNAIDS Action Framework: universal access for men who have sex with men, and transgender people. Geneva, Switzerland: UNAIDS/UNDP; 2009.

Vaggione JM. La Iglesia Católica frente a la política sexual: la configuración de una ciudadanía religiosa. Cad. Pagu [online]. 2017 [citado 5 abr. 2018]; 50 (e175002). Disponível em: <http://dx.doi.org/10.1590/18094449201700500002>.

Venturi G, Bokani V, organizadores. Diversidade sexual e homofobia no Brasil. São Paulo: Editora Perseu Abramo; 2011.

Veras MASM, Calazans GJ, Ribeiro MCAS, Oliveira CAF, Giovanetti MR, Facchini R, França IL, McFarland W; SampaCentro Study Group. et al. High HIV prevalence among men who have sex with men in a time-location sampling survey, São Paulo, Brazil. AIDS Behav. 2015; 19(9):158998.

Vianna ARB, Carrara S. Sexual politics and sexual rights in Brazil: a case study (2007). In: Parker $R$, Petchesky R, Sember R, editors. SexPolitics: reports from the Front Lines. Rio de Janeiro: Sexuality Policy Watch; 2007 [cited 2018 Apr 17]. Cap. 2 - Brazil, p. 27-51. Available from: <http://www.sxpolitics.org/frontlines/book/index.php> 
Vianna ARB, Lacerda P. Direitos e políticas sexuais no Brasil: o panorama atual. Rio de Janeiro: CLAM/IMS/CEPESQ ; 2004.

Voirol O. A esfera pública e as lutas por reconhecimento: de Habermas a Honneth. Cadernos de Filosofia Alemã. 2008;11(33-56).

WHO/UNAIDS. Initiating second generation HIV surveillance systems: practical guidelines. Geneva; 2002. [cited 2018 Apr 27]. Available from:

<http://www.who.int/hiv/pub/surveillance/en/isbn9291732192.pdf>.

WHO/UNAIDS. Monitoring the declaration of commitment on HIV/AIDS: guidelines on construction of core indicators: 2008 reporting. [UNAIDS/07.12E / JC1318E]. Geneva; 2008 [cited 2018 Apr 27]. Available from:

<http://data.unaids.org/pub/Manual/2007/20070411 ungass core indicators manual en.pd $\underline{f}$

WHO/UNAIDS. Practical guidelines for intensifying HIV prevention: towards universal access. Geneva; 2007 [cited 2018 Apr 27]. Available from:

$<$ http://data.unaids.org/pub/Manual/2007/20070306 prevention guidelines towards univer sal access en.pdf>.

WHO/UNAIDS. Technical consultation on male circumcision and HIV prevention: research implications for policy and programming. Montreux, Switzerland; 2007 [cited 2018 Apr 17]. Available from:

<http://apps.who.int/iris/bitstream/handle/10665/43751/9789241595988_eng.pdf?sequence $=1>$

Young Rebecca M., Meyer Ilan H. The Trouble With "MSM" and "WSW": Erasure of the SexualMinority Person in Public Health Discourse. Am J Public Health. 2005; 95: 1144-1149. doi:10.2105/AJPH.2004.046714 


\section{APÊNDICE}

\section{Roteiro de Entrevista $-1^{\text {a }}$ tomada}

1. Olá, gostaria de pedir que você se apresente falando seu nome, idade, formação

2. Pode me contar como você se vinculou ao campo de:

a. Políticas de aids, mais particularmente das políticas de prevenção do HIV e da aids?

b. Políticas voltadas à população LGBT?

3. Pode me ajudar a construir uma linha do tempo das políticas de prevenção do HIV voltadas para homens que fazem sexo com homens?

4. Quais as principais políticas formalizadas de prevenção voltadas para HSH?

a. Explorar:

i. Que conceitos orientavam a proposta e as ações de prevenção? (vulnerabilidade, risco acrescido, populações-chave, direitos, prevenção combinada, gerenciamento de risco, etc.)

ii. Para quem se dirigia cada uma destas propostas (categorias mobilizadas: HSH, gay, homossexual, LGBT...)

iii. Quais demandas tais políticas visavam responder (expectativas intersubjetivas; qual o motor desta proposição)

iv. Você consegue contar em que contexto surgiu tal proposição de política?

v. Quem eram os sujeitos envolvidos na articulação desta proposta?

5. Quais considera os momentos mais marcantes (positivos e negativos)

6. Quais você considera os principais sucessos e êxitos no âmbito das políticas de prevenção voltadas para HSH?

7. Quais você considera os principais fracassos, conflitos e tensões no âmbito das políticas de prevenção voltadas para HSH?

8. Quais as principais alianças e articulações para o estabelecimento de políticas de prevenção voltadas para HSH?

9. Como você entende o papel do ativismo, de um ativista?

10. Quais os problemas a serem enfrentados pelo ativismo, pelos ativistas?

11. Em seu entendimento, qual a melhor estratégia para enfrentá-los? 
12. Que documentos você indica para ajudar a compor esta linha do tempo das políticas de prevenção do HIV e da aids para HSH? 


\section{Eifla \\ MEDICINA \\ एTP \\ COMITÊ DE ÉTICA EM PESQUISA}

\section{APROVAÇÃO}

O Comitê de Ética em Pesquisa da Faculdade de Medicina da Universidade de São Paulo, em sessão de 11/05/2016, APROVOU ○ Protocolo de Pesquisa no 140/16 intitulado: "POLÍtTCAS PÚBLICAS DE SAÚDE E RECONHECIMENTO: UM ESTUDO SOBRE PREVENÇÃO DA INFECÇÃO PELO HIV PARA HOMENS QUE FAZEM SEXO COM HOMENS NA CIDADE DE SÃO PAULO." apresentado pelo D epartamento de MEDICINA PREVENTTVA

Cabe ao pesquisador elaborar e apresentar ao CEPFMUSP, os relatórios parciais e final sobre a pesquisa (Resolução do Conselho Nacional de Saúde $n^{0} 466 / 12$, inciso IX.2, letra " $c^{\prime \prime) . ~}$

Pesquisador (a) Responsável: José Ricardo de Carvalho Mesquita Ayres Pesquisador (a) Executante: Gabriela Junqueira Calazans

CEP-FMUSP, 11 de Maio de 2016.

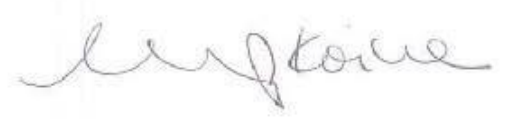

Profa. D ra. Maria Aparecida Azevedo Koike Folgueira Coordenador

Comitê de Ética em Pesquisa 
PARECER CONSUBSTANCIADO CEP FMUSP

\begin{tabular}{|c|} 
USP - FACULDADE DE \\
MEDICINA DA UNIVERSIDADE \\
DE SĀO PAULO - FMUSP
\end{tabular}

\section{DADOS DA EMENDA}

Titulo da Pesquisa: Politicas publicas de saude e reconhedimentoc um estudo sobre prevençlo da irtecgáo pelo HV para homers que tazem sexo com homens

Pesquisador: Joed Ricardo de Carvalno Mesquita Ayres

Ároa Temática:

Vorsẫ: 2

CAAE: 55760616.4 .0000 .0065

Instituiç5̄o Proponente:Faculdade de Modicira da Universidade de Sáo Paulo

Patrocinador Principal: Financiamerto Próprio

\section{DADOS DO PARECER}

Número do Parocer: 2.470 .525

Aprosentop̧ấo do Projeto:

Estudo qualitativo onde serfo realizadas ertrevistas semiestrutumdas com gestores de polificas publicas de prevenghto e ativistas dos movimentos LGBT e de aids. Nas

quais serf́o investigados: trajetbria profissional e como este tem olhado historicamente para o campo de

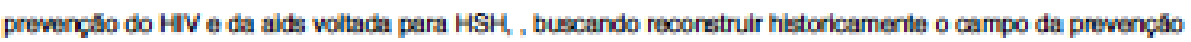
do HIV e da aids voltada para HSH no pals e ce entrevistados serto comidadoesa fazer uma reflexáo critica sobre os limiles e as poesibilidades das politicas pCblicas de peevençio do HIV voltadas pana HSH.

Objetivo do Pesquisa:

Compreender de que forma processos de (ndo)reconhecimento, ou desrespeito, no ambito do cuidado publico de sabide, compreendido como corjurto de pollticas, servigos e ap̧és voltadas à prevençấo do HIV e da aids, contribuem para os processos de vulnerablizagáo de homens que fazem sexo com homens $(\mathrm{HSH})$ ao HIV e aे aids.

Avalisção dos Piscos a Benaficios:

Risco minimo seráo realizadas apenas entrevistas.

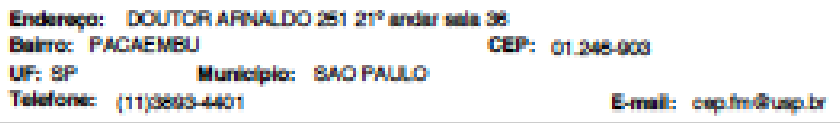




\section{USP - FACULDADE DE MEDICINA DA UNIVERSIDADE DE SĀO PAULO - FMUSP}

Corthuaplo de Paveor: 2 . 60 . sas

Comentários e Consideraçōes sobre a Pesquisa:

adequada para o objektwo proposto

Considerap̧ós sobre os Termos de apresentação obrigstória:

adequado

Recomendap̧óos:

nenhuma

Conclusōes ou Pendências e Lista de Inadequsp̧óos:

aprovado

Considerapóos Finais a critório do CEP:

Este parecer fol elaborado basoado nos documentos abaixo molscionados:

\begin{tabular}{|c|c|c|c|c|}
\hline Tipo Documanto & Arquino & Poetagem & Autior & Situaçilo \\
\hline $\begin{array}{l}\text { Informaçdes Błalcas } \\
\text { do Projelo }\end{array}$ & $\begin{array}{l}\text { PB_INFOAMAC_CES_BASICAS_104112 } \\
7 \text { E1.pd }\end{array}$ & $\begin{array}{c}06 / 12 / 2017 \\
08: 22: 10\end{array}$ & & Aceito \\
\hline $\begin{array}{l}\text { Projeto Detalnado } / \\
\text { Brochura } \\
\text { Imventigadoc }\end{array}$ & $\begin{array}{l}\text { ProjetpdeDoultorado_Emenda_CEP_V2. } \\
\text { pdf }\end{array}$ & $\begin{array}{c}06 / 12 / 2017 \\
06: 1734\end{array}$ & $\begin{array}{l}\text { Gabriela Junqueira } \\
\text { Calazars }\end{array}$ & Aceito \\
\hline Outros & $\begin{array}{l}\text { parecer_projeto_JoseficardoeGabriela. } \\
\text { pdf }\end{array}$ & $\begin{array}{c}2904 / 2016 \\
16.27-36\end{array}$ & $\begin{array}{l}\text { Gabriela Junqueira } \\
\text { Calazans }\end{array}$ & Aceito \\
\hline Outros & $\begin{array}{l}\text { CADMSTRO_CEP_FMUSP_JoseAlicard } \\
\text { ceGabricla.pdf }\end{array}$ & $\begin{array}{c}2904 \sqrt{2016} \\
16.26: 11\end{array}$ & $\begin{array}{l}\text { Gabriela Junqueira } \\
\text { Calazars }\end{array}$ & Aceito \\
\hline Folha de Rosito & $\begin{array}{l}\text { folha_de_roeto_projeto_JcesPicardoeg } \\
\text { abriala_pdf }\end{array}$ & $\begin{array}{c}2904 / 2016 \\
16.1850\end{array}$ & $\begin{array}{l}\text { Gabriela Junqueira } \\
\text { Calazans }\end{array}$ & Aceito \\
\hline $\begin{array}{l}\text { TCLE / Termos de } \\
\text { Assentimento f } \\
\text { Justificativa de } \\
\text { Ausalncia }\end{array}$ & TCLE_Ertrevistas.pdil & $\begin{array}{c}0504 / 2016 \\
20: 18: 59\end{array}$ & $\begin{array}{l}\text { Gabriela Junqueira } \\
\text { Calazars }\end{array}$ & Aceito \\
\hline
\end{tabular}

Situaçẫo do Parocer:

Aprovado

Nocossita Aprocisçâo do CONEP:

Nilo

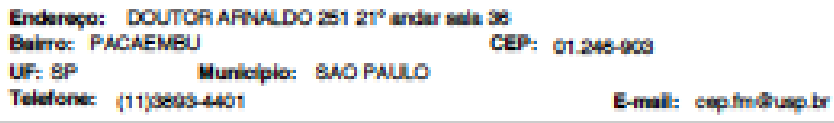




\section{USP - FACULDADE DE \\ MEDICINA DA UNIVERSIDADE \\ DE SĀO PAULO - FMUSP}

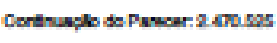

SAO PALLO, 19 de Janeiro de 2018

Assinado por:

Maria A parecida Azevodo Kolke Folgueira

(Coordenador)

Endereş: DOUTOR AFNADO 251 21\% andar ande 38

Baire: PMCAEMEL

CEP: OT.24s-900

UF: $B P$

Munielpia: BNOPAuLO

E-mal: explmausp br 


\section{TERMO DE CONSENTIMENTO ENTREVISTADOS}

\section{FACULDADE DE MEDICINA - UNIVERSIDADE DE SÃO PAULO / FMUSP \\ Termo de Consentimento Livre e Esclarecido \\ Entrevistados}

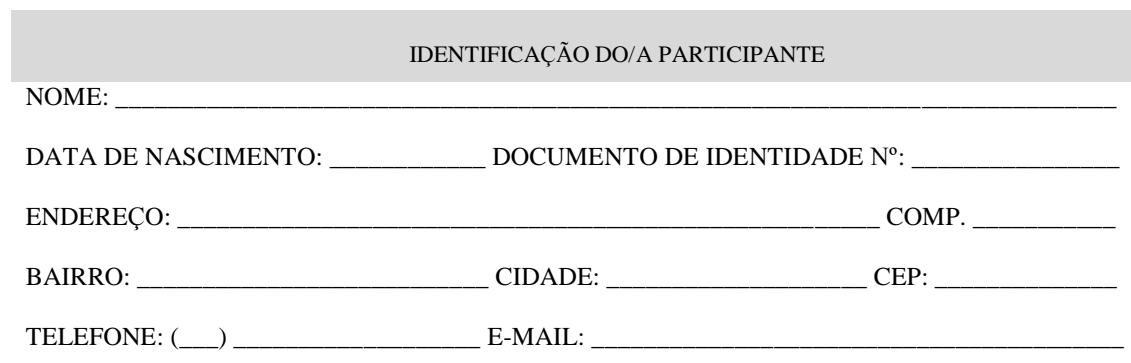

INFORMAÇÕES SOBRE A PESQUISA

TÍTULO: Políticas públicas de saúde e reconhecimento: um estudo sobre prevenção da infecção pelo HIV para homens que fazem sexo com homens na cidade de São Paulo

OBJETIVO: compreender de que forma processos de (não)reconhecimento, ou desrespeito, no âmbito do cuidado público de saúde, compreendido como conjunto de políticas, serviços e ações voltadas à prevenção do HIV e da aids, contribuem para os processos de vulnerabilização de homens que fazem sexo com homens (HSH) ao HIV e à aids.

PESQUISADORA: Gabriela Junqueira Calazans

VÍNCULO INSTITUCIONAL: Esta pesquisa faz parte do estudo de doutorado da presente pesquisadora, realizado no Departamento de Medicina Preventiva da Universidade de São Paulo, sob a orientação do Prof. Dr. José Ricardo de Carvalho Mesquita Ayres.

AVALIAÇÃO DE RISCO DA PESQUISA: Risco mínimo DURAÇÃO: 24 meses

\section{CONSENTIMENTO}

Você está sendo convidado/a a participar desta pesquisa, por meio de uma entrevista a ser realizada em duas tomadas, com duração média de duas horas e meia, de acordo com sua disponibilidade. A entrevista será gravada e transcrita para registro das informações. Seu conteúdo será utilizado para a produção de trabalhos científicos e possivelmente será armazenado em repositório de acesso público.

A identificação da entrevista e a citação de seus depoimentos serão feitas conforme sua preferência:

( ) com identificação de sua autoria;

( ) sem identificação, sendo garantido seu anonimato.

Caso deseje, você terá acesso à transcrição da entrevista e poderá fazer alterações ou retirar trechos que não queira tornar públicos.

Sua participação nesta pesquisa é voluntária, não propiciará nenhuma compensação financeira, nem benefício 


\section{CARACTERIZAÇÃO DOS INTERLOCUTORES ENTREVISTADOS}

\begin{tabular}{|c|c|c|}
\hline \multicolumn{3}{|c|}{ Gestores } \\
\hline Entrevistado & Nascimento (década) & Formação \\
\hline Paulo Roberto Teixeira & 1940 & $\begin{array}{l}\text { Graduação em medicina, com } \\
\text { especialização em } \\
\text { dermatologia, saúde pública e } \\
\text { formação em medicina do } \\
\text { trabalho. }\end{array}$ \\
\hline \multicolumn{3}{|c|}{ Engajamento e atuação política em Aids (a partir da década de 80) } \\
\hline 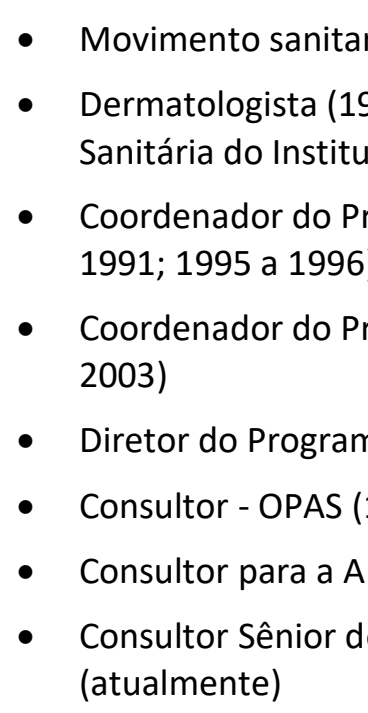 & $\begin{array}{l}\text { eados da década de } 197 \\
\text { iretor (1983), Divisão de } \\
\text { aúde - SES-SP } \\
\text { a Estadual de DST/Aids - } \\
\text { a Nacional de DST/Aids d } \\
\text { ids - OMS (2003) }\end{array}$ & $\begin{array}{l}\text { Sseníase e Dermatologia } \\
\text { SP (1983 a 1987; } 1990 \text { a } \\
\text { inistério da Saúde (2000 a }\end{array}$ \\
\hline \multicolumn{3}{|c|}{ Engajamento e atuação política LGBT (a partir da década de 70) } \\
\hline \multicolumn{3}{|c|}{$\begin{array}{l}\text { - Participação em grupo de discussão sobre homossexualidade, organizado por João } \\
\text { Silvério Trevisan (1976) } \\
\text { - Grupo Somos/SP (1978-9) }\end{array}$} \\
\hline Entrevistado & Nascimento (década) & Formação \\
\hline Maria Clara Gianna & 1960 & $\begin{array}{l}\text { Graduação em medicina, } \\
\text { residência médica em } \\
\text { medicina social }\end{array}$ \\
\hline \multicolumn{3}{|c|}{ Engajamento e atuação política em Aids (a partir da década de 80) } \\
\hline \multicolumn{3}{|c|}{$\begin{array}{l}\text { - Contato com os primeiros casos em estágios no Hospital Emílio Ribas, no } 50 \text { e } 60 \\
\text { anos da graduação (1984-5) } \\
\text { - Entrevistas para preenchimento das fichas de Investigação Epidemiológica, Seção de } \\
\text { Epidemiologia do Hospital Emílio Ribas, em estágio da Residência em Medicina } \\
\text { Social (1986-7) } \\
\text { - Centro de Referência e Tratamento em Doenças Sexualmente Transmissíveis e Aids } \\
\text { (CRT-DST/Aids) (1988-atual) }\end{array}$} \\
\hline
\end{tabular}


- Diretora do CRT-DST/Aids - SES-SP, revezando-se entre Diretoria e Diretoria-Adjunta (1994-atual)

\begin{tabular}{|c|c|c|}
\hline \multicolumn{3}{|c|}{ Engajamento e atuação política LGBT } \\
\hline Entrevistado & Nascimento (década) & Formação \\
\hline Ivo Brito & 1950 & $\begin{array}{c}\text { Graduação em Sociologia e } \\
\text { Política }\end{array}$ \\
\hline \multicolumn{3}{|c|}{ Engajamento e atuação política em Aids (a partir da década de 90) } \\
\hline
\end{tabular}

- Professor e pesquisador, Departamento de Ciências Sociais e Núcleo de Estudos em Saúde Coletiva, Centro de Ciências da Saúde - UFPB (1981-1995)

- Realização de Pesquisa de Diagnóstico Rápido sobre aids em áreas de garimpo, como pesquisador do Núcleo de Estudos de Saúde Pública - UnB (1995)

- Assessor técnico nas áreas de Prevenção e Ações Estratégicas - DIAHV, MS (19962003; 2004-2013)

- Consultor técnico no Projeto para o Fortalecimento do Sistema Angolano de Educação para o Enfrentamento do HIV/AIDS, UNDP/Angola (2003-4)

\section{Engajamento e atuação política LGBT}

\begin{tabular}{|c|c|c|}
\hline \multicolumn{3}{|c|}{ Ativistas } \\
\hline Entrevistado & Nascimento (década) & Formação \\
\hline Jorge Beloqui & 1940 & $\begin{array}{c}\text { Graduação e doutorado em } \\
\text { Matemática }\end{array}$ \\
\hline
\end{tabular}

Engajamento e atuação política em Aids (a partir da década de 80)

- Grupo Pela Vidda/SP (1989-1995)

- Grupo de Incentivo à Vida (GIV) (1995-atual)

- Conselho consultivo, Associação Brasileira Interdisciplinar de Aids (ABIA) (1995atual)

- Grupo de Trabalho em Propriedade Intelectual - GTPI (2002-atual)

- Núcleo de Estudos para Prevenção da AIDS (NEPAIDS-USP) (1991-atual)

- Representante das ONGs/Aids no Comitê Nacional de Vacinas Anti-HIV/Aids, MS (1992-2011)

- Boletim Vacinas Anti-HIV/Aids (1992; 1995; 1999-atual)

Engajamento e atuação política LGBT (a partir da década de 70)

- Grupo Somos/RJ (1979-1981)

- Grupo Somos/SP em (1981-1984) 


\begin{tabular}{|c|c|c|}
\hline Entrevistado & Nascimento (década) & Formação \\
\hline $\begin{array}{l}\text { Veriano de Souza Terto } \\
\text { Júnior }\end{array}$ & 1960 & $\begin{array}{c}\text { Graduação em Psicologia, } \\
\text { Mestrado em Psicologia e } \\
\text { Doutorado em Medicina } \\
\text { Social }\end{array}$ \\
\hline \multicolumn{3}{|c|}{ Engajamento e atuação política em Aids (a partir da década de 80 ) } \\
\hline \multicolumn{3}{|c|}{$\begin{array}{l}\text { - Grupo Pela Vidda/RJ (1989) } \\
\text { - Associação Brasileira Interdisciplinar de AIDS - ABIA (1990-2012; 2015-atual) }\end{array}$} \\
\hline \multicolumn{3}{|c|}{ Engajamento e atuação política LGBT (a partir da década de 80) } \\
\hline \multicolumn{3}{|c|}{$\begin{array}{l}\text { - Grupo Somos/RJ e grupo Somos/ Auê (1980-1984) } \\
\text { - Grupo Somos/SP (1981-1984) }\end{array}$} \\
\hline Entrevistado & Nascimento (década) & Formação \\
\hline Beto de Jesus & 1960 & $\begin{array}{c}\text { Graduações em Filosofia e } \\
\text { Teologia }\end{array}$ \\
\hline \multicolumn{3}{|c|}{ Engajamento e atuação política em Aids (a partir da década de 80 ) } \\
\hline \multicolumn{3}{|c|}{$\begin{array}{l}\text { - Grupo de apoio, Hospital Emílio Ribas - SES-SP (1983) } \\
\text { - } \text { Projeto Quero Fazer, Associação Espaço de Prevenção e Atenção Humanizada - } \\
\text { - } \text { Atuação como consultor independente em projetos de prevenção e testagem } \\
\text { voltados a LGBT } \\
\text { - } \\
\text { AIDS Healthcare Foundation (AHF) (2013-atual) }\end{array}$} \\
\hline \multicolumn{3}{|c|}{ Engajamento e atuação política LGBT (a partir da década de 9 0) } \\
\hline \multicolumn{3}{|c|}{$\begin{array}{l}\text { - Participação individual no 170 Encontro da Associação Internacional de Lésbicas, } \\
\text { - Gays, Bissexuais, Trans e Intersex (ILGA), no Rio de Janeiro (1995) } \\
\text { - } \text { - } \text { Arupo CORSA (1996-?) } \\
\text { reproduão como consultor independente sobre educação, direitos sexuais e } \\
\text { - } \text { Associação da Parada do Orgulho de Gays, Lésbicas, Bissexual e Transgêneros de } \\
\text { - São Paulo - APOGLBT (?) } \\
\text { - Integra a ABGLT (?), ILGA (?), tendo ocupado diferentes posições nas organizações }\end{array}$} \\
\hline Entrevistado & Nascimento (década) & Formação \\
\hline $\begin{array}{l}\text { Matheus Emilio Pereira da } \\
\text { Silva }\end{array}$ & 1990 & Graduando em direito \\
\hline \multicolumn{3}{|c|}{ Engajamento e atuação política em Aids (a partir da década de 2010) } \\
\hline
\end{tabular}


- Agente de prevenção no Viva Melhor Sabendo Jovem, parceria da Secretaria Municipal da Saúde de São Paulo com a ONG Viração e a UNICEF (2016)

- Representa o Pela Vidda/SP na Vice-Presidência do Fórum de ONG/Aids do Estado de São Paulo (2017-atual)

Engajamento e atuação política LGBT (a partir da década de 2010)

- Menino Gay ${ }^{119}$ - Empoderamento LGBT, página e comunidade no Facebook (2013)

- Família Stronger (2014)

- Projeto Purpurina, Grupo de Pais de Homossexuais - GPH (2014-2015)

- GT da Juventude, Associação da Parada do Orgulho de Gays, Lésbicas, Bissexual e Transgêneros de São Paulo - APOGLBT (2015-atual)

\begin{tabular}{|c|c|c|}
\hline Entrevistado & Nascimento (década) & Formação \\
\hline Gabriel Estrela & 1990 & $\begin{array}{c}\text { Graduações interrompidas } \\
\text { em comunicação, } \\
\text { biomedicina e teatro. } \\
\text { Artista, YouTuber e consultor } \\
\text { sobre HIV. }\end{array}$ \\
\hline \multicolumn{2}{|c|}{ Engajamento e atuação política em Aids (a partir da década de 2010) }
\end{tabular}

- Escrita e encenação da peça de teatro "Boa sorte" sobre sua experiência com o HIV (2013)

- Casa de Apoio Vida Positiva (2014)

- Participação informal nas três versões do Curso de Jovens Lideranças, DIAHV e UNAIDS, em parceria com UNFPA, UNESCO e UNICEF $(2015,2016)$

- Começa a carreira de ativista nas redes sociais falando publicamente da sua soropositividade

- Atualmente, tem página no Facebook e canal sobre HIV e saúde sexual no YouTube chamado Projeto Boa Sorte ${ }^{120}$ e perfis no Instagram e Twitter (2015)

\begin{tabular}{|c|c|c|}
\hline \multicolumn{3}{|c|}{ Engajamento e atuação política LGBT } \\
\hline Entrevistado & Nascimento (década) & Formação \\
\hline Carué Contreiras & 1970 & Graduação em medicina \\
\hline \multicolumn{3}{|c|}{ Engajamento e atuação política em Aids (a partir da década de 2010) } \\
\hline
\end{tabular}

$119 \mathrm{https://www.facebook.com/ODiarioDeUmGay/}$

120 Projeto Boa Sorte nas redes sociais: página no Facebook (https://www.facebook.com/projetoboasorte/), canal no YouTube (https://www.youtube.com/channel/UCcg2yzyxjl1Lc8LMjo6y1Tg), perfil no Twitter (https://twitter.com/ProjetoBoaSorte) e no Instagram (https://www.instagram.com/ProjetoBoaSorte/). 


\begin{tabular}{|c|c|c|}
\hline \multicolumn{3}{|c|}{$\begin{array}{l}\text { - } \text { Colaborador da Agência de Notícias da Aids }{ }^{121} \text { (2014-atual) } \\
\text { - Rede Nacional de Pessoas Vivendo Com HIV/Aids - RNP+-SP (2017-atual) } \\
\text { - Educador comunitário das pesquisas sobre PrEP injetável, CRT-DST/Aids - SES-SP } \\
\text { (2016-atual) }\end{array}$} \\
\hline \multicolumn{3}{|c|}{ Engajamento e atuação política LGBT (a partir da década de 2010) } \\
\hline \multicolumn{3}{|c|}{$\begin{array}{l}\text { - Conferência Municipal LGBT (2016) } \\
\text { - Coletivo A Revolta da Lâmpada (?-atual) } \\
\text { - Coletiva Médica LGBT (2017-atual) }\end{array}$} \\
\hline Entrevistado & Nascimento (década) & Formação \\
\hline Ramón Soares & 1990 & $\begin{array}{l}\text { Graduando em Pedagogia, } \\
\text { formado em ballet clássico e } \\
\text { contemporâneo, jazz e } \\
\text { design de interiores, atua } \\
\text { como ator e bailarino }\end{array}$ \\
\hline \multicolumn{3}{|c|}{ Engajamento e atuação política em Aids (a partir da década de 2010) } \\
\hline \multicolumn{3}{|c|}{$\begin{array}{l}\text { - Aproximação com o tema, há dois anos atrás, por meio de um roommate positivo. } \\
\text { - Participação no Curso Participação Juvenil, Ativismo e Direitos Humanos em HIV- } \\
\text { AIDS no Estado de São Paulo }{ }^{122} \text {, da Rede de Jovens São Paulo Positivo em parceria } \\
\text { CRT-DST/AIDS } \\
\text { - Coletivo Loka de Efavirenz }{ }^{123} \text { (2016-atual) }\end{array}$} \\
\hline \multicolumn{3}{|c|}{ Engajamento e atuação política LGBT (a partir da década de 2010) } \\
\hline $\begin{array}{l}\text { - Na década de } \\
\text { movimento de } \\
\text { estudantil }\end{array}$ & $\begin{array}{l}\text { meio da aproximação } \\
\text { e posteriormente com }\end{array}$ & $\begin{array}{l}\text { ual, já na graduação, com o } \\
\text { ovimento LGBT e movimento }\end{array}$ \\
\hline
\end{tabular}

${ }^{121} \mathrm{http} / / /$ agenciaaids.com.br

122 O Curso de Participação Juvenil, Ativismo e Direitos Humanos em HIV-AIDS no Estado de São Paulo, realizado nos dias 7 a 10 de julho de 2016 e foi promovido pela Rede de Jovens São Paulo Positivo em parceria com a Coordenação Estadual de DST/AIDS da Coordenadoria de Controle de Doenças da Secretaria de Estado da Saúde de São Paulo, contando com o apoio do Departamento Nacional de DST, AIDS e Hepatites Virais do Ministério da Saúde, do Programa Municipal de DST/Aids da Secretaria Municipal de Saúde de São Paulo, do Programa Conjunto das Nações Unidas sobre HIV/AIDS - UNAIDS, do Fundo das Nações Unidas para a Infância - UNICEF, da Organização das Nações Unidas para Educação, Ciência e Cultura - UNESCO, do Fundo de População das Nações Unidas - UNFPA, do Fórum de ONG Aids de São Paulo, da Rede Nacional de Pessoas vivendo com HIV e AIDS de São Paulo - RNP +, do Movimento Nacional de Cidadãs PositHIVas de São Paulo - MNCP e do Projeto Viva Melhor Sabendo Jovem. O curso era voltado a adolescentes e jovens com idade entre 15 e 29 anos e tinha como objetivo formar lideranças juvenis para o fortalecimento do enfrentamento à epidemia de HIV/Aids e foi realizado em julho de 2016. Para mais informações: http://agenciaaids.com.br/noticia/rede-de-jovens-sp-realiza-curso-departicipacao-juvenil-ativismo-e-direitos-humanos-em-hiv-aids-no-estado-de-sao-paulo/ http://fundoposithivo.org.br/rede-de-jovens-promove-curso-para-formar-liderancas/ ${ }^{123}$ https://www.facebook.com/LokadeEfavirenz/ 